\title{
Financial reporting regulation for small and medium sized private firms : an empirical analysis of compliance, perceptions, costs, and usefulness
}

Citation for published version (APA):

Bollen, L. H. H. (1996). Financial reporting regulation for small and medium sized private firms : an empirical analysis of compliance, perceptions, costs, and usefulness. [Doctoral Thesis, Maastricht University]. Rijksuniversiteit Limburg. https://doi.org/10.26481/dis.19960118lb

Document status and date:

Published: 01/01/1996

DOI:

10.26481/dis.19960118lb

Document Version:

Publisher's PDF, also known as Version of record

Please check the document version of this publication:

- A submitted manuscript is the version of the article upon submission and before peer-review. There can be important differences between the submitted version and the official published version of record.

People interested in the research are advised to contact the author for the final version of the publication, or visit the DOI to the publisher's website.

- The final author version and the galley proof are versions of the publication after peer review.

- The final published version features the final layout of the paper including the volume, issue and page numbers.

Link to publication

\footnotetext{
General rights rights.

- You may freely distribute the URL identifying the publication in the public portal. please follow below link for the End User Agreement:

www.umlib.nl/taverne-license

Take down policy

If you believe that this document breaches copyright please contact us at:

repository@maastrichtuniversity.nl

providing details and we will investigate your claim.
}

Copyright and moral rights for the publications made accessible in the public portal are retained by the authors and/or other copyright owners and it is a condition of accessing publications that users recognise and abide by the legal requirements associated with these

- Users may download and print one copy of any publication from the public portal for the purpose of private study or research.

- You may not further distribute the material or use it for any profit-making activity or commercial gain

If the publication is distributed under the terms of Article 25fa of the Dutch Copyright Act, indicated by the "Taverne" license above, 


\section{Financial Reporting Regulation for Small and Medium Sized Private Firms}

an empirical analysis of compliance, perceptions, costs, and usefulness 



\section{Financial Reporting Regulation \\ for Small and Medium Sized Private Firms}

an empirical analysis of compliance, perceptions, costs, and usefulness

\section{PROEFSCHRIFT}

ter verkrijging van de graad van doctor

aan de Rijksuniversiteit Limburg te Maastricht, op gezag van de Rector Magnificus, Prof. Mr. M.J. Cohen, volgens het besluit van het College van Dekanen, in het openbaar te verdedigen op donderdag 18 januari 1996 om 14.00 uur door

Laurentius Helena Hubertus Bollen 


\section{Promotores:}

Prof. dr W.F.J. Buijink

Prof. dr J.H.R. van de Poel

Beoordelingscommissie:

Prof. dr J.G. Backhaus (voorzitter)

Prof. dr M.G. Faure

Prof. dr S.J. Maijoor

Prof. dr L.G. van der Tas RA (Erasmus Universiteit Rotterdam) 


\section{ACKNOWLEDGEMENTS}

Many have contributed to the, unanticipated, fact that I started working as a teacher and as a researcher at the University of Limburg which finally led to the coming about of this dissertation.

First of all, Willem Buijink has been my mentor at the university from the first day I started working there in 1985. It is his interest in empirical research in financial accounting that has greatly influenced and shaped the structure of this dissertation. In fact, when it became clear that legal changes had made it possible for me to get my doctor's degree by writing a dissertation, it was he, together with Jan van de Poel, who suggested that I should consider this option seriously. After some initial hesitation from my side, his and Jan's encouragements made me seriously start the preparation of this thesis. Also, without his help in the final stages of my research, this thesis surely never would have been completed.

Jos and Tjeu Blommaert have greatly influenced my activities as a teacher. Their inspired and inspiring vision on teaching business economics has greatly shaped my own vision on the teaching to university students. But at least equally important is the fact that they have always paid great attention to the personal affairs and problems of the people that surround them. In a world that's becoming more and more clinical their personal touch is a rare and precious asset.

My colleagues at the accounting department I would like to thank for their collegiality and friendship that have made me come to work with pleasure (almost) every day. Special thanks to Gerard Mertens, Luc Quadackers, Frank Hartmann, Harold Hassink, Roger Meuwissen, Rolf Wenemoser, Marc Gulikers, Bram Beek, Henk Brink, Tom Groot, Frans Volmer, Ton van Reeken, Sonja Passau, Ilse Gronenschild, Miranda van den Boorn and Els van Aernsbergen.

My former neighbour at the university, Eugene Schenk, and my current neighbour Eddy Vaassen I both would like to thank for the fact that their door always has been, and still is, open for me. Many times they had to listen to my complaints and annoyances but nonetheless they have always remained good friends.

I would like to thank Jürgen Backhaus, Michael Faure, Steven Maijoor and Leo van der Tas for judging the final version of the manuscript and for providing useful comments. Also, I thank Rob Bradley for checking the readability of the text. 
The Chamber of Commerce of Maastricht, particularly Ardi Assink, and the Nederlandse Orde van Accountants-Administratieconsulenten (NOvAA) supported parts of the empirical research, for which I'm very grateful. The Maastricht Accounting and Auditing Research Center (MARC) I thank for providing financial assistance to print the dissertation.

I dedicate this work to Anita and Tim. Many times they have permitted me to put my duties as a teacher and a researcher above my duties as a husband and a father. But at the right times they have always made me see that the really precious things in live can not be found at work but only with the people you love.

Maastricht, October 1995 


\section{CONTENTS}

\section{CHAPTER 1. INTRODUCTION}

1.1 The regulation of financial reporting $\ldots \ldots \ldots \ldots \ldots \ldots \ldots \ldots 11$

1.2 Differential financial reporting regulation $\ldots \ldots \ldots \ldots \ldots \ldots \ldots 13$

1.3 Financial reporting regulations for small and medium-sized firms $\ldots \ldots 16$

1.4 Purpose and outline of the dissertation $\ldots \ldots \ldots \ldots \ldots \ldots \ldots 18$

Chapter 2. Differential Financial Reporting Regulation: THEORY AND EVIDENCE

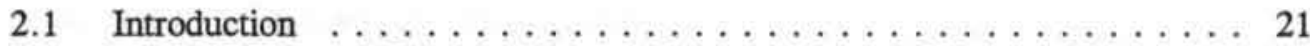

2.2 Theories of financial reporting regulation $\ldots \ldots \ldots \ldots \ldots \ldots \ldots 22$

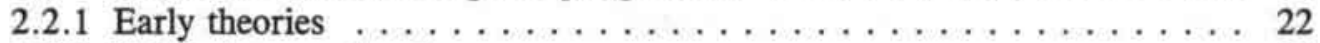

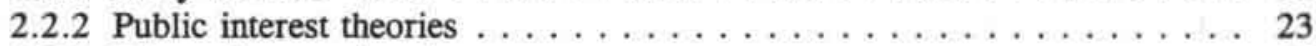

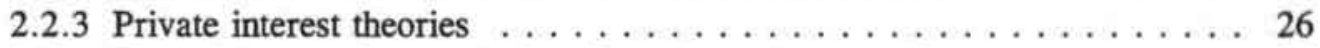

2.3 Financial reporting regulation, firm size and ownership structure . . . . 28

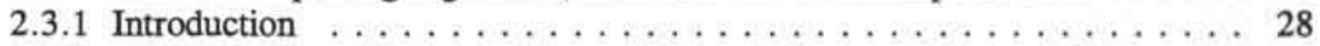

2.3.2 Financial reporting regulation and firm size $\ldots \ldots \ldots \ldots \ldots \ldots 29$

2.3.3 Financial reporting regulation and ownership structure $\ldots \ldots \ldots \ldots 48$

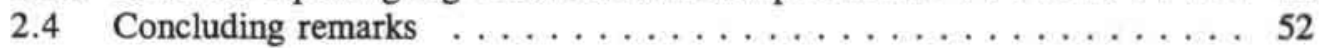

CHAPTER 3. COMPLIANCE OF SMALL PRIVATE COMPANIES WITH FINANCIAL REPORTING REGULATION

3.1 Introduction $\ldots \ldots \ldots \ldots \ldots \ldots \ldots \ldots \ldots \ldots \ldots \ldots$. 59

3.2 Non-disclosure of financial statements by small firms . . . . . . . 60

3.3 Characteristics of small firm financial statements . . . . . . . . 66

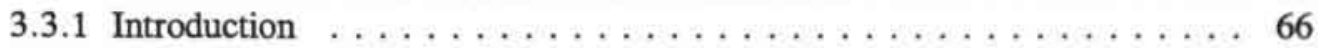

3.3.2 Relation to existing empirical research $\ldots \ldots \ldots \ldots \ldots \ldots \ldots 68$

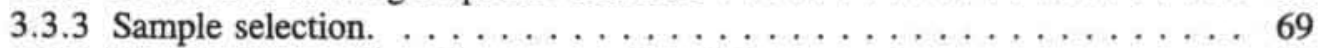

3.3.4 The timeliness of small company financial statements. . . . . . 72

3.3.5 Formal disclosure requirements $\ldots \ldots \ldots \ldots \ldots \ldots \ldots \ldots \ldots$

3.3.6 The information volume of small firms' financial statements . . . . . . 79

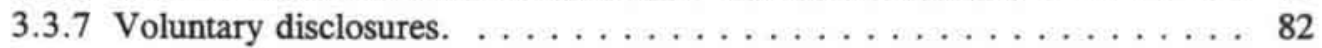

3.3.8 Concluding remarks. $\ldots \ldots \ldots \ldots \ldots \ldots \ldots \ldots \ldots \ldots \ldots$ 
3.4 Determinants of regulatory compliance of small firms.

3.4 .1 Introduction. $\ldots \ldots \ldots \ldots \ldots \ldots \ldots \ldots \ldots \ldots \ldots \ldots \ldots$

3.4.2 Independent variables $\ldots \ldots \ldots \ldots \ldots \ldots \ldots \ldots \ldots \ldots \ldots \ldots$

3.4.3 Dependent variables $\ldots \ldots \ldots \ldots \ldots \ldots \ldots \ldots \ldots \ldots \ldots . \ldots \ldots$

3.4 .4 Univariate results $\ldots \ldots \ldots \ldots \ldots \ldots \ldots \ldots \ldots \ldots \ldots \ldots \ldots \ldots$

3.4.5 Multivariate results $\ldots \ldots \ldots \ldots \ldots \ldots \ldots \ldots \ldots \ldots .68$

3.5 Concluding remarks. $\ldots \ldots \ldots \ldots \ldots \ldots \ldots \ldots \ldots \ldots \ldots$

\section{APPENDICES TO CHAPTER 3}

Appendix 3A. Data on the number of annual accounts disclosed $\ldots \ldots \ldots 93$

Appendix 3B. Financial reporting lags $\ldots \ldots \ldots \ldots \ldots \ldots \ldots \ldots .95$

Appendix 3C. Summary of results $\ldots \ldots \ldots \ldots \ldots \ldots \ldots \ldots \ldots \ldots$

Appendix 3D. Univariate analysis . . . . . . . . . . . . . 100

Appendix 3E. Univariate and multivariate analysis for the paired sample . . . 103

Appendix 3F. Correlations for independent variables . . . . . . . . 105

CHAPTER 4. SMALL FIRMS' MANAGEMENT PERCEPTIONS ON FINANCIAL DISCLOSURE AND DISCLOSURE COSTS FOR SMALL PRIVATE FIRMS

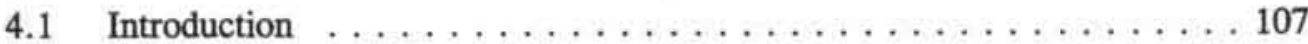

4.2 Relation to existing empirical research. . . . . . . . . . . . . 109

4.3 Research design. . . . . . . . . . . . . . . . . . 110

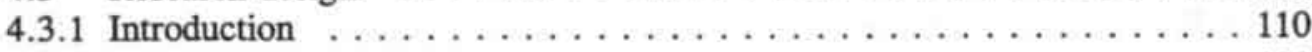

4.3.2 Research method. . . . . . . . . . . . . . . . . . . 111

4.3 .3 Sample selection . . . . . . . . . . . . . . . . . 112

4.3.4 Response analysis. . . . . . . . . . . . . . . . 114

4.3.5 Respondents' characteristics. . . . . . . . . . . . . . 115

4.4 Perceptions of small firm managers on financial reporting issues. . . . . 118

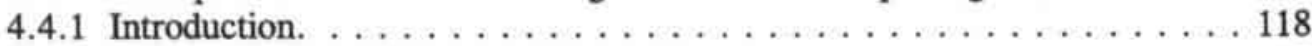

4.4 .2 Financial reporting regulation. $\ldots \ldots \ldots \ldots \ldots \ldots \ldots \ldots \ldots \ldots \ldots \ldots \ldots \ldots$

4.4.3 Users of small firm financial statements. . . . . . . . . . . . 122

4.4.4 Disclosure of specific items. . . . . . . . . . . . . 124

4.4.5 Effect of financial accounting disclosure on competitive position. . . . . 126

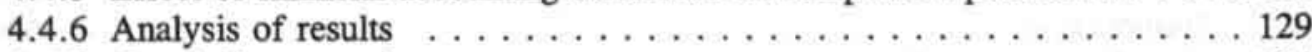

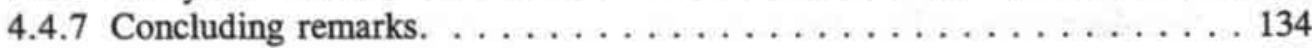

4.5 Small firms' disclosure costs $\ldots \ldots \ldots \ldots \ldots \ldots \ldots \ldots \ldots \ldots \ldots \ldots$

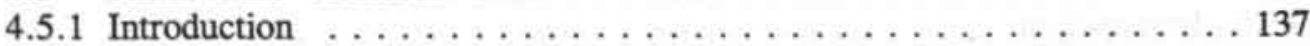

4.5 .2 Qualitative analysis . . . . . . . . . . . . . . . 139

4.5.3 Quantitative analysis . . . . . . . . . . . . . . . 140

4.5.4 Cross analysis of cost data $\ldots \ldots \ldots \ldots \ldots \ldots \ldots \ldots \ldots \ldots \ldots \ldots \ldots \ldots$

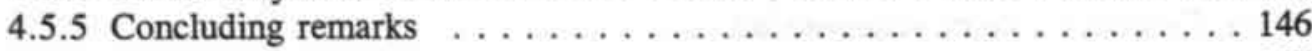

4.6 Some final remarks. $\ldots \ldots \ldots \ldots \ldots \ldots \ldots \ldots \ldots \ldots \ldots \ldots \ldots \ldots$ 
CHAPTER 5. THE USEFULNESS OF MEDIUM SIZED COMPANIES' FINANCIAL STATEMENTS TO LOAN OFFICERS

5.1 Introduction . . . . . . . . . . . . . . . . . . . . . 149

5.2 Relation to existing empirical research. . . . . . . . . . . . . . . 150

5.3 Research design . . . . . . . . . . . . . . . . . . . . . 152

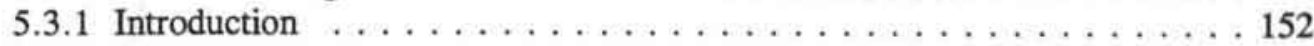

5.3 .2 Research method . . . . . . . . . . . . . . . . . . 152

5.3 .3 Sample selection . . . . . . . . . . . . . . . . . . . 152

5.3 .4 Response analysis . . . . . . . . . . . . . . . . . 153

5.3.5 Respondents' characteristics . . . . . . . . . . . . . 153

5.4 Perceptions of loan officers on financial reporting issues . . . . . . . . . 154

5.4 .1 Introduction . . . . . . . . . . . . . . . . . . 154

5.4 .2 Sources of financial accounting information $\ldots \ldots \ldots \ldots . \ldots 154$

5.4 .3 Importance of financial statement elements . . . . . . . . . . 159

5.4 .4 Information needs of loan officers and firm size . . . . . . . . . . 164

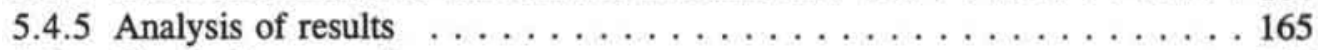

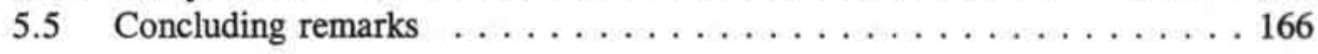

CHAPTER 6. SUMMARY AND DISCUSSION

6.1 Introduction . . . . . . . . . . . . . . . . . . . 169

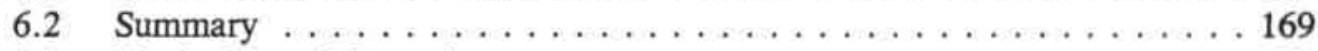

6.3 Limitations of the study. . . . . . . . . . . . . . . . . . 172

6.4 Suggestions for further research $\ldots \ldots \ldots \ldots \ldots \ldots \ldots \ldots$

\section{APPENDICES}

Appendix I . . . . . . . . . . . . . . . . . . . . . . 177

Appendix II . . . . . . . . . . . . . . . . . . . . . . . . . . . . . . . . . 189

Appendix III . . . . . . . . . . . . . . . . . . . . . 197

REFERENCES . . . . . . . . . . . . . . . . . . . . 205

SAMENVATting . . . . . . . . . . . . . . . . . . . 219

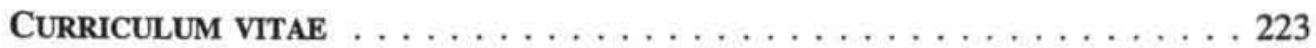




\section{Chapter}

\section{Introduction}

The objective of this dissertation is to contribute to the literature on the economic effects of financial reporting regulation ${ }^{1}$. It adds to the existing studies in this area by focusing on small and medium-sized private companies ${ }^{2}$ in an economy. More specifically, it (1) studies compliance by small private companies in the Netherlands with financial reporting regulation, (2) looks at the way in which financial reporting regulation is perceived by Dutch small company managers as well as credit analysts dealing with smaller firms, and (3) attempts to measure the costs of compliance imposed on small private companies as a result of financial reporting regulation. These three aspects are the subjects of empirical investigations.

\subsection{The regulation of financial reporting}

Businesses constitute the supply side of the market for accounting information, through their financial reporting activities. Various groups of users of financial reporting information make up the demand side. In most market economies, the market for financial accounting information is increasingly influenced by compulsory standards and

\footnotetext{
${ }^{1}$ As used in this dissertation, the term financial reporting regulation is intended to include all regulations (e.g. laws, rules and standards) that affect the characteristics (i.e. timing, content, form and verification) of financial reporting practice (see also Lev [1988, p. 1]). Financial reporting regulation takes the form of either financial reporting legislation through company law or financial reporting standards issued by governmental bodies or by private organisations. In the Netherlands, company law is the primary source of financial accounting regulations.

${ }^{2}$ In this dissertation, a public company is defined as a company whose shares are officially listed. In the same way, a private company is defined as a company whose shares are not publicly listed. In the Dutch context, a naamloze vennootschap (NV) refers to a public limited liability company that may have its shares traded on a stock exchange, but which is allowed to block the transfer of its shares. A besloten vennootschap (BV) is a private limited liability company the shares of which cannot be freely transferred. Although the Dutch term 'besloten vennootschap' is not fully equivalent to the US term 'private company', both definitions share the basic characteristics of a limited number of shareholders and a less distinct separation of management and ownership.
} 
government legislation. This increase in the intensity of financial reporting regulation has not gone unchallenged, and has resulted in an elaborate debate on the desirability of financial reporting regulation. The prime focus in this debate has been on the position of large, publicly listed firms, as pointed out by Taylor and Turley [1986, p. 19].

However, recent developments within European economies (e.g. the introduction of the Fourth EC Directive) have led to the regulation of financial reporting by companies that are neither public nor large. Hence, the debate on financial reporting regulation deserves to be extended to include arguments for and against the regulation of financial reporting activities by smaller or private companies. Essentially, such a debate should concentrate on two issues:

1. How does the firm size or ownership structure affect the supply of financial accounting information? This area involves such questions as: what incentives do small company managers have to voluntarily disclose accounting information and what are their views on mandated financial reporting? How do small company managers react to financial reporting regulation in terms of compliance with these regulations? And, does regulation have a disproportionate economic effect on small or private companies? Can it be shown, for example, that small private companies bear disproportionately higher direct costs (e.g. information production and information disclosure costs) as a result of accounting regulation? Indirect costs (e.g. competitive disadvantages) may also be relatively higher for these firms.

2. How does the firm size or ownership structure affect the demand for financial accounting information? Among the topics which need to be discussed in this respect are: who are the primary users of accounting information on small private companies and are these any different from the primary users of the financial statements produced by large public firms? Are there differences in the information needs of users depending on the size or ownership structure of the firm they are interested in? Will regulatory requirements that are designed for large public firms ensure the provision of information that meets the needs of users of small company accounting information?

It is these questions which this dissertation addresses. Given the fact that the bulk of the financial accounting literature has concentrated on the accounting environment of large public firms, the study presented in this dissertation deviates from most existing studies on financial reporting regulation by focusing on small and medium-sized private companies. Essentially, it explores an application of the arguments used in the debate on financial reporting regulation to the case of small and medium-sized firms. It examines in detail the typical characteristics of the accounting environment of small and medium-sized private companies, the main differences with the accounting environment of large public firms, and the implications of these differences for the debate on the necessity of financial reporting regulation. Given the domination within the empirical literature of studies on the demand for financial reporting information, this study also differs by focusing to a large extent on the supply side of the accounting information market. The effect of financial reporting regulation on small and medium-sized private companies is investigated empirically by studying (1) compliance with current legal requirements, (2) the way in which small company managers perceive financial reporting 
regulation, (3) the cost effects of financial reporting regulation on small private companies, and (4) the views of loan officers on the financial information issued by medium-sized companies.

The remainder of this chapter proceeds as follows. The first part (section 1.2) introduces the primary topics which this dissertation addresses. It describes the context in which the debate on accounting regulation for small and medium- sized privately owned firms has evolved and introduces the key issues in this debate. Section 1.3 discusses the importance of the issue of financial reporting regulation for small and medium-sized companies in a European context. The latter part of this chapter (section 1.4) gives an outline of the dissertation and introduces the remaining chapters.

\subsection{Differential financial reporting regulation}

In the accounting literature, attention has been given to the impact of financial reporting regulation on small and medium-sized private firms only since the late seventies, especially after initial research showed that compliance costs per monetary unit of sales were considerably higher for smaller firms [SEC, 1977]. These findings raised questions about the desirability of uniform disclosure across all firms [Horwitz and Kolodny, 1982 , p. 31]. Given the continuous growth in the regulation of financial reporting in most western countries, the suggestion was raised that extensive regulations place an undue burden on the reporting firms. Although this standards overload argument was also directed at the experience of large public firms [see Hammill, 1979, Tweedie, 1981], the main concern was whether existing or proposed regulations would have a disparate impact on small or privately owned firms. Hence, a case was made for the introduction of differential reporting regulation where the implementation of financial reporting regulation depended on the characteristics of the firms involved, the information needs of the primary external parties and the application of a cost/benefit analysis of such regulations [Gutberlet, 1983].

The determination of a starting point for the implementation of differential financial reporting regulations depends greatly on the implied purpose of disclosing the financial statements in question. The role of the annual report in stewardship would seem to call for differential regulations based on legal status. The use of accounting information as a monitoring device will be more prominent in relation to public firms, where there are a large number of shareholders and an autonomous board of directors. In private firms, however, the distinction between owners and managers is less clearcut and shareholders are often active as managers. If, on the other hand, the need of external users is advocated as the primary objective of financial accounting, firm size would seem to be a more important factor. In the case of a smaller firm, the number of potential user groups is smaller, the number of users within each group is smaller and users may be in a better position to get the information they desire without legal interference. In this context, Traas [1976] distinguishes three firm models: 
the proprietary model, where the firm is essentially an extension of the owner. The firm is closely related to the individual owner and there is no separation of ownership and control. Given the close relation between business information and personal information on the owner, there is little demand for the disclosure of financial accounting information and the accounting information produced is relevant chiefly for the owner himself;

- the closed (or classical) model, where there is a formal separation between ownership and control, but where the owners of the firm are still very active as managers;

- the open model, where the firm is described as a coalition of participants, in which the role of financial accounting information is to provide participants with information which they can use to decide on the continuation of their relationship with the firm.

The open model would typically fit a large public company, whereas the closed model could be typified by a medium-sized private company. The classification presented does not, however, provide a rigorous and easy means of categorising any individual firm. In principle, a small private firm may well fit the prescription of the open model. Also, there is no unambiguous relation between the models specified in respect of the amount and content of the accounting information which is to be disclosed. The classification presented does, however, draw attention to the fact that financial reporting requirements should not necessarily be uniform for all firms. As a result, different financial reporting requirements may be called for in relation to different types of firms. Hence, the relevance of the arguments used in the discussion of the desirability of financial reporting regulation, which usually apply to large companies that are listed on a stock market and in whose economic well-being a large number of societal groups are interested, may well change when applied to non-large, non-public firms.

This dissertation is concerned with the financial reporting regulation debate, focusing on non-large (i.e. small and medium-sized) private companies. A primary topic in this context is the discussion of differential financial reporting regulations for small or privately owned firms. Although the arguments used in the differential reporting debate are not always clearly distinguished when applied to small firms versus privately owned firms, a closer look indicates that both characteristics may result in different approaches to the issue of exempting firms from accounting regulation. Obviously, most of the differential financial reporting arguments have been put forward in the context of firms that are both small and privately owned ${ }^{3}$. For this reason, the focus in this dissertation is on small and medium-sized private firms ${ }^{4}$. It thereby circumvents the application of

\footnotetext{
${ }^{3}$ The term small closely held firm is sometimes used in this context. This may be defined as a small firm with a limited number of owners who are generally closely involved in the management of the firm.
}

${ }^{4}$ The term 'small and medium-sized private firms' is not necessarily the equivalent of the more general term 'small and medium-sized enterprises' (SME) or its Dutch synonym 'Midden- en kleinbedrijf. The latter term (or its abbreviation, MKB) is widely used in Dutch, and appears in the names of numerous committees and institutes. Nevertheless, it is very hard to find a 
differential reporting arguments to small public companies and large private companies, and focuses on those firms for which differential financial reporting requirements may be most called for.

In Europe, the differential reporting issue has gained increasing importance as a result of the Fourth EC Directive on corporate financial reporting. This Directive contains exemptions for small and medium-sized firms, apparently following the standards overload argument. Thus, the Directive depicts a convenient example of many of the difficulties addressed in this debate, such as:

1. How should the firms that are to be exempted from (part of) the regulations be defined? Should such a definition be based on firm size or on some other characteristic such as legal status? Can one conclude, for example, that full disclosure would impose disparate costs on small firms and can it be shown to what extent the exemptions provided shield the firms exempted from disproportionate cost effects? Also, any definition based on firm size (as is used in the Directive) raises the problem of which variables to use as a proxy for firm size and what boundaries to set to define small or medium-sized firms.

2. What regulations should these firms be exempted from? Should exemptions only include disclosure requirements (i.e. the volume of the information disclosed) or should differential measurement rules be included (i.e. relating to the content of the information disclosed)?

Economic arguments have played a dominant role in the differential reporting debate. First, there is a belief that compliance costs are disproportionately higher for small and privately owned firms. Second, the benefits of disclosing general purpose financial statements seem relatively small for small private firms because of the limited number of potential users of such information. Moreover, these users could have different information needs when dealing with small or closely held firms. However, although these beliefs are frequently expressed, they are rarely empirically investigated. It is the aim of this dissertation to contribute to the empirical literature on the economic effects of financial reporting regulation for small and medium-sized private firms, within the framework of the Dutch financial reporting regulatory context.

precise definition of this term. Even one the most prestigious Dutch dictionaries ('Van Dalen Groot Woordenboek der Nederlandse Taal') provides only the following meaningless definition: "firms that are not very large". Many statistical reports also tend to define the term by a similar process of negative contrast:

"Firms performing government or semi-government tasks, or active in the agricultural, fishing or mining industry, or having more than a hundred employees, are not defined as small or medium-sized firms" [Thurik, 1990].

In this dissertation, the term 'small and medium-sized private firms' is used in the context of company law definitions, that are typically based on a combination of three measures: total assets, total annual sales and the number of employees. 
The economic effects of financial reporting regulation have received only limited attention in Dutch accounting literature [Van de Poel, 1988, p. 20]. Studies by Mertens [1991] and Maijoor [1991] have contributed to this field of research, in line with the observations made by Bouma [1988, p. 285] and Van der Grinten [1981] that an evaluation of the costs and benefits of financial reporting regulation deserves more attention in the Netherlands. Studies on the effects of financial reporting regulation on small and medium-sized firms are almost non-existent in the current Dutch accounting literature ${ }^{5}$. Apart from a limited number of studies of the contents of small companies' financial statements [e.g. NOvAA, 1986] and the use of medium-sized companies' financial statements by bankers [NOvAA, 1991b], small and medium-sized company financial reporting and the regulation thereof have not received much attention from Dutch accounting scholars. This dissertation attempts to fill this gap.

\subsection{Financial reporting regulations for small and medium-sized firms}

The following observation is fundamental to this dissertation. Prior to 1984, Dutch company law exempted virtually all private companies from mandated financial accounting disclosures, leaving the supply of accounting information by these firms to market forces ${ }^{6}$. With the adaptation of Dutch company law to the Fourth Directive in 1983, all public and private companies, irrespective of their size, had to prepare annual accounts in some form ${ }^{7}$. This situation is in sharp contrast with that in the US, where the Securities and Exchange Commission (SEC) is concerned solely with publicly listed companies subject to the Federal securities legislation that it administers [Zeff, 1994, p. 23]. These companies constitute only a small fraction of the total number of businesses in the US (see table 1.1).

Most other US companies, although they may be subject to State company law requirements, are not required to disclose any financial statements periodically or to have their financial statements audited [Zeff et al., 1992, p 357, ftn 47]. In contrast with the harmonisation efforts of the EC, little has been done in the US to harmonise state company laws and there has never been a general Federal corporation law, nor is there at present a strong movement in favour of such legislation [Landau, 1988, p. 56].

\footnotetext{
${ }^{5}$ A small number of studies have attempted to measure the cost for small and medium-sized firms of complying with all the various administrative obligations (e.g. ACE-Resultants [1984] and Leerstoel Marktbeleid [1991]), while other studies have focused on the compliance costs relating to taxation regulations (e.g. Snijder [1981] and Allers [1994]).

${ }^{6}$ Private companies were subject to the provisions of the Corporate Financial Statements Act only if their share capital was in excess of $f 500,000$ or if their total assets were in excess of $f 8$ million and they employed at least 100 staff.
}

${ }^{7}$ Dutch company law requirements also apply to cooperatives and mutual insurance companies. Such firms are not, however, discussed in this dissertation. 
Instead, state corporate laws develop in an environment of competition between states which should ensure the enactment of corporate laws that meet the needs of the business community [Landau, 1988, p. 62]. Others, however, feel that the competition between state regulations is more of a "race to the bottom", leaving few states with effective requirements on the disclosure and auditing of financial statements [Zeff et al., 1992, pp. 356-357].

Table 1.1. The scope of financial reporting regulations in the US and the Netherlands.

\begin{tabular}{lccc}
\hline & $\begin{array}{c}\text { Estimated total number } \\
\text { of businesses }\end{array}$ & $\begin{array}{c}\text { Estimated number of companies } \\
\text { affected by financial reporting } \\
\text { regulations }\end{array}$ \\
\hline United States $^{1}$ & $13,300,000$ & 10,000 & $(0.08 \%)$ \\
Netherlands $^{2}$ & 471,000 & $175,000^{3}$ & $(37.2 \%)$ \\
\hline
\end{tabular}

1. The data on the US data have been supplied by Evans [1987, pp. 657-674].

2. The data on the Netherlands have been supplied by the Central Office of Statistics, "Statistiek van het ondernemingen en vestigingenbestand 1987", Voorburg.

3. The figures presented are based on the total number of public companies, private companies and cooperatives. The number of annual accounts disclosed may be lower due to noncompliance or exemptions. The total number of companies affected by financial reporting regulations in the European Community is estimated at 2,500,000 [OECD Working Group on Accounting Standards, 1987, "Availability of Financial Statements", Working Document No. 2, OECD, Paris].

As a result of the limited scope of the US federal financial reporting regulations, both the SEC and the FASB may have relatively little need to be concerned about the costs that accounting and disclosure standards might impose on small and medium-sized companies which have not entered the securities market. However, given the broad scope of the European company law requirements, interest in the economic effects of financial reporting regulations on small and medium-sized companies ought to be much greater in Europe. Although the Fourth Directive does provide exemptions for small and medium-sized firms, these are mainly concerned with disclosure requirements relating to the volume of the financial statements, while relatively little attention has been directed to harmonising measurement requirements pertaining to the content of the financial statements [van der Tas, 1992, p. 250]. Very little empirical evidence has been presented on the effect of such exemptions on the cost imposed on small and mediumsized companies.

The task of enforcing financial reporting rules also seems comparatively easy in the US, as opposed to the job of the numerous enforcement agencies in Western European countries, which have to deal with perhaps tens or even hundreds of thousands of companies affected by regulatory accounting rules [Zeff, 1994, p. 23]. Nevertheless, although the problems of enforcing compliance can be expected to be substantial in most EC countries, it seems that, within most EC countries, little attention has been given to the need for securing actual compliance with the standards [Zeff, 1994, p. 4]. Again, 
empirical evidence on compliance with European financial reporting regulations is rather scarce.

\subsection{Purpose and outline of the dissertation}

This dissertation originated from a research project that was aimed at a cost-benefit analysis of Dutch financial reporting regulation. Part of the research project focused on the effects of financial reporting regulation on small and medium-sized private firms ${ }^{8}$. The results of this study are presented in this dissertation.

Consequently, the main objective of this thesis is to determine the effects of the change in the regulatory requirements on financial reporting which was introduced in the Netherlands in 1983 on small Dutch companies. Building on the existing literature on the effect of accounting regulation, the empirical chapters in this dissertation investigate the impact of financial reporting regulation on small companies in terms of (1) compliance with current legal financial reporting requirements, (2) the way in which the managers of small firms perceive current financial reporting regulations, (3) the accounting costs imposed on small companies as a result of current financial reporting requirements, and (4) the views of a primary user group of small and medium-sized firm financial reports, i.e. bankers, on the usefulness of the financial reporting information supplied by these firms.

The remainder of this dissertation proceeds as follows. Chapter 2 discusses the theoretical debate on financial disclosure regulation with respect to its implications for small and medium-sized privately owned firms. The arguments raised in the debate on the desirability of financial accounting regulation are evaluated in the context of small and medium-sized private firms, focusing finally on the standards overload debate and the desirability of differential financial reporting regulations. The existing empirical literature on the economic effects of financial reporting regulation and its implications for small and medium-sized private firms are also discussed in this chapter.

Chapters 3 and 4 report on an empirical investigation into compliance with, perceptions of and the costs of financial reporting regulation by and for small Dutch private companies. The quality, quantity and timeliness of the information disclosed by small firms as a result of company law requirements is investigated in chapter 3 . Financial reports disclosed by small firms are examined in relation to the years 1984 (immediately ensuing the introduction of the financial reporting regulations for small companies) and 1990 , so as to reveal any changes in the disclosures made by small firms over time. Chapter 4 presents the results of a questionnaire survey of small firm owner/managers.

\footnotetext{
${ }^{8}$ A second study originating from the initial cost-benefit project is Maijoor [1991]. It includes empirical studies on the effect of Dutch financial reporting regulation on (1) the choice of legal status by Dutch firms and (2) the Dutch audit industry.
} 
This survey focuses on the way in which the respondents perceive prevailing financial reporting regulations and the costs imposed on small firms by these regulatory requirements.

Chapter 5 reports on an empirical study of the views of credit analysts dealing with small and medium-sized private firms, as to the usefulness and importance of financial reports supplied by these firms.

The final chapter (chapter 6) summarizes the results of the empirical studies and evaluates the effects of the regulatory change in the financial reporting environment on small and medium-sized private companies. Some suggestions for further research into the question of the regulation of financial reporting by small and medium-sized private companies are also given here. 


\section{Differential Financial Reporting Regulation: Theory and Evidence}

\subsection{Introduction}

The existence of various exemptions for small and/or private firms in current financial reporting regulations, such as the Fourth EC-Directive, seems to indicate regulators do appreciate the reality of disparate economic effects of regulation for these firms (see Appendix I for descriptions of current differential financial reporting regulations in the Netherlands and three other countries). But the financial accounting literature provides no explicit theoretical framework for explaining the existence of such exemptions. Although there are economic theories explaining the existence of financial reporting regulations using either public interest or private interest argumentations, these have been almost exclusively developed in the context of large publicly listed firms. The issue of providing exemptions for firms with specific characteristics (e.g. small or private) is hardly dealt with in these theories. Also, the empirical evidence provided in this area is largely oriented towards large public firms. Despite increasing interest in small firms, little research can be found on whether financial reporting regulations have a disparate effect on smaller businesses or on whether there are economic reasons for allowing differential financial reporting regulation ${ }^{1}$ for small and medium-sized privately held businesses. Consequently, the rationalisation of the existence of exemptions based on public interest or private interest arguments is largely an empirical issue that has yet to be resolved. Policy makers who look for economic guidance on how to differentiate between financial reporting requirements for different business sizes will find that there is much talk but few facts. The purpose of this chapter is to introduce an outline theory on financial accounting disclosure regulation for small and medium-sized private firms. As such, this chapter provides a fundamental frame of reference for the empirical chapters in the remainder of this dissertation (chapters 3, 4 and 5).

\footnotetext{
' For our purposes differential reporting regulation can be defined as "the practices which reflect an adoptive form of financial accounting and reporting in which the implementation of measurement and disclosure standards [...] depends upon either the characteristics and relevant information needs (based upon purpose) of the primary external parties at interest in financial reports issued by smaller privately owned businesses or application of cost/benefit ratio analysis" [Gutberlet, 1983, p. 17].
} 
In applying the regulatory debate to small and medium-sized private companies, three basic issues need to be addressed:

1. Should the financial reporting activities of small and medium-sized firms be regulated? This discussion is an extension of the more general regulatory debate on whether regulation of financial reporting activities by firms is desirable. The public interest and private interest theories of financial reporting regulation and their application to the small private firm setting will be the subject of section 2.2 of this chapter.

2. Given the existence of financial reporting regulation, the next issue is whether financial reporting regulation should be different for small and medium-sized private firms as opposed to large public companies. The differential reporting debate provides arguments for and against differences in regulations based mostly on differences in firm size (discussed in section 2.3.2) or ownership structure (discussed in section 2.3.3). Also, the existing empirical research on the economic consequences of financial reporting regulations for the small private firm context will be discussed in order to reveal areas requiring further empirical evidence on the economic effects of financial reporting regulation for small and medium-sized private firms.

3. If it can be argued that financial reporting regulation should be different for small and medium-sized private firms, the third issue is how differential reporting regulation for small and medium-sized private firms should be implemented. Various implementations of differential financial reporting regulation have been suggested, all emphasising their potential effect on relieving the suggested disproportionate economic consequences for small and medium-sized private companies. The question of how differential reporting regulations should be introduced and the various ways regulators have dealt with this problem are discussed in Appendices I and II at the end of this dissertation.

\subsection{Theories of financial reporting regulation}

Excellent and elaborate discussions of the theoretical financial reporting regulation debate are available [e.g. Watts and Zimmerman, 1986, chapter. 7, Beaver, 1989, chapter 5, Wolk et al., 1992, chapter 4, Easterbrook and Fishel, 1984, pp. 680-696, Bromwich, 1985, chapter 4, Benston, 1976, chapter 4, and Maijoor, 1991, chapter 3]. The aim of this section is to review the arguments advanced in the regulatory debate and to review these arguments in the context of a the small and medium-sized private company. Also the section will provide an overview of the empirical evidence on the existence of economic effects for these firms.

\subsubsection{Early theories}

Theories of financial reporting regulation attempt to explain the existence of financial reporting regulation. Early theoretical rationales for the regulation of financial accounting originated from the concern of accounting researchers with prescribing 
how firms should report in order to provide a 'fair' presentation of the firm's financial situation. Regulation would direct the financial accounting policies of reporting firms thus ensuring the provision of 'good' financial accounting and preventing the abuse resulting from inadequate financial reporting. These early approaches to the theory of financial reporting regulation proved to be unsatisfactory because they ignored the economic effects of regulation on the parties concerned. For example, the various groups of users of financial accounting information and their specific information needs were in fact disregarded as it was conceded that 'good' financial accounting information was in the interest of all possible users.

\subsubsection{Public interest theories}

An alternative theoretical approach to accounting regulation stresses the role of the information receiver and focuses on the utility of accounting disclosures in decision making processes. Based on the alleged inadequacy of markets to ensure the provision of adequate financial accounting information, theories were developed explaining why financial reporting regulation had evolved, using the public interest as an overriding argument. The central issue in the public interest arguments is whether or not there are some flaws in a private sector accounting information market (i.e. some 'market failures') that would lead to the conclusion that governmental regulation is a desirable solution to avoid such flaws and secure an optimal level of production of accounting information [Beaver, 1989, p. 178]. These market failures or externalities include (1) the public good problem, (2) information asymmetry, (3) the speculation problem [Watts and Zimmerman, 1986, p. 162-169] ${ }^{2}$. To correct these imperfections, government regulation is called for. Elaborate discussions of the market failures mentioned can be found in Easterbrook and Fishel [1984, pp. 680-696], Bromwich [1985, chapter 4], Watts and Zimmerman [1986, chapter 7], Benston [1980, chapter 4], and Maijoor [1991, chapter 3]. The arguments in favour of a regulated accounting information market ${ }^{3}$ imply that, given the existence of certain market failures, regulation can improve the information market's efficiency in a Pareto sense.

2 Early rationales for government intervention in the market for accounting information are discussed by Leftwich [1980] and Watts and Zimmerman [1986, pp. 138-162]. These include management monopoly control of information, naive investors and functional fixation, and the uselessness of accounting information due to divers and subjective accounting procedures. Assuming efficient capital markets, most of these rationales seem to have limited scope [Watts and Zimmerman, 1986, p. 162].

${ }^{3}$ In this context, an unregulated accounting information market does not necessarily imply that all government involvement is absent. The government still has to penalize fraud and enforce contracts between individuals. In a free accounting information market, however, the government should not be involved in specifying contracts through prescriptions on the contents or volume of accounting information to be produced and disclosed. 
Critics of the public interest theories subsequently contested the existence or materiality of the market failures suggested, or the ability of regulatory activities to eliminate such failures. It has been argued that the market failure analysis overlooks strong incentives in the competitive capital market for the demand and supply of information [Horwitz and Kolodny, 1982, p. 6]. In order to attract capital suppliers, firms can benefit from the disclosure of adequate information, while investors can reveal their preferences for information by offering higher prices for shares of firms that do provide information conform their needs. Ultimately, both suppliers and users of accounting information would benefit from information production conform the preferences of investors ${ }^{4}$. Also, by introducing the concept of non-zero contracting costs, the desirability of regulation becomes subject to its ability to reduce contracting costs more efficiently than private arrangements [Watts and Zimmerman, 1986, p. 169]. A further important criticism against financial reporting regulation is that, whereas a free market may lead to underproduction of information, regulation may result in an overproduction of information. In a regulated environment, public goods are costless (or at least subsidised). As a result, users tend to overstate their real demand because there is no charge for it [Wolk et al., 1992, p. 90]. Since accounting information has public good characteristics, a regulated market may lead to an overproduction of accounting information.

The public interest debate on the desirability of financial reporting regulation is almost exclusively directed towards large publicly quoted firms, that have ready access to external capital markets for equity and debt finance [Keasey and Watson, 1993 , p. 39]. Public interest arguments in favour of financial reporting regulation mainly are based on the role of accounting information in capital markets. It is normally assumed that firm shares are frequently traded, that there are strong incentives to obtain and process information about firms and that the capital market is efficient in processing this information and pricing the firms' stock [Watts and Zimmerman, 1986, p. 162]. Moreover, shareholders are assumed to own diversified portfolios and to enjoy the full benefits of limited liability [Keasey and Watson, 1993, p. 39]. This setting, however, seldom fits the situation of the small company sector. Small public company equity is less likely to be frequently traded, which makes exiting from such a firm more difficult and costly. Also, small public company investors normally have tied up a large part of their wealth in the enterprise, which makes them less likely to achieve well-diversified portfolios. Small

4 Other incentives for voluntary disclosure by managers are provided by agency theory based on the suggestion that managers are motivated to provide accounting information in order to minimize agency costs, which is in their self-interest [Watts and Zimmerman, 1986, p. 196]. Agency theory, however, builds on the role of accounting information as a monitoring device in contracts between agents (e.g. management) and principals (e.g. shareholders), while public interest theories build on the hypothesis that accounting numbers are a source of information for investment and valuation decisions. To link both premises, it should be clear that accounting information used in contracts is valuable to investors, and vice versa [Watts and Zimmerman, 1986, p. 198]. 
public companies typically have few outside investors and major shareholders of these firms often are directly involved in decisions on firm-activities.

The emphasis on capital markets also makes the arguments used to advocate or oppose financial reporting regulation difficult to apply to private companies, since these firms do not have their shares quoted on a securities market. Consequently, the arguments used to advocate or oppose financial reporting regulation may have considerably different implications in the small and medium-sized private firm context [Keasey and Watson p. 39]. Also, agency theory provides a number of reasons why the role of accounting would be different in private versus public firms. Firstly, in private firms there is less separation of ownership and control which would make the use of explicit contracts between owners and managers of the firm less imperative. In a private firm the owner-managers are more likely to own a large portion of the firm's shares since the firm owners are more likely to be active as managers. As a result, firm managers are more likely to act in the interest of outside shareholders and also shareholders are better able to directly monitor the actions of management and rely less on incentive contracts using accounting numbers. Secondly, in private firms, the lack of separation of ownership and control gives the owner-manager both the scope and the incentives to engage in opportunistic behaviour at the expense of outside factor suppliers. The extensive information asymmetry between the owner manager and outside parties makes the use of accounting numbers in contracts with outside parties more difficult. As a result more emphasis may be placed on alternative bonding and signalling devices in private firms and less emphasis may be placed on accounting numbers. If there is less use for accounting information in private firms then, as a result, financial reporting regulations may have different economic effects on private firms than on public firms.

In case of the Fourth EC Directive, and the impact it has on the financial reporting regulations of small and medium-sized private firms, the 'public interest' that presumably is served by the Directive is to further enhance the freedom of establishment for companies, to facilitate the trade within the EC as well as cross border transactions. As an important means to achieve this objective, it was felt that harmonisation of company law was necessary to provide an equal level of protection for members (shareholders and employees) and other persons (mainly creditors) in all Member States. It was found important that companies that are in competition with one another should publish financial information that can be regarded as equivalent, particularly in the case of limited liability companies. In the context of small and medium-sized private firms it is important to mention that in the first proposal for the Fourth Directive, issued in 1968, the proposed regulations applied only to public limited liability companies. Furthermore, this proposal entailed an option to include exemptions for small public liability companies and public limited liability companies that were familiy businesses. However, in the final version the scope of the Fourth Directive was extended to all public as well as private limited liability companies, although some partial exemptions for small and medium-sized firms were included. 
The discrepancy between the original proposal for the Fourth Directive and the final Directive as it was issued in 1973, particularly with respect to the regualtions for small and medium size private firms, casts some doubts on whether pursuing the public interest can explain the accounting regulations as laid down in the Fourth Directive. It seems that in order to understand the existence of the Fourth Directive, the proces by which the Directive was created has to be taken into account. Therefore, a historical overview of the advancement of the regulations for small and medium-sized private firms within the Fourth Directive, is provided in appendix I at the end of this dissertation.

\subsubsection{Private interest theories}

From the economics literature, empirical inconsistencies between the regulators' actions and the public interest hypothesis led to a questioning of the assumption that politicians are motivated by social welfare considerations [Watts and Zimmerman, 1986 , p. 175-176]. As a result, an alternative theory of financial reporting regulation was built on the assumption that politicians, similar to all other parties in the financial accounting arena, act in their own interest. Private interest theories build on the premise that (1) regulation has wealth-distributing effects and (2) all parties involved (including regulators) act from self-interest. Under these assumptions, the political process is delineated as a competition for wealth transfers [Watts and Zimmerman, 1986, p. 222]. The outcome of the political process in terms of regulations, depends on the lobbying activities of various parties (receiving and providing benefits resulting from the regulation), whose involvement (and success) depends on information and organisation costs. Regulators play their own role in this setting, also acting from self-interest, seeking wealth transfers via the political process [Watts and Zimmerman, 1986, p. 226] ${ }^{5}$. The actions of politicians, and the extent to which they can pursue their private interest, are dependent on the strength and number of other interest groups, favouring or opposing these actions.

According to the private interest theory of accounting regulation, the outcome of the political process depends on the lobbying activities of various parties (receiving and providing benefits resulting from the regulation), whose involvement (and success) depends on information and organisation costs. Information costs arise from the necessity to keep track with all (proposed) regulation and to estimate of the wealth transfers to be expected from them. Since expected wealth transfers would be trivial for individuals, information costs would generally exceed expected benefits at the individual level. Therefore interest groups exist, emanating from economies of scale in gathering relevant information. The size of these interest groups is limited by their

s Private interest behaviour of politicians includes actions indirectly increasing politicians' wealth, such as transferring control of resources to government, and granting favours to interest groups to ensure sufficient votes in future elections. 
effectiveness, which depends on their ability to influence the political process, i.e. their organisation costs. First, they have to be able to present views representing, ideally, a consensus view of all its members, which depends on the homogeneity of interests of group members. Second, large interest groups are more likely to attract stronger opposition from those providing the wealth transfers and will encounter more incentives for group members to free ride.

Based on the work of Downs [Downs, 1957] and Olson [Olson, 1965], Sutton [1984] and Lindahl [1987] have tried to expand the lobbying literature to the case of financial reporting, putting emphasis on the cost and benefits of lobbying behaviour. Both articles try to describe which parties are expected to gain the highest net benefits from lobbying and therefore will most actively lobby on accounting standards. Sutton [1984, p. 82] argues that any party will only engage in lobbying activities if the benefits expected from lobbying exceed the costs, subject to the probability that lobbying will influence the rule-making decision. Lindahl [1987, p. 61] extended the analysis of Sutton by incorporating a free rider problem which will restrain parties from lobbying (even if they expect net benefits) if they are assured that another party will engage in the same lobbying activity. The implication of the analysis on the level of individual lobbying are that

1. firms are more likely to engage in lobbying then users because firms generally are more wealthy then users. Also users generally are holding diversified portfolios which can be rearranged to counter any economic effects from an accounting standard, instead of engaging in lobbying. Firms are generally less diversified and can only at great expense avoid economic effects of accounting standard by changing its line of business [Sutton, 1984, p. 86];

2. large firms are more likely to engage in lobbying then small firms because benefits from lobbying are positively related to firm size. Large firms are more likely to receive large enough benefits from the lobbying activity to overcome the free rider problem, restraining smaller firms from lobbying and costless benefiting from others [Lindahl, 1987, p. 62]. Also. since successful influence through lobbying is generally preceded by resource expenditures, it is often suggested that larger firms, with larger resources, have an edge over smaller firms in the amount of pressure they can exert on regulators [Brown and Feroz, 1992, p. 720].

On the group level, where individuals create organisations for lobbying purposes as a cost sharing mechanism, smaller groups are more likely to be more successful because (1) they have relatively lower organisation costs, and (2) they are better able to monitor compliance with group goals and overcome free riding [Lindahl, 1987, p. 63]. Since producers of accounting information (accountants and firms) are smaller and more homogeneous groups and are better represented in existing organisations, they are more likely to engage in collective lobbying than users [Sutton, 1986, p. 86].

Both Sutton and Lindahil recognise that their theories are difficult to test empirically, given the fact that it is hard to find evidence of the magnitude, nature and timing of 
lobbying activities [Maijoor, 1991, p. 72]. In fact, very few empirical studies have assessed the costs and benefits of lobbying activities and no studies have provided evidence that smaller firms are less successful in the political process ${ }^{6}$. Therefore it remains unclear whether the existence of regulations for small and medium firms or the existence of exemptions for these firms can be explained by the disability c.q. ability of smaller firms to influence the regulatory process

With respect to the Fourt EC Directive, as has been mentioned before, the discrepancy between the original proposal for the Fourth Directive and the final Directive as it was issued in 1973, particularly with respect to the regulations for small and medium-sized private firms, may be an illustration of how private interest arguments and lobbying activities may affect the outcome of the financial reporting regulation process. The historical overview of the advancement of the regulations for small and medium-sized private firms within the Fourth Directive, provided in Appendix I at the end of this dissertation, provides some evidence that the European accounting regulation may be a result of a political proces, in which economic reasoning and lobbying activities from interested parties play an important role. Especially the opposition of small and medium-sized firms in Germany has been a strong force to limit the effects of the EC financial reporting regulations for such firms. However, these efforts that have for example resulted in several propositions to completely exempt a number of small closely held companies from the Fourth Directive, have not always been very succesfull.

\subsection{Financial reporting regulation, firm size and ownership structure}

\subsubsection{Introduction}

In the remainder of this chapter, the arguments used to defend and oppose the introduction in financial reporting regulations of exemptions based on firm size or ownership structure will be presented and discussed. Also, existing empirical evidence relating to the arguments advanced will be reviewed. Most arguments used to defend differential financial reporting regulations emerge from the presumed

\footnotetext{
6 In empirical tests of private interest regulation theory, firm size is a frequently used explanatory variable for explaining and predicting accounting policies of management and lobbying behaviour of interested parties. The interpretation of the observed effects of firm size, however, is hard to substantiate. The use of firm size as a proxy for the political sensitivity of a firm is often criticised as other factors beside the firm's size affect its political visibility (e.g. industry, recent price increases, the influence of unions). Also, the correlation between firm size and political visibility may be ambiguous as large firms may not only bear higher political costs but also may receive more substantial political benefits (e.g. loans or subsidies). These restrictions demand great caution in the interpretation of the effect of firm size in empirical tests [Watts and Zimmerman, 1986, p. 239].
} 
existence of differential economic effects for firms that are either small or private. Empirical research on the economic effects of financial reporting regulation tries to estimate the benefits or costs related to financial reporting regulation, by using methods to either directly or indirectly measure those costs and benefits or to identify the perceptions of respondents on cost-benefit issues. In the discussion of these studies that will be presented in this chapter, evidently, the focus will be on the direct and indirect implications of the results of the studies discussed for the financial reporting environment of small and medium-sized privately held firms.

In the financial accounting literature there is no systematic line of research dealing with financial reporting in the context of small private firms. The bulk of the empirical literature on the economic effects of financial reporting regulation has been directed towards large publicly held firms. Nevertheless, the results of some of these studies may have implications for the small private firm context. Regarding the effect of firm size on financial reporting, evidence from studies on (1) capital market reactions to financial disclosures, (2) the timeliness of disclosure, (3) compliance with disclosure regulations, (4) the use of financial reports by outside parties, (5) compliance costs and (6) competitive disadvantages may provide evidence for differential economic effects for smaller firms. Many of the studies in these areas deal with small private firms and therefore may provide evidence for the impact of firm size as well as the impact of ownership structure on the economic effects of financial reporting and its regulation. Distinctive research on financial reporting in private versus public firms includes studies on (1) accounting method choice in private firms, (2) the usefulness of private firms' financial statements to outside stakeholders.

As mentioned before, most empirical studies in this area have focused on companies that are both small as well as private. However, the arguments in the differential reporting debate should be separated between the impact of firm size and the impact of ownership structure on the financial reporting environment of firms, since these characteristics may result in different approaches to the issue of exempting firms from financial reporting regulation. Therefore, the first part of this section will focus on the arguments and accompanying empirical evidence based on firms size (2.3.2), followed by the a discussion of the impact of ownership structure on financial reporting issues (2.3.3). At the end of this section both approaches will be evaluated and connected (2.3.4).

\subsubsection{Financial reporting regulation and firm size}

The arguments presented in favour of different financial reporting regulation for small firms have evolved around a large number of issues, including the role of accounting information of small firms in capital markets, the reduced usefulness of small companies' financial statements as a result of a lack of timeliness and extensive non-compliance with disclosure regulations, the presumption that the primary user 
groups of small firms' financial statements are different compared to large firms and the assumption that user groups may have different information needs when dealing with small firms. As a result, the benefits from mandatory financial disclosure for small firms may be much lower than in the context of large public firms. Also, the costs of complying with financial reporting regulation as well as the competitive disadvantages resulting from financial disclosures may be relatively higher for smaller firms. These issues will be dealt with consecutively in the following sections.

\subsubsection{Firm size and security prices}

Empirical research into the role of financial reports of small versus large companies in capital markets has indicated that security price reactions are stronger for smaller firms because there are fewer alternative sources of information available to the market [Zeghal, 1984, p. 300]. A potential explanation for this finding is that investors can potentially earn greater trading profits by developing information to complement financial statements of large firms than by doing so for small firms. This results in less privately developed information on small companies being available which increases the importance of publicly disclosed accounting information by small firms [Atiase, 1980, p. 25]. Consequently, publicly disclosed accounting information should generate a more extensive market reaction for small companies than for large companies. Studies by Grant [1980], Atiase [1985], Kross and Schroeder [1988] Lobo and Mahmoud [1989] and Zeghal [1984], all show that price reactions to earnings announcements are invertedly related to firm size ${ }^{7}$ while Bamber [1986, 1987] finds that trading volume reactions follow the same pattern of correlation with firm size. It has also been shown that the capital market is able to anticipate large companies' future earnings at an earlier point in time than small companies' earnings [Freeman, 1987]. Also, in the case of a small firm the market reaction persists for a longer period of time indicating that small companies' earnings announcements are more surprising and take more time for investors to interpret and act upon [Bamber, 1987]. Apparently, less information is available about small firms, resulting in less accurate and more diffuse investors' earnings expectations and greater reliance on the companies' earnings announcements for security pricing [Atiase et al. 1988, p. 23].

Capital market research hence shows that security price and trading volume reactions are larger for earnings announcements of smaller firms, indicating that publicly

7 The study by Grant [1980] did not actually consider a size effect but showed that security price reactions to interim reports were smaller for firms listed on the New York Stock Exchange (NYSE) compared to firms whose equity securities are traded over the counter (OTC). Since the latter group is generally relatively small, it could be argued that the results also support the size effect. Further research by Atiase [1987] suggests that the firm size effect can be found for NYSE as well as OTC firms and that an exchange-effect can be found after controlling for firm size. 
disclosed information may be more valuable to investors dealing with small firms. However, the evidence of strong investor reactions to small firms' earnings announcements is not necessarily inconsistent with the assumption that small companies provide information that users do not need or do not understand. While the earnings disclosures may be informative, other disclosures could still be unnecessary or confusing [Atiase et al., 1988, p. 21]. A further complication is that security price reactions are also a function of the timeliness of the earnings releases. If it can be shown that reporting lags systematically vary with firm size, the increased stock price reactions to earnings releases of small firms may be resulting from differences in the timeliness of earnings releases rather than the size of the reporting firm. Therefore, studies on the timeliness of disclosures by smaller firms and their implications for the studies on security price reaction will be discussed in the following section.

\subsubsection{Firm size and the timeliness of disclosures}

The intensity of market reactions to earnings releases is a function of their timeliness [Givoly and Palmon, 1982, p. 487]. Longer reporting lags provide the opportunity for more of the information in the financial report to be supplied by other sources (e.g. search activities by investors or predictions from earnings reports released by other firms), resulting in lower market reactions [Chambers and Penman, 1984, p. 21]. Empirical data supports this assumption, provided that timeliness is defined as the date of announcement relative to the expected date of announcement (and not relative to the end of the financial year for the firm) [Chambers and Penman, 1984, p. 22]. This 'timing effect' was found to be persistent whether the earnings announcement (1) contained good or bad news, (2) was an annual or interim announcement, (3) was made by large or small firms [Kross and Schroeder, 1984, p. 173, Atiase, Bamber and Tse, 1989].

Studies showing larger market reactions for smaller firms (section 2.3.2.1) are confounded by these findings, given the fact that small firms generally have larger reporting lags [Dyer and McHugh, 1975, Courtis, 1976, Chambers and Penman, 1984] and that the timeliness of the reports are negatively correlated with the firm's profitability [Courtis, 1976, p. 50] ${ }^{8}$. The firm size effect on the timeliness of

3 The profitability effect stems from the discretion of managers on the timing of information releases in the sense that the announcement of 'bad' news is intentionally delayed [Givoly and Palmon, 1982, p. 488, Patell and Wolfson, 1982, p. 523, Kross and Schroeder, 1984, p. 164]. An alternative explanation for the delayed announcement of 'bad' news is that a longer period of time is required to audit earnings reports reflecting bad news [Trueman, 1990, p. 286]. In fact, Givoly and Palmon [1982, p. 491] suggest that the length of the audit is the single most important determinant of the timeliness of earnings announcements. Initially it was hypothesised that larger companies would present more auditing problems and therefore would require a longer time period to complete the audit 
disclosures is explained from the premise that large firms have better data processing devices and control procedures, resulting in faster preparation of the financial statements and also shorter audit periods. Also, large firms can claim higher priority from audit firms and 'purchase' less delay [Givoly and Palmon, 1982, p. 500, Haw and Ro, 1990, p. 558-559]. Haw and Ro [1990] have tested the effect of firm size on market reaction to earnings releases controlling for the timeliness of the earnings releases and found some evidence that the firm size effect disappears for firms with corresponding reporting lags. Their study seems to indicate that differences in stock price reactions for firms of different sizes may be explained by differences in reporting lags and not by firm size as such.

Several studies have looked at the timeliness of disclosures by small firms that are not active in the securities markets (e.g. Tsang [1986], Robertson [1986]). These studies all show that a large portion of small firms disclose their annual accounts well over a year after the end of the financial year. Therefore, the usefulness of such disclosures to interested parties may be doubted. In these studies, the timeliness of disclosure typically is used as a measure of compliance with financial reporting regulations. In studies among large firms, non-compliance with accounting regulations is often ignored. In the small firm sector, however, non-compliance seems to be a much more serious problem. Several studies in various countries have demonstrated a considerable level of non-compliance by small firms with financial reporting regulations. These studies will be discussed in the following section.

\subsubsection{Firm size and compliance with disclosure regulations}

The potential of government regulation to facilitate the use of financial accounting information of small firms often is questioned. Of course, company law and accounting standards can reduce the range of possible accounting alternatives for managers, thus reducing management chances to manipulate the accounting information disclosed, and can also provide guidelines to ensure a minimum level of financial disclosures by firms. But the enforcement of such regulations in the small firm sector, given the large number and heterogeneity of firms, would provide an immense task for any regulator. In fact it has been suggested that "many of the financial reporting requirements appear not to be as vigorously enforced as they are for widely held, publicly listed enterprises" [Keasey and Watson, 1988] and also that

[Gilling, 1977, p. 35]. However, empirical results indicated the reverse to be true [Gilling, 1977, p. 35]. Later studies have tested a large number of alternative explanatory variables [e.g. Ashton, Willingham and Elliot, 1987, Ashton, Graul and Newton, 1989 and Carslaw and Kaplan, 1991], generally resulting in relatively low performing prediction models for audit delay. Other studies, however, have shown that the audit of qualified financial reports is more time-consuming and results in a reduction of the timeliness of the report [Whittred, 1980, Keller, 1986]. 
in most European countries comparatively little attention has been given to securing actual compliance with accounting standards [Zeff, 1994, p. 3].

The effectiveness of government regulation to prevent misrepresentations in financial reporting may be established by studying non-compliance. Firms can either ignore certain requirements for the disclosure of particular information items or they can diminish the usefulness of such information by delaying the disclosure of the financial statements. A number of studies have examined the contents of financial statements disclosed. Literature on the contents of disclosures contains surveys of corporate disclosures (1) to simply array the information content, or (2) to document disclosure levels under different regulatory systems, or (3) to make inferences about disclosure adequacy using disclosure indexes from the perspective that more disclosure is better [Ball and Foster, 1982, pp. 198-199]'.

Studies that have surveyed the financial statements of small firms have shown considerable non-compliance with accounting standards or disclosure requirements. A study of small company financial reporting by Carsberg et al. [1985, chapter 4] includes a small survey of accounts from small UK firms, filed with the Registrar of Companies. The analysis of accounts was conducted in order to assess the quality of the accounts filed, in terms of (1) the extent of compliance with accounting standards and company law requirements and (2) the presentation of information, taking into account understandability. The level of (detectable) non-compliance with accounting standards and the Companies Act 1981 varied with specific requirements from $34 \%$ of non-compliance with SSAP 12 ('Accounting for depreciation') to full compliance with SSAP 6 ('Extraordinary items and prior year adjustments') and the disclosure of the directors' remuneration or the auditors' remuneration as required by the Companies Act. Out of the total sample of 113 accounts, 34 were rated as 'poor' in terms of understandability ${ }^{10}$. Further tests revealed a statistically significant positive association between the quality of filed accounts and (1) company-size, (2) the level of audit fees, (3) the inclusion of an audit report and (4) the level of compliance with accounting standards.

Tsang [1986] presents a detailed study of 58 small UK-firms regarding the quality of the information presented and the level of compliance with the 1981 Companies Act. A subjective classification procedure, much like the procedure used in the Carsberg

9 More recent examples of disclosure content studies are Jegers and Buijink [1987], Tonkin [1989], Cooke [1989] and Forker [1992].

10 The classification was based on subjective categorisation by members of the research team, characterised as recently qualified accountants with relatively little experience but upto-date technical knowledge [Carsberg, 1985, p. 77]. The authors therefore add a warning to treat the assessment of quality with great care because of its highly subjective nature, but seem to be able to conclude from the results of several statistical tests that the quality rating process was reasonably reliable [Carsberg, 1985, p.78]. 
study, resulted in a quarter of the accounts to be classified as 'poor', a result fairly consistent with the Carsberg study. The research also showed that from a sample of 256 accounts, $35 \%$ were filed too late, which is, according to Tsang, a reflection of the difficulties of small companies in completing their accounts [Tsang, 1986, p. 55].

Robertson [1986] analyzed a sample of 100 small Scottish manufacturing companies that had fewer than 300 employees, in order to gain (1) a better understanding of the problems related to the auditing of small companies and (2) a better understanding of the preparation and disclosure of small firms' financial statements. The results of the study show that $30 \%$ of the accounts had not been filed within the required time period. Consistent with Tsang, it was found that the smaller the company the more likely it was to have filed statements late [Robertson, 1986, p. 9]. Compliance with accounting standards (SSAPs) varied widely, with high non-compliance figures for SSAP 15 on deferred taxes $(32 \%)$ and SSAP 12 on depreciation (23\%). The author also found rather poor compliance with the Companies Act 1981.

Morris and Omrod [1990] studied UK company financial statements in order to establish 1986 practice of the filing of abridged accounts. Regarding the quality of the information provided in the financial statements examined, the authors remark that "many instances were noted where the disclosure provisions relating to the accounts contained in the 1981 Companies Act, did not appear to be complied with, although the auditors did not comment on this fact" [Morris and Omrod, 1990, p. 13].

The studies of Morris and Omrod, Tsang and Robertson also looked into the extent to which small firms took advantage of the possibility to file abridged accounts. Morris and Omrod found that out of 83 firms that filed accounts, $33(40.2 \%)$ filed abridged accounts, $40(48.2 \%)$ voluntarily filed full accounts and $9(10.6 \%)$ filed full accounts because they were required to do so ${ }^{11}$. Robertson's [1986, p. 11] findings are highly consistent with Morris and Omrod, as he found that $34 \%$ of the firms in his sample that were eligible to file abridged accounts, actually did so. Tsang found that $25(43.1 \%)$ of the companies in his sample filed abridged accounts in the first year they were permitted to do so, while 6 firms $(10.3 \%)$ modified their accounts only in the second year they were permitted to. The results of Morris and Omrod and Tsang also indicate that companies that voluntarily filed full accounts generally appeared to be the smaller companies.

Bollen [1986] studied 94 annual reports of Dutch firms, including 64 small firms. The financial statements reviewed were the first published by these firms after the regulatory change of 1984 , and involved the first mandatory disclosure for Dutch

\footnotetext{
" Most of these companies were required to disclose full accounts because of the size of the holding company. For one firm that also filed full accounts there was insufficient information to determine the reason.
} 
small and medium-sized firms (for details on the financial reporting requirements for small Dutch firms, see Appendix III). The results show considerable deviation from disclosure requirements, more seriously in the annual reports of smaller firms than of larger ones. A similar research, published in 1986 by the Dutch Association of Certified Accountants (Nederlandse Orde van Accountants-Administratieconsulenten, NOvAA) reviewed 150 financial statements over 1984, filed at the Commercial Register. Of these, four did not provide a balance sheet or accompanying notes, eight only provided a balance sheet and sixteen used a form completely different from the mandatory models provided in the Civil Code. Even in providing the most elementary information like the accounting policies followed in valuation and income calculation, a large number of companies failed to adequately comply with the regulatory requirements. An evaluation of the results of both studies mentioned shows considerable incompleteness of the accounts filed in the first year small firms had to disclose their annual accounts. Roos [1992] partly replicated both studies, using annual reports of 30 small firms concerning 1990. From the results of the study it can be concluded tentatively that the disclosures made in 1990 are generally more in compliance with the regulatory requirements compared to those of 1984 [Roos, 1992, p. 50]. Nevertheless, $97 \%$ of all accounts studied were still disclosed after the latest date legally permitted, and also none of the accounts studied complied with all legal requirements.

Other research demonstrates a reason for concern with the compliance of small companies with accounting standards in countries outside of Europe. Ingram et al. [1977] provide empirical data on the disclosure practices of small or closely held businesses in the US, by analyzing the unaudited financial statements of small businesses with which CPAs have been associated. The analysis of 169 statements shows a considerable number of inconsistencies with the disclosure requirements prescribed by GAAP that apply to both audited and unaudited financial statements of both large and small enterprises. The authors conclude that disclosure in the sampled financial statements is just as inadequate for items that are basic to fair presentation, such as alternative accounting procedures, as it is for items that may be irrelevant in most cases, such as earnings per share.

Ramsay and Sutcliffe [1986], in an Australian study on the financial statements of 423 unaudited exempt proprietary companies ${ }^{12}$, analyze the extent of compliance by proprietary companies with aspects of particular Australian Statements of Accounting

\footnotetext{
12 The provisions of the Australian Companies Act and Codes establish two types of exempted proprietary companies: audited exempt and unaudited exempt. Audited exempt companies are not required to file their annual financial statements. Unaudited exempt companies must file a certified copy of the company's financial statements prepared in accordance with the Act and have to be in compliance with the Statements of Accounting Standards issued by the Society and the Institute of Chartered Accountants in Australia [Ramsay and Sutcliffe, 1986, p. 49].
} 
Standards. Non-compliance with six accounting standards (AAS 1 through 6) ranged from $44 \%$ to $90 \%$. Comparing these results with several similar studies on financial reports of listed public companies indicated a much higher level of non-compliance among the financial statements of exempt proprietary companies.

Table 2.1. Studies on small firms' compliance with financial reporting regulation

\begin{tabular}{lll}
\hline Study & Country & Research sample \\
\hline Ingram, Guy, Merei, Justis [1977] & US & 169 small or closely held businesses \\
Carsberg [1985] & UK & 113 small companies \\
Tsang [1986] & UK & 58 small companies \\
Robertson [1986] & UK & 100 small manufacturing companies \\
Bollen [1986] & Netherlands & 64 small companies \\
NOvAA [1986] & Netherlands & 150 small companies \\
Ramsay and Sutcliffe [1986] & Australia & 423 unaudited proprietary companies \\
Morris and Omrod [1990] & UK & 83 small companies \\
Roos [1992] & Netherlands & 30 small companies \\
\hline
\end{tabular}

Although all studies mentioned in this section, indicate that in the small firm sector, considerable non-compliance with financial disclosure regulations does occur, none of these studies provide any explanations for the existence or the level of noncompliance observed. All the same, the occurrence of significant non-compliance does indicate that regulators may have difficulty enforcing financial reporting regulations in the small firm sector, possibly due to the large number and heterogeneity of firms. An alternative explanation may be that regulators just have not put much effort into trying to enforce these regulations. Since most public attention is oriented towards large public companies, regulators may have incentives to spend most of their resources on ensuring adequate financial reporting in that sector. Given the relatively minor attention paid to securing compliance with small firm accounting regulations, the usefulness of mandatory accounting disclosures by 
small firms may be questioned ${ }^{13}$. The following section will further discuss research on the usefulness of small firm financial statements.

\subsubsection{Firm size and the use of financial statements}

The parties interested in the financial reporting of large companies are numerous, heterogeneous and with dissimilar objectives [Gutberlet, 1983, p. 18]. In this setting the financial report contains information to satisfy the information needs of various groups whose information needs are largely unknown. It has been argued that the primary user groups for small firms are less diverse, more easily identifiable and their information needs are better known [Gutberlet, 1983, p. 18]. From this assumption it has been argued that the content of the disclosed financial accounts of a small firm should differ from that of a large firm for two reasons:

1. There are fewer potential users of the financial information disclosed by small firms. For large firms, an extensive list of potential financial statement users can be formatted ${ }^{14}$. It is unlikely, however, that such a large number of different users would be interested in the financial statements of a small firm. Therefore, even if all information required by regulation is relevant there are few users to benefit from it. If the number of potential users of small firm financial statements is smaller, this would result in fewer potential benefits and higher accounting costs per user.

is Also, the use of alternative devices to ensure the quality of financial information disclosed, such as a mandatory audit, does not seem to be very useful in the small firm context. The limited formal internal controls within most small companies and the limited means of verifying whether any controls that do exist have been overridden by the management, raises doubts concerning the feasability of a small firm audit [Keasey, Watson and Wynarczyk, 1988, p. 124]. Furthermore, based on the assumption that small firms are more often audited by small audit firms, the adherence to accounting and auditing standards by small firm auditors may be less and auditor independency may be more of a problem. It has therefore been argued that "the audit of small firm financial statements does not appear to provide external stakeholders with much ground for supposing they are not being misled" [Keasey and Watson, 1993, p. 58].

14 Such a list could include owners, lenders, suppliers, potential investors and creditors, employees, management, directors, customers, financial analysts and advisors, brokers, underwriters, stock exchangers, lawyers, economists, taxing authorities, regulatory authorities, legislators, financial press and reporting agencies, labour unions, trade associations, business researchers, teachers and students and the public [FASB, SFAC 1, p. 24]. 
2. The information needs of users differ when dealing with firms of different sizes. The information needs of users dealing with small firms might be different compared to the information needs of similar users dealing with large firms, for three reasons: $a$. Users, when dealing with small firms, are involved with different decisions and therefore (1) need other information or (2) ascribe different relevance to particular information items. For example, a small company may have only a bank lender making short term decisions, whereas a large company usually has numerous investors and creditors making various types of decisions [FASB, 1981, p. 30].

b. Users dealing with small firms have different decision-making models. The basic issues here are (1) whether users of small firms' financial statements are substantially less sophisticated than their large company counterparts, and, if so, (2) whether this lack of sophistication renders the information generated by current regulation less useful. Although it seems reasonable to assume that banks will assign their more experienced loan officers to large loans and their less experienced officers to loans of smaller size, it does not necessarily mean these officers associated with smaller loans are confused by current regulation [Murray and Johnson, 1983, pp. 8-9].

c. Groups involved with small firms have a different relationship with these firms and as a result have access to sources of information additional to the financial statements. Their knowledge of the enterprise affairs may be more intimate or they may be in a position to obtain the information they need directly from a small firm from knowledge about the management of the firm and detailed information of the company's plans [Abdel-Khalik, 1983, pp. 81-83]. As a result certain financial statement items may be less useful to these users.

In order to gather empirical evidence on the arguments presented above, the first issue would be to establish whether the information needs of a particular user vary with the size of the reporting firm. Several empirical studies have specifically looked into differences in user needs as a result of the size of the reporting firm. Falk et al. [1976] looked into the information needs of commercial lending officers when dealing with financial statements of closely held companies. The study produces a list of 43 financial statement items and the importance lending officers attached to each item. Baker [1990] tried to establish whether loan officers would charge higher interest premiums if the financial report of a company was not audited or if the financial statements were not based on GAAP but were income-tax based. The results of the study indicate that financial statements that are not audited or not GAAP-based, may (separately) result in higher interest premiums. Obviously, such reports will be most often used by small closely held firms. In both studies however, the results are not directly compared to information needs related to large public firms.

Stanga and Tiller [1983] compared the information needs of bank loan officers making lending decisions that involve large public companies with the information needs of bank loan officers making lending decisions involving small private companies. The authors conclude "that the information needs of bank loan officers do not differ substantially between large public companies and small private 
companies". Information needs were not identical but the responses were substantially similar for loan officers of large banks and those of smaller banks (which were assumed to be more familiar with decision processes involved in evaluating loans for small companies). A similar study by Berry, Citron and Jarvis [1987] used a postal questionnaire and interviews to study the perceptions of UK bankers on the information requirements when dealing with large and small companies. The results of the study show that irrespective of the size of the company they are dealing with, bankers use the full financial statements as the primary source of accounting information. It was, however, also found that there were differences in emphasis placed on certain information-items as a result of the complexity of the business and the availability of alternative information sources, indicating that on a more detailed level the information needs of bankers are different when they are dealing with smaller firms.

Since in some countries small firms are allowed to disclose abridged financial statements, some studies have looked at the effect of such reduced disclosure on the user groups, particularly bankers. Berry, Citron and Jarvis [1987] show that the audited full statutory accounts are the most important source of financial information used by bankers irrespective of the size of the company they are dealing with. They also found it to be unlikely that in the case of small firms alternative sources of information could replace the statutory accounts as most of these are not readily available. From the results of their study, the authors conclude that a move towards a reduction in disclosure requirements for small firms is not likely to reduce the burden on these firms unless an alternative approach to lending is taken by bankers. Morris and Omrod [1990], surveying assessment agencies and credit managers, also find the full filed accounts, when they are available, to be the single most important source of information for both groups when dealing with small firms. If modified (abridged) accounts were filed by a small company, the respondents in the study felt it would be possible to compensate half of the information lost through other sources of information but that the costs to obtain this information would be considerable [Morris and Omrod, 1990]. Both the studies by Berry Citron and Jarvis [1987] and Morris and Omrod [1990] as well as a study by Egginton [1977] show that lending bankers dealing with small firms rely extensively on other sources of information in addition to the annual report, particularly plant visits and internal bank records of past experiences with the client. These sources of non-accounting information are more important in the context of a small firm to compensate for the restricted number of alternative sources of information on these firms.

On the issue of whether accounting information disclosed by small firms is useful given the decision making processes of users of such information, there is virtually no research available ${ }^{15}$. Empirical research on the use of accounting information in

15 Some evidence may be gathered from research by Libby [1975] indicating there is no significant difference in the ability to predict company failure using accounting information 
banks' loan-granting decisions has shown that accounting information plays an important part in this context ${ }^{16}$, but few of these studies have specifically looked at loan granting decisions in a small firm context. Danos, Holt and Imhoff [1989] conducted an experimental study on the use of accounting data in the lending decisions in the context of medium-sized firms. As far as the decision models of bankers dealing with small versus large firms are concerned, no empirical literature has been published to our knowledge ${ }^{17}$.

The empirical studies presented in this section do not seem to provide strong evidence of differences in information needs of bankers when dealing with small versus large firms. However, several points should be taken into account here. Firstly, in most of the studies bankers indicated that the full statutory accounts are preferred over abridged accounts. Secondly, bankers require the statutory accounts to be audited and rely much less on internal management accounts that are not audited by an external accountant. Therefore the mandatory disclosure of unaudited abridged accounts, as in the Dutch company law, does not seem to fit the information needs of bankers very much. Also, none of the studies mentioned here considered the reliance of bankers on regulation to ensure an adequate level of financial accounting

between a group of bankers with large customers and a group with smaller customers. Keasey and Watson [1986a, 1986b, 1987, 1988] have conducted a series of studies concerning the predictability of small company failure. The results of these studies indicate that public information on small firms does not result in adequate failure prediction by credit analysts. The authors also concluded that "the ratios selected for this study do not allow the same level of accuracy to be achieved as that obtained in the majority of the large company studies" [Keasey and Watson, 1986b]. Including non-financial information in the evaluation process resulted in only marginally better predictions [Keasey and Watson, 1987]. In a further study the same authors find the inclusion of information on nonsubmission of accounts an improvement to models of small firms' failure prediction, contrary to studies including the same kind of information in failure prediction models for large firms [Keasey and Watson, 1988]. According to the authors the lower failure prediction ability of small company models results from the inherent variability of small company performance over time, the ability of the director/manager to manipulate or exclude transactions from the books and the less stringent reporting requirements for small companies [Keasey and Watson, 1988].

16 For a more elaborate discussion of this line of research see for example Foster [1986] and Griffin [1987].

17 Campbell [1984] studied the decision processes of bank loan officers using protocol analysis, to determine whether two proposed and two implemented differential requirements in GAAP had any effect on the credit decisions involving small closely held companies. The study, however, included only 4 loan officers, and the cases used in the study mostly included information items most loan officers were very unfamiliar with. Therefore, the results of the study are of little use in assessing the usefulness of Little-GAAP financial statements in the small firm context. 
information or the ability of banks to force small firms into the preparation of full audited accounts in the absence of a statutory requirements to do so. And finally, it should be remembered that in questionnaire studies, users tend to overstate their information needs since they are in no way affected by the costs of producing that information. The costs of complying with financial reporting regulations will be the topic of the following section.

Table 2.2. Survey studies on the usefulness of accounting information disclosed by small firms.

\begin{tabular}{|c|c|c|c|}
\hline Study & Research topic & Research sample & $\begin{array}{l}\text { Response } \\
\text { rate }\end{array}$ \\
\hline $\begin{array}{l}\text { Falk, Gobdel and Nauss } \\
\text { [1976] }\end{array}$ & $\begin{array}{l}\text { Effect of auditing on the } \\
\text { usefulness of small firm } \\
\text { financial accounting } \\
\text { disclosures (US) }\end{array}$ & $\begin{array}{l}950 \text { commercial } \\
\text { lending officers }\end{array}$ & $25.0 \%$ \\
\hline Egginton [1977] & $\begin{array}{l}\text { Information used in } \\
\text { evaluating borrowing } \\
\text { requests from small firms }\end{array}$ & $\begin{array}{l}91 \text { bank branch } \\
\text { managers }\end{array}$ & $90 \%$ \\
\hline Stanga and Tiller [1983] & $\begin{array}{l}\text { Information needs of loan } \\
\text { officers dealing with large } \\
\text { versus small companies (US) }\end{array}$ & 400 bankers & $57.5 \%$ \\
\hline Abdel-Khalik [1983] & $\begin{array}{l}\text { Perceptions on financial } \\
\text { disclosure regulations for } \\
\text { private firms (US) }\end{array}$ & $\begin{array}{l}554 \text { bank employees } \\
530 \text { managers } \\
1.100 \text { CPAs }\end{array}$ & $\begin{array}{l}24.0 \% \\
18.7 \% \\
30.0 \%\end{array}$ \\
\hline $\begin{array}{l}\text { Berry , Citron and Jarvis } \\
\text { [1987] }\end{array}$ & $\begin{array}{l}\text { Perceptions of bank } \\
\text { managers on information } \\
\text { requirements when dealing } \\
\text { with large and small } \\
\text { companies (UK) }\end{array}$ & 108 banks & $57 \%$ \\
\hline $\begin{array}{l}\text { Morris and Omrod } \\
\text { [1990] }\end{array}$ & $\begin{array}{l}\text { Perceptions on the disclosure } \\
\text { of abridged financial state- } \\
\text { ments by small firms (UK) }\end{array}$ & $\begin{array}{l}93 \text { assessment agencies } \\
105 \text { credit managers }\end{array}$ & $\begin{array}{l}20.4 \% \\
28.3 \%\end{array}$ \\
\hline Baker [1990] & $\begin{array}{l}\text { Effect of GAAP and } \\
\text { auditing on the usefulness of } \\
\text { financial statements to loan } \\
\text { officers (US) }\end{array}$ & 230 loan officers & $?$ \\
\hline
\end{tabular}

\subsubsection{Firm size and compliance costs}

Probably the most frequently used argument to advocate differential financial reporting regulations for small firms, relates to the costs of adhering to accounting standards and financial reporting regulations. Regulatory costs are said to be borne disproportionately by small companies, resulting from relatively higher production costs and larger competitive disadvantage costs. A small company may not have anyone in its employ to maintain accounting records and may rely more heavily on 
the outside CPA to perform accounting tasks, obviously resulting in higher fees. Also, a small company's outside accountant will probably be required to educate his client to ensure a sufficient level of knowledge of the enterprise's activities and financial condition and the applicable accounting principles so that the client can accept responsibility regarding the fairness of valuation and presentation and adequacy of disclosure. The outside CPA is likely to be a small practitioner incurring relatively greater costs for maintaining his professional expertise to deal with complex accounting rules. Small firms are relatively infrequently confronted with complex measurement and disclosure rules and therefore lack the possibility of developing routine procedures and the advantage of economies of scale large firms enjoy as a result of a highly defined process used to handle a large number of similar transactions or events [Murray and Johnson, 1983, p. 12]. Finally, large firms can spread fixed production costs of regulation over larger revenues.

For empirical studies on the costs of financial reporting regulations, an essential problem is to gather reliable cost-estimates. Firstly, this kind of data is hardly available in many countries because the disclosure of the costs related to the production and distribution of annual accounts is not mandated. But even when these figures can be derived from firms, strong incentives exist to distort the information provided on the cost effects of regulations. Therefore, cost data provided by firms have a serious danger of being over-estimates ${ }^{18}$. A second problem is that many of the costs related to financial reporting regulations are indirect costs that are difficult to trace and even more difficult to measure ${ }^{19}$.

18 The extreme difficulty to gather reliable estimates on the costs of regulation is well demonstrated by Benston [1984]. During legal proceedings concerning the 'Line of Business Program' (LB Program) of the Federal Trade Commission (FTC), both the FTC and the firms opposing the LB Program came up with estimates on the costs for firms to comply with the program. The FTC estimated annual costs per firm ranging from $\$ 10,000$ to $\$ 20,000$ in the first year and from $\$ 5,000$ to $\$ 10,000$ in subsequent years. These estimates where based on data from 25 firms, that ranged from $\$ 40,000$ to $\$ 2,000,000$ (average $\$ 548,000$ ) and were corrected by the FTC for firm size, the number of LBs and for (suspected) over-estimation of costs by the firms. Estimates of the opposing firms, based on detailed data provided by five firms, were at least 30 times higher. Initial start-up costs were estimated from $\$ 350,000$ to $\$ 1,800,000$ and annual maintenance costs ranged from $\$ 95,000$ to $\$ 325,000$. The judge presiding the legal proceedings concluded the companies' estimates where not representative of the costs for all firms and also believed that the estimates of the opposing firms overstated the actual cost [Benston, 1984, p. 134]. Benston, however, provides evidence that the FTCs estimates were also inaccurate because "the assumption on which the FTCs cost estimation procedure rests is demonstratively not valid" and "the methods [..] followed [..] seem very crude - even dishonest" [Benston, 1984, pp. 134-135].

19 Empirical studies on the costs of financial reporting regulations are Bastable [1977], Phlips and Zecher [1981], Horwitz and Kolodny [1982] and Espahbodi and Hendrickson [1986]. These studies, however, include only large firms and suffer from the use of very 
Nair and Rittenberg [1983] address the issue of the relationship between the size of business and accounting costs both qualitatively and quantitatively, using a questionnaire survey of CPAs, bankers and businessmen of relatively small businesses. The qualitative analyses show strong agreement across the three groups that accounting costs for small businesses are disproportionately high compared to their larger counterparts. In the quantitative analyses, a distinction is made between annual cost of accounting personnel (averaging $\$ 219,000$ ) and annual fees paid to outside CPAs (averaging $\$ 28,000$ ). The results showed a significant negative correlation between the annual fees paid to an outside CPA as a percentage of some measure of firm size, and the size of the firm measured by sales, total assets, number of employees and number of shareholders. This relationship is consistent regardless the type of outside accountant (Big 8 - Non-Big 8) and the type of service provided (audit, review or compilation). From the negative relationship between internal accounting personnel costs and firm size also reported in the study, the authors conclude that the proportionately higher CPA fees paid by smaller companies can not be explained from the supposition that small firms may be hiring a CPA for work done by internal accountants in larger businesses. Although this result seems rather counter-intuitive the authors provide no further comment on this finding. Whether accounting costs are disproportionately higher for small firms can not be concluded from the study since this would require a comparison between accounting costs and benefits [Nair and Rittenberg, 1983, p. 241]. Benefits, however, were not investigated in the study.

Another strand of research has concentrated on the determinants of the audit fees charged to companies. In these studies, models of the audit fee-setting process are built, relating the audit fee charged to auditor and auditee characteristics ${ }^{20}$. A number of these studies has concentrated on audit pricing for large versus small firms and on differences between the pricing behaviour of large versus small audit firms in these respective company sectors (e.g. Simunic [1980], Francis and Stokes [1986], Francis and Simon [1987] and Brinn et al. [1991]). These studies generally indicate that the models used to explain the audit fee setting process for large (auditee) firms are less suited to be used with small firms. When applied to small firms, the models built explain less of the variability in audit fees and also incorporate a larger number of significant explanatory variables, both suggesting the small firm audit fee model may

small sample sizes. Bastable [1977] used data from only 14 firms and Philips and Zecher [1981] from 22 firms. Espahbodi and Hendrickson [1986] used data from 11 firms which, however, was of less influence on the results of their study because (1) the data were used to estimate the total costs for a group of 22 firms and (2) the costs-figures, even if misstated by $1000 \%$, would not have effected the conclusions of their study [Espahbodi and Hendrickson, 1986, p. 48]

20 Most of these studies have concentrated on large firms. For an overview and discussion of existing empirical research in this area see Francis and Simon [1987] and Brinn et al. [1991]. 
be more complex in nature [Brinn et al., 1991, p.10]. The studies also provide evidence for the existence of a price-premium paid by relatively small auditees dealing with large audit firms [Francis and Simon, 1987, p. 147], indicating small auditees pay relatively larger audit fees when dealing with a large audit company, while for large auditees the size of the audit firm has no effect on the audit fee paid.

A Dutch study by Bak et al. [1985] showed that the total cost of the external accountants as a percentage of sales, are negatively correlated with firm size, confirming the findings of Nair and Rittenberg. The cost of the internal accountants of a company as a percentage of the company's sales, however, were positively related with firm size. Hence, Dutch smaller companies tend to employ external accountants for activities for which larger companies use internal accountants. However, the study mentioned here involved relatively large, mostly publicly traded firms and may therefore have limited applicability to small closely held firms.

The application of audit fee research to the small private firm setting may be limited because performing an audit may not be the most important service provided by an external accountant to these firms. Page [1984], Carsberg et al. [1985] and Humphrey and Turley [1986, p. 29] found that the most important service of professional accountants to small firms are the preparation of the accounts and tax advice. The preparation of the accounts was also perceived to be the most timeconsuming (i.e. the most costly) activity of the external accountant. The average yearly fee paid by small UK firms reported in empirical studies ranges from $£ 1200$ for firms with 5 to 10 employees [Carsberg, 1985] to $£ 2164$ for firms with 10-20 employees [Robertson, 1986, p. 23]. Research among small company auditors indicates that of the fees paid by small companies, $23 \%$ is accounted for by audit services, indicating that at an aggregate level the small company audit is not a major source of fees to auditors [Humphrey and Turley, 1986, p. 30].

A considerable number of studies does not aim at measuring the cost and benefits of financial reporting regulation, but tries to identify the perceptions of respondents on the economic effects of financial reporting regulation ${ }^{21}$. To resolve the problem of gathering reliable cost-benefit estimates, these studies use the degree of consensus among interested parties on cost-benefit issues as a measure of the reliability and magnitude of the costs of financial reporting regulations (see table 2.3).

Studies by Abdel-Khalik [1983, p. 57-67] and Nair and Rittenberg [1983, p. 236238] asked respondents (small firm managers and CPAs) to indicate the five main reasons for increases in total accounting costs. The results of Nair and Rittenberg

21 Studies involving large firms by Mautz and May [1978], Horwitz and Kolodny [1982], McKinnon [1984], Butterworth and Falk [1984] and Gray and Roberts [1986] all use questionnaires to study respondents' views on the economic effects of financial accounting regulation. These studies usually include financial analysts, corporate executives and CPAs. 
indicate that businessmen are much less likely to blame the increased complexity of accounting regulations for an increase in their accounting costs. $75 \%$ of the CPAs and $35 \%$ of the managers thought that the reduction in accounting costs from not having to comply with existing accounting standards in 14 areas would be greater than 5 percent. Nevertheless the increase in accounting standards was rated as the second most important factor in increasing accountants' fees by both CPAs and managers. In both studies, general inflationary conditions were perceived to have caused most of the fees' increases by both groups of respondents.

Table 2.3. Studies on perceptions on the costs of financial reporting regulation

\begin{tabular}{|c|c|c|c|}
\hline Study & Research topic & Research sample & $\begin{array}{l}\text { Response } \\
\text { rate }\end{array}$ \\
\hline $\begin{array}{l}\text { Nair and Rittenberg } \\
\text { [1983] }\end{array}$ & $\begin{array}{l}\text { Accounting costs of small } \\
\text { privately held businesses }\end{array}$ & $\begin{array}{l}99 \text { businessmen } \\
70 \text { CPAs } \\
121 \text { bank employees }\end{array}$ & $\begin{array}{l}68.7 \% \\
77.1 \% \\
57.8 \%\end{array}$ \\
\hline Abdel-Khalik [1983] & $\begin{array}{l}\text { Perceptions on financial } \\
\text { disclosure regulations for } \\
\text { small private firms. }\end{array}$ & $\begin{array}{l}554 \text { bank employees } \\
530 \text { managers } \\
1.100 \text { CPAs }\end{array}$ & $\begin{array}{l}24.0 \% \\
18.7 \% \\
30.0 \%\end{array}$ \\
\hline Page [1984] & $\begin{array}{l}\text { Perceptions on financial } \\
\text { disclosure regulations for } \\
\text { small firms. }\end{array}$ & $\begin{array}{l}413 \text { small firm } \\
\text { directors }\end{array}$ & $41.0 \%$ \\
\hline Carsberg [1985] & $\begin{array}{l}\text { Perceptions on financial } \\
\text { disclosure regulations for } \\
\text { small firms. }\end{array}$ & $\begin{array}{l}113 \text { small company } \\
\text { executives } \\
50 \text { auditors }\end{array}$ & $\begin{array}{l}44.0 \% \\
-*\end{array}$ \\
\hline Keasey and Short [1990] & $\begin{array}{l}\text { Perceptions on accounting } \\
\text { burden imposed by financial } \\
\text { reporting regulations }\end{array}$ & $\begin{array}{l}100 \text { small firm } \\
\text { managers }\end{array}$ & $100 \%$ \\
\hline
\end{tabular}

* Most of the auditors in this sample were from the auditing firms of the companies that participated in the study, that were interviewed with permission (and through intervention) of these companies.

UK studies by Page [1984] and Carsberg et al. [1985] indicate that the mandatory filing is seen, both by managers and auditors, as the most important administrative burden which small firms are facing. Auditing costs were considered less burdensome. Keasey and Short [1990] studied (UK) small firm perceptions on the relative burden of annual account preparation and their relation with firm size, firm organisation, firm financing and type of accounting procedures. By means of a questionnaire study, small firm managers were asked to rank the burden of preparing annual accounts against the burden resulting from other administrative requirements (e.g. tax information, bank information). The results of their study, involving twelve explanatory variables (including firm size, firm age, and experience of the owner in 
business $)^{22}$, indicate that the perceived relative burden of preparing annual accounts is not influenced by any of the factors investigated (Keasey and Short, 1990, p. 310). Also, less than half of the respondents indicated that the burden of annual account preparation was one of the top four out of eight administrative requirements presented to them, indicating financial reporting is not considered to be an important burden by many small firms.

\subsubsection{Firm size and competitive disadvantages}

A frequently used argument to oppose mandated financial disclosure for small companies is that disclosure might have a substantial negative effect on the competitive position of these firms. Salamon and Dhaliwal [1980, p. 557] argue that opportunity costs of disclosure are greater for small firms because disclosures will tell competitors much more about the details of the managerial practices of small firms than they do of the practices of large firms. However, the effect of firm size on opportunity costs, such as competitive disadvantage costs, is not very clear-cut. In fact, it is debatable whether any competitive disadvantages result from financial disclosure regulation. It can be argued that each company would be better off when provided with more information about competitors. This proposition, however, implies that all of the companies competing in a market need to comply with the same financial accounting regulations. If, however, some of these firms do not have to publish accounts, competitive disadvantages could well exist ${ }^{23}$. The magnitude of these competitive costs depends on the nature of the information to be disclosed, the nature of the firm and the nature of the competition.

Foster [1980] comments on the argument that firms will suffer from competitive disadvantages when supposedly sensitive items are disclosed, by stating that there is very little empirical evidence to substantiate this argument:

22 The model included ten dummy variables code 1 if (1) the firm was an incorporated company, (2) benefits from the preparation of accounts were perceived, (3) a large accounting firm was used, (4) all general accounting needs of the firm were believed to be provided by its professional firm of accountants, (5) the accounts were prepared externally by an accountancy firm, (6) management accounts were prepared at least monthly, (7) the volume of turnover had grown between 1982 and 1986, (8) computers were used by the firm to prepare annual accounts, (9) the owner/founder had previous business experience and (10) start-up advice was received. Additionally, firm size was measured by the natural $\log$ of the number of employees and firm age was measured by its natural log.

23 In the Netherlands this argument applies for example to subsidiary companies that are consolidated in the accounts of the parent-company, and also to proprietorships. 


\begin{abstract}
"apart from a questionnaire by Mautz and May there is little empirical research that pertains to this argument. Empirical research that probes reasons for a 'competitive disadvantage' would appear to be very useful to a policy maker" [Foster, 1980, p. 524].
\end{abstract}

The research of Mautz and May [1978] was not intended to measure competitive disadvantage costs. They merely tried to find out whether these costs were recognized by managers and by financial analysts and found that there were differences in the perceptions on competitive disadvantage costs resulting from financial disclosure between the groups as well as considerable differences within each of the these groups.

The existence of competitive disadvantages resulting from financial reporting activities is an area that is typically covered by perception studies. Mautz and May [1978] studied the perceptions of corporate executives and financial analysts of competitive disadvantages resulting from financial disclosure. By far the greater part of the respondents from both groups finds that existing (in 1978) disclosure levels had not affected or increased the competition in the US economy, while only a relatively small number felt that it lead to a decrease in competition [Mautz and May, 1978, p. 99]. Slightly more than half of all corporate executives felt that there was a degree of competitive disadvantage in existing (1978) reporting requirements while only less than one third of the analysts felt the same. Although differences between the perceptions of both groups where identified, differences of opinion within each of the groups were at least as great.

Page [1984, pp. 276] also comments on the use of small company accounting information by competitors. From the results of a survey among 413 active and independent small companies, Page concludes that "there does not seem to be extensive experience of identified harm arising from disclosure of financial information". Furthermore, $72 \%$ of the respondents indicated that during the last year they had no cause to gather and examine publicly filed information about a business contact company. As to the use of publicly filed information concerning the respondent's firm by any competitors to the filing firm's disadvantage, $10 \%$ of the respondents were aware of such an event. Although most respondents did not give any details of these instances, the events mentioned were (a) the use of information by business contacts, (b) approaches to purchase the company and (c) information used in credit evaluation [Page, 1984, p. 276].

Following Page, Carsberg et al. [1985] also investigated competitive disadvantage costs. Managers of small firms generally believed that their accounts contained items they would rather not disclose to their competitors. On the other hand, there was disagreement on the question whether other companies' accounts were of use to their business. Of the respondents, $10 \%$ had investigated the accounts of another company in the last 3 years and $38 \%$ had done so indirectly (through purchasing external services). The main reason for this lack of interest in competitors' accounts was said 
to be the tendency of these figures to be out of date. Although many managers (66\%) find there are items in the accounts they would rather not disclose to competitors, an equal number of respondents $(64 \%)$ does not mind how much information is publicly disclosed, as long as the cost of producing the accounts is kept down [Carsberg et al., 1985, p. 32].

\subsubsection{Financial reporting regulation and ownership structure}

Many authors have pointed out that firm size might not be the key-criterion for granting exemptions from financial reporting regulation. It has been argued that the most important factor in determining whether a firm should be compelled to provide certain accounting information is the ownership structure of the firm and not its size. The arguments used to advocate differential regulations for private firms as opposed to public firms ${ }^{24}$ concentrate on the specific characteristics of private firms that may give rise to the idea that they should be exempted from financial reporting regulations. The central issue is that, in comparison to a public firms, different relationships exist between a private firm and interested parties such as managers, owners and outside stakeholders (i.e. banks). Therefore, the role of accounting information is different within privately held firms which as a result could give rise to different financial reporting requirements.

\subsubsection{Ownership structure and the primary users of financial reports.}

Regarding the purpose of financial statements of public firms, the focus has predominantly been on the information needs of investors who are regarded as the primary user group of annual accounts. With private firms, (potential) investors may be of less importance since shares of private firms are not publicly traded and the number of investors associated with a private firm is generally far smaller compared to a public firm of comparable size. Absentee-owners and lenders seem parties of more importance when considering the goal of private firms' financial statements (see table 2.4).

\footnotetext{
24 Although it is primarily the public-private company dichotomy that is addressed when differential regulation based on legal form is discussed, other differences in legal forms may also lead to different reporting rules. Financial reporting regulation in most countries is limited to certain businesses mostly excluding firms with full liability. The Fourth EC Directive only applies to limited liability companies, and mutual insurance companies. As a result all proprietorships are excluded from the regulations, as are less frequently used legal forms like general partnerships (vennootschap onder firma), civil law companies (maatschappen) and limited partnerships (commanditaire venootschappen). Later amendments on the Fourth and Seventh EC Directives, however, have extended the scope of Dutch financial accounting legislation to a subset of general partnerships and limited partnerships [Nederlandse Staatscourant, September 30, 1991, p. 5].
} 
Table 2.4. Parties with interests in financial reports issued by smaller privately owned businesses (adapted from Gutberlet, 1983, p. 19]

\begin{tabular}{|l|l|}
\hline \multicolumn{2}{|c|}{ Present and prospective owners } \\
\hline \multicolumn{1}{|c|}{ Internal } & \multicolumn{1}{c|}{ External } \\
\hline $\begin{array}{l}\text { Owner-manager } \\
\text { Other owners actively involved }\end{array}$ & $\begin{array}{l}\text { Absentee owners } \\
\text { Prospective owners }\end{array}$ \\
\hline \multicolumn{1}{|c|}{ Internal } & \multicolumn{1}{c|}{ External } \\
\hline \multicolumn{1}{|c|}{ Other parties at interest } \\
\hline Professional manager & $\begin{array}{l}\text { Lenders and other creditors (primary) } \\
\text { Taxing authorities } \\
\text { State and federal regulatory agencies } \\
\text { Bonding companies } \\
\text { Credit agencies }\end{array}$ \\
\hline
\end{tabular}

If investors are not the principal users of small businesses' financial statements, the accounting rules defined for public firms that are aimed at the needs of investors may not be appropriate in the context of a private firm. As current standards are primarily designed for the parties interested in publicly owned entities, members of other userclasses (which may be primary users of information about privately owned businesses) may incur substantial costs from analysis and interpretation only to find that the information is of little or no interest to them.

An essential empirical issue to substantiate this argument, is to establish whether information needs do actually vary between user groups. Various empirical studies have focused on differences in information needs between two or more groups of users. These studies typically use a list of information items, which are rated in terms of usefulness by various user groups (mostly investors and bankers). A US study by Benjamin and Stanga [1977] reported that the preferences of commercial bank loan officers and professional financial analysts for the disclosure of accounting items in financial statements differed significantly for 51 out of the 79 items mentioned in the questionnaire. This result would indicate that the information needs of both groups differ considerably. The results of this study were contradicted by Firth [1978], who reported no important differences in disclosure needs of UK financial analysts and bank loan officers regarding 75 items similar to those used in the Benjamin and Stanga study. McCaslin and Stanga [1986] looked into the differences in preferences for methods of measurement in financial statements between chartered financial analysts and chief commercial loan officers in the US. Their results are consistent with the study of Firth as they find only a small number of significant differences between the measurement needs of bankers and analysts.

The results of the studies mentioned here, tentatively suggest that the information needs of investors and bankers may be generally similar. So, the mere fact that not investors but bankers may be the primary users of private company financial 
statements, does not provide much reason for differential financial reporting regulations for these firms. Nevertheless, there may be other reasons why the information needs of users dealing with private firms may be different from those of users dealing with public firms. These arguments, that are based on the role of accounting information within private firms, will be discussed next.

\subsubsection{Ownership structure and the stewardship function of accounting information}

In privately owned businesses the number of owners is much smaller and there is less diversity in their objectives and consequently their information needs. Also, owners may have an intimate ownership-management relationship and in many instances ownership and management are synonymous [Gutberlet, 1983, pp. 18-20]. Other owners might have a non-management position within the firm and are actively involved in its operations. In those instances in which an owner is not an active participant in the management of the enterprise he may still have the authority to obtain the information desired for decision-making purposes. Hence, as a consequence of proximity, association, or access to information, absentee owners may not need all the information an investor in public firms may need [Gutberlet, 1983, p. 20].

Very few empirical studies have looked at differences in the role of accounting information within private versus public firms. Penno and Simon [1986] have focused on differences in accounting method choice between private and public firms. If private firms are more likely to be owner-controlled than public firms and the use of accounting numbers as a performance metric for resolving incentive problems is more a characteristic of management-controlled firms, we may expect to see differences in accounting choice between publicly traded and privately held firms [Penno and Simon, 1986, p. 562]. The results of the study provide evidence that such differences do exist.

\subsubsection{Ownership structure and the monitoring function of accounting information}

Regarding private companies, the stewardship role of the financial statements related to the separation of ownership from control may be considerably less relevant, since most major shareholders are usually also the directors of the enterprise and thus have direct control over operational and strategic decision making [Keasey and Watson, 1993, p. 41]. Nevertheless, the information asymmetry problem may still be a major concern in the private firm context. The lack of separation of ownership from control, coupled with the limited liability, gives the owner/manager both the scope and the incentive to engage in opportunistic activities at the expense of other factor suppliers. Although a large majority of private firm owner-managers may have no 
intention of acting opportunistically, great uncertainty and the lack of reliable information about the firm and its owner-managers mean that outside stakeholders are often unable to distinguish successfully between the opportunistic and nonopportunistic firm. Hence, the closely held nature of these firms makes adequate monitoring of the firm by creditors difficult and relatively costly. This would place particular importance on the role of accounting information in reducing uncertainty by facilitating the monitoring of small firm owner-managers by external contracting parties such as bankers, creditors, taxing authorities, etc.

However, in a private firm setting, bonding and signalling behaviour will be likely to be of more importance to outside stakeholders than historical financial information on the firm's performance [Keasey and Watson, 1993, p. 42]. To fulfil its role, accounting information has to be perceived to posses a number of characteristics: it has to be seen as credible, reliable, relevant and timely. The significant information asymmetry problems within a private firm, resulting from the owner-manager's full scrutiny over business decisions and the choice of accounting methods to report on the firm's financial position, as well as the lack of incentives for third parties such as analysts to overcome information deficiencies by collecting and analyzing information for sale, given the limited size of the market for financial information on individual private firms, may strongly hamper the use of financial accounting information by stake holders [Keasey and Watson, 1993, p. 46]. Whether this would result in an increased desirability of financial reporting regulation, from an economic point of view depends on the effectiveness of government intervention compared to alternative arrangements to achieve an adequate level of financial information production.

Bankers can reduce the risk asymmetry with limited liability company managers by granting loans only on a short term basis and securing them on the personal assets of the owner. In this way, banks are able to discourage owner-managers from undertaking excessively risky projects. On the other hand, owner-managers will tend to over emphasize short term solvency and over-invest in safe, saleable assets, though this may not be optimal in business terms. Also, owners with good projects but little collateral may end up not being financed. Thus, private firm owners have incentives to engage in signalling activities. Given the difficulty of proving the credibility of accounting information produced by the firm, alternative solutions may be sought, such as establishing a good reputation, or strong and frequent relationships with fewer stake holders thereby voluntary bonding the firm [Keasey and Watson, 1993, p. 61]. The availability of alternative ways of solving agency problems would reduce the necessity of financial reporting by smaller private firms. These arguments would indicate that there is little need for financial reporting regulation regarding the private firm.

Empirical studies have shown that the perceptions of user-groups, such as investors and bankers, of the usefulness of private firm financial statements differ considerably from the perceptions of firm managers and CPAs on this point. A FASB study on financial reporting by privately owned companies showed strong disagreement 
between practitioners and bankers on this theme. Practitioners argue that (1) less reliance is placed on the financial statements of private companies and (2) more information can be obtained from private companies at request. Bankers stated that the same information is needed from public and private companies for making similar decisions and that they are not always as successful in obtaining information from private companies at request [Abdel-Khalik, 1983, pp. 80-81]. Nair and Rittenberg [1983] conducted a survey-study among (1) CPAs who have small and/or private businesses as their clients, (2) managers of privately held businesses and (3) bankers who grant loans to small and/or private businesses. Their findings also indicate that there are considerable differences in perceptions between businessmen and CPAs versus bankers on the issue of varying information needs of users dealing with small or private firms versus users dealing with large public firms.

There is little empirical evidence that accounting information disclosed by private firms is significantly different from accounting information disclosed by public firms. For example, the findings of capital market research have limited bearing on the arguments for differential reporting requirements for private versus public firms since the studies in this area only deal with public firms. Consequently, the empirical evidence on the firm size effect found in capital market studies (see section 2.3.2.1) applies only to publicly held companies. The potential differential information content of financial statements of private versus public companies has virtually not been addressed in empirical research [Atiase, Bamber and Freeman, 1988, p. 25]. An exception is a study on audit delay by Ashton, Willingham and Elliot [1987], that has shown that the explanation that large firms have better control procedures and can claim higher priority from audit firms and 'purchase' less delay may only hold for public firms as they found a positive relationship between timeliness and firm size for nonpublic companies. The results of this study also show that audit delay (which is a measure of the timeliness of disclosures) is significantly larger for companies that are not publicly traded. In addition, Carslaw and Kaplan [1991] found that audit delay was longer for firms which are largely owner-controlled compared to companies that were manager-controlled. These results would indicate that it is more difficult to audit private companies, resulting in longer reporting lags for these firms.

\subsection{Concluding remarks}

In this chapter, the application of existing economic theories of financial reporting regulation to the small private firm context has been explored. Next, the debate on differential reporting standards for small or private companies was presented. The arguments used to defend exemptions from financial reporting regulation based on firm size were presented and the difficulties of following such an approach to the differential reporting problem were discussed. Then, the discussion switched to the ownership structure of businesses and arguments were presented to advocate differential financial reporting regulation for private firms. 
Whether the existence of differential reporting systems can be explained by public interest arguments or from private interest theory remains largely an empirical question. To test the public interest explanation it should be established whether the actual economic effects of the regulation are in line with the intended economic effects expressed by regulators. Private interest explanations depend on the ability to explain existing regulations from economic effects on parties concerned and the organization and information costs of these parties. However, it is not the aim of this dissertation to provide evidence whether the current financial reporting regulations can be explained from public interest of from private interest arguments.

On the question whether financial reporting regulations should be uniform for all firms, most attention has been focussed on the need for exemptions for either small firms or private firms. A problem with empirical studies on small firms is that there is no general consensus on when a firm is to be defined as a small firm. Therefore the studies in this area tend to have very different sets of firms included in their samples. This makes the results of these studies often difficult to compare. And even if empirical evidence would show that financial reporting regulations have disproportionate economic effects for smaller firms it would be extremely difficult to decide on an adequate cut-off point to separate smaller firms from large firms.

This problem generally applies to providing exemptions to small firms. Any regulator that wants to implement differential reporting regulations based on firm size has to solve the problem of defining the set of firms that these exemptions should apply to. This constitutes a major drawback in building differential reporting regulations on firm size.

In the case of private versus public firms the basic issue is that financial reporting regulation that is aimed at protecting the primary user group of financial statements of public firms, investors, does not seem to be adequate for private firms. In private firms there is much less distinction between ownership and control and also the number of shareholders and the transfer of shares is more more restricted. However, private companies that have limited liability still may need to be regulated to protect outside stakeholdes such as bankers. In this respect it is argued that information asymetry problems may be much larger in private firms. However, there are much more private firms than there are public firms. This makes the enforcement of compliance with financial reporting regulations for private firms a much larger problem. If compliance can not be adequately ensured, bankers may rely much more on alternative monitoring devices and alternative sources of information. In that case the effectiveness of financial reporting regulations for private firms to protect bankers may be questionable.

In the debate on standards overload and differential reporting the distinction between small versus large firms and public versus private companies is often intertwined. It also seems that most attention has been on firms that are small as well as private, as is underlined by a remark of the FASB that "most concerns about financial reporting by private companies have focused on small business" [FASB, 1981, p. 
33]. Several studies have indicated that small firm managers consider the ownership structure the most significant characteristic to distinguish them from other companies [McCahey, 1987]. Page found that in $95.9 \%$ of the small independent companies in his sample $50 \%$ voting control was in the hands of two owners owning most shares and in $77.5 \%$ of the cases these two shareholders had almost complete control given by possession of $75 \%$ or more of the share capital [Page, 1984, p. 274]. Chittenden [1989] studied the legal structure of small UK firms and found $50 \%$ were limited companies, $25 \%$ were partnerships and the rest were sole traders. Family businesses ( $98 \%$ or more of the partners or shareholders are members of one family) are an extremely important part of the small business sector, as $82.5 \%$ of the partnerships and $63 \%$ of the companies are family owned.

In the Netherlands, many private firms are small firms with a small degree of separation of ownership and control [Slagter, 1983, p. 143]. In 1983, when the Fourth Directive was implemented in the Dutch company law, $63 \%$ of all private companies had less than 10 employees, while $98 \%$ of all private companies did not meet the characteristics of a large firm, as defined by company law [Maijoor, 1991, p. 146].

Table 2.5. Acceptability of differential reporting in relation to firm characteristics.

\begin{tabular}{l|cc}
\hline \multirow{4}{*}{ Private firms } & Small firms & Large firms \\
\cline { 2 - 4 } Public firms & + & $+/-$ \\
\hline
\end{tabular}

If differential reporting regulation is to be introduced, it will be most easily accepted for small or medium-sized private companies. The position of the large private companies and the small public companies in the differential reporting debate is much more complicated. Knutson and Wichmann explicitly distinguish between the small/large and the private/public dimension of the differential reporting problem. Their study among 659 CPAs (with a response rate of $35.8 \%$ ) suggests that in the CPAs views regarding the importance of disclosure requirements, disclosure requirements should be equal for all public companies but should be less for private companies (versus public companies) and for small private companies (versus large private companies) [Knutson and Wichmann, 1985]. A similar study among 273 Australian accountants (response rate $33 \%$ ) confirms these findings as the results show that legal structure is an important factor in the applicability of accounting requirements and size is an important factor for private companies but not for public companies and sole traders [Holmes et al., 1991, p. 128]. It thus seems that in the view of auditors, differential reporting regulation would be less acceptable for small public firms while differential regulations for large private firms might be more tolerable (see table 2.5). 
But ultimately, no matter how difficult the definition of criteria for the application of differential reporting rules might be, it should not lead to a denial of differential reporting, impeding many companies that feel burdened by complex accounting standards solely because arbitrary criteria may exclude some that also arguably need relief. And even if firms were to be permitted to avoid certain recognition or measurement requirements when this may not be the preferable course of action, these entities should be few in number [Larson and Kelly, 1984, p. 84]. Various solutions to the standards overload for small closely held firms have been suggested and implemented (see Appendix I and II). It seems, however, that each of these solutions has distinctive implications for the various elements of the standards overload problem. Also, most of the solutions suggested, while solving some of the problems connected with a standards overload, tend to create additional problems of their own. From the point of simplicity, total exemption for small private firms from all financial reporting regulation would seem to be the most appropriate solution to the standard overload problem. Such an approach follows the clear principle that a firm either has use for the financial report and consequently will prepare such a report complying with all accounting regulations, or a firm has no use for an annual report and thus is relieved from all financial reporting regulations. Following these arguments, there is no place for a mandatory simplified, summary, abridged or otherwise impaired report that would almost inevitably be in conflict with presenting a true and fair view. The problem of defining firms that should be exempted as well as the factual disclosure of accounting information by exempted firms could largely be left to market forces, relying on adverse economic consequences for firms that inappropriately fail to disclose full accounts.

What role can an accounting researcher, studying the economic effects of financial reporting regulation, play in explaining and improving financial reporting regulation? It is generally acknowledged that the feasibility of a full cost benefit analysis of financial reporting regulation is, at the least, highly questionable [Sunder, 1988, Demski, 1973]. Whether one system of standard setting and enforcement is 'best' therefore cannot be determined [Benston, 1980, p. 51] $]^{25}$. Economic research can provide evidence of the consequences of financial reporting regulation but it cannot provide a basis for judging the desirability of those effects. The role of the researcher therefore is restricted to providing evidence of the economic effects of financial reporting regulation [Sunder, 1988, p. 41]. Though the benefits (net of costs) of accounting standards to society cannot, in principle, be measured, it may be possible to assess "the benefits and costs to groups of similarly affected individuals

2s Some authors have argued the desirability of efficiency effects can be assessed by economics while the desirability of distributional effects cannot, while others have argued convincingly that either evaluation lies beyond the boundaries of accounting and even economics. Judging the desirability of economic effects involves political choices and cannot be dealt with from an economic perspective. These discussions, as well as alternatives to an economic approach are extensively described by Maijoor [1991]. 
can be indicated and perhaps measured, the results of which should aid those interested in making judgements about the desirability of alternative types of accounting standards and methods of enforcement" [Benston, 1980, p. 51].

From the overview presented in this chapter, it should be clear that empirical research into the economic consequences of financial reporting regulation is far from conclusive. The studies presented are inevitably incomplete in identifying all cost and benefits and in including all parties affected by regulation. Also, there are serious difficulties in measuring costs as well as benefits, which makes the use of subjective criteria like perceived costs and benefits inevitable. Furthermore, it is very difficult to assess the net benefits or costs to be attributed to regulation compared to a situation of voluntary disclosure. Researchers reviewing the empirical literature, derive contradictory conclusions ranging from the statement that "this evidence leads one to doubt, though not entirely discount, the value to the public [...] of government required disclosure" [Benston, 1976, p. 97] to the observation that "there is no good evidence that the rules are (a) harmful, or (b) very costly" [Easterbrook and Fishel, 1984 , p. 714].

From the existing research into the costs and benefits of financial reporting regulation for small closely held firms, it can not be concluded whether a standards overload problem actually exists. It seems further evidence on a large number of areas is necessary, such as:

a. the applicability to small and medium-sized private companies of research on large public firms. Most empirical studies on the economic effects of financial reporting regulation relates to large public firms. Whether the results of those studies also apply to the small private firm context remains unclear. Only few researchers have incorporated small or private firms in their samples. And even fewer studies explicitly test differences between public versus private firms and small versus large firms. Such research can indicate to what extent existing research on large firms can be useful in the standards overload debate. It also pertains to the basic question whether financial reporting regulation should be different for small closely held firms from a user oriented perspective.

b. compliance with financial reporting regulations. The financial reporting practice of small firms seems to be an issue of considerable concern. Non-compliance. with financial reporting regulations may be an option used by firms to avoid accounting costs resulting from these regulations. Small firms tend to file accounts late and the contents of the accounts often are not (fully) in compliance with relevant standards or regulations. As a result the quality of the information provided in these accounts is often dubious. All these elements indicate that managers of small firms do not very much appreciate the value of disclosing the financial accounts to third parties.

c. the relationship between accounting costs and firm size. Some studies have indicated that small private firms are disproportionately bearing the costs of financial reporting regulation. Given the difficulty of getting reliable accounting cost estimates, further evidence is needed to verify the findings of existing studies. The conclusion that small closely held firms bear proportionately higher compliance costs 
would, in combination with the conclusion that the number of users of small firms' financial statements is also smaller, indicate that small closely held firms are put in a negative position by financial reporting regulation compared to large firms.

d. the relationship between small private companies and the primary users of their financial statements. If financial reporting regulation is a means of protection for the primary users of financial accounting information, it should be established whether primary users of financial statements of small closely held firms are in a position to get the information they need without intervention from the government or a private standard setting body. If so, financial reporting regulation would be abundant for these firms because the market would ensure a sufficient level of information disclosure. Primary users (firm-owners and banks as indicated by research) can demand the information they need. If the company refuses it either has to pay higher costs (capital costs, tighter loan restrictions, etc.) or the user will break the relationship with the company (does not grant the loan). If so, regulation could be avoided for these firms regardless of the information needs and decision models of primary user groups. Evidently, other user-groups in this situation would have trouble in finding information on small firms, but it is not clear whether these groups, which would likely consist of a limited number of individuals, should be protected by financial reporting regulation.

The change in financial reporting regulations in the Netherlands provides an excellent opportunity to obtain information on the economic effects for small private firms. For these firms, the regulatory change embodied a change from a largely unregulated to a more strictly regulated financial accounting environment. In the following chapters, empirical studies will be presented concerning the impact of Dutch financial reporting regulation on small private firms in terms of (1) compliance with regulation (chapter 3), (2) perceptions of small private firms' management on financial reporting regulation and the costs of financial reporting regulation to these firms (chapter 4). Finally, the usefulness to credit analysts of financial reports of mediumsized private companies will be explored in chapter 5 . 


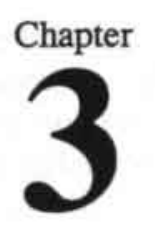

\section{Compliance of Small Private Companies with Financial Reporting Regulation}

\subsection{Introduction}

Empirical studies into the economic effects of financial reporting regulation, usually contain few references to the level of compliance with the regulations studied. In doing so, they implicitly assume full compliance by all firms concerned. In the small firm context, where compliance with financial reporting requirements and the quality of the financial statements disclosed seem to be matters of considerable concern, evidence on the level of non-compliance with financial reporting requirements is of particular importance (see chapter 2).

The importance of the degree of compliance with financial reporting regulations seems obvious as it effects both costs and benefits to be expected from disclosure regulation. The expected benefits from financial reporting regulation - e.g. the provision of more and better financial accounting information - will decrease considerably if there is a substantial level of non-compliance. Also, through non-compliance, firms might attempt to reduce information production costs or avoid (perceived) competitive disadvantages ${ }^{1}$. In spite of the many potential economic effects of the level of compliance with regulation, little empirical evidence can be found on the extent of non-compliance or on factors explaining observed compliance [Buijink, 1992, p.41].

Objections against financial reporting regulations can be expressed in various stages of the regulators' decision-making process. Once regulation has been passed, noncompliance with regulation can involve (1) the non-disclosure of financial statements, (2) deliberate deferral of the disclosure of mandated information to reduce its timeliness and (3) the omission of certain required information in financial statements or the misuse of 'mistakes' or vagueness to cover certain information. In the remainder of this chapter, empirical evidence on these three issues will be presented. First, the overall level of non-disclosure of financial statements by small Dutch firms will be studied (section 3.2). Next, the results of an inspection of financial statements disclosed by small Dutch firms will be presented, emphasizing the timeliness and the content of the

\footnotetext{
${ }^{1}$ These cost-savings, again, may be offset by actions of government agencies or user-groups, leading to the payment of fines or resulting in litigation costs.
} 
information disclosed (section 3.3). Finally, an exploratory examination of determinants of the observed level of compliance will be presented (section 3.4). A detailed description of the company law requirements for the preparation and disclosure of Dutch small firm financial statements is provided in Appendix III, to serve as a background for the present chapter as well as the two following.

\subsection{Non-disclosure of financial statements by small firms}

At the time of the adaptation of the Dutch company law to the Fourth EC Directive in 1983, the opposition from small firms against (the first-time) disclosure of annual accounts was extensive [e.g. Wittenburg, 1985, Van Duuren, 1986, Poorthuis, 1990]. The opposition of the small firm sector was most distinctly demonstrated by the reluctance of these firms to meet the disclosure requirements ${ }^{2}$. The financial statements for 1984 should have been filed at the Chambers of Commerce by approximately February 10th, 1986 at the latest. By the end of January 1986, out of a total of 172,400 small firms that were subject to the company law requirements, only $30 \%$ mandated to file accounts had done so ${ }^{3}$ [Bollen, 1986]. In March 1986, one month after the final date of publication of financial statements for $1984,40 \%$ of all statements to be disclosed had not yet been received at the Chambers of Commerce [Van Duuren, 1986] ${ }^{4}$.

From these figures, however, it can not be concluded that all firms that had not complied with the legal requirement to file financial statements, did so intentionally. For

${ }^{2}$ Another example of the opposition of firms against the disclosure regulations is represented by a law suit that was filed by twelve Dutch private companies in 1987 and finally was decided on by the European Committee for Human Rights. The companies claimed that the mandatory disclosure of financial statements violated article 8 of the European Treaty on Human Rights, which states that every individual is entitled to privacy concerning his personal live and undisturbed pleasure from his properties. However, the claim of the companies to be exempted from the disclosure requirements was denied based on the argument the disclosure of financial statements serves a legitime purpose, being the economic wellbeing of the country and the protection of the rights of third parties.

${ }^{3}$ The reluctance of small firms to meet the financial disclosure requirements is not a Dutch exclusive. Weilbach [1991, p. 800 and 1992, p. 935] has suggested that in Germany as many as $90 \%$ of the limited liability companies do not publish their accounts, although they are legally required to do so.

4 Apart from refusing to conform to the regulation, firms can also try to avoid it. Maijoor [1991] provides evidence that in 1970 the vast majority of Dutch public companies confronted with new accounting regulation evaded the financial reporting requirements by changing legal form from public company (Naamloze Vennootschap, NV) to private company (Besloten Vennootschap, BV). In 1983, such a reaction by firms could hardly be found because the costs of switching to a legal form discharged of the obligation to disclose annual accounts would have been substantial (see Maijoor, 1991, pp. 147-151]. 
most firms involved, the regulatory change in 1983 represented the first financial reporting requirements ever. Consequently, many firms may have been unaware of these new financial reporting requirements. Also, necessary adaptation of their administrative systems in order to produce the information required by the new company law may have hindered the timely disclosure of financial statements of many small firms. But also, many small firm managers may have followed a 'wait and see' strategy, to await the reaction of the government towards non-compliance with the company law requirements [Wittenburg, 1985].

Table 3.1 Disclosures of public and private companies (1984-1992)

\begin{tabular}{|c|c|c|c|c|c|c|}
\hline \multirow[t]{2}{*}{$\begin{array}{l}\text { Financual } \\
\text { year }\end{array}$} & \multirow[t]{2}{*}{$\begin{array}{r}\text { Private } \\
\text { companies }\end{array}$} & \multirow[t]{2}{*}{$\begin{array}{r}\text { Public } \\
\text { companies }\end{array}$} & \multirow[b]{2}{*}{ Total } & \multicolumn{2}{|c|}{$\begin{array}{c}\text { Change in relation to } \\
\text { previous year }\end{array}$} & \multirow{2}{*}{$\begin{array}{c}\begin{array}{c}\text { Change in } \\
\text { relation to } \\
1984\end{array} \\
\text { Perc. }\end{array}$} \\
\hline & & & & Abs & Perc. & \\
\hline 1984 & 83,560 & 672 & 84,232 & & & \\
\hline 1985 & 97,615 & 979 & 98,594 & 14,362 & $17.05 \%$ & $17.05 \%$ \\
\hline 1986 & 117,826 & 1,196 & 119,022 & 20,428 & $20.72 \%$ & $41.30 \%$ \\
\hline 1987 & 136,388 & 1,573 & 137,961 & 18,939 & $15.91 \%$ & $63.79 \%$ \\
\hline 1988 & 156,910 & 1,738 & 158,648 & 20,687 & $14.99 \%$ & $88.35 \%$ \\
\hline 1989 & 183,203 & 1,979 & 185,182 & 26,534 & $16.73 \%$ & $119.85 \%$ \\
\hline 1990 & 205,162 & 2,039 & 207,201 & 22,019 & $11.89 \%$ & $145.99 \%$ \\
\hline 1991 & 222,693 & 2,150 & 224,843 & 17,642 & $8.51 \%$ & $166.93 \%$ \\
\hline 1992 & 239,289 & 2,089 & 241,378 & 15,256 & $6.75 \%$ & $186.56 \%$ \\
\hline
\end{tabular}

source: Database Foundation of the Chambers of Commerce.

The number of annual accounts disclosed in the Netherlands has risen considerably since the introduction of the Fourth EC Directive. The data presented in table 3.1 represent the number of disclosures by Dutch public and private companies, per financial year the statements relate to. Since 1984, the first financial year to which the revised company law applied, the number of disclosures has risen consistently to a total of 241.378 concerning the financial year $1992^{5}$, a rise of over $186 \%$ compared to the number of disclosures relating to 1984 . Evidently, part of the increase in the number of disclosures results from an increase in the number of public and private companies. But also a rise in the level of compliance with the disclosure regulations may explain the increase in

s The data presented were collected in the autumn of 1994. The number of disclosures is determined by the number of firms that has met the dislosure requirements, either by filing the financial statements or by filing a statement of liability (see Appendix III). 
the number of disclosures ${ }^{6}$. Recent data indicate that the overall level of compliance has risen considerably in later years. Poorthuis [1990, p. 56] estimates the level of compliance with the financial reporting regulations in 1989 at $70 \%$.

Table 3.2 Financial statement disclosures by small Dutch firms

$1984^{3}$

172,400

$47-50 \%^{3}$

Level of compliance with

disclosure requirements
$1991^{2}$

248,839

$86.43 \%$

1. data from van Duuren [1986]

2. data from Database Foundation of the Chambers of Commerce.

3. corrected for incomplete data (see Appendix 3A for details)

From detailed data concerning the financial year 1991 derived from the Database Foundation of the Chambers of Commerce, an accurate estimate of the number of nondisclosing firms can be derived (see table 3.2 and Appendix 3A). From these data it can be concluded that with respect to 1991 , overall compliance by small Dutch companies with the financial reporting requirements varies from $70 \%$ to $100 \%$ depending on the Chamber of Commerce-district, and averages at $86 \%$. Out of a total of 248,839 small companies that are mandated to file their annual accounts, some 34,000 had not filed their accounts concerning the financial year 1991 by June 1993 . The vast majority of the financial statements filed are disclosed by small companies. Out of a total of 224,843 disclosures concerning $1991,3,000(1.3 \%)$ came from large firms, 6,778 (3.0\%) came

\footnotetext{
${ }^{6}$ The database from which the data presented were gathered only includes the most recent legal form of each firm. As a result the number of private and public companies in earlier years could not be derived. Although other statistics present the number of companies per year (e.g. the Central Bureau of Statistics), these data suggest that the number of private companies is smaller than the number of disclosures as reported by the Chambers of Commerce, which seems impossible. Therefore, compliance figures for each separate year could not be determined.

${ }^{7}$ Statistics on the level of non-reporting firms in the UK are provided by Morris and Omrod [1990] who studied UK company financial statements in order to establish 1986 practice regarding the filing of abridged accounts. From their initial sample of 255 firms, 155 (61\%) had not filed any financial statements and 32 of these had failed to file accounts in at least two consecutive years. However, many firms in the sample (104) were newly incorporated or inactive companies. Excluding these firms from the analysis, it seemed that of the remaining 151 firms, 51 (33.8\%) were in clear default with the filing requirements of the Companies Act.
} 
from medium-sized firms and between 196,461 (87\%) and 215.063 (95.7\%) came from small firms ${ }^{8}$.

The level of compliance varies considerably across the various Chambers of Commerce (see Appendix 3A). In the largest district, Amsterdam, the level of compliance is the lowest $(70 \%)$, while in the district of Deventer, which is one of the smallest districts, all firms meet the financial disclosure requirements. Generally, the level of compliance is negatively correlated with the size of the district measured by the number of firms registered, both in 1984 and $1991^{\circ}$. The differences between districts also may be the result of the dissimilarity in actions taken by Chambers towards firms that do not file any accounts or file accounts that clearly do not meet the regulatory requirements. The formal task of the Chambers of Commerce is restricted to accepting the accounts and does not include the responsibility to take any actions against firms that do not file accounts. Nevertheless, some Chambers have taken some action against non-compliance by sending mailings to firms, urging them to file their accounts, or by returning financial accounts that grossly violate the regulatory requirements ${ }^{10}$.

Through non-compliance, firms may attempt to reduce information production costs or avoid (perceived) competitive disadvantages. These cost-savings may be offset by actions of government agencies or user-groups resulting in the payment of fines or litigation costs. From an economic standpoint,, the level of compliance may depend on a number of factors (Posner [1992, ch. 7]):

$a$. the potential benefits (or cost-savings) to the offender resulting from non-compliance; $b$. the potential costs of non-compliance to the offender (the cost of crime);

\begin{abstract}
${ }^{8}$ A number of firms $(18,602,8.3 \%)$ did not file financial statements but filed a document that exempted the firm from the financial disclosure requirements. For example, firms that are a group-company having its financial data disclosed in the consolidated financial statements of the parent company, are exempted from the mandatory filing of the financial statements and have met the disclosure requirements if they file a 'statement of liability' (see Appendix III). For these companies it can not be established from the database of the Database Foundation of the Chambers of Commerce whether they are to be classified as a small, a medium-sized or a large firm. In general, however, these statements mostly relate to small firms.
\end{abstract}

9 The correlation between the number of firms registered in a district and the level of compliance for 1984 is -0.19 and for 1991 is -0.68 .

${ }^{10}$ Currently, a new bill is being prepared by the Dutch government that will give the Chambers of Commerce the right to dissolve a private companies if two of the following four violations have occurred:

- the company is at least one year late with filing its financial statements;

- the company is at least one year late with paying its contribution for the Chamber of Commerce;

- the company is at least one year late with entering its directors in the registrar of companies;

- the company is at least one year late with filing its tax-return. 
c. the risk of detection that is a result of the level of enforcement, that in itself is a result of the costs of catching and convicting an offender;

$d$. other factors such as the financial means of the offender to pay any potential fines, the (moral) willingness to commit an illegal act, the response to punishment, etc.

ad a.

The costs of meeting the regulatory financial reporting requirements will be discussed extensively in chapter 4 . For now, it will only be mentioned that the cost-savings from non-disclosure generally will increase with the size of a firm although it can be shown that accounting costs tend to be proportionally higher for small firms compared to large firms. It should also be mentioned that even for small firms the accounting costs generally present only a relatively small fraction of the total annual costs of a firm.

\section{ad b.}

The punishment for violating the financial reporting regulations in the Netherlands consists of a combination of a fine, imprisonment and liability. Non-compliance with the obligation to disclose the annual accounts in the Netherlands constitutes a criminal offence. Initial fines for not disclosing the annual account can be as high as $f 25.000$,and may result in a maximum of six months of imprisonment for the firm's directors. Also the court can set the obligation to disclose the required information after all. Violation of this obligation may result in a fine of maximum $f 100.000$,- and a maximum of 6 years of imprisonment [Beckman, 1994, p. 149].

All interested parties may institute civil proceedings in the appropriate court to require the filing of the financial statements.

In case of insolvency, a firm's directors can be held personally liable for any deficits if they have not met the obligation (1) to keep books properly, (2) to prepare a balance sheet and a profit and loss account annually, (3) to retain the accounting information for a designated period of time or (4) to disclose the financial statements annually.

A further consequence of not disclosing the annual accounts may result from a bill that currently is being prepared by the Dutch government and that will give the Chambers of Commerce the right to dissolve a private company if two of the following four violations have occurred:

- the company is at least one year late with filing its financial statements;

- the company is at least one year late with paying its contribution for the Chamber of Commerce;

- the company is at least one year late with entering its directors in the registrar of companies;

- the company is at least one year late with filing its tax-return.

ad c.

Kelly-Newton [1980, p. 128] discusses the importance of the policy maker's power for the likelihood of compliance. The likelihood and magnitude of punishment actions by regulatory bodies will obviously influence conformity with disclosure regulations issued. However, with a large number of firms affected by accounting regulations, the 
effectiveness of coercive government actions seems limited ${ }^{11}$. With respect to financial reporting regulation, Zeff [1994, p. 23] has argued that in Western European countries that have to deal with a large number of companies affected by regulatory accounting rules, the problems of enforcing compliance can be expected to be substantial.

Non-compliance with financial reporting regulations through non-disclosure constitutes a highly visible violation of these regulations. Therefore, for large firms, that are monitored by a relatively large number of interested parties, the risk of detection is high. For small firms, however, the risk of detection may be much lower given the large number of firms and the limited economical impact each individual firm has. Therefore the chance of requisition of disclosure by some interested party may be low. A rigid enforcement of the financial reporting regulations for small firms, therefore, would involve considerable social costs and effort from the government.

The Dutch regulatory system, however, does not provide in a systematic check of all annual accounts filed at the Chambers of Commerce. The formal task of the checking of filed accounts in the Netherlands lies with the 'Economische Controle Dienst' (ECD). In 1985 the ECD inspected 12,000 firms and fined 50\% of them, but since then the number of inspections $(3,810$ in 1988) as well as the number of fines (33\%) has gradually declined [Poorthuis, 1990] ${ }^{12}$

\section{ad d.}

Other economic factors, such as the financial means of the offender to pay any potential fines or the ability to pay lawyers and litigation costs, also may explain differences in the level of compliance between individuals or firms, or groups of individuals or firms [Becker, 1968, p. 198].

In the case of financial reporting regulation differences between the level of compliance between large firms and small firms may be explained by the fact that the fine for violating the disclosure requirements may harm smaller firms more severely since larger firms have larger resources to pay fines. Also smaller firms are less able to spend resources on preventing conviction through good lawyers and legal appeals. Furthermore, since the benefits of violation are smaller to small firms, these firms not

\footnotetext{
"Also, coercive actions may enhance overt behavioral compliance with regulations, but on the other hand may not affect, or even hinder, attitudinal acceptance of new regulations, resulting in long term non-compliance through covert actions (e.g. by finding loopholes in the regulations or by avoiding regulations by transforming the firm's situation or actions).

${ }^{12} \mathrm{~A}$ change in the risk of detection is argued to have more effect than a change in the level of punishment [Becker, 1968, p. 180]. However, an increase in the risk of detection is more expensive while an increase in the level of punishment is fairly cheap.
} 
only are less able, but also less willing to spend resources to prevent conviction (e.g. through bribery $)^{13}$.

Concluding, it would seem that the level of non-compliance among small firms with financial reporting regulation could result from the relatively low benefits to be expected from non-disclosure and from the relatively high potential punishment related to nondisclosure. With respect to the risk of detection it can be mentioned that non-disclosure constitutes a highly visible violation of the company law but that the risk of detection decreases with firm size.

In recent years, the declining number of inspections by the ECD may have resulted in a further decline in the risk of detection since for smaller firms the chance of requisition of disclosure by other interested parties may be low. However, the actions of the ECD shortly after the introduction of the Fourth Directive, may have convinced many small firms that the risk of detection would be high. Although the actions of the ECD have decreased considerably since then, many firms, once they had started to prepare and disclose their annual accounts, may have remained doing $\mathrm{so}^{14}$.

Although the number of disclosures by small firms has risen considerably since 1985 , the mere filing of a document with the title 'Financial statements' printed on the cover does not necessarily mean that the information provided is actually useful. The usefulness of the financial statements disclosed to interested parties heavily depends on the timeliness, quality and quantity of the information provided. This is investigated in the next section.

\subsection{Characteristics of small firm financial statements}

\subsubsection{Introduction}

The compliance of publicly available financial statements with prevailing financial reporting regulation has been the theme of various empirical studies (see chapter 2). With the introduction of the Fourth EC Directive in the national legislation of its member countries, a series of studies has concentrated on the contents and form of accounts of small firms to assess the quality of the accounts filed. The quality of the accounts filed can be considered an indication of the costs financial accounting regulation imposes on small firms: a low level of compliance and a poor quality of

13 As Becker [1968, p. 198] points out, these relationships also depend on the sort of punishment (e.g. a fine or imprisonment)

${ }^{14}$ Also, the level of automation among the Chambers of Commerce has increased considerably over the last few years. Therefore, the task of the ECD to detect the non-disclosure of annual reports may be much easier now, resulting in an increase in the risk of detection for firms. 
presentation of information suggest that the financial burden on small companies, resulting from financial accounting disclosure requirements, is significant.

In this section, the results of a detailed examination of financial statements disclosed by small Dutch firms will be presented to assess the level of compliance with the regulatory requirements and to provide an overview of current small firm financial reporting practice. Our main emphasis will be on the development of financial reporting practice over a period of time since the introduction of the obligatory disclosure of financial statements in 1984.

The regulatory requirements as well as the exemptions for small firms are different for the preparation of the financial statements and for the disclosure of the financial statements (see Appendix III). Since the analysis presented here is based on the information filed at the Chambers of Commerce, this study only concerns compliance with disclosure requirements. Information about the level of compliance with financial reporting requirements regarding the preparation of accounts can only be assessed if firms disclose information in excess of the disclosure requirements, e.g. by disclosing the full financial statements prepared rather than the abridged financial statements based on the disclosure-exemptions for small firms.

A major difficulty in assessing the level of compliance with regulatory disclosure requirements is introduced by the fact that it is troublesome to determine whether information-items required to be disclosed by company law that are not incorporated in a firm's financial statements are omitted because the information requested is not applicable to the firm or because the firm does not comply with the legal requirements. Items that are not applicable to a firm's situation may be omitted from the financial statements without any further comment. Also, firms may leave out any information that is not material, i.e. not of sufficient importance to users to meet the costs necessary to include the information in the accounts. Therefore the level of compliance as well as the quality of the information disclosed can only be assessed using a conservative approach, assuming all information not included in the financial statements analyzed constitutes no violation of the legal requirements. As a result, any indication of the level of compliance or the quality of the information disclosed constitutes an optimistic estimation, that may actually be lower if firms have left out any information unjustified.

The study presented in this section will provide data on the disclosure practice of small firms, affected by the 1984 adaptation of Dutch law to the Fourth EC Directive. The results of an inspection of 144 small firms' financial statements will be presented. Financial statements examined are taken from 1984 and 1990 to check for any changes in the disclosures made by small firms over a length of time.

In section 3.3.2, the relation between our research and existing empirical literature on small firms' disclosure practices will be discussed. Further details on research design and sample selection will be presented in section 3.3 .3 and the results of the study will be presented in section 3.3 .4 to 3.3 .7 . In the subsequent section, firm characteristics 
will be used to explain the level of compliance among the small firms studied, using disclosure indexes (section 3.4).

\subsubsection{Relation to existing empirical research}

The results of the studies on the disclosure practices of small firms discussed in chapter 2 provide an, albeit rather restricted, basis for drawing general conclusions about the quality of small firm financial statements and the level of compliance with prevailing financial reporting regulations. The studies cover a number of countries (such as the US, UK, Australia and the Netherlands) and varying levels of regulation. Also, diverging definitions of small firms are used and in several studies the research design does not leave the results open for generalisation.

Nevertheless, from the results presented in these studies some general tendencies can be observed, which can be summarised as follows:

1. The occurrence of a considerable level of non-compliance in small firms' financial statements with existing accounting regulations is evident from all studies cited, although the actual level of non-compliance varies considerably among firms and accounting standards studied.

2. Among the authors cited, there is a general concern about the quality of the information provided in small firm financial statements. The fact that some of the small firms' accounts are prepared or audited by an external accountant does not seem to guarantee an adequate quality of disclosure [Morris and Omrod, 1990, p. 13].

3. Publicly available accounting information on small firms tends to be rather outdated as a considerable number of small firms fails to file the accounts within the time limits prescribed [Tsang, 1986, Robertson, 1986].

4. Few studies have looked at the level of voluntary disclosures made in addition to the information required by regulations. The scant data available suggest that small firms have little incentives to provide such information in the accounts filed. Several UKstudies, however, have indicated that an important number of small firms publish full accounts even though they are allowed to file abridged accounts [e.g. Tsang, 1986, Robertson, 1986, Morris and Omrod, 1990]. This type of 'voluntary' disclosure may be explained by the fact that abridged accounts have to be prepared in addition to the full accounts and therefore may result in higher disclosure costs for the firms involved. Contrary to these UK findings, a number of Dutch studies has shown that only few Dutch small firms provide any information not required by law and most of these firms take full advantage of the exemptions provided [Bollen, 1986, NOvAA, 1986].

In the remainder of this chapter, a study will be presented concerning the financial accounting disclosures made by small Dutch firms, which adds to the previously mentioned studies in two ways:

1. Most studies look at compliance at one moment in time, often shortly after the introduction of some kind of new legislation. The study presented here will explicitly look at the change in quality and the level of compliance over a period of time. The 
accounts studied are from 1984 and 1990, thereby taking into account a period of 7 years after the regulatory change in 1984. The study will focus on (1) the timeliness of disclosures by small firms, (2) the compliance with formal financial reporting requirements and (3) the (voluntary) disclosure of financial accounting information not mandated by company law.

2. Only few studies use statistical tests to assess the relationship between quality or compliance with explanatory variables other than firm size. Exceptions are the questionnaire-studies by Holmes and Nichols [1989] and Keasey and Short [1990] that provide some initial insight into the relationship between small firms, accounting information and accounting information requirements. In section 3.4 of this chapter, explanations for differences in level of compliance and quality will be examined. Since there is little theory to guide the choice of explanatory variables, this part of the study is exploratory. Building on the theoretical discussion and the relevant existing empirical evidence (see chapter 2), a number of potential explanatory variables will be tested.

\subsubsection{Sample selection.}

In the research presented in this chapter, the contents of financial statements of small companies are studied to determine the timeliness, the quantity and the quality of the financial information disclosed. The original accounts, filed at the Registrar of Commerce at the various Chambers of Commerce, were used in this study. Financial accounts regarding the financial year 1984 (when not available, 1985) and 1990 (when not available, 1989) were selected.

The sample of small firms to be included in the study was selected from the Database Foundation of the Dutch Chambers of Commerce. The characteristics used to select firms to be included in the sample are described in table 3.3.

Table 3.3 Sample selection criteria.

1. Banks and insurance companies are excluded

2. Legal form is private company.

3. Number of personnel is more then 1 but less then 50 .

4. Firms are selected from 10 Chambers of Commerce.

The selection criteria used are motivated as follows:

ad 1. Banks and insurance companies were excluded from the sample because of the special requirements for these firms in Dutch company law.

ad 2. Dutch company law applies to (1) public companies, (2) private companies, (3) general partnerships, (4) limited partnerships and (5) civil law companies. The vast majority of these firms are private companies [see Appendix 3A, table 3A.2]. As in this study our main interest is in small private companies, other legal forms have been excluded. 
ad 3. The legislative definition of a small firm is based on three criteria: total sales, total assets and average number of personnel. The database of the Database Foundation only included information on the number of personnel, which consequently is the sole size-criterion used. The size of the selected companies were checked based on the data on sales and assets provided in the financial statements disclosed. To exclude inactive or dormant companies from the sample, a minimum-level of personnel of 1 was used. ad 4. There are 35 Chambers of Commerce in the Netherlands. Since the accounts to be used had to be studied at the Chamber it had been filed, a limited number of Chambers was selected to avoid excessive travelling-time. The ten Chambers selected were regionally spread over the Netherlands and included both large and small Chambers of Commerce ${ }^{15}$.

Using these criteria, an initial firm sample of 160 firms was constructed. During the process of gathering the annual accounts of these firms, a number of firms (5) turned out to be medium-sized firms and therefore were excluded from the sample. Also, for a number of firms the financial statements could not be retrieved, either because the firm had filed a statement of liability exempting it from disclosing its financial statements or because the firm had not met the disclosure requirements. Ultimately, a usable sample of 169 annual accounts from a total of 139 firms remained.

Table 3.4 Sample construction

\begin{tabular}{lcccc}
\hline & $\begin{array}{c}\text { Number of } \\
\text { firms }\end{array}$ & \multicolumn{3}{c}{ Number of accounts } \\
\cline { 3 - 5 } & & 1984 & 1990 & Total \\
\hline Initial selection & 160 & - & - & - \\
Not a small firm & 5 & - & - & - \\
Statement of liability & 16 & - & - & 99 \\
\hline Usable sample of firms & 139 & & 32 & 169 \\
- no accounts filed & & 67 & 97 & 144 \\
- accounts retrieved & 114 & 72 & 72 & 60 \\
\hline Equal sized sample & 30 & 72 & 30 & - \\
Paired sub-sample & & 30 & & \\
\hline
\end{tabular}

From the total usable sample of 169 accounts two sub-samples were constructed. To obtain a sample with an equal number of financial statements from both periods, an equal sized sub-sample of 144 accounts from 114 small firms was constructed, relating to 72 accounts for 1984 and 72 accounts for 1990. For a number of firms in this sample, the financial statements from both 1984 and 1990 were available. These firms were used to construct a paired sub-sample, containing 30 firms with accounts available for 1984 as well as for 1990 (see table 3.4).

is The districts selected were: Amsterdam, Arnhem, Breda, Eindhoven, the Hague, Maastricht, Rotterdam, Utrecht, Venlo and Zwolle. 
Firm size characteristics of the firms included in the various samples are provided in table 3.5. All data presented are based on the financial statements that were filed by the firm at the Chamber of Commerce. Comparing the characteristics for 1984 and 1990 it can be concluded that, in terms of number of employees, the financial statements concerning 1990 relate to firms that on average are larger than the firms with financial statements concerning 1984. This result pertains to both samples constructed. With respect to total assets, firms are larger in 1990 compared to 1984 only for the paired sample. For the full sample differences in total assets between 1984 and 1990 are not significant (see panel C. of table 3.5).

Table 3.5 Firm size characteristics

Panel A. Descriptive statistics for total assets

\begin{tabular}{lllrrrr}
\hline Total assets & & $\mathrm{N}$ & Average & Std. dev. & Min. & Max. \\
\hline Full sample & 1984 & 72 & $1,715,966$ & $1,994,428$ & 29,870 & $11,304,197$ \\
& 1990 & 72 & $2,754,687$ & $5,219,618$ & 120,373 & $42,191,352$ \\
Paired & 1984 & 30 & $1,212,910$ & $1,098,269$ & 40,000 & $5,220,124$ \\
sample & 1990 & 30 & $2,115,478$ & $2,339,100$ & 120,373 & $12,753,429$ \\
\hline
\end{tabular}

Panel B. Descriptive statistics for number of employees

\begin{tabular}{lcccccc}
\hline Number of employees & $\mathrm{N}$ & Average & Std. dev. & Min. & Max. \\
\hline Full sample & 1984 & 72 & 14.51 & 9.58 & 1 & 38 \\
& 1990 & 72 & 21.08 & 12.27 & 4 & 60 \\
Paired & 1984 & 30 & 16.15 & 10.44 & 2 & 38 \\
sample & 1990 & 30 & 24.60 & 13.47 & 11 & 60 \\
\hline
\end{tabular}

Panel C. Mann Whitney U tests comparing sample means

Total assets

1.58

$2.93 * * *$
Number of employees

Full sample : 1984 vs 1990

Paired sample : 1984 vs 1990

$3.07^{* * *}$

Significance levels are indicated as * for $\alpha=0.1,{ }^{* *}$ for $\alpha=0.05$ and $* * *$ for $\alpha=0.01$.

Data for 1990 are corrected for inflation.

These tests on difference in firm size between 1984 and 1990 are important because differences in firm size introduce a difficulty in interpreting any changes in disclosure characteristics between 1984 and 1990, since it is difficult to establish whether an observed change can be attributed to an increase in firm size or to any learning effects resulting from dealing with financial reporting over a longer period of time. Since differences in firm size over time are smallest for the full sample, the discussion in the 
remainder of this chapter will be concentrated on the results for that sample. Nevertheless, all tests presented have been conducted for both the full sample of 144 accounts as well as the paired sample of 60 accounts and any material differences between the results for both samples will be mentioned.

\subsubsection{The timeliness of small company financial statements.}

Many studies have focused on the timing of accounting information releases by public firms (see chapter 2) but evidence on the timeliness of financial disclosures by private firms seems virtually non-existent [Atiase, Bamber and Freeman, 1988, p. 300]. This section presents evidence on the timeliness of financial accounting disclosures by small Dutch private companies that are subject to the 1983 Dutch Company Act. To determine any changes in reporting lags over time, the timeliness of disclosures is studied at two moments in time, involving the disclosure of financial statements on 1984, immediately after the enactment of the company law requirements for small private firms, and the disclosure of accounts on 1990.

Three measures of timeliness are used. Preparation lag is defined as the time from the end of the financial year to the date of approval of the accounts by the shareholders meeting. The filing lag is defined as the time from the approval of the accounts by the shareholders meeting to the date of filing of the accounts at the Chamber of Commerce. Reporting lag is defined as the time from the end of the financial year to the date of the filing of the accounts at the Chamber of Commerce.

Dutch company law requires that the preparation of financial statements is completed within five months after the ending of the financial year (see Appendix III). Within six months after the ending of the financial year, the annual accounts have to be presented at the annual meeting of shareholders that has to approve (or disapprove) the financial statements. Next, the balance sheet and the notes thereto have to be filed at the Chamber of Commerce within 8 working days. This would mean that the financial statements would have to be filed at the Chamber of Commerce no longer than 203 days after the end of the financial year.

The annual meeting of shareholders can, however, agree to extend the period for preparing the accounts by a maximum of six months. Then, the accounts have to be presented to the shareholders' meeting no longer than two months after the preparation is completed. The accounts have to be presented for approval to the shareholders no longer than 13 months after the ending of the financial year. Consequently, the ultimate date of filing the financial statements over the financial year $199 \mathrm{x}$ is somewhere around february 12 th, $199(x+2)$, some 408 days after the ending of the financial year.

Information on the date of approval of the accounts and the date of disclosure should be available for all financial statements filed at the Chambers of Commerce. Firms have to indicate the date of approval by the shareholders' meeting in the notes to the balance 
sheet. The Chamber of Commerce indicates the date of receipt on each of the disclosed financial statements. Based on this information an analysis can be made on the timeliness of filing of small firms' financial statements.

Frequency distributions for the reporting lags in 1984 and 1990 are presented in figure 3.1. For 1984 , the disclosure of annual reports is strongly clustered between 200 and 400 days after the end of the financial year. In 1990, the distribution has shifted to the left, centering around a 200-300 days time lag. In 1984, 37.5\% of all reports were filed within 365 days while in 1990 this has grown to $63.4 \%$. Also the number of reports filed extremely late (after 550 days) has declined from $10(14 \%)$ in 1984 to $1(1.5 \%)$ in 1990.

Figure 3.1 Frequency distribution for reporting lag in 1984 and 1990.

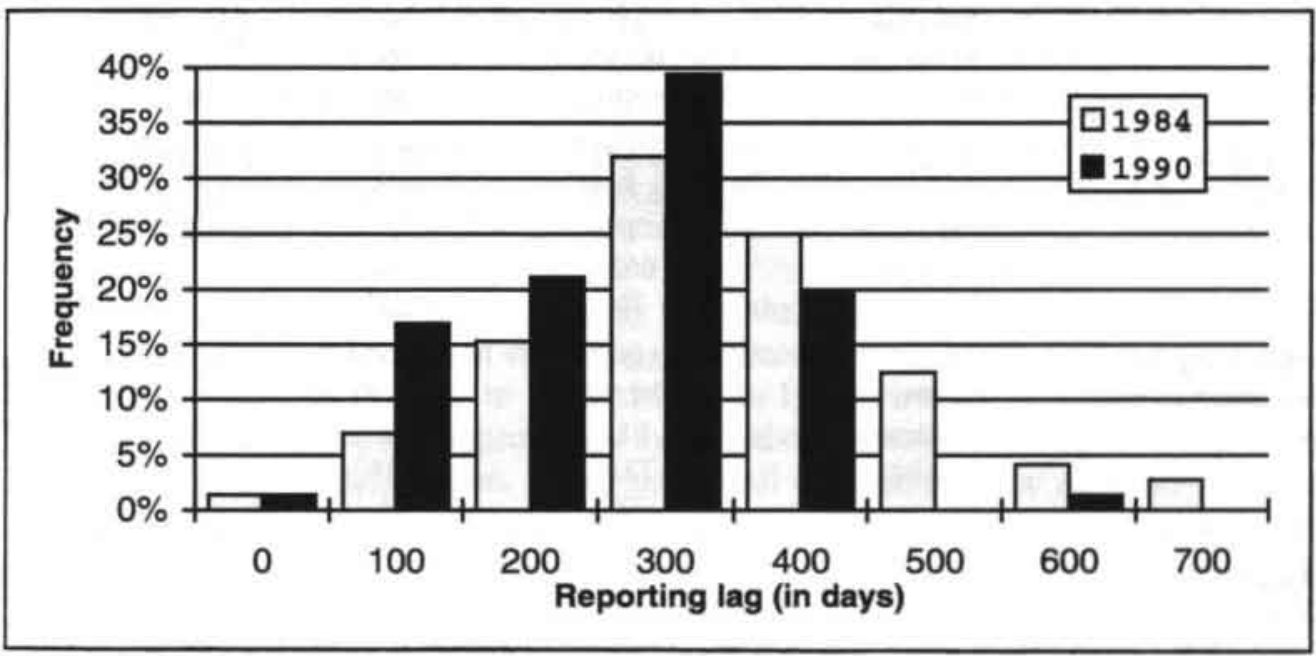

Summary statistics for preparation, filing and reporting lags are presented in panel A. of table 3.6. The time lag between the end of the financial year and the filing of the financial statements on average is 388 days in 1984 and has declined with more than $18 \%$ to 316 days in 1990 . This constitutes a significant decline in reporting-lag over this period. The longest delay between the end of the financial year and the disclosure of the financial statements was 722 days ( 8 days short of two years) for 1984 and 648 days (over 21 months) for the accounts of 1990.

Note that few firms file their financial statements within the 'normal' period of 203 days at the Commercial Register (table 3.6, panel B.). For the majority of firms it seems that the shareholders have agreed to extend the date of preparation, since the financial statements were not filed within $\mathbf{2 0 3}$ days after the ending of the financial year. None of the financial statements included any reference to such an agreement. Apparently, a large number of small firms encounter situations that lead to a deferral of the preparation of the annual accounts. In 1984 the adjustment to the new regulatory 
requirements could provide an explanation for this deferral. But even in 1990, seven years after the introduction of these requirements, many small firms still seem to have great difficulty in preparing their financial statements within six months. The preparation lag has declined from 277 days in 1984 to 262 days in 1990, but this is not a statistically significant reduction.

Table 3.6 Analysis of preparation lag, filing lag and reporting lag.

Panel A.

\begin{tabular}{llccc}
\hline & & 1984 & 1990 & $\begin{array}{c}\text { Mann Whitney } \\
\text { U test }\end{array}$ \\
\hline $\begin{array}{l}\text { Preparation lag } \\
\text { (number of days) }\end{array}$ & Mean & 277.06 & 262.75 & $\mathrm{z}=0.876$ \\
& St.dev. & 123.04 & 96.15 & \\
& Minimum & 43 & 56 & $(\mathrm{p}=0.38)$ \\
& Maximum & 602 & 396 & \\
& $\mathrm{~N}$ & 70 & 69 & \\
Filing lag & Mean & 113.73 & 52.82 & $\mathrm{z}=1.985$ \\
(number of days) & St.dev. & 153.45 & 79.26 & \\
& Minimum & 1 & 0 & $(\mathrm{p}<0.05)$ \\
& Maximum & 662 & 364 & \\
& $\mathrm{~N}$ & 70 & 68 & \\
Reporting lag & Mean & 388.43 & 316.25 & $\mathrm{z}=3.313$ \\
(number of days) & St.dev. & 134.77 & 106.23 & \\
& Minimum & 81 & 85 & $(\mathrm{p}<0.001)$ \\
& Maximum & 722 & 648 & \\
\hline & $\mathrm{N}$ & 72 & 71 & \\
\hline
\end{tabular}

Panel B.

\begin{tabular}{lcccc}
\hline & Delay in days & 1984 & 1990 & Chi-square test \\
\hline Preparation lag & $<=181$ & $21(30.0 \%)$ & $15(21.7 \%)$ & $\chi^{2}=8.214$ \\
$\left(\mathrm{~N}=139^{*}\right)$ & $<=396$ & $43(61.4 \%)$ & $54(78.3 \%)$ & $(\mathrm{p}=0.016)$ \\
& $>396$ & $6(8.6 \%)$ & $0(0.0 \%)$ & \\
Filing lag & $<=12$ & $21(30 \%)$ & $25(36.2 \%)$ & $\chi^{2}=3.139$ \\
$\left(\mathrm{~N}=138^{*}\right)$ & $>12$ & $49(70 \%)$ & $43(62.3 \%)$ & $(\mathrm{p}=0.208)$ \\
& $<=203$ & $6(8.3 \%)$ & $13(18.3 \%)$ & $\chi^{2}=8.149$ \\
Reporting lag & $<=408$ & $40(55.6 \%)$ & $46(64.7 \%)$ & $(\mathrm{p}=0.017)$ \\
$\left(\mathrm{N}=143^{*}\right)$ & $>408$ & $26(36.1 \%)$ & $12(16.9 \%)$ & \\
\hline
\end{tabular}

*In 5 cases the date of the shareholders meeting could not be derived from the financial statements. In 1 case the date of filing was not indicated on the financial statsments filed.

An alternative explanation could be that firms deliberately defer the preparation of the accounts to delay the disclosure of the financial information as much as possible. Further evidence for the intentional stalling of the filing of the financial statements could 
be provided by data on the filing lag. Firstly, firms may want to stall the disclosure of the financial statements by stalling the filing of the accounts in addition to deferring the preparation of the accounts. In this scenario, both the preparation lag and the filing lag should not have declined much in 1990 . This hypothesis is supported only partly by the data. Although in 1990 all of the accounts in the sample were approved within 396 days, $43(59.7 \%)$ of these firms did not file their accounts within 12 days after the approval by the shareholders (see panel B of table 3.6). Nevertheless, in 1990 firms on average filed their accounts 52 days after approval by the shareholders meeting, which is significantly less than the 113 days (166 days for the paired sample) recorded for the period 1984. The number of firms filing the accounts within 12 days after approval by the shareholders has declined only marginally and the largest delay between approval and filing of the accounts in 1990 was still 364 days.

The decline of the average filing lag does not support the idea of firms deliberately stalling the disclosure of the accounts. However, since the ultimate goal is only to lengthen the reporting lag, either the preparation or the filing of the financial statements could be stalled. This hypothesis is supported by the fact that the preparation lag and the filing lag are negatively correlated $(r=-0.4326, p<0.01)$. This result would indicate that firms stall either the preparation or the filing of the accounts, but not both.

With time, the number of firms evidently filing their financial statements late (i.e. not within the 'maximum' period of 408 days), and consequently violating the company law, has declined from $26(36.1 \%)$ to $12(16.9 \%)^{16}$. In 1990 , virtually of all these firms had their accounts prepared and approved by the shareholders meeting within 396 days after the ending of the financial year, but chose to stall disclosure of the accounts with, on average, over four months. These results again support the hypothesis that it is not exceptional for small firms to delay the disclosure of the financial accounts firstly by extending the period allowed for preparation with the maximum period legally allowed and secondly by delaying the filing of the accounts substantially ${ }^{17}$.

Eventually all firms in the sample filed their accounts, possibly to avoid any fines for violating the company law. However, these disclosure were made with the knowledge that information disclosed well over 13 months after the ending of the financial year, may be of little use to anyone.

${ }^{16}$ The 1984 results are consistent with studies by Robertson [1986, p. 9], Tsang [1986, p. 55] and NOvAA [1986, p. 17] which all surveyed the timeliness of disclosures by small firms within one or two years after a regulatory change, and found that respectively $30 \%, 35 \%$ and $52 \%$ of the companies in their samples had not filed the financial statements within the required time period.

${ }^{17}$ Corresponding data for the paired sub sample of accounts are presented in Appendix 3B. The results presented there are generally in line with the results for the full sample as presented in this section. 


\subsubsection{Formal disclosure requirements}

Most provisions in Dutch company law deal with the content of the financial statements to be prepared and disclosed, and determine the items to be included and the accounting rules to be used in the financial statements. Additionally, the company law provides a number of requirements concerning the lay out of the accounts and the sequence and naming of items to be disclosed. These formal requirements involve issues like the paper-size to be used, the language the financial statements have to be presented in, the lay out of the financial statements and the signing of the financial statements by the company directors (see Appendix III). As part of the research, all annual accounts were checked in the way these formal requirements were met. The results are presented in Appendix 3C, table 3C.1.

\subsubsection{The use of balance sheet models.}

Compliance with formal requirements, especially those concerning the lay out of the financial statements, can be of considerable importance to users. The use of standard models enhances the comparability of information between firms and between years. The provision of obligatory standard models in the company law, therefore, should enhance the usefulness of financial statements of firms considerably, provided that firms do not grossly deviate from these models.

Table 3.7 Use of standard models for balance sheet and profit and loss account

\begin{tabular}{llcc}
\hline & Standard model used & 1984 & 1990 \\
\hline Balance sheet & Account form & $9(12.5 \%)$ & $7(9.7 \%)$ \\
& Columnar form & $62(86.1 \%)$ & $63(87.5 \%)$ \\
& None & $1(1.4 \%)$ & $2(2.8 \%)$ \\
Profit and loss account & Categorical & - & $8(66.7 \%)$ \\
& Functional & $2(100 \%)$ & $2(16.7 \%)$ \\
& None & - & $2(16.7 \%)$ \\
\hline
\end{tabular}

Dutch company law specifies a number of lay out models for both statements to be used by small firms (see Appendix III for a detailed description). For the balance sheet, four models are presented, of which two (a columnar and an account form model) are designed specifically for small firms. The classification of the balance sheets disclosed turned out to be relatively straightforward, as only one copy in 1984 and 2 copies in 1990 deviated so much from any model that they could not be classified (see table 3.7). From the results on the paired sample (not presented here) it can be concluded that few firms ( 1 out of 30 firms in the sample) have changed the balance sheet format with time.

In 1984, 28 (38.9\%) firms in the sample used an exact or almost exact copy of one of the standard models provided by company law. By 1990 this number had risen to 44 (61.1\%). All other balance sheets, although mostly based on one of the standard models, 
deviated from the standard model by adding new items to the model or by using alternative items or alternative categorisation of standard items. In 1984, 30 (41.7\%) balance sheets included one or more items not mentioned in the standard-model. Most of these deviations were breakdowns of one of the standard-items, which is permitted. Also, a large number of balance sheets lacked a number of items provided on the standard models. In 1990, firms followed the standard models more closely. Details on standard-items were still provided, but were placed in the notes to the balance-sheet.

Other formal requirements (e.g. the provision to state the way the distribution of profits is incorporated in the balance sheet) not only enhance the comparability of the information provided but also present information that is essential for the interpretation of the figures provided in the balance sheet. At this point. a considerable number of firms $(41.3 \%$ in $1984,27.8 \%$ in 1990$)$ does not provide this information as required (see Appendix 3C, table 3C.2).

\subsubsection{Appearance of balance sheet items}

All individual items appearing in the balance sheets disclosed were compared to the items available in the standard balance sheet model. For all general-level items (referred to as group-headings here) the results are presented in table 3.8.

Table 3.8 Occurrence and naming of group-headings in the balance sheet

\begin{tabular}{lccccccccc}
\hline & \multicolumn{4}{c}{1984} & \multicolumn{3}{c}{1990} \\
\cline { 2 - 9 } & $\begin{array}{l}\text { Rele- } \\
\text { vant }\end{array}$ & $\begin{array}{c}\text { Itern } \\
\text { present }\end{array}$ & $\begin{array}{c}\text { Naming } \\
\text { correct }\end{array}$ & $\begin{array}{c}\% \text { in- } \\
\text { correct }\end{array}$ & $\begin{array}{c}\text { Rele } \\
\text { vaut }\end{array}$ & $\begin{array}{c}\text { Item } \\
\text { present }\end{array}$ & $\begin{array}{c}\text { Narning } \\
\text { correct }\end{array}$ & $\begin{array}{c}\text { \% in- } \\
\text { correct }\end{array}$ \\
\hline Fixed assets & 70 & 64 & 59 & 15.7 & 68 & 64 & 61 & 10.3 \\
Current assets & 72 & 69 & 66 & 8.3 & 72 & 68 & 65 & 9.7 \\
Equity & 72 & 69 & 67 & 6.9 & 72 & 70 & 70 & 2.8 \\
Provisions & 44 & 44 & 41 & 6.9 & 53 & 53 & 51 & 3.8 \\
Long term debt & 40 & 40 & 35 & 12.5 & 45 & 45 & 40 & 11.1 \\
Short term debt & 69 & 69 & 60 & 13.0 & 71 & 71 & 62 & 12.7 \\
\hline Totals & 367 & 355 & 328 & $10.6 \%$ & 381 & 371 & 349 & $8.4 \%$ \\
\hline
\end{tabular}

For these items, any deviation from the exact naming in the standard model is prohibited. Group-headings may be omitted, however, if they do not apply to the firm's situation. In 1984 , a total of $27(7.6 \%)$ deviations were found in $11(15.3 \%)$ balance sheets, a number that had decreased to $22(5.9 \%)$ deviations in $10(13.8 \%)$ accounts in 1990. In some cases a group-heading was left out while it was clear from other items on the balance sheets or from the accompanying notes that the item should have been mentioned. Including these deficiencies, the number of group-item errors has declined slightly from $10.6 \%$ in 1984 to $8.4 \%$ in 1990 . 
For all items in the standard models other than group-headings, the naming may differ from the model naming if the new name chosen is 'equally informative'. Since it is hard to infer when a naming is no longer to be considered 'equally informative', in the analysis presented below no distinction will be made between deviations that can be considered permissable and those that might be non-permissable (see table 3.9).

Table 3.9 Use of deviating names for items in the balance sheet

\begin{tabular}{llccc}
\hline & & 1984 & 1990 & $\begin{array}{c}\text { Mann } \\
\text { Whitney U } \\
\text { test }\end{array}$ \\
\hline Use of deviating item-names per & mean & 1.778 & 1.028 & $\mathrm{z}=-2.720$ \\
balance sheet (all accounts) & minimum & 0 & 0 & \\
& maximum & 16 & 12 & $(\mathrm{p}=0.065)$ \\
& st. deviation & 2.800 & 2.175 & \\
Use of deviating item-names per & $\mathrm{N}$ & 72 & 72 & \\
balance sheet (accounts with at & minimum & 2.909 & 2.643 & $\mathrm{z}=-0.674$ \\
least one deviation) & maximum & 1 & 1 & \\
& st. deviation & 3.094 & 12 & $(\mathrm{p}=0.499)$ \\
& $\mathrm{N}$ & 44 & 2.831 & \\
\hline
\end{tabular}

The number of deviations is much higher compared to the results for the groupheadings ${ }^{18}$. Details on the naming of individual items are presented in appendix 3C, table 3C.3. By 1990, the average number of deviations, counting all accounts, has declined significantly. This result mainly stems from the fact that the number of accounts with deviations has declined (from $44(61.1 \%)$ in 1984 to 28 (38.9\%) in 1990) while the number of deviations per non-standard account has remained fairly constant ( 2.9 in 1984, 2.6 in 1990). From these results it again seems clear that more firms tend to follow the standard models more closely in 1990. Also, with the exception of a few extreme cases, most deviations do not seem to conflict with the understandability or comparability of the balance sheets presented ${ }^{19}$.

${ }^{18}$ A special case has to be made for the inclusion of government grants in the balance sheet. In the prescribed models no item is presented to incorporate government grants. Company law permits adding items to the balance sheet if none of the available items seems to be appropriate. The most important government grant for small firms, Government Investment Grant (Wet Investerings Premies, WIR), was changed considerably in 1986 which resulted in large differences at this point between the accounts of 1984 and 1990. To avoid any difficulties, all items related to government grants were left out of the analysis.

19 The item 'other reserves' has the largest number of deviations from the standard naming (see Appendix 3C, table 3C.3). Most firms, however, used names like 'general reserves' or just 'reserves', which, in most cases anyway, may be considered equally informative. 


\subsubsection{The information volume of small firms' financial statements}

Although the quantity of information provided in financial statements has no direct bearing on the quality of the information provided, an analysis of the volume of information included in the financial statements disclosed gives an insight into the extent of the disclosures made by small firms. In some cases the quality and quantity of information are very closely related, such as in the disclosure of the accounting principles used in the valuation of items on the balance sheet. Inadequate disclosure of such elementary items relates directly to the usefulness and the quality of the information provided in the financial statements disclosed.

Table 3.10 Volume of information disclosed

\begin{tabular}{ccc}
$\begin{array}{c}1984 \\
(\mathrm{~N}=72)\end{array}$ & $\begin{array}{c}1990 \\
(\mathrm{~N}=72)\end{array}$ & $\begin{array}{c}\text { Mann Whitney U } \\
\text { test } \\
\text { 2 score ( } \mathrm{p} \text { value) }\end{array}$ \\
\hline 3.431 & 3.958 & $1.297(0.195)$ \\
2.7 & 3.2 & \\
\hline
\end{tabular}

Number of pages

Number of elements

2.7

3.2

Number of accounts containing a:

- Directors report

- Balance sheet

- Profit and loss account

- Notes to the balance sheet

- Notes to the P\&L account

- General notes

- Auditor's report

$2(2.8 \%)$

$72(100 \%)$

$2(2.8 \%)$

$68(94.4 \%)$

$2(2.8 \%)$

$49(68.1 \%)$

$4(5.6 \%)$

Number of items in:

- Balance sheet

- Profit and loss account

- Notes to financial statements
$15.0(\mathrm{~N}=72)$

$22.5(\mathrm{~N}=2)$

$9.3(\mathrm{~N}=69)$
$2(2.8 \%)$

$72(100 \%)$

$12(16.7 \%)$

$69(95.8 \%)$

$12(16.7 \%)$

$57(79.2 \%)$

$7(9.7 \%)$

The annual accounts of a Dutch small firm on average covers three and a half page in 1984 and has extended to almost four pages in 1990 (see table 3.10). Most accounts consist of three elements: the balance sheet, the notes to the balance sheet and the general notes. A small number of firms (4 in 1984 and 3 in 1990) disclosed only a balance sheet, thereby clearly violating the company law requirements to disclose a number of notes to the balance sheet. On the other hand other accounts included a profit and loss account or an auditor's report, thereby disclosing more information than required. The average number of financial statement-elements was 2.7 in 1984 and 3.2 in 1990 . In most cases the general notes were not clearly separated from the notes to the balance sheet, so that the average number of elements as separated in the actual accounts is slightly less (2.25 in 1984 and 2.14 in 1990).

The number of items on the balance sheet declined from 15.0 in 1984 to 14.4 in 1990 (the number of items in the prescribed standard balance sheet lay out is 23 for the 
account form model and 19 for the columnar model). The number of items in the accompanying notes increased slightly from 9.3 in 1984 to 10.3 in 1990 . As indicated before, this illustrates the fact that in 1990 firms tended to follow the standard balance sheet models provided in the company law more closely and moved details on these items to the accompanying notes.

A further indication of the amount of information incorporated in small firms' annual accounts, is provided by the number of specifications for balance sheet items that are disclosed (see table 3.11). The items in the standard balance sheet model may be supplemented or replaced by an itemization. These breakdowns are mostly voluntary information disclosures. although for the owners' equity, a breakdown and table of changes is mandated to be incorporated in the notes to the balance sheet.

Table 3.11 Specification of balance sheet items

\begin{tabular}{|c|c|c|c|c|c|c|}
\hline & & & 84 & & 90 & Mann Whimey \\
\hline & & $\begin{array}{l}\text { No. of } \\
\text { accounts }\end{array}$ & $\begin{array}{l}\text { Specifica- } \\
\text { tions per } \\
\text { account }\end{array}$ & $\begin{array}{l}\text { No. of } \\
\text { accounts }\end{array}$ & $\begin{array}{l}\text { Specifica- } \\
\text { tions per } \\
\text { account }\end{array}$ & $z$ score (p-value) \\
\hline $\begin{array}{l}\text { Location of } \\
\text { specification }\end{array}$ & $\begin{array}{l}\text { Balance sheet } \\
\text { Notes }\end{array}$ & $\begin{array}{l}11 \\
66\end{array}$ & $\begin{array}{l}3.545 \\
5.682\end{array}$ & $\begin{array}{c}6 \\
69\end{array}$ & $\begin{array}{l}3.667 \\
6.203\end{array}$ & $\begin{array}{l}0.724(0.469) \\
1.122(0.262)\end{array}$ \\
\hline $\begin{array}{l}\text { Type of } \\
\text { specification }\end{array}$ & $\begin{array}{l}\text { Numerical } \\
\text { Textual }\end{array}$ & $\begin{array}{l}56 \\
67\end{array}$ & $\begin{array}{l}3.214 \\
3.940\end{array}$ & $\begin{array}{l}53 \\
68\end{array}$ & $\begin{array}{l}2.585 \\
4.838\end{array}$ & $\begin{array}{l}1.213(0.225) \\
2.516(0.012)\end{array}$ \\
\hline & Total & 71 & 6.254 & 71 & 6.563 & $0.408(0.684)$ \\
\hline
\end{tabular}

Specifications of balance sheet items can be located either in the balance sheet (in addition to or replacing one of the standard items) or in the accompanying notes. The vast majority of all commentaries were placed in the notes to the balance sheet $(92.9 \%)$. The vast majority of the specifications of balance items were of a verbal nature. Of all commentaries counted (910, an average of 6.4 per account), $34.9 \%$ (317) included numeric information while all others were entirely textual. The number of numerical commentaries and that of textual commentaries are negatively correlated $(r=-0.44)$, indicating that firms tend to treat these as substitutes rather than that firms providing a large number of numerical commentaries also provide a relatively large number of textual notes. A total of 2 accounts (1 in both 1984 and 1990) contained no commentaries on balance sheet items at all and were in clear violation with multiple disclosure regulations ${ }^{20}$. Furthermore, 35 accounts included only textual commentaries.

${ }^{20}$ As mentioned before, a total of seven accounts (4 in 1984 and 3 in 1990) included no accompanying notes. Five of these, however, included at least some specifications in the balance sheet. 
The notes to the balance sheet have to provide a range of information items, mostly as a supplement to items appearing on the balance sheet (see appendix III). Firms may leave any information out of the financial statements if an item does not apply to the firm's situation or if the item is of such insignificance that it can be left out without violating the required insight into the firm's financial position. Obviously, this creates a serious problem in evaluating compliance since it is very hard to determine whether the absence of an item of information constitutes a violation of company law requirements, or whether the item is left out for reasons within the legal provisions. Consequently, as mentioned before, any indication of the level of compliance or the quality of the information disclosed constitutes an optimistic estimation, which may actually be lower if firms have left out any information unjustifiedly.

Details on the items specified in the notes to the balance sheet are presented in Appendix 3C (table 3C.4). Compliance levels for 1990 vary strongly from as high as $93 \%$ ( $80 \%$ in 1984 ) for depreciation methods used for tangible assets to $22 \%$ ( $28 \%$ in 1984) for accounts receivable falling due within one year. For most of the items for which the level of compliance can positively be established, compliance has improved over time. Nevertheless, it is clear that most financial statements' notes entail only a fraction of the number of items required by law. This, however, might be due to the fact that most items required generally do not apply to small firms so that the omissions of items can not be positively identified as non-compliance with financial reporting regulations.

Table 3.12 Valuation methods

\begin{tabular}{llcccccccccc}
\hline & \multicolumn{1}{c}{1984} & \multicolumn{1}{c}{1990} \\
\cline { 2 - 11 } & $\mathrm{N}$ & $\begin{array}{c}\mathrm{HC} \\
\%\end{array}$ & $\begin{array}{c}\mathrm{CC} \\
\%\end{array}$ & $\begin{array}{c}\mathrm{NV} \\
\%\end{array}$ & $\begin{array}{c}\mathrm{NM} \\
\%\end{array}$ & $\mathrm{~N}$ & $\begin{array}{c}\text { HC } \\
\%\end{array}$ & $\begin{array}{c}\text { CC } \\
\%\end{array}$ & $\begin{array}{c}\text { NV } \\
\%\end{array}$ & $\begin{array}{c}\mathrm{NM} \\
\%\end{array}$ \\
\hline Intang. fixed assets & 15 & 80 & - & - & 20 & 12 & 50 & - & - & 50 \\
Tangible fixed assets & 60 & 88 & - & - & 12 & 69 & 91 & - & - & 9 \\
Financial fixed assets & 28 & 21 & 7 & 43 & 29 & 20 & 25 & - & 40 & 35 \\
Stocks & 50 & 78 & - & - & 22 & 61 & 87 & - & - & 13 \\
\hline
\end{tabular}

$\overline{\mathrm{HC}}=$ Historical cost, $\mathrm{CC}=$ Current cost, $\mathrm{NV}=$ Net asset value, $\mathrm{NM}=$ Not mentioned

An essential item in the accompanying notes concerns the disclosure of accounting policies used for valuation. The accounting policies have to be disclosed for any of the items presented in the financial statements. For the valuation of assets and liabilities, firms may choose the cost price or productions cost (historical cost) and also, for tangible and financial fixed assets and stocks, the current value may be used ${ }^{21}$. The disclosures on valuation principles and the valuation methods used are presented in table 3.12. Sample firms almost exclusively use historical cost for the valuation of assets, except for the valuation of financial assets where the net asset value is mostly

${ }^{21}$ The 'General Order on Current Cost' of December 22, 1983 entails detailed prescriptions on the content, limits and application of restatement of assets at current costs. 
used to value subsidiaries. None of the small firms used current cost asset valuation for other than the financial assets ${ }^{22}$. However, a notable number of firms did not provide any information on asset valuation, although this information is essential for understanding the financial statements. Also, this situation does not seem to have improved over time.

\subsubsection{Voluntary disclosures.}

In the previous section the focus was on information required by company law and compliance of small Dutch firms with financial accounting disclosure requirements. In this section the emphasis will be on the voluntary disclosures made by small firms.

Small firms may have various incentives to disclose information in addition to the information legally required:

1. Additional information may be required to enable users to form a well-founded opinion of the company's assets, liabilities and results. Such additions are not of a strictly voluntary nature, since in principle they are required by law.

2. Firms may be unwilling to pay the extra costs of differentiating between accounts prepared and accounts disclosed. Therefore they may choose to disclose the prepared accounts, although these may well include more information than legally required to be disclosed.

3. Firms may be unaware of all legal requirements and exemptions provided in the company law requirements.

4. Firms may find it beneficial to provide more information than is strictly required, e.g. if the information in the financial statements is to be used in the process of acquiring a bank loan.

Since it is impossible to determine from the financial statements disclosed the reason for any disclosure made, in this section voluntary disclosures are defined as any information provided in the financial statements that is not specifically required by company law.

From table 3.13 it is clear that the number of voluntary disclosed items has increased since 1984. This is primarily due to the fact that more firms have enclosed some kind of non-mandatory information and only slightly results from an increase in the number of voluntary disclosures per account. This result is particularly caused by the increasing number of firms that has disclosed a profit and loss account and the notes thereto. The number of accounts with voluntary information has increased from $56(77.8 \%)$ in 1984 to $70(97.2 \%)$ in 1990 and the number of items disclosed voluntarily has increased from

2 Firms using current cost need to provide information on how the current costs are determined. Also, firms using production costs for valuing an asset have to explain whether interest on debts has been capitalised. None of the financial statements examined included any details on these items. 
2.25 items per account in 1984 to 3.66 items in 1990 . So, although many accounts entail some items not specifically required by company law, even with the increase in voluntary disclosures, the number of items disclosed in 1990 by small firms in addition to the company law requirements is generally limited.

Table 3.13 Voluntary information disclosure

\begin{tabular}{lcccccc}
\hline $\begin{array}{l}\text { Voluntary information } \\
\text { disclosures }\end{array}$ & \multicolumn{2}{c}{1984} & \multicolumn{2}{c}{1990} & $\begin{array}{c}\text { Mann Whitney } \\
\text { U test } \\
\text { z-score } \\
\text { (p-value) } \\
\text { accounts }\end{array}$ \\
\hline All accounts & 72 & $\begin{array}{c}\text { No of } \\
\text { items per } \\
\text { account }\end{array}$ & $\begin{array}{c}\text { No. of } \\
\text { accounts }\end{array}$ & $\begin{array}{c}\text { No of } \\
\text { items per } \\
\text { account }\end{array}$ & \\
$\begin{array}{l}\text { Accounts with voluntary } \\
\text { disclosures only }\end{array}$ & 56 & 2.75 & 72 & 3.55 & $3.266(0.001)$ \\
\hline
\end{tabular}

\subsubsection{Concluding remarks.}

This section has provided some descriptive results on the timeliness, quantity and quality of financial reporting disclosures made by small firms. Annual accounts were studied for 1984, the first year the company law requirements for small firms were in effect, and 1990.

From the data on the period of time firms take to prepare and file their accounts, it seems it is common practice among small firms to extend the 'normal' period to prepare their annual accounts with the maximum allowable period of 6 months. For some reason, small firms generally do not prepare their financial statements within $\mathbf{5}$ months after the end of the financial year. For 1984, this can be explained by the fact that many firms may have had difficulty in adjusting to the new regulatory requirement. But even in 1990 only a small fraction of small firms filed its accounts within six months after the end of the financial year. An alternative explanation therefore could be that many small firms deliberately defer the preparation of the annual accounts, or stall the filing of the accounts after they have been approved by the shareholders meeting. Although all firms in the sample eventually filed their accounts, possibly to avoid any fines for violating the company law, most firms did so in the knowledge that their accounts were filed well over 13 months after the ending of the financial year.

The comparability of financial information disclosed by small firms does not seem to pose any serious troubles. The majority of firms use an exact copy of one of the balance sheet models provided in company law. Also, most deviations from these models generally do not seem to harm the understandability of the information disclosed. The volume and quality of information disclosed in the notes to the balance sheet seem to be much more of a problem. In many cases vital information (e.g. accounting policies used) is missing and the extent of the information provided in the notes is in most cases 
very limited. Also, there seems to be little improvement at this point with time. A major difficulty here is that it is very hard to establish whether the omission of certain information required by Law is a result of that information not being applicable to the firm's situation or that the firm does not comply with the legal requirements. For those items where the level of compliance could be positively established it can be concluded that the level of compliance varies strongly depending on the particular information requested.

\subsection{Determinants of regulatory compliance of small firms.}

\subsubsection{Introduction.}

Compliance of companies with financial accounting regulation varies among firms, but there are few empirical studies on the determinants of the observed degree of compliance. Although firm size has been repeatedly suggested as a main factor in the financial accounting burden imposed on firms, few studies have empirically investigated the relationship between financial accounting disclosures and firm characteristics [Buijink, 1992, p. 41]. Only two studies, by Holmes and Nichols [1989] and Keasey and Short [1990], have modelled the financial reporting activities of small firms (see also chapter 2).

Foster [1986], summarises a number of factors as determinants of the timeliness and quality of financial accounting information of companies ${ }^{23}$. The variable most consistently reported as significant in studies examining differences in disclosure policy across firms, is firm size [Foster, 1986, p. 44]. Firm size, however, is used as a proxy for various underlying factors, such as political costs, information production costs and litigation costs, which makes it hard to explain the results of empirical studies. Other variables suggested are industry as a proxy for competitive disadvantage costs, leverage and non-management ownership as a proxy for agency costs and leverage, profitability and liquidity as proxies for competition for acquiring capital (e.g. bank loans) [Buijink, 1992, p. 42].

\footnotetext{
${ }^{23}$ These factors, however, are used by Foster to explain voluntary disclosure by firms and may have limited applicability to disclosure policies of firms towards mandated disclosure. Although these factors may be important in explaining the position of firms taken towards proposed regulations and lobbying activities to influence these proposals, other factors may dominate the decision of firms to (not) comply with passed regulations.
} 


\subsubsection{Independent variables}

Using the data from the compliance study discussed in section 3.3, a number of empirical regularities reported in the financial accounting literature can be tested. The following explanatory variables are used ${ }^{24}$ :

SIZE

Firm size, measured by the firm's total assets. Larger firms are hypothesised to have better accounting procedures, relatively lower accounting costs and higher potential benefits from financial reporting activities, resulting in better reporting characteristics (i.e. timeliness, quantity and quality of information). Also, smaller firms are politically less visible resulting in a reduced chance of the government monitoring the quality of financial statements, also resulting in lower litigation costs.

LEVERAGE Leverage, calculated as equity over total assets. Firms with more debt are hypothesised to encounter stronger demands for financial accounting information from outside capital suppliers resulting in improved financial reporting characteristics.

SBI (1-6) Dummy variables for industry. Although the financial reporting characteristics may vary between industries (e.g. as a result of varying competitive disadvantages), the sign of the relationship is unclear. It has been suggested that financial firms are more timely reporters since they are less engaged in time-consuming activities such as counting inventory [Courtis, 1976, p. 53]. However, financial firms are not included in our sample.

ACCOUNTANT Dummy variable coded 1 if the accounts are prepared by an external accountant and code 0 if the accounts are prepared by firm employees. Given the expertise of a professional accountants with company law requirements the quality of the information disclosed is hypothesised to improve if an external accountant prepared the accounts. Also, the volume of information disclosed is hypothesised to increase when an external accountant is involved since the accountant will be more aware of all company law requirements and will be less inclined to leave out any item of information. However, the firm's management may decide to leave certain items out of the financial statements when it is actually disclosed which would reduce the effect of the external accountant on the volume of information disclosed. The effect on the timeliness of the financial statements is unclear. Although hiring an external accountant may speed up the preparation of the accounts, firms that prepare the accounts internally may have better accounting and control procedures. Furthermore, the impact of the external accountant on the filing of the accounts seems minimal since this is primarily a matter for the firm itself.

${ }^{24}$ Where appropriate, the data for 1990 are deflated in terms of 1984 guilders. 
PERIOD (0-1) Dummy variable coded 1 if the dependent variable is calculated from accounts of 1990 and code 0 if the dependent variable is calculated from accounts of 1984. Financial reporting characteristics are hypothesised to improve over time as firms are getting more familiar with financial reporting procedures and regulatory requirements.

\subsubsection{Dependent variables}

Various proxies for the timeliness, quantity and quality of small firm financial disclosures are used as dependent variables. For timeliness three measures are used: preparation lag (PREPARE), filing lag (FILE) and reporting lag (REPORT), as defined section 3.3.4. Increasing lags relate to decreasing timeliness of disclosures. The quantity of small firm information disclosures is measured by the number of items in the balance sheet and the accompanying notes (ITEMCNT), the number of specifications of balance sheet items (SPECCNT) and the number of voluntarily disclosed items (VOLUNT). The quality of the information disclosures is measured by the number of deviating names for group-headings (HEADNAME) and the number of deviating names for all balance sheet items (ITEMNAME). As a consequence, the level of quality of financial disclosures in our study is exclusively related to the comparability of the information provided. Increasing numbers of deviations relate to a decrease in the comparability of the information disclosed.

The expected signs for the relationships between dependent and independent variables are summarised in table 3.14 .

Table 3.14 Determinants of the financial information disclosure of small firms

\begin{tabular}{lccccc}
\hline Dependent variables & Firm size & Leverage & Industry & $\begin{array}{c}\text { External } \\
\text { accountant }\end{array}$ & Period \\
\hline Timeliness & + & - & $+/$ & $+/$ & + \\
- PREPARE & - & + & & & - \\
- FLE & - & + & & & - \\
- REPORT & - & + & & + & + \\
Quantity & + & - & $+/$ & + & + \\
- ITEMCNT & + & - & & + & + \\
- SPECCNT & + & - & & + & + \\
- VOLUNT & + & - & & + & - \\
Quality & + & - & $+/$ & + & - \\
- HEADNAME & - & + & & - & + \\
- ITEMNAME & - & + & & & \\
\hline
\end{tabular}




\subsubsection{Univariate results}

Descriptive univariate statistics for the dependent variables are presented in Appendix $3 D^{25}$. A summary of the statistical tests performed is presented in table 3.15 . Rank correlations are reported for ordinal independent variables (SIZE, LEVERAGE), Kruskal Wallis tests are performed for categorical data (SBI) and Mann-Whitney U tests are performed for dichotomous variables (ACCOUNTANT, PERIOD).

Table 3.15 Summary results of univariate analysis

\begin{tabular}{|c|c|c|c|c|c|}
\hline & $\begin{array}{l}\text { SIZE } \\
\text { Spearman } \\
\text { rank correl. }\end{array}$ & $\begin{array}{l}\text { LEVERAGE } \\
\text { Spearman } \\
\text { tank correl }\end{array}$ & $\begin{array}{c}\text { SBI } \\
\text { Krusical Wallis } \\
\text { test } \\
\left(x^{2}\right)\end{array}$ & $\begin{array}{c}\text { ACCOUNT } \\
\text { Mamn Whitney } \\
\text { U test } \\
\text { (z score })\end{array}$ & $\begin{array}{c}\text { PERLOD } \\
\text { Mann Whitney U } \\
\text { test } \\
\text { (z score) }\end{array}$ \\
\hline \multicolumn{6}{|l|}{ Timeliness } \\
\hline - PREPARE & $0.119^{*}$ & -0.075 & 2.40 & $2.61^{* * *}$ & -0.87 \\
\hline - FILE & $-0.126^{*}$ & 0.013 & 1.35 & $-1.38^{*}$ & $-1.98 * *$ \\
\hline - REPORT & 0.007 & $-0.115^{*}$ & 3.23 & $1.55^{*}$ & $-3.31 * * *$ \\
\hline \multicolumn{6}{|l|}{ Quantity } \\
\hline - ITEMCNT & $0.269 * * *$ & $-0.134 *$ & 5.59 & -0.81 & 0.79 \\
\hline - SPECCNT & $0.313^{* * *}$ & -0.082 & $14.34 * *$ & 0.23 & 0.40 \\
\hline - VOLUNT & $0.345^{* * *}$ & $-0.114^{*}$ & 9.11 & -0.75 & $3.26 * * *$ \\
\hline \multicolumn{6}{|l|}{ Quality: } \\
\hline - HEADNAME & $-0.286^{* * *}$ & 0.098 & -3.59 & $-2.65^{* * * *}$ & -0.26 \\
\hline - ITEMNAME & $-0.306^{* * *}$ & 0.053 & -3.98 & $-1.64^{*}$ & $-2.72 * *$ \\
\hline
\end{tabular}

One-tailed probability levels are indicated by $*$ for $\alpha=0.10,{ }^{* *}$ for $\alpha=0.05$ and *** for $\alpha=0.01$ (for SBI, 2-tailed probability levels are reported)

The results found in the univariate analysis suggest that:

1. Firm size significantly affects the quality and quantity of the information disclosures by small firms. Both the quality and quantity of the information disclosed increase with firm size. The time to prepare the accounts generally increases with firm size, except for the largest firms in the sample (see Appendix 3D, table 3D.1). The time to file the accounts generally decreases with firm size, which is primarily caused by the extreme filing lags of the very small firms in the sample. Statistically, the effect of firm size on the timeliness of the accounts, however, is mostly only marginally significant.

2. The hypothesized effect of leverage on the quantity and quality of information disclosed is mostly as predicted. The effect on timeliness is mixed and not consistent with the predicted sign. The results found are only marginally significant in a few cases (REPORT, ITEMCNT) and not significant for most independent variables

\footnotetext{
${ }^{25}$ Results for the full sample and the paired sample are very similar. Therefore only the results for the full sample will be discussed in the remainder of this section. Univariate and multivariate results for the paired sample are provided in Appendix 3E.
} 
3. The timeliness, quantity or quantity of financial information disclosures do not systematically vary with industry (at a 1-digit level). Although there is a significant result found for one individual item (SPECCNT), there is no consistent relationship between industry and the timeliness, quality or quantity of the information disclosed. 4. The hiring of an external accountant to prepare the annual accounts improves the quality of information disclosed. Also, firms hiring an external accountant to prepare the annual accounts, have longer preparation lags. On the other hand, the time to file the accounts after they have been approved by the shareholders meeting decreases when an external accountant is hired. The effect on the volume of information disclosed is limited and mostly not as predicted.

5. With time, the timeliness, quality and quantity of information disclosed by small firms have improved. Preparation lags have decreased only marginally. A strong decrease in filing lags, however, resulted in a significant decrease in reporting lags. The effect on the quantity and quality of the information disclosed is as predicted but only significant for the voluntary disclosure of information (VOLUNT) and the naming of balance sheet items (ITEMNAME).

\subsubsection{Multivariate results}

To assess the partial effect of each explanatory variable, holding all other variables constant, and to test the combined explanatory power of the set of explanatory variables, the following multiple regression model was estimated:

$$
D E P=a_{0}+a_{1} S I Z E+a_{2} L E V E R A G E+a_{3} A C C O U N T A N T+a_{4} P E R I O D+\sum_{i=1}^{6}\left(a_{5} S B I_{i}\right)
$$

The model was estimated for each of the dependent variables defined in the previous sections, resulting in eight models to be tested. The results of the multivariate analysis are presented in table 3.16 and Appendix $3 \mathrm{E}$ for the paired sample.

Table 3.16 depicts a significant effect of PERIOD in the models using FILE, REPORT, VOLUNT and ITEMNAME as the dependent variable. Similar results are found for ACCOUNTANT with PREPARE, HEADNAME with ITEMNAME and SIZE with VoLUNT. Partial effects of the other explanatory variables are not significant at the 0.1 significance level. These results are generally consistent with the univariate analysis regarding the effect observed for PERIOD and ACCOUNTANT. The absence of any partial effect of LEVERAGE and SBI is also consistent with the outcome of the univariate analysis. The effect of SIZE on the quantity and quality of the information disclosures, however, has disappeared in most of the multivariate models tested. 
Table 3.16 Multiple regression coefficients.

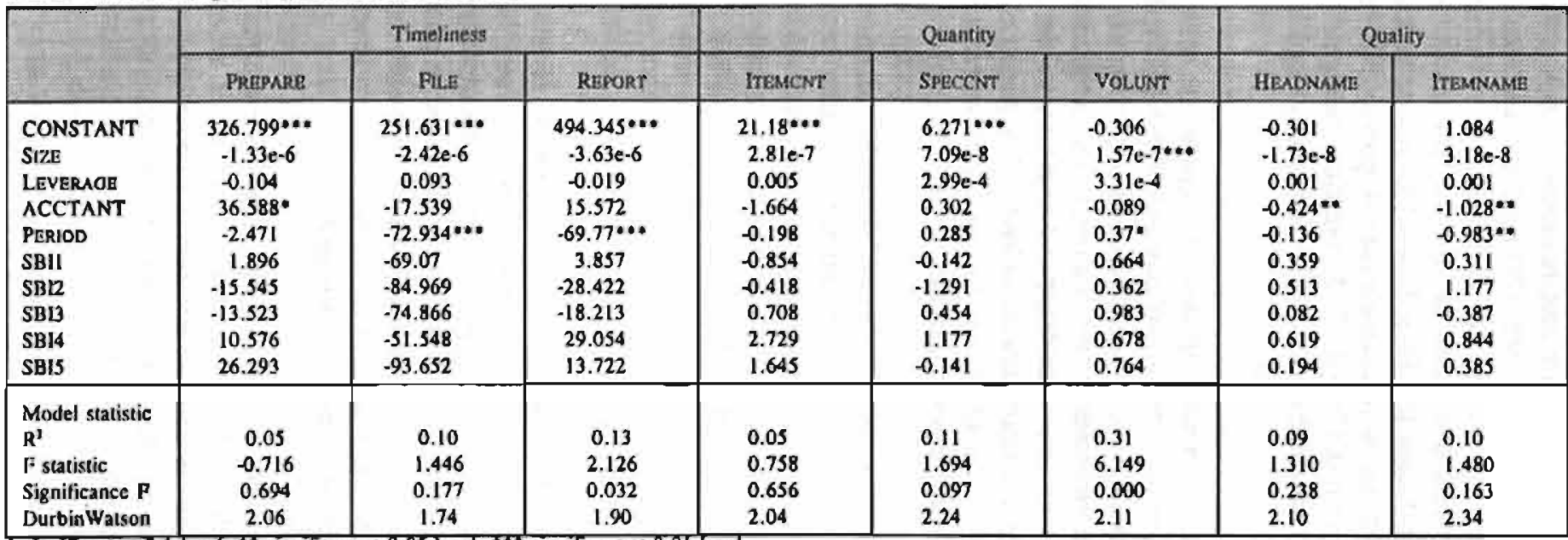

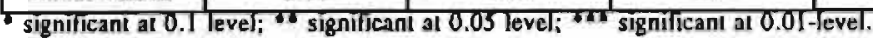

Table 3.17 Predicted signs and univariate and muttivariate results.

\begin{tabular}{|c|c|c|c|c|c|c|c|c|c|c|c|c|}
\hline & \multicolumn{3}{|c|}{ Firm size } & \multicolumn{3}{|c|}{ Leverage } & \multicolumn{3}{|c|}{ Accountant } & \multicolumn{3}{|c|}{ Period } \\
\hline & Pred. & Univ. & Multiv. & Pred. & Univ. & Multiv. & Pred. & Univ. & Multiv & Pred. & Uniy. & Maltiv \\
\hline Timellness & + & I & + & - & +1 & $+^{\prime}$ & +1 & .1 & .1 & + & + & + \\
\hline Quantity & + & + & + & - & - & + & + & +1 & +1 & + & + & +1 \\
\hline Quality & + & + & $+1-$ & - & - & - & + & + & + & + & + & + \\
\hline
\end{tabular}

sign for FILE-variable is opposic 
The performance of most of the models is weak. $R^{2} s$ are mostly around or below 0.10 . F statistics are significant only for REPORT $(\alpha \leq 0.05)$, SPECCNT $(\alpha \leq 0.1)$ and VOLUNT $(\alpha \leq 0.01)$. For all other models the null hypothesis that the explanatory variables collectively do not affect the dependent variable cannot be rejected (for $\alpha \leq 0.10)^{26}$, althouugh the results are marginally significant for FILE $(\alpha=0.18)$ and ITEMNAME $(\alpha=0.16)$. The regression models based on the paired sample (see Appendix 3E, table $3 E .2)$ perform slightly better. $R^{2} s$ range from 0.12 to 0.47 . F statistics are significant for REPORT ( $\alpha \leq 0.05)$, VOLUNT $(\alpha \leq 0.01)$ and FILE $(\alpha \leq 0.1)$ and marginally significant for ITEMNAME $(\alpha=0.106)$.

The sign of the coefficients for the PERIOD variable in both the univariate and the multivariate analysis are as predicted and mostly are significant (see table 3.17). For SIZE the results relating to the quality and quantity of information disclosed are generally as predicted. The effect of firm size on the timeliness of disclosures is also as predicted and larger firms have shorter reporting lags. For ACCOUNTANT and LEVERAGE the results are only consistent for the quality of the information disclosed. The hiring of an external accountant has an adverse effect on the timeliness of disclosure whereas the effect on the quantity of information disclosed is not consistent.

Regarding the timeliness of information disclosures the effect of SIZE, LEVERAGE and ACCOUNTANT on the filing lag (FILE) is opposite to the sign for the two other proxies for timeliness (PREPARE and REPORT). Finally, differences in disclosure characteristics between firms of different industries can be found but are neither consistent nor significant in both the univariate and multivariate analysis.

\subsection{Concluding remarks.}

In this chapter the compliance of Dutch small firms with financial accounting regulation is analyzed. It was found that compliance with formal requirements, mostly facilitating the comparability of the information disclosed over time and over firms, does not seem to be an area of great concern. A common strategy followed by small firms is to take an exact copy of a standard model and to leave the items that are not applicable to the firm's situation without an amount. This strategy also seems to be common practice among accounting firms preparing small firms' financial statements.

Most compliance problems pertain to the notes to the balance sheet. The amount of information disclosed is rather limited. It is, however, not always clear whether omissions are cases of non-compliance or just a result of the item not being applicable to the firm's situation. Also, the number of items disclosed voluntarily is limited

${ }^{26}$ Autocorrelation (see Durbin Watson statistics in table 3.16) and multicollinearity (see correlation matrix in Appendix 3F, table 3F.1) do not seem to pose any serious problems. 
although many accounts disclosed entail at least some items not specifically required by company law.

An interesting finding concerns the timing of filing accounts at the Chamber of Commerce. The time lag between the approval of the annual accounts by the shareholders meeting and the filing of the accounts has decreased with time. This result is consistent with the effect predicted from the existence of learning effects that will result in an improvement of the timeliness of filing over time. However, most firms in 1990 still violate the requirement to file the accounts within 8 working days after approval by the shareholders meeting. In fact, the average filing lag in 1990 is still over 52 days. Although a compliance study, solely based on the information provided in the financial statements disclosed, does not provide any explanations for these results found, it may well be that small firms deliberately tend to delay the disclosure of the accounts. This effect is stronger for smaller firms. In fact, the financial statements of the majority of the sample firms are not filed within 13 months after the ending of the financial year and consequently may be of little use to anyone.

In section 3.4 , the relationship between the timeliness, quantity and quality of financial accounting disclosures by small firms and a number of firm characteristics is analyzed. The results both the univariate and multivariate analysis indicate there has been an improvement in the timeliness, quality and quantity of information provided in small firms' annual accounts. The quality of such information also is improved if an external accountant is hired to prepare the accounts. Furthermore, the quality and quantity of the information disclosed increases whith firm size. The effect of other explanatory variables such as leverage or industry generally are not significant, although there is some indication that the quality of the information disclosed is positively related to leverage.

It should be recognised that the analysis provided does not include all relevant explanatory variables, due to a lack of available data (e.g. profitability and management ownership structure). A variable that may be of particular importance in a small firm setting is the influence of a dominant individual on a firm's disclosure policy. The presence of a dominant personality, controlling the accounting procedures within a company and the lack of governance devices (e.g. an auditor) within small firms, may very well have a substantial effect into the accounting disclosures of small firms. Research on the dominant individual explanation is, however, very sparse and mostly based on anecdotes [Foster, 1986, p. 44, Forker, 1992, p. 117].

The results of this and other studies on the quality of small firms' financial accounts indicate that small firms are not really convinced of the desirability of disclosing their annual accounts. The timeliness and volume of information disclosed particularly seem to limit the usefulness of small firm financial statements. From compliance studies, however, it is hard to infer what the underlying factors are that influence small firms' disclosure policy. Is it that small firms want to keep their financial information private to avoid any competitive disadvantage costs? Or it is that information production costs 
are a serious burden to small firms resulting in minimal information disclosures? To present further information on the effects on the disclosure policies of small firms, a study on the perceptions of small firms' managers and an investigation of information production costs and firm size will be presented in chapter 4 . 
Appendix 3A. Data on the number of annual accounts disclosed.

Table 3A.1. Compliance by small Dutch firms with financial accounting regulations.

\begin{tabular}{|c|c|c|c|c|}
\hline \multirow{3}{*}{ Chamber of Commerce } & \multicolumn{4}{|c|}{ Level of compliance } \\
\hline & \multicolumn{2}{|c|}{$1984^{1}$} & \multicolumn{2}{|c|}{$1991^{2}$} \\
\hline & $\begin{array}{c}\text { Number of small } \\
\text { companies }\end{array}$ & $\begin{array}{l}\text { Level of } \\
\text { compliance }\end{array}$ & $\begin{array}{c}\text { Number of small } \\
\text { companies }^{3}\end{array}$ & $\begin{array}{l}\text { Level of } \\
\text { compliance }\end{array}$ \\
\hline Alkmaar & 3,100 & $66 \%$ & 5,034 & $87 \%$ \\
\hline Amersfoort & 2,700 & $45 \%$ & 4,393 & $90 \%$ \\
\hline Amsterdam & 20,000 & $40-50 \%$ & 31,695 & $70 \%$ \\
\hline Apeldoorn & NA & NA & 8,906 & $98 \%$ \\
\hline Arnhem & 7,000 & $45 \%$ & 9,721 & $88 \%$ \\
\hline Breda & 5,600 & $50 \%$ & 8,319 & $93 \%$ \\
\hline Delft & 2,000 & $40 \%$ & 4,461 & $96 \%$ \\
\hline Den Bosch & 7,000 & $50 \%$ & 8,582 & $95 \%$ \\
\hline Den Haag & 10,200 & $40 \%$ & 13,131 & $88 \%$ \\
\hline Deventer & 1,500 & $55 \%$ & 1,514 & $100 \%$ \\
\hline Dordrecht & 5,000 & $50-55 \%$ & 8,527 & $83 \%$ \\
\hline Eindhoven & 7,000 & $55-60 \%$ & 10,499 & $84 \%$ \\
\hline Enschede & NA & NA & 7,487 & $98 \%$ \\
\hline Gouda & 3,000 & $35-40 \%$ & 4,319 & $93 \%$ \\
\hline Groningen & 2,400 & $60 \%$ & 4,771 & $97 \%$ \\
\hline Haarlem & 6,800 & $50 \%$ & 9,625 & $80 \%$ \\
\hline Harderwijk & 1,800 & $47 \%$ & NA & NA \\
\hline Heerlen & 3,400 & $50 \%$ & 4,410 & $96 \%$ \\
\hline Hengelo & 6,400 & $45-50 \%$ & NA & $\mathrm{NA}$ \\
\hline Hilversum & 4,500 & $50-60 \%$ & 6,176 & $84 \%$ \\
\hline Hoorn & 2,400 & $40-50 \%$ & 3,672 & $82 \%$ \\
\hline Leeuwarden & 4,000 & $50 \%$ & 5,412 & $95 \%$ \\
\hline Leiden & 6,000 & $50 \%$ & 7,579 & $85 \%$ \\
\hline Lelystad & NA & NA & 2,248 & $98 \%$ \\
\hline Maastricht & 1,500 & $40-45 \%$ & 2,751 & $92 \%$ \\
\hline Meppel & 3,000 & $60 \%$ & 3,983 & $98 \%$ \\
\hline Middelburg & 2,000 & $50-60 \%$ & 2,866 & $93 \%$ \\
\hline Nijmegen & 2,800 & $50 \%$ & 4,013 & $82 \%$ \\
\hline Roermond & 2,300 & $60 \%$ & 3,137 & $97 \%$ \\
\hline Rotterdam & 12,000 & $40 \%$ & 23,747 & $78 \%$ \\
\hline Terneuzen & 1,200 & $50 \%$ & 1,389 & $95 \%$ \\
\hline Tiel & 1,800 & $40-50 \%$ & 3,004 & $89 \%$ \\
\hline Tilburg & 3,300 & $70 \%$ & 8,586 & $94 \%$ \\
\hline Utrecht & 10,000 & NA & 15,467 & $85 \%$ \\
\hline Veendam & 1,400 & $55 \%$ & NA & NA \\
\hline Venlo & 2,800 & $50-55 \%$ & 3,499 & $98 \%$ \\
\hline Vlaardingen & 3,200 & $25 \%$ & NA & NA \\
\hline Waalwijk & 2,600 & $45 \%$ & NA & NA \\
\hline Zaandam & 1,700 & $70 \%$ & 2,540 & $90 \%$ \\
\hline Zutphen & 5,000 & $50-55 \%$ & NA & NA \\
\hline Zwolle & 4,000 & $50 \%$ & 3,376 & $99 \%$ \\
\hline Totaal & 172,400 & $47-50 \% 4$ & 248,839 & $86.43 \%$ \\
\hline
\end{tabular}

1. data from 1984 from van Duuren [1986].

2. data from 1991 from the Database Foundation of the Chambers of Commerce.

3. Firm-size is based on the data provided in the annual accounts disclosed. For firms that are exempted from the disclosure of financial statements, firm-size can not be determinded. Therefore, the total number of small companies is calculated by the total number of companies mandated to disclose annual accounts minus the total number of large and medium sized firms that have disclosed annual accounts. So, in calculating the number of small firms, full compliance by large and medium sized firms is assumed.

4. corrected for data not available from the district of Utrecht. 
Table 3A.2. Number of annual accounts disclosed (1991)

\begin{tabular}{|c|c|c|c|c|}
\hline District & $\begin{array}{c}\text { Large } \\
\text { companies }\end{array}$ & $\begin{array}{l}\text { Medium-sized } \\
\text { companies }\end{array}$ & $\begin{array}{c}\text { Small } \\
\text { companies }\end{array}$ & Total \\
\hline Alkmaar & 54 & 185 & 4,140 & 4,379 \\
\hline Amersfoort & 9 & 11 & 3,521 & 3,541 \\
\hline Amsterdam & 157 & 161 & 19,656 & 19,974 \\
\hline Apeldoorn & 147 & 451 & 7,981 & 8,579 \\
\hline Arnhem & 155 & 407 & 7,836 & 8,398 \\
\hline Breda & 100 & 151 & 6,891 & 7,142 \\
\hline Delft & 66 & 91 & 4,042 & 4,199 \\
\hline Den Bosch & 170 & 401 & 7,251 & 7,822 \\
\hline Den Haag & 240 & 212 & 10,422 & 10,874 \\
\hline Deventer & 24 & 39 & 1,322 & 1,385 \\
\hline Dordrecht & 38 & 208 & 6,685 & 6,931 \\
\hline Eindhoven & 119 & 379 & 8,380 & 8,878 \\
\hline Enschede & 54 & 286 & 6,684 & 7,024 \\
\hline Gouda & 91 & 292 & 3,724 & 4,107 \\
\hline Groningen & 98 & 150 & 4,166 & 4,414 \\
\hline Haarlem & 71 & 190 & 7,040 & 7,301 \\
\hline Heerlen & 43 & 127 & 3,781 & 3,951 \\
\hline Hilversum & 32 & 32 & 4,844 & 4,908 \\
\hline Hoorn & 26 & 76 & 2,858 & 2,960 \\
\hline Leeuwarden & 96 & 172 & 4,652 & 4,920 \\
\hline Leiden & 70 & 209 & 5,994 & 6,273 \\
\hline Lelystad & 9 & 83 & 1,982 & 2,074 \\
\hline Maastricht & 25 & 31 & 2,320 & 2,376 \\
\hline Meppel & 43 & 176 & 3,572 & 3,791 \\
\hline Middelburg & 68 & 121 & 2,559 & 2,748 \\
\hline Nijmegen & 35 & 182 & 3,141 & 3,358 \\
\hline Roermond & 80 & 157 & 2,824 & 3,061 \\
\hline Rotterdam & 371 & 384 & 16,756 & 17,511 \\
\hline Terneuzen & 13 & 76 & 1,280 & 1,369 \\
\hline Tiel & 9 & 91 & 2,524 & 2,624 \\
\hline Tilburg & 145 & 409 & 7,695 & 8,249 \\
\hline Utrecht & 206 & 438 & 11,917 & 12,561 \\
\hline Venlo & 35 & 163 & 2,971 & 3,169 \\
\hline Zaandam & 21 & 60 & 1,991 & 2,072 \\
\hline Zwolle & 82 & 177 & 3,059 & 3,318 \\
\hline Total & 3,002 & 6,778 & 196,461 & $206,241^{*}$ \\
\hline
\end{tabular}

A total of 18,602 firms filed a statement of liability and is therefore exempted from the mandatory filing of the financial statements. Including these firms, the total number of disclosures in 1991 amounts to 224,843 . 
Appendix 3B. Financial reporting lags (paired sample results)

Table 3B.1. Summary statistics for the paired sample

\begin{tabular}{llccc}
\hline & & 1984 & 1990 & $\begin{array}{c}\text { Wilcoxon signed } \\
\text { rank test }\end{array}$ \\
\hline $\begin{array}{llccl}\text { Preparation lag } \\
\text { (number of days) }\end{array}$ & Avg. & 261.45 & 246.93 & $\mathrm{z}=0.068$ \\
& St.dev. & 130.86 & 97.69 & \\
& Minimum & 46 & 56 & $(\mathrm{p}=0.95)$ \\
& Maximum & 602 & 396 & \\
& $\mathrm{~N}$ & 29 & 30 & \\
Filing lag & Avg. & 166.45 & 39.59 & $\mathrm{z}=3.382$ \\
(number of days) & St.dev. & 180.34 & 41.14 & \\
& Minimum & 4 & 0 & $(\mathrm{p}<0.001)$ \\
& Maximum & 662 & 163 & \\
& $\mathrm{~N}$ & 29 & 29 & \\
Reporting lag & Avg. & 420.17 & 284.5 & $\mathrm{z}=3.471$ \\
(number of days) & St.dev. & 155.28 & 101.14 & \\
& Minimum & 141 & 85 & $(\mathrm{p}<0.001)$ \\
& Maximum & 722 & 490 & \\
& $\mathrm{~N}$ & 30 & 29 & \\
\hline
\end{tabular}

Table 3B.2. Timeliness statistics for the paired sample

\begin{tabular}{llccc}
\hline & Delay in days & 1984 & 1990 & $\begin{array}{c}\text { Chi-square } \\
\text { statistic }\end{array}$ \\
\hline $\begin{array}{llcc}\text { Preparation lag } \\
\left(\mathrm{N}=59^{*}\right)\end{array}$ & $<=181$ & 12 & 8 & 5.562 \\
& $<=396$ & 14 & 22 & $(\mathrm{p}=0.062)$ \\
Filing lag & $>396$ & 3 & 0 & \\
$\left(\mathrm{~N}=58^{*}\right)$ & $<=12$ & 5 & 9 & 1.574 \\
Reporting lag & $>12$ & 24 & 20 & $(\mathrm{p}=0.455)$ \\
$\left(\mathrm{N}=59^{*}\right)$ & $<=203$ & 3 & 6 & 9.588 \\
& $<=408$ & 13 & 20 & $(\mathrm{p}=0.008)$ \\
\hline
\end{tabular}

* For 1 annual report the date of the shareholders meeting could not be determined. Also, in 1 case the date of filing was not indicated on the accounts filed. 


\section{Appendix 3C. Summary of results}

Table 3C.1. Formal disclosure requirements

\begin{tabular}{llcc}
\hline $\mathrm{N}=144$ & & 1984 & 1990 \\
\hline Language used & Dutch & $71(98.6 \%)$ & $68(94.4 \%)$ \\
& Other & $1(1.4 \%)$ & $4(5.6 \%)$ \\
Page-size is A4 & Yes & $71(98.6 \%)$ & $71(98.6 \%)$ \\
& No & $1(1.4 \%)$ & $1(1.4 \%)$ \\
Balance sheet on separate page & Yes & $69(95.8 \%)$ & $69(95.8 \%)$ \\
& No & $3(4.2 \%)$ & $3(4.2 \%)$ \\
Signature of directors & Yes & $64(88.9 \%)$ & $70(97.2 \%)$ \\
& No & $8(11.1 \%)$ & $2(2.8 \%)$ \\
Comparative figures & Yes & $61(84.72 \%)$ & $66(91.7 \%)$ \\
& No & $11(15.28 \%)$ & $6(8.3 \%)$ \\
\hline
\end{tabular}

Table 3C.2. Indication of the way for which the distribution of income is accounted for in the balance sheet

\begin{tabular}{lcc}
\hline $\mathrm{N}=144$ & 1984 & 1990 \\
\hline A. Mentioned in balance sheet & $\mathbf{4 2}(\mathbf{5 8 . 3 \% )}$ & $\mathbf{5 2}(\mathbf{7 2 . 2 \% )}$ \\
- Before profit distribution & $5(6.9 \%)$ & $3(4.2 \%)$ \\
- After profit distribution & $37(51.4 \%)$ & $49(68.1 \%)$ \\
& & \\
B. Not mentioned in balance sheet & $\mathbf{3 0}(\mathbf{4 1 . 3 \% )}$ & $\mathbf{2 0}(\mathbf{2 7 . 8 \% )}$ \\
- Before profit distribution & $10(13.9 \%)$ & $0(0.0 \%)$ \\
- After profit distribution & $12(16.7 \%)$ & $9(12.5 \%)$ \\
- Unknown & $8(11.1 \%)$ & $11(15.3 \%)$ \\
\hline
\end{tabular}


Table 3C.3. Occurence and naming of major items in the balance sheet

\begin{tabular}{lcccc}
\hline & \multicolumn{2}{c}{1984} & \multicolumn{2}{c}{1990} \\
\cline { 2 - 5 } & Item present & Name correct & Item present & Name correct \\
\hline Intangible fixed assets & $15(20.8 \%)$ & $15(100 \%)$ & $12(16.7 \%)$ & $12(100 \%)$ \\
Tangible fixed assets & $60(83.3 \%)$ & $54(90.0 \%)$ & $69(95.8 \%)$ & $67(97.1 \%)$ \\
Financial fixed assets & $28(38.9 \%)$ & $26(92.9 \%)$ & $20(27.8 \%)$ & $19(95.0 \%)$ \\
Stocks & $50(69.4 \%)$ & $48(96.0 \%)$ & $61(84.7 \%)$ & $60(98.4 \%)$ \\
Debtors & $67(93.0 \%)$ & $62(92.5 \%)$ & $72(100 \%)$ & $71(97.2 \%)$ \\
Investments & $3(4.2 \%)$ & $3(100 \%)$ & $8(11.1 \%)$ & $8(100 \%)$ \\
Liquid assets & $64(88.9 \%)$ & $61(95.3 \%)$ & $72(100 \%)$ & $69(95.8 \%)$ \\
Prepayments and accrued income & $34(44.4 \%)$ & $32(94.1 \%)$ & $23(31.9 \%)$ & $23(100 \%)$ \\
\hline Called up share capital & $71(98.6 \%)$ & $54(76.1 \%)$ & $69(95.8 \%)$ & $65(94.2 \%)$ \\
Share premium account & $4(5.6 \%)$ & $4(100 \%)$ & $3(4.2 \%)$ & $3(100 \%)$ \\
Revaluation reserves & $5(6.9 \%)$ & $5(100 \%)$ & $2(1.4 \%)$ & $2(100 \%)$ \\
Statutory reserves & $8(11.1 \%)$ & $7(87.5 \%)$ & $23(31.9 \%)$ & $23(100 \%)$ \\
Other reserves & $58(80.6 \%)$ & $30(51.7 \%)$ & $57(79.2 \%)$ & $35(52.2 \%)$ \\
Profit & $18(25.0 \%)$ & $7(38.9 \%)$ & $4(5.6 \%)$ & $4(100 \%)$ \\
Provisions & $44(61.1 \%)$ & $41(93.2 \%)$ & $53(73.6 \%)$ & $51(96.2 \%)$ \\
Long term liabilities & $40(55.6 \%)$ & $35(87.5 \%)$ & $45(62.5 \%)$ & $40(88.9 \%)$ \\
Current liabilities & $69(95.8 \%)$ & $60(86.9 \%)$ & $72(100 \%)$ & $62(86.1 \%)$ \\
Accruals and deferred income & $27(36.1 \%)$ & $25(92.3 \%)$ & $20(27.8 \%)$ & $19(95.0 \%)$ \\
\hline
\end{tabular}


Table 3C.4. Required notes to the financial statements

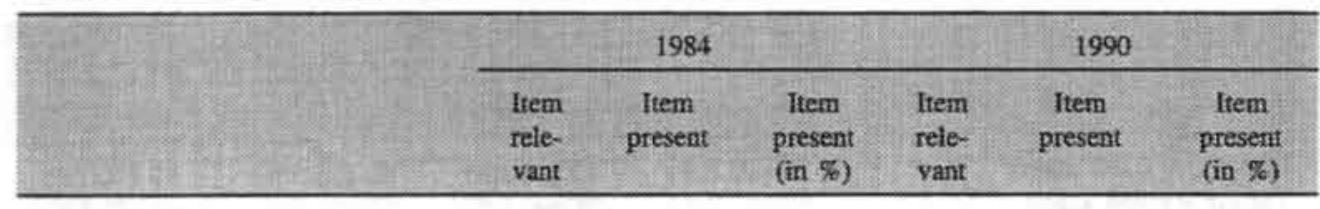

\section{A. Debtors}

- amount falling due within one year

$\begin{array}{cc}67 & 19 \\ ? & 4\end{array}$

$\begin{array}{ccc}28.4 \% & 72 & 16 \\ - & ? & 3\end{array}$

$22.2 \%$

- loans to (former) directors and (former) commisioners

B. Information about debts

- liabilities not due within 5 years

- collateral provided for debts

$\begin{array}{cc}40 & 10 \\ ? & 2 \\ ? & 2 \\ ? & \end{array}$

- guarantees given in behalf of third parties

- long term financial obligations not

?

appearing in the balance sheet

C. Translation of foreign currencies

- principles for translation

- treatment of exchange differences

$\begin{array}{cc}10 & 25.0 \% \\ 22 & - \\ 2 & - \\ 7 & -\end{array}$

$\begin{array}{lc}45 & 15 \\ ? & 27 \\ ? & 3 \\ ? & 12\end{array}$

$33.3 \%$

$-$

37

12

D. Depreciation methods

- Intangible fixed assets

- Tangible fixed assets

- Financial fixed assets

$? \quad 2$

10

6

E. Shareholders equity

- capital issued, paid and called

- changes in share capital

$\begin{array}{ll}15 & 3 \\ 60 & 48 \\ 28 & 17\end{array}$

3

$20.0 \%$

12

3

64

$25.0 \%$

28

$80.0 \%$

69

$92.8 \%$

$60.7 \% \quad 20$

12

$60.0 \%$

- Details on self owned share capital

$\begin{array}{cc}? & 4 \\ ? & 10 \\ ? & 0\end{array}$

F. Details on statutory reserves

8

2

$25.0 \%$

23

12

$52.2 \%$

G. Average number of personnel

72

49

$68.1 \%$

72

61

$84.7 \%$

H. Subsidiairies

- part in issued capital

- name of the subsidiairy

- domicile of the subsidiairy

?

\begin{tabular}{lll}
- & $?$ & 8 \\
- & $?$ & 7 \\
- & $?$ & 7 \\
\hline
\end{tabular}


Table 3C.5. Voluntary notes to the financial statements

\begin{tabular}{llccc}
\hline & \multicolumn{3}{c}{1984} & \multicolumn{2}{c}{1990} \\
\cline { 2 - 5 } & $\begin{array}{c}\text { Item } \\
\text { present }\end{array}$ & $\begin{array}{c}\text { Item } \\
\text { present } \\
\text { (in \%) }\end{array}$ & Item present & $\begin{array}{c}\text { Item } \\
\text { present } \\
\text { (in \%) }\end{array}$ \\
\hline Financial statement section & 2 & $2.8 \%$ & 2 & $2.8 \%$ \\
\hline A. Directors' report & 2 & $2.8 \%$ & 12 & $16.7 \%$ \\
B. Profit and loss account & 2 & $2.8 \%$ & 12 & $16.7 \%$ \\
C. Notes to Profit and loss account & 4 & $5.6 \%$ & 7 & $9.7 \%$ \\
D. Auditor's report & & & & \\
\hline Information items & 7 & $9.7 \%$ & 12 & $16.7 \%$ \\
\hline A. Information about personnel & 0 & $0.0 \%$ & 2 & $2.8 \%$ \\
- segmentation of personnel & 2 & $2.8 \%$ & 6 & $8.3 \%$ \\
- mutations in personnel & information about wages and salaries & & & \\
paid & 2 & $2.8 \%$ & 2 & $2.8 \%$ \\
B. Expected future developments & 2 & $2.8 \%$ & 6 & $8.3 \%$ \\
C. Salaries of directors & 2 & $2.8 \%$ & 1 & $1.4 \%$ \\
D. Cash not at free disposal to the firm & 2 & & & \\
E. Ratios & 3 & $4.2 \%$ & 2 & $2.8 \%$ \\
\hline
\end{tabular}




\section{Appendix 3D. Univariate analysis}

One-tailed probability levels are indicated by $*$ for $\alpha=0.10,{ }^{* *}$ for $\alpha=0.05$, *** for $\alpha=0.01$

Table 3D.1. Timeliness, quality and quantity of financial accounting disclosure per class of total assets.

\begin{tabular}{|c|c|c|c|c|c|c|}
\hline Total assets & $<500,000$ & $\begin{array}{l}500,000- \\
1,000,000\end{array}$ & $\begin{array}{l}1,000,000 \\
2,500,000\end{array}$ & $\begin{array}{r}2,500,000 \\
5,000,000\end{array}$ & $\underset{5,000,000}{>}$ & $\begin{array}{c}\text { Rank } \\
\text { correlation }\end{array}$ \\
\hline$N=$ & 28 & 23 & 60 & 24 & 9 & 144 \\
\hline \multicolumn{7}{|l|}{ Timeliness } \\
\hline - PREPARE & 239 & 274 & 278 & 295 & 228 & $0.119^{*}$ \\
\hline - FILE & 125 & 56 & 78 & 69 & 89 & $-0.126^{*}$ \\
\hline $\begin{array}{l}\text { - REPORT } \\
\text { Quantity }\end{array}$ & 365 & 329 & 356 & 368 & 304 & 0.007 \\
\hline - ITEMCNT & 21.39 & 25.26 & 23.35 & 26.75 & 28.67 & $0.269 * * *$ \\
\hline - SPECCNT & 5.04 & 5.86 & 6.45 & 7.67 & 7.00 & $0.313^{* * *}$ \\
\hline - VOLUNT & 0.82 & 2.13 & 2.28 & 2.33 & 13.00 & $0.354^{* * *}$ \\
\hline \multicolumn{7}{|l|}{ Quality: } \\
\hline - HEADNAME & 0.57 & 0.95 & 0.15 & 0.04 & 0.00 & $-0.286^{* * *}$ \\
\hline - ITEMNAME & 2.11 & 3.13 & 0.88 & 0.42 & 0.89 & $-0.306^{* * * *}$ \\
\hline
\end{tabular}

Table 3D.2. Timeliness, quality and quantity of financial accounting disclosure per class of leverage (equity/total assets)

\begin{tabular}{lrrrrr}
\hline Leverage & $<0$ & $0-0.25$ & $0.25-0.50$ & $>0.50$ & $\begin{array}{c}\text { Rank } \\
\text { correlation } \\
\mathrm{N}=\end{array}$ \\
\hline Timeliness & 17 & 69 & 36 & 22 & 144 \\
\hline - PREPARE & 268 & 277 & 275 & 239 & -0.075 \\
- FLE & 92 & 90 & 73 & 69 & 0.013 \\
- REPORT & 362 & 365 & 346 & 313 & $-0.115^{*}$ \\
Quantity & & & & & \\
- ITEMCNT & 27.06 & 23.99 & 23.86 & 23.05 & $-0.134^{*}$ \\
- SPECCNT & 6.88 & 6.32 & 6.47 & 5.64 & -0.082 \\
- VOLUNT & 2.11 & 2.71 & 2.14 & 3.72 & $-0.114^{*}$ \\
Quality: & & & & & \\
- HEADNAME & 0.00 & 0.46 & 0.22 & 0.36 & 0.098 \\
- ITEMNAME & 0.82 & 1.57 & 1.00 & 2.00 & 0.053 \\
\hline
\end{tabular}


Table 3D.3. Timeliness, quality and quantity of financial accounting disclosure per 1 digit SBI industry

\begin{tabular}{lrrrrrr}
\hline Industry & Manuf. & $\begin{array}{c}\text { Construc- } \\
\text { tion }\end{array}$ & $\begin{array}{c}\text { Retail/ } \\
\text { Wholesale }\end{array}$ & Transport & $\begin{array}{c}\text { Bussiness/ } \\
\text { Finance }\end{array}$ & Service \\
$\mathrm{N}=$ & 32 & 28 & 35 & \multicolumn{1}{c}{15} & 20 & 4 \\
\hline Timeliness & & & & & & \\
- PREPARE & 272 & 256 & 252 & 283 & 296 & 268 \\
- FILE & 91 & 69 & 84 & 118 & 76 & 147 \\
- REPORT & 364 & 328 & 336 & 401 & 368 & 361 \\
Quantity & & & & & & \\
- ITEMCNT & 22.94 & 23.04 & 24.71 & 26.27 & 25.95 & 23.75 \\
- SPECCNT & 6.34 & 5.14 & 6.91 & 7.53 & 6.45 & 6.50 \\
- VoLUNT & 2.06 & 1.54 & 3.80 & 1.26 & 5.35 & 0.75 \\
Quality: & & & & & & \\
- HEADNAME & 0.37 & 0.54 & 0.14 & 0.67 & 0.20 & 0.00 \\
- ITEMNAME & 1.34 & 2.07 & 0.74 & 2.00 & 1.50 & 1.00 \\
\hline
\end{tabular}

* 10 cases could not be classified due to missing data

** based on a series of Kruskal Wallis tests for differences between classes of industry, a significant effect can only be found for the VoLUNT variable ( 2 tailed, $\alpha=0.1$ ).

Table 3D.4. Timeliness, quality and quantity of financial accounting disclosure and the external accountant.

\begin{tabular}{lccc}
\hline $\begin{array}{l}\text { Preparation of } \\
\text { accounts }\end{array}$ & Internal & External accountant & $\begin{array}{c}\text { Mann Whitney U test } \\
\text { (z score) }\end{array}$ \\
$\mathrm{N}=$ & 47 & 97 & 144 \\
\hline Timeliness & & & \\
- PREPARE & 242 & 283 & $2.61^{* * *}$ \\
- FILE & 88 & 81 & $-1.38^{*}$ \\
- REPORT & 333 & 362 & $1.55^{*}$ \\
Quantity & & & -0.81 \\
- ITEMCNT & 25.85 & 23.36 & 0.23 \\
- SPECCNT & 6.28 & 6.34 & -0.75 \\
- VOLUNT & 3.62 & 2.18 & $-2.65^{* * *}$ \\
Quality: & & & $-1.64^{* *}$ \\
\hline - HEADNAME & 0.60 & 0.21 & \\
- ITEMNAME & 1.92 & 1.16 & \\
\hline
\end{tabular}


Table 3D.5. Timeliness, quality and quantity of financial accounting disclosure over time.

\begin{tabular}{|c|c|c|c|}
\hline Time & 1984 & 1990 & $\begin{array}{c}\text { Mann Whitney U test } \\
\text { (z score) }\end{array}$ \\
\hline $\mathrm{N}=$ & 72 & 72 & 144 \\
\hline \multicolumn{4}{|l|}{ Timeliness } \\
\hline - PREPARE & 277 & 262 & -0.87 \\
\hline - FLEE & 113 & 52 & $-1.98 * *$ \\
\hline - REPORT & 388 & 316 & $-3.31^{* * *}$ \\
\hline \multicolumn{4}{|l|}{ Quantity } \\
\hline - ITEMCNT & 23.96 & 24.39 & 0.79 \\
\hline - SPECCNT & 6.25 & 6.56 & 0.40 \\
\hline - VOLUNT & 1.75 & 3.55 & $3.27^{* * *}$ \\
\hline \multicolumn{4}{|l|}{ Quality: } \\
\hline - HEADNAME & 0.38 & 0.29 & -0.26 \\
\hline - ITEMNAME & 1.78 & 1.03 & $-2.72^{* *}$ \\
\hline
\end{tabular}




\section{Appendix 3E. Univariate and multivariate analysis for the paired sample}

Table 3E.1 Summary results of univariate analysis

\begin{tabular}{|c|c|c|c|c|c|}
\hline$N=60$ & $\begin{array}{c}\text { SIZE } \\
\text { Spearman } \\
\text { rank correl. }\end{array}$ & $\begin{array}{l}\text { LEVERAGE } \\
\text { Spearman } \\
\text { rank correl. }\end{array}$ & $\begin{array}{c}\text { SBI } \\
\text { Kruskal Waltis } \\
\text { test } \\
\text { (Chi-Square) }\end{array}$ & $\begin{array}{c}\text { AccounT } \\
\text { Mann Whitney U } \\
\text { test } \\
\text { (z score) }\end{array}$ & $\begin{array}{c}\text { PERIOD } \\
\text { Signed rank test } \\
\text { ( } z \text { score })\end{array}$ \\
\hline \multicolumn{6}{|l|}{ Timeliness } \\
\hline - PREPARE & $0.371^{* * *}$ & -0.187 & 5.53 & 1.064 & 0.068 \\
\hline - FILE & $-0.349 * * *$ & -0.092 & 4.04 & 0.254 & $3.382^{* * * *}$ \\
\hline - REPORT & 0.023 & -0.129 & 8.59 & -0.614 & $3.471 * * *$ \\
\hline \multicolumn{6}{|l|}{ Quantity } \\
\hline - ITEMCNT & 0.156 & 0.042 & 3.67 & -0.601 & 0.071 \\
\hline - SPECCNT & 0.165 & -0.034 & 8.26 & 0.589 & 0.178 \\
\hline - VOLUNT & $0.258 * *$ & 0.056 & 2.32 & -1.118 & $2.710^{* * *}$ \\
\hline \multicolumn{6}{|l|}{ Quality: } \\
\hline - HEADNAME & $-0.355^{* * *}$ & -0.072 & $12.05^{* *}$ & -1.012 & -0.741 \\
\hline - ITEMNAME & $-0.254^{* * *}$ & -0.111 & 7.77 & -0.776 & $-1.493^{*}$ \\
\hline
\end{tabular}

One-tailed probability levels are indicated by $*$ for $\alpha=0.10,{ }^{* *}$ for $\alpha=0.05$ and $* * *$ for $\alpha=0.01$ (for SBI, 2 -tailed probability levels are reported) 


\begin{tabular}{|c|c|c|c|c|c|c|c|c|}
\hline & \multicolumn{3}{|c|}{ Timeliness } & \multicolumn{3}{|c|}{ Quantity } & \multicolumn{2}{|c|}{ Quality } \\
\hline & PREPARE & FILE & REPORT & ITEMCNT & SpbCCNT & YoLUNT & HEADNAME & ITEMNAME \\
\hline CONSTANT & 177.701 & 280.749 & $382.656 * 4 *$ & $18.789^{*}$ & $6.531 *$ & -0.547 & -0.121 & 1.771 \\
\hline SEE & $1.6 \mathrm{e}-5$ & $-1.1 e-5$ & $7.2 e-6$ & $8.8 c-7$ & $3.0 c-7$ & $3.6 \mathrm{e}-7^{+\infty}$ & $8.5 \mathrm{e}-8$ & $-8.3 \mathrm{e}-8$ \\
\hline LEVERAGE & -0.052 & 0.010 & -0.041 & 0.016 & 0.002 & 0.001 & 0.002 & 0.004 \\
\hline ACC.TANT & 17.929 & -29.527 & -15.42 & -3.106 & 0.820 & 0.034 & -0.640 & -1.152 \\
\hline PERIOD & -19.597 & -131.75860 & $-149.862 * * *$ & -1.382 & 0.076 & 0.222 & -0.412 & -1.582 \\
\hline Sel1 & 117.112 & -4.256 & $179.190^{*}$ & -0.652 & 0.420 & 0.660 & 0.629 & 1.025 \\
\hline $\operatorname{sen}$ & 69.746 & -36.939 & 99.318 & 1.131 & -1.376 & 0.641 & 0.505 & 1.113 \\
\hline Sen & 106.358 & 17.834 & $188.397^{\circ}$ & -1.233 & -0.067 & 1.306 & -0.102 & -0.597 \\
\hline Sold & 147.226 & -10.850 & 200.901 & 5.826 & 1.752 & 1.047 & 1.357 & 3.069 \\
\hline SBIS & 2.807 & 148.728 & 217.654 & -5.260 & -0.296 & 0.828 & 1.836 & 5.375 \\
\hline Model stacs: & & & & & & & & \\
\hline & 0.16 & 0.29 & 0.35 & 0.12 & 0.17 & 0.47 & 0.20 & 0.25 \\
\hline F statistic & 1.004 & 2.046 & 2.75 & 0.756 & 1.076 & 4.752 & 1.272 & 1.738 \\
\hline Signif. F & 0.451 & 0.056 & 0.012 & 0.657 & 0.398 & 0.000 & 0.276 & 0.106 \\
\hline Durb Watson & 2.20 & 1.71 & 2.28 & 2.02 & 2.49 & 2.33 & 1.97 & 1.98 \\
\hline
\end{tabular}

* significant at 0.1 level; * significant at 0.05 level; ** significant at 0.01 -lcvel. 


\section{Appendix 3F. Correlations for independent variables}

Tabel 3F.1 Spearman rank correlation coefficients (full sample)

SIZE LEVERAGE ACCOUNTANT SBI

\begin{tabular}{|c|c|c|c|c|}
\hline LEVERAGE & $\begin{array}{l}-.0781 \\
N(144) \\
\text { Sig.352 }\end{array}$ & & & \\
\hline ACCOUNTANT & $\begin{array}{l}-.0568 \\
\text { N(144) } \\
\text { Sig.499 }\end{array}$ & $\begin{array}{l}.1404 \\
\mathrm{~N}(144) \\
\text { Sig.093 }\end{array}$ & & \\
\hline SBI & $\begin{array}{l}.0300 \\
\text { N(134) } \\
\text { Sig. } 731\end{array}$ & $\begin{array}{l}.0422 \\
\mathrm{~N}(134) \\
\text { Sig.628 }\end{array}$ & $\begin{array}{l}.0529 \\
\text { N(134) } \\
\text { Sig. } 544\end{array}$ & \\
\hline PERIOD & $\begin{array}{l}.1814 \\
\text { N(144) } \\
\text { Sig.030 }\end{array}$ & $\begin{array}{l}.0501 \\
\mathrm{~N}(144) \\
\text { Sig. } 551\end{array}$ & $\begin{array}{l}.1629 \\
\mathrm{~N}(144) \\
\text { Sig.051 }\end{array}$ & $\begin{array}{l}-.0397 \\
\mathrm{~N}(134) \\
\text { Sig.649 }\end{array}$ \\
\hline
\end{tabular}




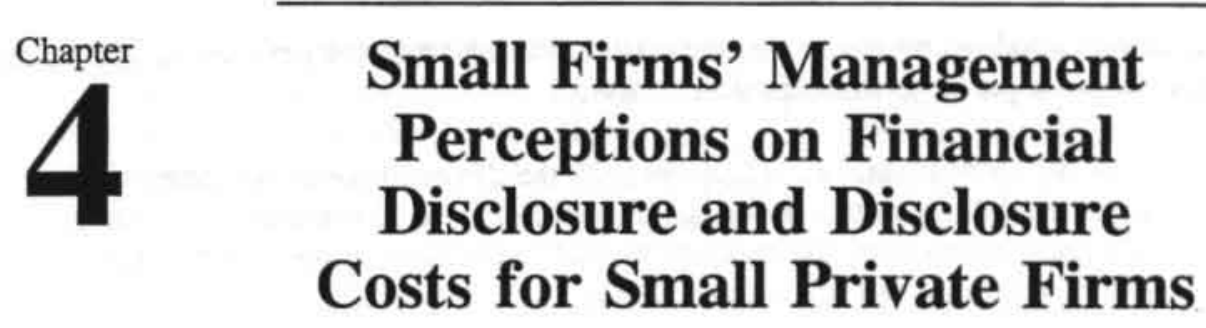

\subsection{Introduction ${ }^{1}$}

Perceptions of participants in the corporate disclosure process, form an important input in the governmental debates on financial reporting regulation and also in the corresponding financial accounting literature. The views of parliament on the anticipated impact of the adaptation of the Dutch legislation to the Fourth EC Directive on the participants of the corporate disclosure process can be found in the reports of the parliamentary debates ${ }^{2}$. Given the evident lack of empirical evidence on these matters (see chapter 2), it is hardly surprising that the views on the presumed impact of the proposed financial reporting regulations are quite diverging.

Some parliamentary members felt the proposed adaptation of the Dutch company law was not far-reaching enough and should be extended to include proprietorships as well ${ }^{3}$. Other members of parliament suggested that the proposed regulatory changes were far too extensive and a motion was submitted, urging the minister to keep the EC Directives as limited as possible ${ }^{4}$. To substantiate this motion, the following statement of a Dutch

' This chapter is based on two previously published articles: Bollen, L.H.H., 1990a, Regulering van jaarverslaggeving: een onderzoek naar percepties van ondernemingen (1), Maandblad voor Bedrijfsadministratie en Organisatie, juli/augustus and Bollen, L.H.H., 1990b, Regulering van jaarverslaggeving: een onderzoek naar percepties van ondernemingen (2), Maandblad voor Bedrijfsadministratie en Organisatie, september. An earlier version of part of this chapter was presented at the 14th Annual congress of the EAA (European Accounting Association) in Maastricht in April 1991. The research project was supported and partly financed by the Chamber of Commerce of Maastricht.

${ }^{2}$ A historical overview of the advancement of the regulations for small and medium-sized firms within the Fourth Directive, is provided in appendix I at the end of the dissertation.

${ }^{3}$ Wessel-Tuinstra (D'66), Tweede Kamer der Staten Generaal, Handelingen, nr. 33, june 1983, p. 4540 .

${ }^{4}$ Motion Tripels/Van de Burg on the size of the EC legislation (16 326, nr. 28). 
scholar was cited, to point out that the costs resulting from the new legislation might be substantial compared to the expected benefits:

"To my conviction, the composers of the [Fourth] Directive have never considered the costs this new legislation shall impose on companies [...]. Also, a critical analysis of the benefits of such legislation seems to be lacking." [translated from Van der Grinten, 1981]

The government, by word of the minister of justice, took the position that financial reporting regulation should be limited to avoid a standards overload, especially where small firms were concerned. But in his opinion all options within the restrictions of the Fourth Directive had been used to limit the regulatory burden for the firms concerned 5 . Also, the minister expressed the belief that the benefits of the implementation of the Fourth Directive would outweigh the costs associated with it. This view apparently was based on his perceptions rather than on empirical facts as he recognized that a costbenefit analysis of the proposed regulation would be very hard, if not impossible to conduct ${ }^{6}$.

Given the difficulty of adequately measuring benefits and costs of (proposed) regulation, many empirical studies use questionnaires to survey the opinion of users and producers of accounting information on the effects of accounting regulation (see chapter 2). Studies among users of accounting information, which dominate this line of research, typically involve the ranking of information items in order of their importance in decision making processes to asses the importance of information-items disclosed in financial statements. Other studies ask respondents to categorize accounting standards based on some costsbenefit criterion.

In the differential reporting regulation debate, perceptions of users and preparers of small firms' accounting information are of particular importance since other research methods (e.g. capital market research) are less suitable in the small private firm context. Questionnaire studies could provide useful insight into questions like:

1. do information needs differ if users are dealing with a small firm instead of a large firm;

2. to what extent is the information disclosed by small firms adequate to fulfil the information needs of users;

3. how do managers of small firms feel about the usefulness of financial reporting (voluntary or mandatory) for their firms or for parties dealing with their firms;

4. how do managers of small firms and users dealing with small firms perceive the adequacy of the current regulatory requirements for small private firms?

s Tweede Kamer der Staten Generaal, Handelingen, nr. 33, june 1983, p. 4543.

${ }^{6}$ Tweede Kamer der Staten Generaal, Handelingen, nr. 33, june 1983, p. 4544. 
The reliability of the outcome of questionnaire-studies may be contested given some inherent methodological limitations. Firstly, respondents might have incentives to misrepresent their preferences. Also, the settings are hypothetical and little attempt is made to determine the reasoning underlying the stated preferences of the respondents [Ball and Foster, 1982, p. 201]. Therefore, questionnaires are not ideal substitutes for actual data.

Most empirical studies in this area have concentrated on the users of accounting information, particularly on investors, thereby largely ignoring other user groups likely to have diverging views such as accountants and management. Obviously, perceptionstudies will gain in reliability if many parties involved in financial accounting were to be included in these studies. On themes where there is consensus within and among different parties involved, perception studies can provide useful input into the accounting regulation debate. Given the existing over-emphasis on users of accounting information, in the first part of this chapter the focus will be on the perceptions of the preparers of financial accounting information, i.e. managers of firms.

In the following section (section 4.2) the relation between our research and existing empirical studies on the perceptions of small firms' management and accountants of financial disclosure will be discussed. The remainder of this chapter consists of a questionnaire-study among managers of Dutch small firms. After a discussion of the research design (section 4.3), the results of the study will be presented and compared to the results of existing studies (section 4.4).

In the second part of this chapter the focus will be on the accounting costs of small firms. Several studies have shown that small private firms might be disproportionately bearing the costs of financial reporting regulations (see chapter 2). Evidence on the costs of financial reporting for small Dutch firms is, however, non-existent. Therefore, section 4.5 will provide some evidence on the accounting costs for small Dutch firms and also on the relationship between accounting costs and firm size.

\subsection{Relation to existing empirical research.}

Existing studies on the perceptions of producers of accounting information (i.e. managers and accountants) have been discussed in chapter 2 . These studies typically involve small firm management or external accountants dealing with small firms and focus on the perceptions of respondents of (1) the application of prevailing financial reporting regulations to small private firms, (2) the usefulness of accounting information provided by small firms to outside parties, and (3) the costs of financial reporting regulations (e.g. competitive disadvantage costs). The research presented in this chapter will replicate and augment these studies in the Dutch context.

Only a few studies have empirically investigated the costs imposed by financial reporting regulations on small private firms (e.g. Horwitz and Kolodny [1982] and Nair and 
Rittenberg [1983] (for a more detailed discussion see chapter 2)). Although there is some further evidence of accounting costs being disproportionately borne by small firms from research on audit fees, the application of such research to small private firms that are not mandated to have their financial statements audited seems troublesome. The inclusion of accountants' fees as one of the cost categories to be researched in section 4.5, therefore, deserves some further attention. The absence of a mandatory audit for Dutch small firms might raise some doubts to the relevance of accountants' fees for small companies. However, the absence of an audit does not imply that accountants are not involved with smaller firms. Basically, the role of an external accountant in small companies may include (1) the preparation of the annual accounts, (2) the audit of the annual accounts and (3) the provision of advice on general business matters or tax matters. The importance of the external accountant in the accounting procedures of a small firm may be illustrated by the fact that in a study on small UK firms, $72 \%$ of all responding firms agreed or strongly agreed with the statement that the principal burden of preparing annual accounts is the fee paid to the external accountant [Carsberg et al., 1985, p. 32]

As to the relative importance of the various services provided by external accountants, Page [1984], Carsberg et al. [1985] and Humphrey and Turley [1986, p. 29] all found that the most important service of professional accountants to small firms is the preparation of the accounts and tax advice. The preparation of the accounts was also perceived to be the most time-consuming (i.e. the most costly) activity of the external accountant. The average yearly fee paid by small UK. firms reported in empirical studies ranges from $£ 1,200$ for firms with typically 5 to 10 employees [Carsberg, 1985] to $£ 2,164$ for firms with on average 10-20 employees [Robertson, 1986, p. 23]. Research among small company auditors indicates that of the fees paid by small companies, $23 \%$ is accounted for by audit services, indicating that at an aggregate level the small company audit is not a major source of fees to auditors [Humphrey and Turley, 1986, p. 30]. These results indicate that even in the absence of an audit, the fee paid to the external accountant will still constitute a major part of the accounting costs of small firms.

\subsection{Research design.}

\subsubsection{Introduction}

The main concern of the study presented in the first part of this chapter is to investigate the perceptions of small firms' management on financial reporting and the regulation thereof.

${ }^{7}$ In the study, the same statement was presented to accountants dealing with small firms, of whom $58 \%$ agreed or strongly agreed with the statement. 
Specific themes addressed in the study include:

1. the attitude of management towards financial reporting in general;

2. the attitude of management towards current financial reporting regulation;

3. the perceived main purposes and users of small firms' financial statements;

4. factors driving the attitudes of managers, such as information production costs, accountants' fees or competitive disadvantages.

As this kind of research, to our knowledge, is non-existent in the Netherlands, and given the time and financial limits of the study, the primary objective was to conduct an exploratory study into the perceptions of small firms' management on the issues mentioned above. However, when possible, the results of the study will also be used in trying to explain the attitudes of small firm management to financial accounting. Also, the results of the study will be compared to existing studies in this area.

The second part of this chapter is concerned with the costs imposed on small private firms as a result of financial reporting regulations and with the relationship between accounting costs and firm size. The data used in this part of the research were gathered using the questionnaires. The results of this part of the study will be discussed in section 4.5.

\subsubsection{Research method.}

The empirical data for this study were gathered using a postal questionnaire that was sent to small firms ${ }^{8}$. The forms were sent on July 1,1988 and the deadline for responses to be included in the study was September 30, 1988.

The questionnaires mailed were accompanied by a guiding letter, explaining the aim of the study and ensuring the anonymity of the respondents and the confidentiality of the information provided. Finally, a short instruction note was included. After three and a half weeks (July 25, 1988), a reminder was sent to all firms in the sample. To conclude the data collection process, a small telephonic survey among non-responding firms was conducted to gather information on the reasons for not participating in the study. The data gathered from this survey were used in the analysis of non-response bias.

The basic set of questions is divided into five headings:
A. General items including characteristics of respondents;
$B$. Reporting practice of firms in an unregulated environment;
C. Reporting practice of firms in a regulated environment;
$D$. Perceptions on costs and benefits of financial reporting;
$E$. Financial reporting and current regulation and the competitive position of the firm.

${ }^{8}$ The questionnaires used, which are in Dutch, are available from the author. 
The questionnaire was pretested using a small number of small company managers (6) and a number of faculty-members (5). The results of this pilot-study resulted in some adaptations of the questionnaire. A major problem, indicated by the managers involved in the pilot-study, was the length of the questionnaire. Taking into account their comments the questionnaire was revised and a number of questions were removed while a number of other questions were restructured.

In the study three different questionnaires were used that generally address the same items but are slightly adapted to the characteristics of the firms in the sample. The sample of private companies is divided into two subgroups of which one received the basic questionnaire. The other subgroup received a questionnaire in which a number of questions on competitive disadvantages (section E) were rephrased. In the questionnaire that was sent to proprietorships, some questions were rephrased to fit the situation of these firms where it differed from the private companies. Also, some questions were left out as they were of no relevance to these firms 9 .

\subsubsection{Sample selection}

The sample of firms selected for this study consists of Dutch private companies that fit the definition of a small company used in the Dutch company law of 1988 (see Appendix III for more details). A second sample of firms consisted of proprietorships of generally the same size as the companies-sample. This second sample is used as a control group consisting of firms which are considered to be the most direct competitors of small private companies, but are excluded from the legal financial reporting requirements.

Table 4.1. Sample selection criteria

1. Banks and insurance companies are excluded;

2. Legal form is private company or proprietorship;

3. Number of personnel is less than 50;

4. Industry sector is retail/wholesale or construction.

The samples are derived from a database of the Database Foundation of the Dutch Chambers of Commerce, which includes data on virtually all Dutch businesses. The database is fed from the Chambers of Commerce to which all Dutch enterprises are required to register. The database includes address-information along with several firm characteristics such as number of personnel, industry code and legal form. The characteristics used to select firms to be included in the sample are described in table 4.1.

\footnotetext{
${ }^{9}$ Most notably the questions on the effects of the 1984 regulatory change were left out since the new regulations do not apply to proprietorships.
} 
The selection criteria used are motivated as follows:

ad 1. Banks and insurance companies were excluded from the sample because of the deviating financial reporting requirements for these firms in the Dutch company law. ad 2. Dutch company law applies to (1) public companies, (2) private companies, (3) general partnerships, (4) limited partnerships and (5) civil law companies (see Appendix III). The vast majority of these firms are private companies (see Appendix 3A of chapter 3). Since the focus of this dissertation is on small private firms, only private companies were included in the first sample. As mentioned, a second sample consisted of proprietorships that are generally small firms and considered to be direct competitors of private companies, but are not effected by Dutch company law.

ad 3. The legislative definition of a small firm is based on three criteria: total sales, total assets and average number of personnel. The database, however, only included information on the number of personnel, which therefore is the sole size-criterion used. The size of the responding firms were checked with data on sales and assets provided by respondents in the questionnaire.

ad 4. Given the low response rate to be expected from studies among small businesses, firms were selected from two industries to facilitate the testing of industry-effects. Firms were selected from the retail/wholesale sector and construction businesses, which were the industries containing the largest number of firms.

Table 4.2. Sample design.

Construction business

150

120

270
Retail/Wholesale

150

150

\begin{tabular}{lll} 
Companies & 120 & 150 \\
\hline Total & 270 & 300
\end{tabular}

The selected sample consists of $\mathbf{5 7 0}$ firms which are registered at the Chamber of Commerce in Maastricht (see table 4.2). From existing studies among small firms as well as the pilot study, it was clear that non-response to the questionnaire would be a major problem in this study. To motivate sample firms to return the questionnaire the involvement of the Chamber of Commerce of Maastricht in the project was sought ${ }^{10}$. To maximize this effect, only firms that were registered at the Maastricht Chamber of Commerce were selected ${ }^{11}$.

${ }^{10}$ The involvement of the Chamber of Commerce of Maastricht was made clear to the firms in the letter accompanying the questionnaire.

"The necessity of such a strategy may be demonstrated by the results of two later Dutch studies among small and medium-sized firms, which had response rates as low as $5 \%$ and $3 \%$ [Drop and Schuit, 1990, NOvAA, 1991a]. 


\subsubsection{Response analysis.}

From the 570 questionnaires mailed, 144 forms were returned, resulting in an overall response rate of $25.3 \%$. Including the telephonic survey of 20 firms, the total response to the survey is $29 \%$.

Table 4.3. Response rates

\begin{tabular}{llllllll}
\hline & & \multicolumn{2}{l}{$\begin{array}{l}\text { Construction } \\
\text { sector }\end{array}$} & Retail sector & Total sample \\
\hline Proprietorships & Sent & 150 & & 150 & & 300 & \\
& Returned & 43 & $28.7 \%$ & 32 & $21.3 \%$ & 75 & $25.0 \%$ \\
& Usable & 40 & $26.7 \%$ & 27 & $18.0 \%$ & 67 & $22.3 \%$ \\
Companies & Sent & 120 & & 150 & & 270 & \\
& Returned & 40 & $33.3 \%$ & 27 & $18.0 \%$ & 67 & $24.8 \%$ \\
& Usable & 33 & $27.5 \%$ & 19 & $12.7 \%$ & 52 & $19.3 \%$ \\
\hline \multirow{2}{*}{ Total sample } & Sent & 270 & & 300 & & 570 & \\
& Returned & 83 & $30.7 \%$ & 59 & $19.6 \%$ & 142 & $24.9 \%$ \\
& Usable & 73 & $27.0 \%$ & 46 & $15.3 \%$ & 119 & $20.9 \%$ \\
\hline
\end{tabular}

A number of questionnaires was not included in the study for various reasons:

- 11 firms returned the questionnaire unanswered, mentioning they did not fit the (legislative) definition of a small firm;

- 7 forms where returned unanswered because the firm was inactive;

- 2 firms returned the questionnaire unanswered because they where founded less then one year ago, giving them very little experience with accounting matters;

- 5 forms were excluded because they were badly filled out or because too many questions had been left unanswered.

This screening procedure resulted in a total of 119 (20.9\%) usable questionnaires. The sizes and response rates of each sample are given in table $4.3^{12}$.

Several checks were carried out to test for evidence of non-response bias. First, for a number of key-questions in the questionnaire, it was tested wether responses of laterespondents (received at least 6 days after the sending of the reminder (i.e. August 1 , 1988)) deviated from early-respondents. Further, it was tested whether responding firms were larger or smaller than non-responding firms. Two additional tests were carried out to check whether the distribution of legal form and industry of response group, significantly deviated from the original sample. These and other tests conducted gave

${ }^{2}$ The corresponding response rates in analogous studies are 19\% for Abdel-Khalik [1983], $41 \%$ for Page [1984], and $30 \%$ for Carsberg [1985]. These figures indicate the response rate for our study was normal. 
no indication of non-response bias ${ }^{13}$. The sole exception was that respondents from the retail sector tended to be larger then non-respondents from this industry ${ }^{14}$. Also, firms from the construction business were over-represented in the responding group $(\chi 2=12.393, \mathrm{p}<0.05)$

Non-response can partly be explained by the nature of the database used to select the original sample:

- firm size could only be determined by the number of personnel. This may have resulted in medium-sized or large firms receiving the questionnaire, which may have found most of the questions in the study of little relevance to their situation and decided not to return the form;

- some responses indicated that the database was not fully up-to-date. Some questionnaires were returned undeliverable while other firms turned out to be inactive.

Finally the telephonic survey among non-responding firms can provide some further explanations for firms not responding to the survey. The most important reason for not returning the questionnaire turned out to be a lack of time to complete the form (50\%), lack of interest in financial accounting issues (35\%), or privacy considerations $(15 \%)$. The telephone survey also confirmed the limitations of using the Database Foundation database as some firms could not be reached on the phone-number available from the database while some other firms turned out to be at least medium-sized firms.

\subsubsection{Respondents' characteristics.}

\subsubsection{Profile of responding firms}

All firms in the response group, based on the size data provided in the questionnaires, fell within the legislative definition of a small firm. Details on the corresponding size variables used (total assets, total sales and average number of employees) are presented in table $4.4^{15}$.

From table 4.4 it is clear that responding proprietorships are on average smaller than private companies ${ }^{16}$. This, however, also holds for the original samples in the study.

${ }^{13}$ Based on a $\chi^{2}$-test, with $\mathrm{p}>0.1$.

${ }^{14}$ Based on a Mann-Whitney-U test with $\mathrm{p}<0.05$

is The table presented is based on data for the fiscal year 1986, provided by the respondents to the questionnaire.

${ }^{16}$ This conclusion holds for all three size variables, based on a series of Mann-Whitney-U tests, with $\mathrm{p}<0.05$. 
Although the samples for both types of firms were randomly drawn from the same size categories (based on personnel-classes), proprietorships were in general smaller than private firms. Firm size was not dissimilar for firms from different industry-sectors.

Table 4.4. Size characteristics of sample firms

\begin{tabular}{llrrr}
\hline & & Total sample & Proprietorships & $\begin{array}{r}\text { Private } \\
\text { Companies }\end{array}$ \\
\hline Total assets & Avg & $1,228,823$ & 286,726 & $2,190,964$ \\
& St.dev & $3,626,142$ & 269,653 & $4,992,317$ \\
& Minimum & 10,382 & 10,382 & 47,231 \\
& Maximum & $27,025,000$ & $1,200,000$ & $27,025,000$ \\
Total sales & Avg & $2,356,718$ & 646,690 & $4,305,356$ \\
& St.dev & $5,592,015$ & $1,428,939$ & $7,623,668$ \\
& Minimum & 11,980 & 11,980 & 118,122 \\
& Maximum & $40,331,979$ & $9,700,000$ & $40,331,979$ \\
Average number of & Avg & 9.65 & 5.15 & 14.99 \\
employees & St.dev & 11.60 & 7.28 & 13.46 \\
& Minimum & 1 & 1 & 1 \\
& Maximum & 50 & 50 & 50 \\
\hline
\end{tabular}

\subsubsection{Profile of individual respondents}

All questionnaires were addressed to the directors of the firm. From the questionnaires received back, $61 \%$ was actually filled out by one of the directors (table 4.5 ). Most other forms were filled out by the internal accountant $(12 \%)$ or an administrative employee (15\%). Several firms had their forms filled out by their external accountant ${ }^{17}$. These were mostly private companies $(11,21 \%)$ and relatively few proprietorships $(2,3 \%)$.

In terms of educational level and knowledge on current legal requirements, some differences exists between these various groups, most notably concerning internal and external accountants versus other respondents. For both groups of accountants, the educational level and the knowledge of accounting requirements are significantly higher ${ }^{18}$. Accountants are typically expected to have an education in administration $(78.6 \%)$, whereas members of the latter group generally have an education on secondary level.

${ }^{17}$ The external accountant can be a registered accountant but will typically be an accountantadministratieconsulent.

${ }^{18}$ Based on a Mann-Whitney-U test with $\mathrm{p}<0.01$ 
Table 4.5. Summary of respondents characteristics

\begin{tabular}{llllllllll}
\hline & \multicolumn{2}{l}{ Director } & \multicolumn{2}{l}{$\begin{array}{l}\text { Internal } \\
\text { accountant }\end{array}$} & \multicolumn{2}{l}{$\begin{array}{l}\text { Administra- } \\
\text { tive employee }\end{array}$} & \multicolumn{2}{l}{$\begin{array}{l}\text { External } \\
\text { accountant }\end{array}$} \\
\hline Total sample & 73 & $61.4 \%$ & 15 & $12.6 \%$ & 18 & $15.0 \%$ & 13 & $10.9 \%$ \\
Proprietorships & 49 & $73.1 \%$ & 6 & $9.0 \%$ & 10 & $15.0 \%$ & 2 & $3.0 \%$ \\
Private companies & 24 & $46.2 \%$ & 9 & $17.3 \%$ & 8 & $15.3 \%$ & 11 & $21.1 \%$ \\
\hline Age (in years) & 45 & $(8.76)$ & 44 & $(11.3)$ & 40 & $(10.9)$ & 38 & $(12.5)$ \\
Educational level (1-6) & 2.2 & $(0.93)$ & 3.4 & $(0.99)$ & 2.9 & $(1.23)$ & 3.6 & $(1.23)$ \\
Knowledge of current & 2.3 & $(0.81)$ & 3.2 & $(0.64)$ & 2.6 & $(0.92)$ & 3.3 & $(1.38)$ \\
legal requirements (1-5) & & & & & & & & \\
\hline
\end{tabular}

Education categories: (1) elementary level, (2) secondary level, (3) higher education/non-economics, (4) higher education/economics, (5) academic/non-economics, (6) academic/economics)

Knowledge on current legal requirements on a 5 point scale $(1=$ low, $5=$ high $)$

Regarding the level of knowledge of current accounting regulations, based on the judgement of the respondent and indicated on a scale ranging from 1 (no knowledge) to 5 (very high knowledge), accountants score an average of 3.32 , which is significantly higher than the score of the other groups, separately or combined. However, given the fact that accountants are better trained in accounting, the question remains whether the better knowledge of legal requirements is primarily a result of their function as an accountant or a result of their better training. Additional tests show that the level of education is the primary factor explaining the level of knowledge on current accounting regulation ${ }^{19}$.

Comparing the characteristics of respondents from proprietorships with respondents from private companies, it seems that the latter group is better educated and is also more familiar with legal accounting requirements. The difference in educational level is not driven by the fact that more private firms had their external accountant fill out the questionnaire; non-accountants in private companies also had a better education in accounting compared to their counterparts in proprietorships. The differences in

\footnotetext{
${ }^{19}$ This conclusion is based on a series of Mann-Whitney-U tests $(\alpha=0.05)$, where the effect of educational level on knowledge of regulation was tested separately for each function-group and vice versa. The tests indicate that the level of education remains a significant factor for explaining the level of knowledge of regulation when keeping the respondents position constant, while a respondent's position had no significant effect if the level of education was kept constant.
} 
educational level also result in the higher knowledge of current legal requirements for respondents from private companies ${ }^{20}$.

Finally, respondents' characteristics are not different for respondents from a firm in the construction sector versus the retail sector.

Given the somewhat deviating characteristics of accountants, this group will be analyzed separately from other respondents. Although external accountants who answer the questionnaire for their clients may be expected to give answers from the clients' point of view instead of stating their private deliberations on the questions asked, any systematic differences in answers between external accountants and other respondents will be tested for in section 4.4.5.

\subsection{Perceptions of small firm managers on financial reporting issues.}

\subsubsection{Introduction.}

The remainder of the chapter consists of an analysis of the major findings based on the responses to the questionnaires. The analysis presented in this section deals with small firms' management perceptions on the following issues ${ }^{21}$ :

1. the attitudes towards financial reporting in general and the impact of current disclosure regulation on small firms;

2. the perceived users of small firm financial statements;

3. the disclosure of specific items in the financial statements of small firms;

4. the effect of financial accounting disclosures on the competitive position of a small firm.

In the first part of this section, descriptive statistics on the issues mentioned will be presented and compared to the results of previous studies (sections 4.4.2 through 4.4.4). The latter part of this section contains a cross analysis of answers and a statistical analysis of the effect of firm- and respondent characteristics on the answers provided in the questionnaires (section 4.4.5).

\footnotetext{
${ }^{20}$ These findings are based on a series of Mann-Whitney-U tests $(\alpha=0.05)$. Although more private companies have external accountants fill out the questionnaire, the difference in educational level between private companies and proprietorships also holds for the nonaccountant respondents. The difference in knowledge of current legal requirements does not hold if the level of training in accounting is kept constant.

${ }^{21}$ In section 4.5 the part of the questionnaire dealing with the perceived costs and benefits of financial reporting regulation is dealt with.
} 


\subsubsection{Financial reporting regulation.}

The primary objective of the questions in this section concerns the incentives for small firms to disclose financial accounting information to third parties. To test the effect of accounting regulation on the disclosure practice of small firms, disclosures prior to the regulatory change in 1983 (see appendix III) were compared to disclosures since 1984. The effect should be clear for private companies while there should be little differences for the disclosures of proprietorships.

From table 4.6 it is clear that the regulatory change had a dramatic effect on the quantity of disclosures made by small firms. The number of private companies disclosing annual accounts has risen from $9.6 \%$ to $96 \%$ while the number of proprietorships, which were not effected by the mandatory disclosures, publishing financial statements has only risen slightly from 11.9 to $13.4 \%$. Private companies which disclosed their financial statements voluntarily before 1984 (5) were not unanimous in the effect the regulations had on the contents of the financial statements disclosed. One firm indicated that the financial statements after 1984 entailed less information compared to prior years, while two firms indicated the contents of their financial statements had increased as a result of the new regulations. The remaining two firms felt the regulation of the financial accounting disclosure had no effect on the contents of the financial statements they disclosed. Finally, after 1984 a number of firms voluntary disclose information in addition to the information that is required by law ${ }^{22}$.

Table 4.6. Financial reporting disclosure practices

\begin{tabular}{llccc}
\hline & & $\begin{array}{c}\text { Proprietor- } \\
\text { ships } \\
(\mathrm{N}=67)\end{array}$ & $\begin{array}{c}\text { Private companies } \\
(\mathrm{N}=52)\end{array}$ & Total \\
\hline $\begin{array}{l}\text { Disclosure of financial } \\
\text { statements prior to 1984. }\end{array}$ & Yes & $8(11.9 \%)$ & $5(9.6 \%)$ & $13(10.9 \%)$ \\
$\begin{array}{l}\text { Disclosure of financial } \\
\text { statements after 1984. }\end{array}$ & Yes & $59(88.1 \%)$ & $47(90.4 \%)$ & $106(89.1 \%)$ \\
$\begin{array}{l}\text { Additional accounting } \\
\text { disclosures on a regular }\end{array}$ & Yes & $58(86.6 \%)$ & $20(96.2 \%)$ & $59(49.6 \%)$ \\
basis (after 1984). & No & $61(8.9 \%)$ & $12(23.1 \%)$ & $60(50.4 \%)$ \\
\hline
\end{tabular}

A number of conclusions may be drawn from these findings. Regulation has extended disclosure, not only directly by mandating disclosure of financial statements but also by encouraging more firms to publish additional information. It is not clear whether the additional disclosures are made to meet the information needs of specific user-groups

\footnotetext{
${ }^{22}$ Most additional disclosures were made to banks (11x). Other disclosures were made to the Central Bureau of Statistics ( $2 \mathrm{x})$, potential customers (1x), taxing authorities (1x) and industrial organisations $(1 \mathrm{x})$.
} 
or to counter any (perceived) negative effects of the mandatory disclosures. The latter explanation is partially confirmed by the findings of the Carsberg-study, in which $40 \%$ of the respondents found that regulations on the disclosure of financial accounts reduced the usefulness of the accounts. Additional disclosures may also result from requests of users of the disclosed financial statement who find the information required by law not adequate to fit their information needs and therefore request additional disclosures from the firm. In fact, $30 \%$ of the responding managers in the Carsberg-study indicated their bank did ask for additional information [Carsberg et al., 1985, p. 44].

Given the fact that small companies do not seem to have much incentive to disclose their annual accounts voluntarily, it could be expected that the reaction of small firm managers towards mandatory disclosure of the accounts would be hostile. The results of this study only partially confirm this hypothesis (table 4.7). Although a number of respondents from private companies $(14,26.9 \%)$ feel that current disclosure requirements are completely redundant and other respondents $(10,19.2 \%)$ indicate that current legal requirements are far too extensive, there are a considerable number of managers $(26,49.9 \%)$ who have few or no problems with current disclosure regulations.

Table 4.7. Perceptions on financial reporting regulation

\begin{tabular}{llcccc}
\hline & & Private companies & \multicolumn{2}{c}{ Proprietorships } \\
\hline What is your opinion on & 1. Completely redundant & 14 & $26.9 \%$ & 11 & $16.4 \%$ \\
the current legal disclosure & 2. Far too extended & 10 & $19.2 \%$ & 9 & $13.4 \%$ \\
requirements for small & 3. A bit to extended & 6 & $11.5 \%$ & 9 & $13.4 \%$ \\
firms? & 4. Fairly right & 20 & $38.4 \%$ & 30 & $44.8 \%$ \\
& 5. Too limited & 0 & $0.0 \%$ & 1 & $1.5 \%$ \\
& 6. No opinion & 2 & $3.9 \%$ & 7 & $10.5 \%$ \\
& Mean & 2.769 & & 3.328 & \\
& St. deviation & 1.409 & & 1.471 & \\
\hline Should the legal & Yes & 26 & $50.0 \%$ & 10 & $14.9 \%$ \\
requirements apply to & No & 23 & $44.2 \%$ & 55 & $82.9 \%$ \\
proprietorships as well? & No opinion & 3 & $5.8 \%$ & 2 & $3.0 \%$ \\
\hline If current disclosure & Yes & 4 & $7.7 \%$ & - & - \\
regulations were to be & No & 54 & $86.6 \%$ & - & - \\
abolished, would you & No opinion & 3 & $5.8 \%$ & - & - \\
continue to disclose annual & & & & & \\
statements? & & & & & \\
\hline
\end{tabular}

Respondents from proprietorships are generally more positive about the regulatory disclosure requirements, which is hardly surprising given the fact that these firms are not affected by these regulations. Although the reactions towards current company law requirements are at least not overwhelmingly negative, a large majority of private companies $(86 \%)$ would stop disclosing their financial statements if they were no longer required to do so. 
The findings reported here are consistent with the studies by Page [1984], Carsberg [1985] and Abdel-Khalik [1983]. In the Page-study, 52\% of the respondents wanted less disclosure requirements while $43 \%$ of the respondents indicated they had few problems with the amount of information which they were mandated to disclose [Page, 1984, p. 276]. Carsberg et al. [1985, p. 32] found that $64 \%$ of the responding managers did not mind what information had to be filed with the Registrar of Companies as long as the cost of producing the information was kept down. Also, none of the respondents indicated that accounting requirements or accounting standards were a main problem to their business [Carsberg et al., 1985, p. 27]. Abdel-Khalik [1983] studied the satisfaction of small US-firms with generally accepted accounting principle (GAAP). The results of the study indicate that managers were very divided on their evaluation of GAAP. On most of the questions on the perceived advantages and disadvantages of applying GAAP, managers tended to strongly disagree with each other. It should be remembered that private companies in the US do not face statutory or regulatory financial reporting requirements other than for tax purposes.

To gain further insight into the attitudes of small firm managers towards current financial accounting regulations, respondents were asked whether, in their opinion, current legal financial reporting requirements should be extended to include proprietorships as well as private companies. Respondent from private companies disagreed on the subject (see table 4.7) but respondents from proprietorships generally were against such an extension of the company law. Still, a number of proprietorships $(10,14.9 \%)$ indicated that they would have no objection if they were to be obliged to disclose their financial statements.

Table 4.8. Compliance with financial reporting regulation

\begin{tabular}{|c|c|c|c|}
\hline \multicolumn{2}{|l|}{ Question } & \multicolumn{2}{|c|}{ Private companies } \\
\hline Did your financial statements, to your & Yes & 50 & $96.2 \%$ \\
\hline $\begin{array}{l}\text { knowledge, comply fully with the legal } \\
\text { requirements? }\end{array}$ & No & 2 & $3.9 \%$ \\
\hline Did your financial statements, to your & Yes & 9 & $17.3 \%$ \\
\hline $\begin{array}{l}\text { knowledge, contain information not } \\
\text { required by law? }\end{array}$ & No & 43 & $82.7 \%$ \\
\hline Do the internally used financial statements & Yes & 8 & $15.4 \%$ \\
\hline $\begin{array}{l}\text { deviate from the disclosed financial } \\
\text { statements? }\end{array}$ & No & 44 & $84.6 \%$ \\
\hline Did the prepared financial statements & Yes & 13 & $25 \%$ \\
\hline contain a profit and loss account? & No & 39 & $75 \%$ \\
\hline
\end{tabular}

Regarding the compliance with financial reporting requirements, most respondents felt that the financial statements they had disclosed fully complied with all regulatory financial disclosure requirements (table 4.8). Also, a number of respondents indicated that the financial statements contained information that is not required by company law. 
A last item in the questionnaire on accounting regulation concerned the differences between the company law requirements for the preparation versus the disclosure of the financial statements. As indicated in Appendix III, the amount of information required for the prepared financial statements is different from the information to be disclosed. Respondents were therefore asked whether the prepared (internal) financial statements deviated from the financial accounts disclosed. Only a few respondents $(8,15 \%)$ indicated the internal financial statements were different from those disclosed. The requirement to prepare a profit and loss account is only met by a limited number of companies ( $25 \%$ ), which may be caused by the fact that this information does not have to be disclosed.

The results for the level of compliance must be interpreted with caution, because from the respondents' characteristics it is clear that small company managers do not seem to know very much about the legal financial disclosure requirements. So the information provided in chapter 3 , which is based on the actual information disclosed by small firms, would provide more unbiased information on the level of compliance with financial accounting disclosure requirements. The fact that few companies prepare a profit and loss account, however, provides some additional information on the level of compliance with financial accounting preparation requirements, indicating that small firms in general do not produce much information they are not explicitly mandated to disclose, although company law requires them to prepare this information.

\subsubsection{Users of small firm financial statements.}

Any consideration of the perception on the burden (costs) of financial accounting and its regulation should also consider the perceived uses (benefits) of producing and disclosing such reports. Financial accounting information is prepared and disclosed to meet the information needs of users of this kind of information. Since small companies' securities are not traded in the public market, the question of the primary users of small firm financial information is especially interesting. Respondents were asked to rank the importance of various groups as potential users of the financial accounting information disclosed (table 4.9).

Managers rank themselves as the most important user group. On a scale ranging from 0 (not important) to 10 (most important), managers/shareholders received an average of 9.0. Bankers were ranked as the second most important users of financial statements of small companies. The government ranked third, resulting mainly from the perceived use of financial reports by taxing authorities. All other potential user-groups scored very low and obviously were not considered to be important users of small firms' financial statements. An interesting finding is the very low scoring of competitors as potential users of financial statements, indicating that managers do not feel that the information they disclose is widely used by competing firms. 
Table 4.9. Users of small firm financial statements

\begin{tabular}{lcc}
\hline $\begin{array}{l}\text { What user-groups do you consider to be the most important } \\
\text { users of the financial statements? }\end{array}$ & $\begin{array}{c}\text { Mean score } \\
\text { (scale: } 0-10)\end{array}$ & $\begin{array}{c}\text { Standard } \\
\text { deviation }\end{array}$ \\
\hline Managers/Shareholders & 9.043 & 2.596 \\
Other capital suppliers (e.g. banks) & 4.787 & 4.165 \\
Government (including taxing authorities) & 3.170 & 4.198 \\
Financial analysts & 1.660 & 3.252 \\
Employees & 1.064 & 2.633 \\
Suppliers & 0.702 & 2.206 \\
Customers & 0.681 & 2.023 \\
Financial press & 0.511 & 2.020 \\
Investors & 0.484 & 1.943 \\
Competitors & 0.468 & 1.672 \\
\hline
\end{tabular}

The findings reported here are consistent with existing studies. The studies by AbdelKhalik [1983], Page [1984] and Carsberg et al. [1985] all indicate that managers find themselves to be the most important users of their company's financial statements, while bankers were always ranked in the top three. The importance of taxing authorities is somewhat unclear since they were not included as an option in the Abdel-Khalik study, while the results of the Page and Carsberg study are somewhat contradictory. Although both are UK-studies, the results of the study by Page indicate that the use of financial reports in tax computations is considered to be the second most important use of small firm financial account [Page, 1984, p. 275], while the Carsberg-study reports a much lower importance of this function of small firm financial statements [Carsberg et al., 1985, p. 42].

Table 4.10. Importance of annual accounts

Private companies

How important are the financial statements in the total of financial disclosures made by your firm?
1. Its the most important

2. Very important

3. Mediocre

4. Not very important

5. Of no importance

No opinion

Mean

Std. deviation

$\begin{array}{cc}9 & 17.3 \% \\ 14 & 26.9 \% \\ 9 & 17.3 \% \\ 10 & 19.2 \% \\ 9 & 17.3 \% \\ 1 & 1.9 \%\end{array}$

2.981

2.058

The usefulness of financial statements to potential users is influenced by the availability of other sources of financial accounting information of firms. Respondents therefore were asked what role they thought the financial statements play in the total of disclosures made by small firms (table 4.10). The significance of the responses to this question are rather hard to asses. The results do not support the view that the financial accounts are generally regarded as the primary means of financial accounting disclosures made by small firms. Nevertheless, they do play a more or less important role in the 
publishing of financial information in many small firms. It seems clear, however, that small companies have alternative ways besides the annual accounts to supply financial accounting information to interested parties (e.g. through special purpose reports, personal contacts).

The use of financial statements for management decision support is somewhat surprising since it is widely recognized that the infrequency and delay of production of annual accounts severely limits their usefulness for decision and control [Page, 1984, p. 275]. Nevertheless, the Carsberg-study indicates that the majority of managers who used accounts for management purposes thought that they were adequate for that purpose. Annual accounts were particularly used for decisions about dividends and directors' pay and to a lesser extend for decisions on capital expenditures [Carsberg et al., 1985, p. 42]. The financial statements used internally may be different from those that are actually disclosed. This may be especially true in a situation where the statutory requirements for the financial statements' preparations are more extensive than the disclosure requirements, as in the Netherlands. It should therefore be noted that in a number of cases respondents have indicated that their financial statements contained more information than legally required. This extra information might have been added specifically for internal management decisions making. Also, in an number of cases the disclosed accounts did not deviate from the prepared accounts because the prepared accounts, including for example a profit and loss statement, were fully disclosed. In these cases the accounts entailed more information than legally required which may be useful for aiding internal decision making.

\subsubsection{Disclosure of specific items.}

This section will further analyze what information items, for which the disclosure is required by company law, are particularly troublesome to managers of small firms. Respondent were asked to indicate what information items they would be willing to include in their published accounts in the absence of any regulatory obligation to provide the information. The list of information items included a number of general level disclosures (i.e. balance sheet, profit and loss account) and was followed by a list of specific information items which small firms are currently required to include in their financial statements. Respondents answered using a five-point Likert scale, where a score of 1 indicates strong resistance against the publication of the specific information and a score of 5 indicates little resistance against disclosure of the information item. The results are summarized in table 4.11 .

Statistical differences between private companies and proprietorships can be found only for information about employees $(\alpha=0.05)$ and a categorisation of employees $(\alpha=0.1)$. Both results are based on a Mann-Whitney U test. Conform the responses to the questions discussed in the previous section, small firms are not very willing to disclose any financial information in annual reports, given the low scores on almost all of the items in the list. 
Table 4.11. Disclosure of specific annual account items

\begin{tabular}{|c|c|c|c|c|c|c|}
\hline \multirow[t]{2}{*}{ Iterns } & \multicolumn{2}{|c|}{$\begin{array}{l}\text { All respondents } \\
(\mathrm{N}=102)\end{array}$} & \multicolumn{2}{|c|}{$\begin{array}{l}\text { Private company } \\
\qquad(\mathrm{N}=42)\end{array}$} & \multicolumn{2}{|c|}{$\begin{array}{l}\text { Proprietorship } \\
\qquad(\mathrm{N}=60)\end{array}$} \\
\hline & Mean & St.dev. & Mean & St.dev. & Main & St. dev \\
\hline Balance sheet & 2.3750 & 1.7070 & 2.5000 & 1.7838 & 2.3500 & 1.7057 \\
\hline Profit and loss account & 2.1806 & 1.5684 & 2.2500 & 1.7645 & 2.1667 & 1.5422 \\
\hline Notes to the balance sheet & 1.9444 & 1.4230 & 2.5000 & 1.7838 & 1.8333 & 1.3298 \\
\hline Notes to the P\&L account & 1.7917 & 1.2885 & 2.2500 & 1.7645 & 1.7000 & 1.1688 \\
\hline Complementary information & 1.6111 & 1.1328 & 1.8333 & 1.3371 & 1.5667 & 1.0949 \\
\hline Valuation methods & 1.9028 & 1.4058 & 2.4167 & 1.6765 & 1.8000 & 1.3378 \\
\hline Method of depreciation & 2.0556 & 1.4427 & 2.4167 & 1.6765 & 1.9833 & 1.3960 \\
\hline Loans to (former) directors & 1.4028 & .9592 & 1.4167 & .7930 & 1.4000 & .9949 \\
\hline $\begin{array}{l}\text { Loans to (former) } \\
\text { commissioners }\end{array}$ & 1.4444 & 1.0466 & 1.4167 & .7930 & 1.4500 & 1.0958 \\
\hline Changes in equity & 1.5694 & 1.0458 & 1.6667 & 1.0731 & 1.5500 & 1.0484 \\
\hline Division of equity & 1.6528 & 1.2005 & 1.5000 & 1.0000 & 1.6833 & 1.2418 \\
\hline $\begin{array}{l}\text { Information on self owned } \\
\text { share capital }\end{array}$ & 1.4861 & 1.0876 & 1.0833 & .2887 & 1.5667 & 1.1698 \\
\hline Collateral provided for debt & 1.7639 & 1.3054 & 2.0000 & 1.4142 & 1.7167 & 1.2900 \\
\hline Growth in sales & 2.3889 & 1.5615 & 2.2500 & 1.5448 & 2.4167 & 1.5762 \\
\hline Extraordinary revaluations & 2.0139 & 1.3374 & 2.1667 & 1.4035 & 1.9833 & 1.3339 \\
\hline $\begin{array}{l}\text { Costs/benefits and group- } \\
\text { companies }\end{array}$ & 1.6250 & 1.2037 & 1.9167 & 1.3114 & 1.5667 & 1.1842 \\
\hline Extraordinary costs/benefits & 1.6667 & 1.1506 & 1.5000 & .7977 & 1.7000 & 1.2115 \\
\hline Number of employees & 2.8056 & 1.7494 & 1.8333 & 1.4035 & 3.0000 & 1.7563 \\
\hline Division of employees & 2.7222 & 1.7216 & 1.8333 & 1.4035 & 2.9000 & 1.7340 \\
\hline $\begin{array}{l}\text { Obligations not appearing in } \\
\text { the balance sheet }\end{array}$ & 1.9167 & 1.3401 & 1.8333 & 1.0299 & 1.9333 & 1.4006 \\
\hline $\begin{array}{l}\text { Guarantees given on behalf } \\
\text { of third parties }\end{array}$ & 1.9861 & 1.4092 & 1.7500 & .9653 & 2.0333 & 1.4840 \\
\hline List of subsidiaries & 2.2222 & 1.5585 & 1.7500 & .9653 & 2.3167 & 1.6415 \\
\hline
\end{tabular}


All average scores are below the middle score on the scale used (three) - a level that would indicate that respondents in general would be neutral to disclosing the information item. Disclosure of the balance sheet meets relatively little resistance among respondents, along with the disclosure of valuation and depreciation methods used. Surprisingly, the disclosure of the profit and loss account and the 'growth of sales' seem to meet relatively little resistance. Disclosure of both items is not required by company law but it seems that responding firms are not particularly bothered with the disclosure of either item. However, the average scores for these items still indicate that small firms are not very willing to provide this kind of information. There is most resistance to disclosure of information about extraordinary costs and benefits and loans to (former) directors and (former) commissioners.

The standard deviations are rather small for most items, indicating that there is little disagreement among respondents within groups. Also, few differences exist in the answers of respondents from private companies and proprietorships at this point. Generally speaking, private companies seem less negative about disclosing financial accounting information, since for most items the average score for this group of companies is somewhat higher. However, this observation does not hold for all items on the list and only very few differences between respondents from private companies and proprietorships are statistically significant. The only significant differences concern the disclosure of information about the number of employees and the segregation of employees, which meet relatively little resistance among proprietorships while private companies are much more reluctant to provide this information.

\subsubsection{Effect of financial accounting disclosure on competitive position.}

It is often argued that mandatory financial reporting may have a substantial negative effect on the competitive position of firms, most notably on small firms, depending on the nature of the information to be disclosed and the nature and level of competition. Empirical studies on small private firms [e.g. Page, 1984, p. 276 and Carsberg et al., 1985], however, have indicated that the use of competitors' annal accounts among small firms is extremely limited, indicating that there seems to be little reason for concern for substantial competitive disadvantages arising from the disclosure of financial accounting information.

In our study, firms were asked whether they used accounting-information about competitors (table 4.12). Out of the 96 firms which answered this question, 77 (80\%) firms did not gather any information about their competitors. 12 companies use the annual accounts of competitors, 6 of which also gather additional information from other sources, while 13 firms only use other sources such as banks or the press. In total, 84 (87.5\%) did not use annual accounts of competitors in any way. These findings are consistent with a case-study by Van Alten et al. [1988] involving 10 Dutch mediumsized companies, that showed there was little attention paid to competitive analysis while 
annual reports of competitors were considered of little importance to perform a competitive analysis.

Table 4.12. Use of accounting information of competitors

Use of accounting information of competitors $(\mathrm{N}=96)$

No information at all

$77(80.2 \%)$

Use of annual accounts only

$6(6.3 \%)$

Use of other sources only

$7(7.3 \%)$

Use of annual accounts as well as other sources

$6(6.3 \%)$

However, management perceptions on the effect of disclosure on the competitive position of the firm were not in total agreement with these findings (table 4.13). At this point firms were split into two groups, each receiving different sets of questions. One group, consisting of private companies only,was asked whether they thought financial disclosure might lead to a competitive disadvantage for their firm. Out of the 20 companies that answered this question, 7 (35\%) answered the question affirmatively. In addition, these respondents were asked whether they felt current government regulation had a negative effect on their company's competitive position. $60 \%$ (12) thought that this was the case, but only two firms thought that the effect was substantial while all others felt regulation had only a mild effect.

Table 4.13. Potential competitive disadvantages

\begin{tabular}{lcc}
\hline & Yes & No \\
\hline $\begin{array}{l}\text { Disclosure of accounts results in competitive } \\
\text { disadvantages }\end{array}$ & $7(35 \%)$ & $13(65 \%)$ \\
$\begin{array}{l}\text { Current financial accounting regulation results in } \\
\text { competitive disadvantages }\end{array}$ & $12(60 \%)$ & $8(40 \%)$ \\
$\begin{array}{l}\text { Disclosure of accounts results in competitive } \\
\text { disadvantages for competitors }\end{array}$ & $52(52 \%)$ & $38(38 \%)$ \\
$\begin{array}{l}\text { Current financial accounting regulation results in } \\
\text { competitive disadvantages for competitors }\end{array}$ & $55(55 \%)$ & $32(32 \%)$ \\
\hline
\end{tabular}

A second group of companies (private companies as well as proprietorships, $\mathrm{N}=99$ ) was asked whether they thought competitors would suffer any competitive disadvantage if they would have to disclose their accounts. Fifty-two (52\%) companies thought this was the case, while $38(38 \%)$ had an opposite opinion $(9(9 \%)$ respondents did not answer the question). Out of this group of companies, 25 (25\%) believed that current regulation had a substantial negative effect on the competitive position of firms, while $30(30 \%)$ felt that there was only a mild effect and $32(32 \%)$ assumed regulation had no effect at all. Both proprietorships and private companies responded to these questions in a similar way. 
The results of both sets of companies indicate that companies disagree considerably about whether financial disclosure leads to competitive disadvantages. But most companies agree that current regulation does not have a substantial effect on the competitive position of the firms concerned. The importance of general purpose accounting information in this respect, may depend upon the availability of alternative sources of financial information as well as the level of competition firms that are facing. In our sample, virtually all the firms in both industries (construction business and retail/wholesale) found competition was high or very high, so the impact of the level of competition can not be tested. Additionally, the level of competition might have an impact especially if competitors are not required to disclose an annual report. In our sample, private companies in the retail/wholesale-business indicate that there is competition from proprietorships, in contrast to the construction business, where proprietorships were not considered to be important competitors. However, for none of the questions mentioned above could a significant industry-effect be found.

Finally, companies were asked what information-items disclosed by competitors, were regarded as to be of particular importance for competitive analysis. The results were different for private companies and for proprietorships (table 4.14). Not only did they disagree on the relative importance of the items mentioned but also the average scores of proprietorships were much lower, indicating that they felt that none of the information-items mentioned were of very great importance to them.

Table 4.14. Importance of competitors' annual report information items.

\begin{tabular}{lclc}
\hline Private companies & $\begin{array}{c}\text { Mean score } \\
\text { (scale 1-5) }\end{array}$ & Proprietorships & $\begin{array}{c}\text { Mean score } \\
\text { (scale 1-5) }\end{array}$ \\
\hline 1. Notes on P\&L Account & 3.4 & 1. Growth of sales & 2.44 \\
2. Profit and loss account & 3.4 & 2. Number of employees & 2.36 \\
3. Growth of sales & 3.2 & 3. Profit and loss account & 2.36 \\
4. Notes on balance sheet & 3.1 & 4. Notes on P\&L Account & 2.31 \\
5. Securities provided to & 3.0 & 5. List of subsidiaries & 2.25 \\
creditors & & & \\
\hline
\end{tabular}

Private companies were asked which information-items that they had to disclose could lead to competitive disadvantages (table 4.15). The information-items mentioned differ only slightly from those mentioned before as being important information from competitors. Apparently, managers think that the information they find of importance about competitors does not differ much from the information disclosed by their own firm which competitors find of importance.

Most of the results shown in this section indicate that the cost due to competitive disadvantages are not considered to be of much importance among small and mediumsized firms. There is no reason to accept competitive disadvantages as an important argument to oppose accounting regulation. Very little time and effort is spent on competitive analysis by small firms. If small companies conduct a competitive analysis, other information besides annual reports is of at least equal importance. Finally, small 
companies do not think current regulation has a substantial effect on the competitive position of the firms concerned.

Table 4.15. Importance of annual report items to competitors.

What information in your annual report is of most importance to your competitors ?
Score on scale $1-5$

3.6

3.2

3.0

2.9

2.8

\subsubsection{Analysis of results}

In this section, the results provided in the previous section will be analyzed in two ways: 1. Responses to particular questions will be related to respondents characteristics. From this analysis it can be shown whether responses systematically vary with firm characteristics (i.e. industry and firm size) or personal characteristics of respondents). 2. Responses to various questions will be cross analyzed. This analysis will provide some assurance of the consistency in the answers of respondents.

In the analysis provided in this section, two types of tests are generally used: (a) nonparametric tests making evaluative classifications of responses or ranking responses and (b) t-tests. Non-parametric testing is used for two reasons. Firstly, parametric testing requires meeting various conditions for the variables used, such as the drawing of observations from a normally distributed population and, in the case of analysis concerning two groups, equal variances between groups. Non-parametric testing requires much fewer restrictions to the observations used and is particularly useful in the case of relatively small sample sizes. Secondly, most responses are available on nominal (categorical) or ordinal (ordered) scales, which prohibits the use of parametric testing ${ }^{23}$.

The use of Likert-scales in gathering respondents' perceptions requires some additional comments. Likert-scales are used to rank respondents' agreement with propositions presented to them, mostly using a 5-point scale. Two types of problems are typically associated with the use of this type of categorical scale. Firstly, the meaning attributed by various respondents to a particular score might not be uniform. Secondly, the distance between two adjacent scores might not be constant. Thus the meaning of the ranking may differ from one respondent to another and from one statement to another. This makes the use and interpretation of average scores and standard deviations

${ }^{23}$ For a thorough and illuminating discussion of parametric and non-parametric testing, see Siegel and Castellan, 1988, chapter 3. 
problematic. The first problem is dealt with by using an additional testing procedure, recoding the responses in two categories while only classifying the respondents providing the most extreme responses (e.g. category A consists of all respondents giving a score of 1 and category B consists of all respondents giving a score of 5 to a particular statement, while all other respondents are ignored). The use of this procedure (typically involving a Chi-Square test) circumvents the testing of differences in average scores between groups in common parametric and non-parametric tests (e.g. t-tests or MannWhitney U tests). The second problem resulting from the use of Likert-scales is tackled by the cross-correlation of answers to various statements to test the consistency of answers of the respondents.

\subsubsection{Responses and firm- and respondents' characteristics}

The results of the analysis of respondents' answers and respondents' characteristics are presented in tables 4.16 to 4.18 .

Table 4.16. Perceptions and firm- and respondents' characteristics

\begin{tabular}{|c|c|c|c|c|c|c|}
\hline \multirow[t]{2}{*}{ Variable } & \multicolumn{3}{|c|}{ Firm characteristics } & \multicolumn{3}{|c|}{ Respondent's characteristics } \\
\hline & $\begin{array}{l}\text { Legal } \\
\text { form }\end{array}$ & Industry & Firm size & $\begin{array}{l}\text { External } \\
\text { accountant }\end{array}$ & $\begin{array}{l}\text { Knowledge } \\
\text { of company } \\
\text { law }\end{array}$ & $\begin{array}{l}\text { Active in } \\
\text { financial } \\
\text { reporting }\end{array}$ \\
\hline Test & $x^{2}$-test & $\begin{array}{l}x^{2} \text {-test } \\
\text { MWU }\end{array}$ & MWU & $\begin{array}{l}x^{2} \text {-test } \\
\text { MWU }\end{array}$ & $\begin{array}{l}x^{2} \text {-test } \\
\text { MWU }\end{array}$ & $\begin{array}{l}x^{2}-\text { test } \\
\text { MWU }\end{array}$ \\
\hline $\begin{array}{l}\text { Importance } \\
\text { of annual } \\
\text { accounts }\end{array}$ & NA & $\begin{array}{l}0.19 \\
0.79\end{array}$ & 0.15 & $\begin{array}{l}5.38^{* *} \\
2.00^{* *}\end{array}$ & $\begin{array}{l}5.38^{* *} \\
2.31^{* *}\end{array}$ & $\begin{array}{l}0.52 \\
0.89\end{array}$ \\
\hline $\begin{array}{l}\text { Opposing } \\
\text { accounting } \\
\text { regulation }\end{array}$ & $\begin{array}{l}2.23 \\
1.53\end{array}$ & $\begin{array}{l}2.59^{*} \\
1.38\end{array}$ & 0.44 & $\begin{array}{l}0.00 \\
0.42\end{array}$ & $\begin{array}{l}1.12 \\
1.09\end{array}$ & $\begin{array}{l}4.78^{* *} \\
2.11^{* *}\end{array}$ \\
\hline $\begin{array}{l}\text { Extension of } \\
\text { company law } \\
\text { to prop.ships }\end{array}$ & $18.35^{* * *}$ & 0.14 & $3.00^{* * *}$ & 1.44 & $3.97^{* * *}$ & $5.02 * *$ \\
\hline
\end{tabular}

1. MWU $=$ Mann-Whitney $\mathrm{U}$ test.

2. For CHI-square-tests the $x^{2}$-statistic is reported. For Mann Whitney U tests z-scores are reported.

3. Significance levels are indicated as * for $\alpha=0.1, * *$ for $\alpha=0.05$ and *** for $\alpha=0.01$ (all 2-tailed)

Table 4.16 summarizes the analysis of respondents' perceptions on accounting regulation. The results indicate that:

1. respondents that are external accountants and more familiar with financial accounting regulation are more inclined to find that small firms' annual reports are a major source of financial accounting information; 
2. respondents that are actively involved in the process of the financial statement's preparation are less inclined to oppose financial accounting regulation. They also are less opposed to current accounting regulation being extended to include proprietorships; 3. respondents from private companies more often find that current accounting regulation should be extended to include proprietorships. Obviously, proprietorships would rather avoid financial accounting regulation;

4. respondents from larger firms more often find that current accounting regulation should be extended to include proprietorships. Further analysis indicates that this finding mainly results from the fact that private companies in the sample are generally larger than proprietorships;

5. perceptions of external accountants on financial accounting regulation do not deviate significantly from the answers of other respondents.

Table 4.17. Accounting information and firm- and respondents' characteristics

\begin{tabular}{|c|c|c|c|c|c|c|}
\hline \multirow{3}{*}{$\begin{array}{l}\text { Variable } \\
\text { Test }\end{array}$} & \multicolumn{3}{|c|}{ Firm characteristics } & \multicolumn{3}{|c|}{ Respondent's characteristics } \\
\hline & $\begin{array}{l}\text { Legai } \\
\text { form }\end{array}$ & Industry & Firm size & $\begin{array}{l}\text { External } \\
\text { accoun- } \\
\text { tant }\end{array}$ & $\begin{array}{l}\text { Know- } \\
\text { ledge of } \\
\text { company }\end{array}$ & $\begin{array}{l}\text { Active in } \\
\text { financial } \\
\text { reporting }\end{array}$ \\
\hline & $x^{2}$-test & $x^{2}-$ test & MWU & $x^{2}$-test & $x^{2}$-test & $x^{2}$-test \\
\hline $\begin{array}{l}\text { Disclosure through } \\
\text { alternative channels }\end{array}$ & 2.48 & 0.81 & $1.81^{*}$ & 0.39 & 2.06 & 0.83 \\
\hline $\begin{array}{l}\text { Voluntary preparation } \\
\text { under regulation }\end{array}$ & 2.59 & 1.46 & $2.12^{* *}$ & 0.09 & 1.46 & 3.25 \\
\hline $\begin{array}{l}\text { Voluntary disclosure } \\
\text { (no regulation) }\end{array}$ & 0.34 & 0.98 & 0.63 & 1.20 & 1.78 & 0.13 \\
\hline Additional info & NA & 0.96 & 0.21 & $3.53^{*}$ & $5.20^{*}$ & 0.12 \\
\hline $\begin{array}{l}\text { Preparation of } \\
\text { internal accounts }\end{array}$ & NA & 0.54 & 1.28 & 2.53 & 0.72 & $3.48^{*}$ \\
\hline
\end{tabular}

1. MWU = Mann-Whitney U tests; NA = Not Applicable

2. For CHI-square-tests the $x^{2}$-statistic is reported. For Mann Whitney $\mathrm{U}$ tests z-scores are reported.

3. Significance levels are indicated as $*$ for $\alpha=0.1, * *$ for $\alpha=0.05$ and $* * *$ for $\alpha=0.01$ (all 2-tailed)

Table 4.17 summarizes the analysis of the financial accounting activities of firms and firm and respondents' characteristics. The results can be summarized as follows:

1. Larger firms are more active in financial accounting. They more often produce accounting information that is not required to be disclosed (e.g. profit and loss account); they more often prepare separate internal accounts and they more often include information in the annual accounts disclosed that is not required by law;

2. No systematic effect of legal form or industry can be found.

Respondents' characteristics are not supposed to have an effect on the responses regarding financial accounting activities of firms, since the answers do not reflect perceptions. However, due to some personal characteristic some respondents may be 
more informed about the firm's financial accounting activities. Also, it should be established whether respondents with certain characteristics may be systematically manipulating the questionnaire. Consequently, all items included in table 4.17 were correlated with several respondents' characteristics. No systematic effects could be detected.

Table 4.18 summarizes respondents' opinions on the competitive disadvantages of financial accounting disclosure and financial accounting regulation, related to firms' and respondents characteristics. The results found suggest that:

1. larger firms are more active in gathering information about their competitors. They more often use annual accounts and other information sources and they also more often indicate that they would like to have additional information about competitors that is not currently found in annual accounts (e.g. sales and profits);

2. larger firms more often indicate that there is a potential negative effect from financial accounting disclosures;

3. legal form and industry have no systematic effect on the attitude of the firm a this point;

4. respondents' characteristics have no systematic effect on the responses given to these particular questions.

Table 4.18. Accounting information and firm- and respondents' characteristics

\begin{tabular}{|c|c|c|c|c|c|c|}
\hline \multirow[t]{2}{*}{ Variable } & \multicolumn{3}{|c|}{ Firm characteristics } & \multicolumn{3}{|c|}{ Respondent's characteristics } \\
\hline & $\begin{array}{l}\text { Legal } \\
\text { form }\end{array}$ & Industry & $\begin{array}{l}\text { Firm size } \\
\text { MWU }\end{array}$ & $\begin{array}{l}\text { External } \\
\text { accoun- } \\
\text { tant } \\
x^{2} \text {-test }\end{array}$ & $\begin{array}{l}\text { Know- } \\
\text { ledge of } \\
\text { law } \\
x^{2} \text {-test }\end{array}$ & $\begin{array}{l}\text { Active in } \\
\text { financial } \\
\text { reporting }\end{array}$ \\
\hline $\begin{array}{l}\text { Analysis of } \\
\text { competitors' accounts }\end{array}$ & $3.73^{*}$ & 0.04 & $2.59 * * *$ & 0.02 & 0.24 & 0.23 \\
\hline $\begin{array}{l}\text { Analysis of other } \\
\text { information about } \\
\text { competitiors }\end{array}$ & 0.52 & $3.32 *$ & $2.19 * *$ & 1.14 & 1.04 & 1.13 \\
\hline $\begin{array}{l}\text { Need extra } \\
\text { information about } \\
\text { competitors }\end{array}$ & 0.10 & $10.48^{*}$ & $1.65^{*}$ & 0.07 & 0.01 & 1.28 \\
\hline $\begin{array}{l}\text { Disclosure results in } \\
\text { competitive } \\
\text { disadvantages }\end{array}$ & 2.14 & 2.43 & $1.86^{*}$ & 0.28 & 0.46 & 1.85 \\
\hline $\begin{array}{l}\text { Regulation results in } \\
\text { competitive } \\
\text { disadvantages }\end{array}$ & $5.93^{*}$ & 3.75 & 0.57 & 1.70 & 0.72 & 0.41 \\
\hline
\end{tabular}

1. MWU $=$ Mann-Whitney $U$ tests; NA $=$ Not Applicable

2. For CHI-square-tests the $x^{2}$-statistic is reported. For Mann Whitney U tests z-scores are reported.

3. Significance levels are indicated as * for $\alpha=0.1, * *$ for $\alpha=0.05$ and *** for $\alpha=0.01$ (all 2-tailed) 


\subsubsection{Cross analysis of answers}

The consistency of answers provided by respondents can be tested by a cross analysis of related questions. Also, cross analysis is used to test for the consistency between financial disclosure practice and perceptions on financial accounting issues. The results of the tests performed are summarized in tables 4.19 and 4.20 .

Table 4.19. Consistency analysis

\begin{tabular}{|c|c|c|c|c|}
\hline Question 1 & Question 2 & $x^{2}$ test & $\begin{array}{l}\text { Mann- } \\
\text { Whitney U } \\
\text { test }\end{array}$ & $\begin{array}{l}\text { Rank } \\
\text { correlation }\end{array}$ \\
\hline $\begin{array}{l}\text { Opposing financial } \\
\text { disclosure regulation }\end{array}$ & $\begin{array}{l}\text { Extension of disclosure } \\
\text { regulation to } \\
\text { proprietorships }\end{array}$ & $5.71^{* *}$ & NA & $-0.20^{* *}$ \\
\hline $\begin{array}{l}\text { Voluntary preparation } \\
\text { of accounting } \\
\text { information in presence } \\
\text { of regulation }\end{array}$ & $\begin{array}{l}\text { Voluntary disclosure of } \\
\text { accounting information } \\
\text { in absence of regulation }\end{array}$ & 0.016 & NA & 0.015 \\
\hline $\begin{array}{l}\text { Disclosure results in } \\
\text { competitive } \\
\text { disadvantage }\end{array}$ & $\begin{array}{l}\text { Regulation results in } \\
\text { competitive } \\
\text { disadvantage }\end{array}$ & $37.86^{* * *}$ & $5.89 * * *$ & $0.58^{* * *}$ \\
\hline $\begin{array}{l}\text { Analysis of annual } \\
\text { accounts of competitors }\end{array}$ & $\begin{array}{l}\text { Analysis of other } \\
\text { information about } \\
\text { competitors }\end{array}$ & $10.98^{* * *}$ & NA & $0.34 * * *$ \\
\hline $\begin{array}{l}\text { Disclosure through } \\
\text { alternative channels }\end{array}$ & $\begin{array}{l}\text { Including non-required } \\
\text { information in annual } \\
\text { accounts }\end{array}$ & $2.79^{*}$ & NA & $-0.23^{*}$ \\
\hline $\begin{array}{l}\text { Disclosure through } \\
\text { alternative channels }\end{array}$ & $\begin{array}{l}\text { Disclosure results in } \\
\text { competitive } \\
\text { disadvantage }\end{array}$ & $11.59^{* * * *}$ & NA & $0.32^{* * *}$ \\
\hline $\begin{array}{l}\text { Disclosure through } \\
\text { alternative channels }\end{array}$ & $\begin{array}{l}\text { Regulation results in } \\
\text { competitive } \\
\text { disadvantage }\end{array}$ & $6.00^{* *}$ & $2.017^{* *}$ & $0.19 *$ \\
\hline
\end{tabular}

1. Significance levels are indicated as * for $\alpha=0.1, * *$ for $\alpha=0.05$ and $* * *$ for $\alpha=0.01$ (all 2-tailed)

2. NA $=$ Not Applicable

Some brief comments:

1. respondents which indicate that financial accounting regulation is redundant or is far too much extended, do not think that these regulations should be extended to include proprietorships as well;

2. firms that voluntarily prepare accounting information not required by law do not engage in more voluntary disclosures of accounting information; 
3. respondents indicating that the disclosure of financial information may have a negative effect on the disclosing firm's competitive position also indicate that financial accounting regulation may have an identical effect;

4. firms that analyze financial accounts of competitors also use alternative sources to gather information of competitors more frequently;

5. firms using alternative channels to disclose accounting information less frequently include extra (not required by law) information in their financial statements;

6. firms using alternative channels to disclose accounting information, more often agree with the statements that disclosure of annual accounts and financial accounting regulation have a negative effect on the firm's competitive position.

The perceptions of respondents on the importance of the annual accounts and the importance of financial accounting regulation are analyzed in more detail in table 4.20. The results of this analysis indicate that:

1. respondents opposing financial accounting regulation also find financial accounting regulation has a negative effect on the disclosing firm's competitive position;

2. firms opposing financial accounting regulation produce less accounting information, either voluntarily or in a regulated environment. Although the sign of the relationship is consistent over various items, not all of the relationships are statistically significant; 3. firms indicating that the annual report is a major outlet of financial accounting information are more inclined to add extra information in their financial statements; 4. no relationship can be found between the perception on the importance of the annual accounts and the effect of financial accounting disclosure or its regulation on the competitive position of the disclosing firm.

\subsubsection{Concluding remarks.}

In section 4.4 an empirical study was presented, studying the perceptions of small company management on financial accounting disclosure and financial accounting regulation for small firms. In evaluating the results of the study it should be noted that the sample of firms used in this study is not necessarily representative for all Dutch small firms, due to the regional and industry restrictions in selecting the firms included. As such, the study is exploratory and not specifically aimed at generalisability. Given the fact that this is, as far as we know, the first study to examine the perceptions of small firm managers on financial accounting in the Netherlands, and one of the few studies in this field published in the international accounting literature, the results of the study may provide useful insights in the financial accounting environment of small firms.

Firstly, financial accounting disclosure and financial accounting regulation do not seem to be major issues for small companies. The lack of concern with financial accounting is shown by the answers of small company management, indicating that almost half of the companies do not seem to be bothered by current regulation. The reason for this 
Table 4.20. Cross analysis

\begin{tabular}{|c|c|c|c|c|}
\hline $\begin{array}{l}\text { Cross analysis of perceptions or } \\
\text { regulation }\end{array}$ & necessity of accounting & $x^{2}$-test & $\begin{array}{l}\text { MWU } \\
z \text {-score }\end{array}$ & $\begin{array}{l}\text { Rank cor } \\
\text { relation }\end{array}$ \\
\hline $\begin{array}{l}\text { Opposing financial disclosure } \\
\text { regulation }\end{array}$ & $\begin{array}{l}\text { Voluntary disclosure of } \\
\text { accounting information }\end{array}$ & 0.74 & 0.87 & -0.11 \\
\hline $\begin{array}{l}\text { Opposing financial disclosure } \\
\text { regulation }\end{array}$ & $\begin{array}{l}\text { Voluntary preparation of } \\
\text { accounting information }\end{array}$ & 0.40 & 0.74 & -0.06 \\
\hline $\begin{array}{l}\text { Opposing financial disclosure } \\
\text { regulation }\end{array}$ & $\begin{array}{l}\text { Disclosure through other } \\
\text { channels }\end{array}$ & 1.54 & 1.03 & -0.05 \\
\hline $\begin{array}{l}\text { Opposing financial disclosure } \\
\text { regulation }\end{array}$ & $\begin{array}{l}\text { Preparation of separate internal } \\
\text { accounts }\end{array}$ & 1.14 & 0.91 & -0.16 \\
\hline $\begin{array}{l}\text { Opposing financial disclosure } \\
\text { regulation }\end{array}$ & $\begin{array}{l}\text { Disclosure of non-required } \\
\text { information }\end{array}$ & $3.44^{*}$ & $2.12 * *$ & $-0.27 *$ \\
\hline $\begin{array}{l}\text { Opposing financial disclosure } \\
\text { regulation }\end{array}$ & $\begin{array}{l}\text { Disclosure results in competitive } \\
\text { disadvantage }\end{array}$ & 0.28 & 0.77 & 0.05 \\
\hline $\begin{array}{l}\text { Opposing financial disclosure } \\
\text { regulation }\end{array}$ & $\begin{array}{l}\text { Regulation results in competitive } \\
\text { disadvantage }\end{array}$ & $10.89 * * *$ & $2.89 * * *$ & $0.34 * * *$ \\
\hline \multicolumn{5}{|c|}{ Cross anaiysis of perceptions on importance of annual accounts } \\
\hline $\begin{array}{l}\text { Importance of annual } \\
\text { accounts }\end{array}$ & $\begin{array}{l}\text { Voluntary disclosure of } \\
\text { accounting information }\end{array}$ & 0.49 & 0.81 & -0.10 \\
\hline $\begin{array}{l}\text { Importance of annual } \\
\text { accounts }\end{array}$ & $\begin{array}{l}\text { Voluntary preparation of } \\
\text { accounting information }\end{array}$ & 0.00 & 0.24 & 0.00 \\
\hline $\begin{array}{l}\text { Importance of annual } \\
\text { accounts }\end{array}$ & $\begin{array}{l}\text { Disclosure through other } \\
\text { channels }\end{array}$ & 1.94 & 1.41 & 0.21 \\
\hline $\begin{array}{l}\text { Importance of annual } \\
\text { accounts }\end{array}$ & $\begin{array}{l}\text { Preparation of separate internal } \\
\text { accounts }\end{array}$ & 0.40 & 0.95 & 0.09 \\
\hline $\begin{array}{l}\text { Importance of annual } \\
\text { accounts }\end{array}$ & $\begin{array}{l}\text { Disclosure of non-required } \\
\text { information }\end{array}$ & $9.46^{* * * *}$ & $2.74 * * *$ & $0.47^{* * * *}$ \\
\hline $\begin{array}{l}\text { Importance of annual } \\
\text { accounts }\end{array}$ & $\begin{array}{l}\text { Disclosure results in competitive } \\
\text { disadvantage }\end{array}$ & 0.63 & 0.69 & 0.12 \\
\hline $\begin{array}{l}\text { Importance of annual } \\
\text { accounts }\end{array}$ & $\begin{array}{l}\text { Regulation results in competitive } \\
\text { disadvantage }\end{array}$ & 0.10 & 0.57 & 0.01 \\
\hline
\end{tabular}

1. Significance levels are indicated as * for $\alpha=0.1, * *$ for $\alpha=0.05$ and $* * *$ for $\alpha=0.01$ (all 2-tailed)

2. NA $=$ Not Applicable

reaction is certainly not that companies would disclose comparable information in a nonregulated environment. Before the introduction of compulsory publication of annual accounts for small companies, only very few companies disclosed any information. Furthermore, if current regulation were to be abolished, over $90 \%$ would stop disclosing annual accounts. It therefore seems that small and medium-sized companies do not expect to gain much by disclosing financial information. These results are consistent with other research in this area (see e.g. Carsberg et al. [1985], p. 27.). Carsberg's survey-study among small companies indicated that accounting was not perceived as a 
major problem by these firms. Small companies' managers were more troubled by commercial, financial and personnel problems than by accounting problems. Of all administrative activities, preparing the annual accounts was seen as an important burden in cost, time and effort to complete, but tax returns were regarded as the most burdensome.

Costs resulting from competitive disadvantages do not seem to be a valid argument against accounting regulation. Only a small number of small and medium-sized companies gather information about competitors and even if they do so, annual accounts do not seem to be a particularly important source of information. When companies are asked whether they think financial accounting might have a negative effect on the competitive position of the firm, there is considerable disagreement. But when asked whether current disclosure regulation has a negative effect on the competitive position of the firms concerned, most companies agree that there is little or no effect.

Finally, most small firm managers do not seem to appreciate the usefulness of their financial statements to third parties. Managers rank themselves as the most important users of the financial statements, followed at some distance by outside capital suppliers (e.g. banks).

In the following section, evidence on the cost-effects of financial accounting regulation for small companies will be presented. The analysis presented there will focus on the direct cost effects on regulation, particularly the number of hours spent on accounting within firms and the fees paid to external accountants. 


\subsection{Small firms' disclosure costs}

\subsubsection{Introduction}

In this section, the focus will be on the costs of financial accounting for small firms, with special interest for the effect of financial accounting regulation on accounting costs for small firms and the relationship between accounting costs and firm size. One of the arguments frequently used to argue in favour of differentiation in financial accounting regulation is based on the premise that regulation has a disproportional cost effect on small companies. Larger firms can spread fixed accounting costs over larger revenues, are better able to establish routine accounting procedures, and are in a better position to hire specialized personnel to perform accounting tasks (see chapter 2). In this chapter, existing empirical research will be discussed and new data will be presented, testing the argument of disproportional accounting costs for smaller firms.

Classifications of accounting costs are abundant in the accounting literature. Some of these differentiate between direct and indirect (including opportunity) costs of financial disclosure (Benston [1976]). Also, a distinction is made between disclosure costs and regulation costs, where the former result from the preparation and disclosure of accounting information and the latter from regulating accounting disclosure, including the cost of lobbying, litigation and the development and enforcement of rules (Beaver [1989, p. 43]). Although other classifications of accounting costs are conceivable, the classifications mentioned here are of particular importance since they direct attention to two major difficulties in empirical research on accounting costs.

- The direct-indirect dichotomy illustrates the fact that not all cost-effects of accounting regulation are directly traceable nor are they always directly measureable. In fact, it seems evident that for a researcher it would be virtually impossible to asses all costeffects of any regulatory change. As a result, any empirical study on the cost effects of accounting regulation is an incomplete study, as it can only cover a subset of all potential cost effects. Obviously, most existing empirical studies on accounting costs have concentrated on direct costs.

- The disclosure-regulation dichotomy points out that in a regulated environment only a part of all accounting costs result from regulation. In the absence of any accounting regulation, firms would still produce and disclose accounting information. To assess the costs of accounting regulation only the costs above this basic level can be attributed to the regulation. To establish, in a regulated environment, the costs of voluntary accounting information-production and -disclosure which would exist in absence of the regulations present obviously poses a major problem to an accounting researcher.

This section presents an empirical study on (1) the cost effects of the 1984 change in Dutch financial accounting regulation and (2) the relationship between accounting costs and firm size. Since the focus of this dissertation is on small companies, the costcategories studied are those assumed to be the most important to small firms. Our focus on firms results in the exclusion of categories that are not borne by firms, such as 
governmental costs and the costs of analysis and interpretation (see table 4.21). Our focus on small firms suggests the exclusion of various cost-categories that are specifically associated with large firms, such as political, lobbying and litigation costs. Assuming that these costs are of relatively little importance to small firms, the analysis will concentrate on the costs resulting from (1) the production of the accounting information, and (2) the hiring of an external accountant. Indirect cost effects, particularly the costs related to potential competitive disadvantages resulting from financial accounting disclosures, have been dealt with in the previous section.

Table 4.21. Classification of accounting costs

Cost-category Description

Information production resources spent on collecting, processing and organising costs accounting data, putting them into financial statements and distributing this information to parties concerned.

Costs of analysis and interpretation

resources spent on making accounting figures comparable to information from other firms or other years.

Accountants' fees resources spent on the hiring of an external accountant to prepare and/or audit the accounts.

Competitive disadvantages

opportunity costs resulting from competitors using the disclosure to their own advantage, particularly in an international context when less restrictive disclosure regimes for competitors are involved.

Litigation costs cost resulting from (the threat of) law suits against the firm or its managers.

Political costs

Constraints on management behaviour the political system's power to extract and redistribute wealth from companies (for example by increasing tax regulations).

opportunity costs that may be related to the disclosure of forecasting information that puts pressure on management to take actions that result in an actual outcome that is close to the forecasted figure, even if these actions are not optimal from a company (long term) viewpoint.

Governmental costs cost of government intervention in financial disclosure, such as developing rules, monitoring and enforcing them and the filing and reviewing of the information disclosed.

Lobbying costs resources spent to influence the regulatory bodies and the regulatory process.

In testing the cost effects of financial accounting regulation, the problem of the disclosure cost-regulation cost dichotomy, presents relatively few difficulties in our study. The exceptional situation that the regulatory change under investigation constitutes the transition from a non-regulated accounting environment to a regulated accounting environment presents a unique opportunity, since the increase in accounting costs after the introduction of the accounting regulation can be directly associated with 
the costs of complying with these regulations. By comparing the level of accounting costs before and after the regulatory change, a fairly accurate estimation of the cost effects of the regulations can be presented.

The results presented in the following sections are based on the sample of private companies described in section 4.3. However, not all of the responding firms provided data to be used in this study on accounting costs. It seems that for a number of firms the costs of gathering or estimating the requested data on accounting costs were significant. Also, cost-data were only gathered for the sample of private companies and not for the proprietorships. This resulted in 35 questionnaires containing usable estimations of accounting costs.

\subsubsection{Qualitative analysis}

Private companies were asked how much of the time spent on accounting was allocated to each of the following categories: (1) assembling data and keeping records, (2) processing and organising data, (3) producing the actual annual report and (4) the distribution of the annual report. The results indicate that about half of the total costs $(45 \%)$ are spent on collecting data and keeping records. Ori data-processing and organising $35 \%$ is spent, while $16 \%$ is attributed to the actual production of the annual accounts and $5 \%$ to distributing the accounts.

According to company management, the change in regulation in 1984 did have an effect on the total accounting costs. Of the private companies, $67 \%$ indicate that accounting costs have risen. On the other hand, $27 \%$ state that regulation has had little or no effect

Figure 4.1 Subdivision of accounting costs

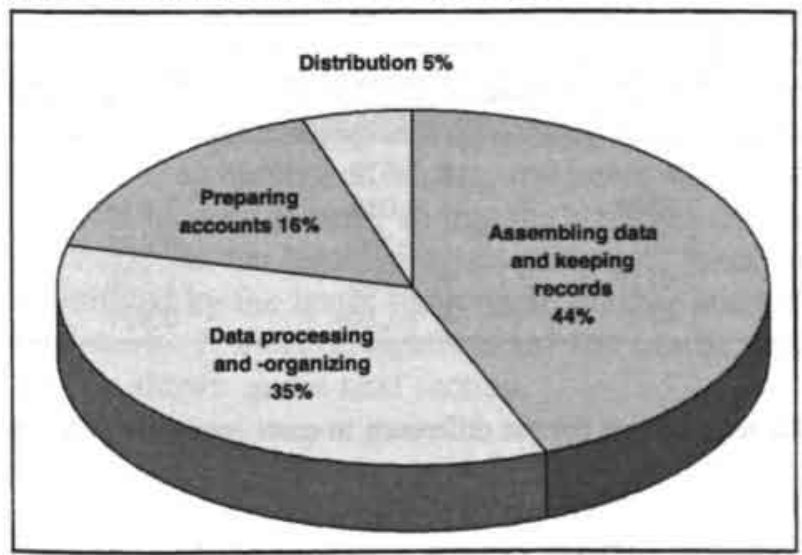

on their accounting costs, which is an interesting result since only few companies published annual accounts before 1984. A possible explanation is that there is a significant difference in the reaction to this question between companies that prepare the annual accounts internally and companies that have their accountant draw up the annual accounts. When the annual accounts are prepared by company employees, the additional costs of complying with the new disclosure

regulations are not very apparent. Companies that hire an accountant are directly confronted with the extra costs if these are reflected in increased fees. Of the latter group, $80 \%$ feel that costs have risen while of the former group only $25 \%$ thinks so 
(using a chi-square test, the hypothesis that there is no difference between the answers of both groups, can be rejected at $\alpha=0.01$ ). In the next sections a closer look will be taken at the costs of producing annual accounts. Attention will be given to production costs as measured by the number of hours spent on accounting within the firm and by the level of fees paid to external accountants. Since the primary interest is in the effect that regulation had on these various cost-categories, the results only concern private companies.

\subsubsection{Quantitative analysis}

\subsubsection{Information production costs}

To study the relationship between accounting costs and financial reporting regulation, companies were asked to state the number of hours spent on accounting over a period of five years (1983 - 1987). The results (see table 4.22) clearly show a steady rise in the time spent on accounting since 1983, ranging from 96.5 hours in 1983 to 107.3 hours in 1987. To study the effect of accounting regulation, our focus here will be on the differences between two consecutive years. A Friedman two-way analysis of variance by rank indicates that the hypothesis that the hours spent in each year between 1983 through 1987 came from the same population, can be rejected with $\alpha=0.01$. The cost increase between 1983 and 1984 was statistically significant, indicating that the new regulation actually did lead to extra working hours in accounting. Using a Wilcoxon signed rank test, the hypothesis that the hours spent on accounting in two consecutive years came from the same population could only be rejected for the years $1983 / 1984$ and $1985 / 1986(\alpha=0.01)$.

Table 4.22. Accounting costs

\begin{tabular}{lclll}
\hline Year & $\begin{array}{c}\text { Hours } \\
(\mathrm{N}=28)\end{array}$ & z-score $^{\prime}$ & $\begin{array}{c}\text { Accountants } \\
(\mathrm{N}=35)\end{array}$ & z-score $^{\prime}$ \\
\hline 1983 & 96.5 & & f. 7,572 & \\
1984 & 100.7 & $2.680^{*}$ & f. 9,019 & $2.936^{*}$ \\
1985 & 101.9 & 1.063 & f. 9,103 & 0.435 \\
1986 & 106.0 & $2.971^{*}$ & f. 9,565 & 1.138 \\
1987 & 107.3 & 1.473 & f. 10,144 & 0.937 \\
\hline
\end{tabular}

* significant at the 0.01 level

${ }^{1} \mathrm{z}$-scores based on Wilcoxon signed rank tests, testing for the difference in costs compared with the previous year

Rather surprisingly, there is no statistical difference in the amount of time spent on accounting between companies that prepare their own accounts and companies that hire an accountant to do so. The latter group is likely to spend less time internally on accounting. The internal accounting costs may be unaffected if the external accountant 
is hired primarily to audit the accounts or for some other reason like tax-consultation. In our case, auditing does not seem to be a plausible explanation since there is no mandatory audit for small Dutch companies. However, the results found here are consistent with the findings of the study by Nair and Rittenberg [1983, p. 243], where the conclusion from the analysis of personnel costs is also that "it cannot be argued that the smaller businesses may be paying to outside CPAs for work done by internal accountants in larger businesses". Neither their study nor the questionnaire used in our study contained any questions that could provide a suitable explanation for this result.

Regarding the relationship between accounting costs and firm size, the data indicate that the size of the company does have an effect on the time spent on accounting. Firstly, the relationship between internal accounting costs and firm size is positive, indicating that larger firms have higher costs. The relationships between the number of hours spent on accounting and firm size can be illustrated by the following estimated OLS-equation which is based on data from 1986 and 1987:

$$
\begin{array}{lll}
\text { HOURS }= & \begin{array}{l}
71.16+0.0238 \times \text { SIZE }(\text { assets } \times f 1000,-) \\
\left(\mathrm{t}=1.933^{*}\right) \quad\left(\mathrm{t}=2.656^{* *}\right)
\end{array} & \begin{array}{l}
\mathrm{R}^{2}=0.21 \\
\mathrm{~F}=7.05^{* *}
\end{array}
\end{array}
$$

The height of the intercept in the equation indicates that a large part of the internal accounting costs are fixed costs, not varying with the size of the firm. Therefore, smaller firms may bear relatively higher costs since they must spread these fixed costs over fewer revenues. Using a Pearson correlation test, the hypothesis that there is no correlation between firm size and internal accounting costs as a part of total assets, can be rejected with $\alpha=0.09$. The negative correlation $(-0.238)$ between both variables indicates that the internal accounting costs do make up a larger part of total assets for small firms. This would imply that smaller companies pay proportionally higher accounting cost.

The results presented in this section should be interpreted with care. Firstly, the time spent on accounting may be affected by other factors like the introduction of computers to perform accounting tasks, leading to a reduction in the number of man-hours. Secondly, as mentioned earlier, the hours spent on accounting by employees may not be clear to management, so that the estimates of the respondents may be rather rough. Furthermore, the correlation-test performed is rather indirect since production costs are substituted by the hours spent on accounting and total assets are used as an estimate of , total costs. A more straightforward test can be performed using accountants' fees, as will be shown in the next section. 


\subsubsection{Accountants' fees}

The private companies questioned were asked to state the annual amount paid to an external accountant from 1983 to 1987 . From 1983 on, the average fee annually paid to the accountant gradually has risen from $f 7,500$ in 1983 to over $f 10,000$ in 1987 (table 4.22$)^{24}$. A Friedman two-way analysis of variance by rank indicates that the hypothesis that the costs spent in each year between 1983 through 1987 came from the same population, can be rejected with $\alpha=0.001$. The effect of the change in regulation in 1984 can be shown by the fact that only the cost-increase in 1984 is significant from a statistical point of view. Using a Wilcoxon signed rank test, the hypothesis that the costs spent on accounting in two consecutive years came from the same population can be rejected only for the years 1983 and $1984(\alpha=0.002)$. The rise in costs in all other years turned out to be statistically insignificant.

In 1984, there was an absolute increase in the amount paid to the external accountant of $19 \%$. This compares to increases of 1 to $6 \%$ in succeeding years. As mentioned earlier, the same results, although less distinct, were found regarding the hours spent internally on accounting so that there is evidence that the change in regulation had a cost-effect on small companies. This can be further emphasized by the fact that neither the hours nor the costs reported in the questionnaire, may be fully related to complying with financial reporting requirements. A part of the accounting-time would have been be spent on gathering and processing other information, for example for internal purposes. Also, although the Carsberg study mentioned earlier indicated that accountants spend most of their time on the preparation of the accounts, some time is also spent on fiscal computations and advice. So the increase in costs specifically concerned with financial accounting might be even more explicit than the figures in this section suggest $^{25}$.

Looking at the size of the companies, large companies pay higher fees to their accountant. As indicated in the previous section, the amount of accounting data to be assembled and processed increases with the size of the company and the work that an accountant has to do increases accordingly. The relationship between accountants' fees and firm size can be described by the following estimated OLS-equation:

$$
\begin{array}{lll}
\text { FEE }= & \begin{array}{l}
5,427+3.562 \\
\left(\mathrm{t}=5.711^{* * *}\right)
\end{array} \underset{\left(\mathrm{t}=3.262^{* * *}\right)}{\operatorname{SIZE}(\text { assets } \times f 1000,-)} & \mathrm{R}^{2}=0.25 \\
& \mathrm{~F}=10.6^{* * *}
\end{array}
$$

${ }^{24}$ A recent study has indicated that the total accounting costs (internal as well as accountants' fees) associated with administrative obligations in 1993 average at $f 21,000$ for small and medium-sized companies. On average $29 \%$ of these costs $(f 6,100)$ were spent on preparing and disclosing the annual accounts [EIM, 1994, pp. 26-27].

${ }^{25}$ The EIM-study among small and medium-sized companies indicated that the accounting costs associated with preparing and disclosing the annual accounts could be reduced by $40 \%$ if current financial reporting regulations were to be abolished [EIM, 1994, p. 32]. 
The height of the intercept in the equation indicates that a large part of the accountants' fees are fixed costs, not varying with the size of the firm. Therefore, smaller firms may bear relatively higher costs since they must spread these fixed costs over fewer revenues.

Our second interest is whether these costs are proportionately higher as size increases. Therefore the ratio between accountants' fees paid and firm size is to be studied. Three measures of firm size are used: total sales, total assets and number of employees. The results indicate an inverted relation between firm size and a ratio between accountants' fees and sales, company assets and number of employees. Using a series of Spearmancorrelation tests, all correlations are negative, indicating that the ratios decline as size increases (table 4.23$)^{26}$.

Table 4.23. Correlation between cost ratios and firm size (all z-scores are significant at the 0.01 level).

\begin{tabular}{llcc}
\hline Variables & N & Correlation & z-score \\
\hline Ratio of accountants' fees to sales, with sales & 32 & -0.800 & -4.455 \\
$\begin{array}{l}\text { Ratio of accountants' fees to total assets, } \\
\text { with total assets }\end{array}$ & 34 & -0.685 & -3.935 \\
$\begin{array}{l}\text { Ratio of accountants' fees to number of } \\
\text { employees, with number of employees }\end{array}$ & 33 & -0.654 & -3.697 \\
\hline
\end{tabular}

An alternative way to demonstrate the relation between accountants' fees and firm size is to split the sample of companies into 4 categories based on sales (table 4.24). Accounting costs as a percentage of total assets are about 4 to 5 times as high for small companies with sales under $f 1,000,000$ compared to companies with sales over $f 10,000,000$. When related to company sales, relative costs for small companies are 10 times as high.

Nair and Rittenberg [1983] also studied the relationship between firm size and accountants' fees, studying firms that, in the classification used in this study, could be defined as medium-sized companies. Their results also show proportionately higher accounting costs for smaller firms, ranging from $0.33 \%$ of sales for smaller companies to $0.15 \%$ for larger companies. A Dutch study among medium-sized firms provides essentially the same results [NOvAA, 1991a, p. 36]. Accountants' fees relative to sales declined gradually with increasing firm size ranging from $0.054 \%$ for firms with sales under $f 10,000,000$ to $0.047 \%$ for firms with sales over $f 100,000,000$. The results of

\footnotetext{
${ }^{26}$ If fees were constant for all firm sizes, the correlation between (1) the ratio of fees paid to sales and (2) sales would still be positive because sales is in both variables. However, since the ratio between fees and sales is positive, the disproportional rise of fees paid as firm size decreases is still clear. Nevertheless, the z-scores and significance of the correlations found should be interpreted with care.
} 
this particular study, however, have to be interpreted with great care as the study suffered from a low response rate. Bak et al. [1985] also investigated accountants' fees in relation to company size, but their sample contained firms that were much larger. For companies with sales less than $f 100,000,000$ they found that the cost of an external accountant related to company sales were $0.17 \%$, a figure that decreases to $0.04 \%$ for companies with sales over $f 5,000,000,000$. For all size-categories, accountants' fees make up only a small percentage of the total cost of the firm, although there has been a rise over the period $1983-1987$ from $1.7 \%$ to $2.3 \%$ when related to total assets.

Table 4.24. Accountants' fees broken down by firm size.

\begin{tabular}{|c|c|c|c|}
\hline Category & $\begin{array}{l}\text { Accountants' } \\
\text { fees as part of } \\
\text { sales }\end{array}$ & $\begin{array}{l}\text { Cost as part of } \\
\text { total assets }\end{array}$ & $\mathrm{N}$ \\
\hline \multicolumn{4}{|l|}{ This study } \\
\hline $\begin{array}{l}\text { Sales } \leq f 1,000,000 \\
f 1,000,000<\text { Sales } \leq f 2,000,000 \\
f 2,000,000<\text { Sales } \leq f 5,000,000 \\
f 5,000,000<\text { Sales }\end{array}$ & $\begin{array}{l}0.01347 \\
0.00720 \\
0.00527 \\
0.00104\end{array}$ & $\begin{array}{l}0.02794 \\
0.01375 \\
0.01273 \\
0.00663\end{array}$ & $\begin{array}{l}7 \\
9 \\
10 \\
6\end{array}$ \\
\hline \multicolumn{4}{|l|}{ Nair and Rittenberg [1983]. p. 241} \\
\hline $\begin{array}{l}\text { Sales } \leq \$ 8,300,000 \\
\$ 8,300,000<\text { Sales }<\$ 19,800,000 \\
\$ 19,800,000<\text { Sales } \leq \text { fl. } 100,000,000\end{array}$ & $\begin{array}{l}0.0033 \\
0.0017 \\
0.0015\end{array}$ & $\overline{-}$ & $\begin{array}{l}18 \\
19 \\
18\end{array}$ \\
\hline \multicolumn{4}{|l|}{ Bak et al. [1985], p. 34} \\
\hline $\begin{array}{l}\text { Sales } \leq f 100,000,000 \\
f 100,000,000<\text { Sales } \leq f 1,000,000,000 \\
f 1,000,000,000<\text { Sales } \leq f 5,000,000,000 \\
f 5,000,000,000<\text { Sales }\end{array}$ & $\begin{array}{l}0.00170 \\
0.00177 \\
0.00061 \\
0.00040\end{array}$ & $\begin{array}{l}- \\
- \\
-\end{array}$ & $\begin{array}{l}- \\
- \\
-\end{array}$ \\
\hline
\end{tabular}

\subsubsection{Cross analysis of cost data}

In this section, the cost-data used in the previous section will be further analyzed in two ways:

1. the cost data will be related to firm-characteristics that are expected to result in differences in accounting costs between firms;

2. the cost data will be related to the characteristics and perceptions of respondents.

This analysis is conducted in order to test the reliability of the cost data provided by the respondents. Firm characteristics that are expected to result in differences in accounting costs between firms are used to test whether cost estimates do vary between firms when expected. For example the hiring of an external accountant to prepare the financial 
statements should result in higher accountants' fees compared to firms that prepare the financial statements internally.

Respondents characteristics and respondent perceptions should not systematically influence the cost data provided by respondents. Therefore the data used in the perception study (section 4.4) will be related to the cost data used in this section to test the effect of respondents characteristics and perceptions on the cost data provided. A summary of the results of the analysis is presented in table 4.25 .

Table 4.25. Analysis of accounting costs

\begin{tabular}{cc}
$\begin{array}{c}\text { Hours } \\
\text { (average }\end{array}$ & $\begin{array}{c}\text { Fee } \\
\text { (average } \\
83-87)\end{array}$ \\
\hline
\end{tabular}

\section{Firm characteristics}

The financial statements are prepared by the external accountant

Voluntary disclosure of financial statements prior to 1984

Voluntary disclosures in financial statements after 1984

\section{Respondent characteristics}

Respondent is an external accountant

Respondent is directly involved with financial reporting

of the firm

\section{Respondent perceptions}

Accounting regulation is redundant

The table presents z-scores based on Mann-Whitney U tests

Significance levels are indicated by * for $\alpha=0.1$ and ** for $\alpha=0.05$

Some brief comments:

1. Of the private companies questioned, $80 \%$ hired an accountant to prepare the annual accounts. As expected, the height of the accountants' fee paid is influenced by whether an accountant is hired to prepare the accounts: companies that prepare the financial statements internally, on average pay lower fees. Using a Mann-Whitney U test, the hypothesis that companies that hire an accountant to prepare their accounts pay the same amount to their accountant as do companies that prepare their own accounts, can be rejected with $\alpha=0.05^{27}$.

2. Firms that voluntarily disclose information not specifically required by company law have slightly higher internal accounting costs. The difference is significant with $\alpha=0.1$.

${ }^{n}$ The differences between the accountants' fees paid by both groups of companies range from $10 \%$ in 1983 to $13 \%$ in 1987 . 
3. Respondents that are actively involved in the process of financial reporting of the firm present higher estimates of the internal accounting costs. This result may be explained from the premise that these respondents have better knowledge of the internal accounting procedures of the firm and consequently are in a better position to make an estimate of the costs associated with these procedures.

4. Respondents who find that financial reporting regulation is redundant present slightly higher estimates of internal accounting costs. The difference is significant with $\alpha=0.1$.

In general there seems to be little reason for concern for bias regarding the cost estimates presented by respondents. Estimates of the fees paid to the external accountant generally vary with firm characteristics as expected and do not systematically vary with respondent characteristics or respondent perceptions. However, the estimates of internal accounting costs should be interpreted with care since there are some correlations to be found with respondents characteristics and perceptions and the estimates of the number of hours spent on accounting within the firm. As mentioned before, the number of hours spent on accounting may not be very clear to the management, so that the estimates of the respondents at this point may be rather rough.

\subsubsection{Concluding remarks}

In this section evidence was provided on (1) the cost-effect of the 1984 change in Dutch financial accounting regulation and (2) the relationship between accounting costs and firm size. The first conclusion that can be drawn from the research presented is that the change in Dutch accounting regulation that became effective in 1984 did have a significant effect on the costs of small private companies, associated with complying to these regulations. This result was found for the number of hours spent on accounting inside the firm as well as the amount paid to hire an external accountant. Also, small firms pay proportionately higher accounting costs, ranging from $1.3 \%$ of sales for smaller firms to $0.1 \%$ for larger firms in the sample. Combining these results with studies of Nair and Rittenberg [1983] among medium-sized firms and Bak et al. [1985] with large firms, small firms seem to pay substantially larger relative accounting costs compared to large firms. However, even for the smallest firms, accounting costs only make up a small fraction of the total company costs. So, from an economic point of view, there is little reason for these companies to worry much about financial accounting ${ }^{28}$.

${ }^{28}$ However, given the large number of small and medium-sized firms, the total societal costs of financial reporting are substantial. The total costs associated with financial reporting by Dutch firms are estimated at $f 2.3 \mathrm{bn}$. The total compliance costs associated with current financial reporting regulation in the Netherlands for 1993 is estimated at $f 1.55$ bn [EIM, 1994, p. 32]. 
From the results of the research presented here, it can not be determined whether small firms pay disproportionately higher accounting costs compared to large firms. Although the existence of a cost effect can be shown, it is not clear from our study what the costeffects for large firms were. Also, our study did not include all accounting costs for small firms, although the costs studied here are assumed to be the most important costcategories for small firms. However, comparing our results to existing research it seems clear that even with the current exemptions for small firms, accounting costs are relatively higher for small firms (e.g. Nair and Rittenberg [1983], Carsberg et al. [1985] and Brock and Evans [1986]).

Also, it can not be concluded from our study why accounting costs are proportionately higher for smaller firms. It may be that the less extensive use of computers performing accounting tasks, the less skilled accounting personnel within small firms or the lack of adequate accounting procedures that leads to more hours spent on accounting by personnel or to more work for an external accountant, resulting in higher fees. Also, higher accountants' fees may result from characteristics of the external accountant or the accountants' firms hired by small companies. The research available, however, has indicated that annual fees paid are higher for smaller firms, regardless of the type of external accountant [Nair and Rittenberg, 1983].

\subsection{Some final remarks.}

In this chapter, evidence has been provided on the perceptions of small firm managers towards financial reporting in general and the impact of financial reporting regulation in particular. Also the costs imposed on small private firms as a result of prevailing financial reporting regulation have been investigated as well as the relationship between accounting costs and firm size.

From the results of this study it is not clear what the benefits derived from the disclosure of annual accounts by small firms are and whether these benefits outweigh the costs of producing this information. The indication that the costs of complying with regulation are proportionately higher for small firms may be considered a finding supporting the idea of lessening the regulatory burden for small firms. However, to fully capture the cost effect of the exemptions provided to small firms, compliance costs of medium-sized and large firms that have less or no exemptions have to be considered. Available Dutch research on compliance costs for medium-sized and large firms seems to indicate that the negative correlation between accountants' fees per unit of sales and firm size is consistent for firms of all sizes [NOvAA, 1991a, Bak et al. 1985]. These results indicate that the effect of the exemptions currently provided for small Dutch firms in reducing compliance costs for these firms is limited as compliance costs are still proportionally higher for small firms. Nevertheless, compliance costs for firms are only one aspect of interest, since the costs of alternative methods of generating accounting information should be considered and the benefits of accounting information should be clear. Therefore, in the next chapter the focus will be on the usefulness of annual reports of medium-sized firms to the primary external users, i.e. loan officers. 


\section{Chapter

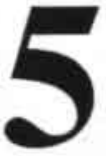 \\ The Usefulness of Medium-Sized Companies' \\ Financial Statements to Loan Officers.}

\subsection{Introduction ${ }^{1}$}

In the chapters 3 and 4 the focus was on the supply side of the financial reporting environment, studying the informational characteristics of annual reports disclosed by small firms (chapter 3) and the perceptions of small firm managers on financial reporting issues, as well as the direct costs of complying with current financial reporting regulations (chapter 4). As was mentioned there, the issues discussed in these studies provide a one-sided view on the issue of financial reporting of smaller firms, as groups on the demand side for financial accounting information are ignored. To construct a more complete characterisation of the financial reporting environment of smaller firms, the potential and actual benefits of financial reporting have to be considered. Therefore, in this chapter the focus will shift to the demand side of the financial reporting environment, studying the use of financial accounting information by bank loan officers dealing with medium-sized firms.

In order to establish the usefulness of financial statements to loan officers dealing with non-large firms, various issues are of particular importance:

1. To what extent do loan officers depend on financial statements to obtain accounting information from smaller firms? Is it true, as has been argued in chapter 2, that bankers have a close relationship with these firms, have detailed knowledge of the smaller firms they are dealing with and have substantial power to obtain any accounting information desired, thereby leaving little significance to the role of financial statements? Or is it true that loan officers are more dependent on the financial statements of smaller firms because for these firms fewer alternative sources of financial information (e.g. press reports, reports of financial analysts) are available? (see chapter 2 for a detailed discussion of these arguments)

\footnotetext{
${ }^{1}$ The research presented in this chapter, was initiated and financed by the 'Nederlandse Orde van Accountants-Administratieconsulenten' (NOvAA). The original study was intended to identify the role of financial statements and the role of the external auditor as well as the auditor's report to loan officers dealing with medium-sized firms. The results of the study have been published (in Dutch) by the NOvAA (see NOvAA [1991b]).
} 
2. What are the characteristics of current financial statements of smaller firms in relation to other sources of financial information on these firms? Is the information included in financial statements of smaller firms perceived to be adequate in terms of relevance, reliability, understandability, timeliness and comparability? It has been suggested that the inadequate timeliness of financial reports hinders the use of this information for specific decision making processes (such as credit analysis). Information about the (perceived) characteristics of financial reports may provide evidence on the effectiveness of current financial reporting regulation to ensure adequate financial reporting of small and medium-sized firms.

3. How important are the various elements of which a financial report generally consists in making credit decisions and how is the quality of these elements perceived by loan officers? The results on these issues may provide evidence for (or against) the introduction of differential disclosure regulation, allowing smaller firms to exclude certain elements from the financial report disclosed.

4. Are the information needs of loan officers different when dealing with firms of different sizes? If so, this may support the demand for differential financial reporting requirements for firms of different sizes to ensure adequate financial reporting (e.g. differential measurement of differential recognition).

5. How homogeneous are the perceptions of loan officers on financial reporting of small and medium-sized firms? Evidently, the importance of the results of research on the perceptions of respondents depends on the level of consensus among respondents as strong diverging opinions on financial reporting issues provide ample basis for making generalisations from the results found.

These questions will be investigated empirically in this chapter. The remainder of this chapter consists of a questionnaire-study among Dutch loan officers. First the relationship between this study and existing empirical research will be discussed (section 5.2), followed by a discussion of the research design (section 5.3). The results of the study will be presented and analyzed in section 5.4 , followed by some concluding remarks at the end of this chapter (section 5.5).

\subsection{Relation to existing empirical research.}

The choice of loan officers in this study on the usefulness of accounting information from smaller firms, results from the general assumption that, after the owner/manager, banks are the second most frequent users of small private firms' financial reports (e.g. Abdel-Khalik, 1983, Page 1984, Carsberg, 1985 and chapter 4 of this dissertation). Since smaller or private firms are not active on a securities market, the primary source of outside capital and consequently the primary external users of the financial statements would be bankers.

Studies among users of accounting information addressing one or several of the issues mentioned in section 5.1, have been discussed in chapter 2. Major issues concerning the small firm context addressed there are (1) the differential information needs of users 
depending on the size of the disclosing firm (e.g. Stanga and Tiller [1983], Berry Citron and Jarvis [1987], Morris and Omrod [1990]), (2) a comparison of differences in information needs of different user groups dealing with small firms (e.g. Benjamin and Stanga [1977], Firth [1978], McCaslin and Stanga [1986]), (3) the effect of an audit on the usefulness of the annual report (e.g. Falk et al. [1976], Baker [1990]), and (4) failure prediction and firm size (e.g. Keasey and Watson [1986a, 1986b, 1987, 1988]). Dutch studies in this area are scarce and deal exclusively with financial reporting by large public firms (e.g. Klaassen and Schreuder [1980]). Studies on the usefulness of financial statements of medium-sized firms have, to our knowledge, not been published before.

The primary reason to focus the research on medium-sized companies results from the presumed role of bankers in smaller firms. Since smaller private firms are less able to obtain additional capital from investors (i.e. the securities market), these firms may be more dependent on raising loans from banks to finance their operations. Given the relatively high risk for banks to deal with small private firms, bankers may place high emphasis on adequate financial reporting requirements to monitor the performance of the firm and to protect their investments. From this, the position of bankers as primary users of small firm financial statements can be hypothesised. The initial concern of the research project presented in this chapter was directed towards the role of accountants and the accountants' report in medium-sized companies. The emphasis on medium-sized companies was motivated by the fact that Dutch company law had permitted the 'smaller' medium-sized firms ${ }^{2}$ to reftrain from an audit for a period of five years after the enactment of the Law in 1984. This temporary exemption had thus ended by 1989 , which made it an opportune moment to study the perceptions of the firms concerned as well as the primary users of medium-sized company financial statements on the importance of a mandatory audit as well as financial reporting in general for 'smaller medium-sized' firms.

Therefore, the research presented here will focus on the role of accounting information in lending agreements between banks and medium-sized companies. The focus on medium-sized firms was also chosen on the premise that within these firms there is substantial separation of ownership and control, making the use of alternative means of securing a loan (e.g. personal liability of the owner-manager) less suitable. Also, it is assumed that these firms are large enough to have a non-trivial amount of long term debt so that bankers will have incentives to monitor the activities of these firms over a longer period of time.

\footnotetext{
${ }^{2}$ The exemptions applied to medium-sized companies with issued capital under $f 500,000$.-, or total assets under $f 8,000,000$.- or fewer than 100 employees, stalling the compulsory audit for these firms till 1989 [Beckman, 1988, p. 165].
} 


\subsection{Research design}

\subsubsection{Introduction}

The objective of the study presented in this chapter is to provide evidence on (1) information needs of loan officers dealing with medium-sized firms, (2) the importance of financial statements of these firms in relation to other sources of financial accounting information and (3) the adequacy of current financial reports of medium-sized firms to meet the information needs of loan officers.

\subsubsection{Research method}

The empirical data used in the study presented here were gathered using a postal questionnaire that was sent to bank-employees working as loan officers ${ }^{3}$. The forms were sent on April 161990 , accompanied by a guiding letter explaining the purpose of the study and ensuring the anonymity of the respondents and the confidentiality of the information provided. After three weeks (May 10, 1990) a reminder was sent to all the banks selected in the sample. The deadline for questionnaires to be included in the study was set for June 15, 1990.

The questions in the questionnaire were structured using three categories, concerning (1) respondents' characteristics, (2) evaluation of financial accounting information sources and (3) the role of the auditor and the auditor's report. All questions were constructed consistently, typically using a 5-point Likert scale to rank the respondents' agreement with the propositions presented in the question.

\subsubsection{Sample selection}

In the Netherlands, some 20 different banks are active at least at a regional level. These banks have, apart from a very large number of branches, over 1600 independent administrative offices. The research constructed here has focused on these independent offices thereby avoiding very small offices that would be more likely to deal primarily with very small firms or not to have a credit-agency at all.

From the 1600 independent offices available, a sample of 200 offices was selected from the address-files of the 'Nederlandse Bankcentrale'. The sample was selected randomly, subject only to the condition of an even geographical spread.

${ }^{3}$ The questionnaire used, which is in Dutch, is available from the author. 


\subsubsection{Response analysis}

Of the 200 questionnaires posted, 92 were returned. Of these, 12 were not filled out because of an incorrect address. This reduces the effective sample to 188 . The 80 usable responses therefore result in an effective response rate of $43 \%$. These results are in line with response rates of similar studies such as Abdel-Khalik [1983], Benjamin and Stanga [1977], Stanga and Tiller [1983] and Morris and Omrod [1990], that report response rates of $35 \%, 34.6 \%, 57.5 \%$ and $37 \%$.

Table 5.1 Response analysis

\begin{tabular}{lc}
\hline Questionnaires mailed & 200 \\
Returned undelivered & 12 \\
Effective sample size & 188 \\
Number of usable reponses & 80 \\
Response rate & $42.55 \%$ \\
\hline
\end{tabular}

Although any response rate below $100 \%$ presents the problem of non-response bias, no formal tests on nonreponse bias were conducted. The database from which the banks were selected presented no suitable characteristics of the banks selected to conduct such tests. Consequently, no formal statement on the representativeness of the respondents can be given. However, both the size of the initial sample and the response rate provide no reason to doubt the representativeness of the responses gathered. Nevertheless, it should be noted that generalisations beyond the data actually gathered cannot be made with complete assurance.

\subsubsection{Respondents' characteristics}

Characteristics of respondents were gathered regarding their age, the level of experience as a loan officer, the level of education, and the familiarity with using financial statements. Summary data with regard to the respondents' age and working experience are presented in table 5.2. The respondents on average have a relatively high level of education, as $87.5 \%$ had at least had training at the higher vocational-level, of whom $35 \%$ had an academic degree. Also, $62.5 \%$ of the respondents had training in business administration or economics ${ }^{4}$.

Relating the various characteristics to each other shows that respondents with a relatively low level of education are more experienced and also are slightly older (see table 5.3). Evidently, the respondents' age and level of experience are also highly positively correlated. Finally, virtually all respondents are adequately familiar with financial

\footnotetext{
${ }^{4}$ These findings indicate that the respondents to the loan officers-study have a higher level of education compared to the respondent from the small firm managers' survey presented in the previous chapter (see section 4.3.5.2).
} 
reports. Over $96 \%$ indicated that they analyzed over 10 annual reports per year, while $98.5 \%$ analyses at least 5 annual reports per year.

Table 5.2 Respondents' characteristics.

\begin{tabular}{lcccc}
\hline $\mathrm{N}=80$ & Average & $\begin{array}{l}\text { Standard } \\
\text { deviation }\end{array}$ & Minimum & Maximum \\
\hline $\begin{array}{l}\text { Age (in years) } \\
\begin{array}{l}\text { Experience } \\
\text { (in years) }\end{array}\end{array}$ & 38.4 & 7.63 & 25 & 60 \\
\hline
\end{tabular}

Table 5.3 Breakdown of respondents' characteristics

\begin{tabular}{lrrr}
\hline Educational level & N & Experience & Age \\
\hline Secondary & 8 & 19.3 & 42.0 \\
Higher vocational & 5 & 12.7 & 37.7 \\
Higher vocational - buss. adm. & 37 & 12.2 & 40.0 \\
Academic & 15 & 10.1 & 35.8 \\
Academic - Economics & 13 & 12.6 & 39.2 \\
Other & 2 & 23.5 & 48.0 \\
Total & 80 & 13.0 & 38.4 \\
\hline
\end{tabular}

\subsection{Perceptions of loan officers on financial reporting issues}

\subsubsection{Introduction}

The remainder of this chapter consists of a presentation of the results of the questionnaire study. Section 5.4.2 addresses the use and importance of various sources of accounting information to loan officers, and section 5.4.3 focuses on the importance of various elements of the financial statements. Section 5.4.4 discusses the relationship between the information needs of loan officers and the size of the firm they are dealing with. The final section (section 5.4.5) presents a comparison of the results of our study with existing empirical studies on the usefulness of accounting information to loan officers dealing with smaller firms.

\subsubsection{Sources of financial accounting information}

The first set of questions in the questionnaire concerned the sources of financial accounting information used by loan officers. To assess the diversity of available sources of information about medium-sized firms and the value of the information supplied through those sources to loan officers, respondents were asked what sources of 
information were used either to get a general picture of a firm's financial situation or to use as an input for a loan decision (table 5.4, panel A). The results indicate that loan officers use a fairly broad set of information sources when dealing with medium-sized firms. This implies that the financial statements of these companies, however important they may be, are not the sole source of accounting information available to loan officers. A number of other sources provide information that is typically used (or useful) for a more general orientation on a firm's financial position (e.g. press articles and industry data).

The indication of most respondents that, in addition to the sources explicitly mentioned in the questionnaire, still other sources of information are used (though mostly for a general orientation) may stress the importance of less formal sources of information such as past experience with the subject company or direct contact with the company's managers. This observation would be in line with other studies concerning loan officers of banks dealing with small and medium-sized firms (e.g. Berry, Citron and Jarvis [1987] and Morris and Omrod [1990]).

In fact, the Morris and Omrod study shows that past experience with the subject company is ranked as the second most important source of information by credit managers dealing with small or medium-sized firms (after the annual report), although the dispersion of scores for this item was quite wide and some respondents did not rate past experience as being an important source of information at all [Morris and Omrod, 1990, pp. 14-16]. Berry, Citron and Jarvis [1987] found that information from personal interviews with representatives of a company and visits to the company's premises were indicated as very important sources of information for loan officers when dealing with small firms.

When faced with a specific loan decision, the financial statements of the subject firm are clearly the most prevalent used source of information. Over $80 \%$ of the respondents indicate that the financial statements are a very important source of information in making loan decisions and the financial statements are on average ranked first in importance of the various sources of information available (see table 5.4, panel A). With an average score of 4.7 (on a scale from 1 to 5 ) annual reports are the single most important source of accounting information used in credit decisions, followed by interim reports (score 3.9) and industry-data (score 3.5). A series of Wilcoxon signed rank tests indicates that the annual reports are significantly more important than any other source of accounting information (table 5.4, panel B and table 5.6). 
Panel A.

\begin{tabular}{|c|c|c|c|c|c|c|c|}
\hline & $\begin{array}{l}\text { Not } \\
\text { used }\end{array}$ & $\begin{array}{c}\text { Usage } \\
\text { General } \\
\text { orientation }\end{array}$ & $\begin{array}{l}\text { Specific } \\
\text { decision }\end{array}$ & Average & $\begin{array}{l}\text { ortance } \\
\text { St.dev. }\end{array}$ & Rank & $\begin{array}{r}\text { Rank } \\
\text { correl. }\end{array}$ \\
\hline Press-articles & 10 & 68 & 2 & 2.45 & 1.02 & 7 & $0.32^{*+*}$ \\
\hline Financial statements & 2 & 2 & 76 & 4.73 & 0.71 & 1 & $0.29 * * *$ \\
\hline Interim reports & 5 & 15 & 60 & 3.94 & 1,02 & 2 & $0.24^{*+}$ \\
\hline Bank-information & is & 22 & 43 & 3.10 & 1.32 & 4 & $0.42+\cdots *$ \\
\hline Reporis of financial analysis & 18 & 33 & 29 & 2.96 & 1.28 & 5 & $0.63=* *$ \\
\hline Indusiry-daca & 4 & 48 & 28 & 3.54 & 0.94 & 3 & 0.04 \\
\hline Other sources & 18 & 50 & 12 & 2.53 & 1.15 & 6 & $0.24 * \star$ \\
\hline
\end{tabular}

\section{Panel B.}

参

\begin{tabular}{|c|c|c|c|c|c|c|c|}
\hline A & Press articles & & & & & & \\
\hline B & Financial stalements & $7.22^{+++}$ & & & & & \\
\hline C & Interim reports & $6.81 * 6 *$ & $5.78^{*+*}$ & & & & \\
\hline D & Bank information & $3.55^{* * *}$ & $6.00 \div 4+$ & $3.90 * * *$ & & & \\
\hline $\mathrm{B}$ & Repors of financial analysts & $3.39^{4 * *}$ & $6.47 * * 4$ & $4.74 * 6 *$ & 0.54 & & \\
\hline $\mathrm{P}$ & Indusiry daia & $5.50^{* * *}$ & $6.19 * * *$ & $3.01 * * *$ & $1.97^{* 4}$ & $2.76 * * *$ & \\
\hline G & Other sources & 0.38 & $6.77 * * *$ & $6.08 * * *$ & $2.23 * *$ & $2.62 * \mathrm{k*}$ & $4.47^{*+*}$ \\
\hline \multicolumn{2}{|c|}{ Wilcoxon signed rank lests ( $z$-scores) } & A & B & C & D & B & $\mathrm{F}$ \\
\hline
\end{tabular}

Kendall coefficienl of concordance: $W=0.4604(p=0.000)$ 


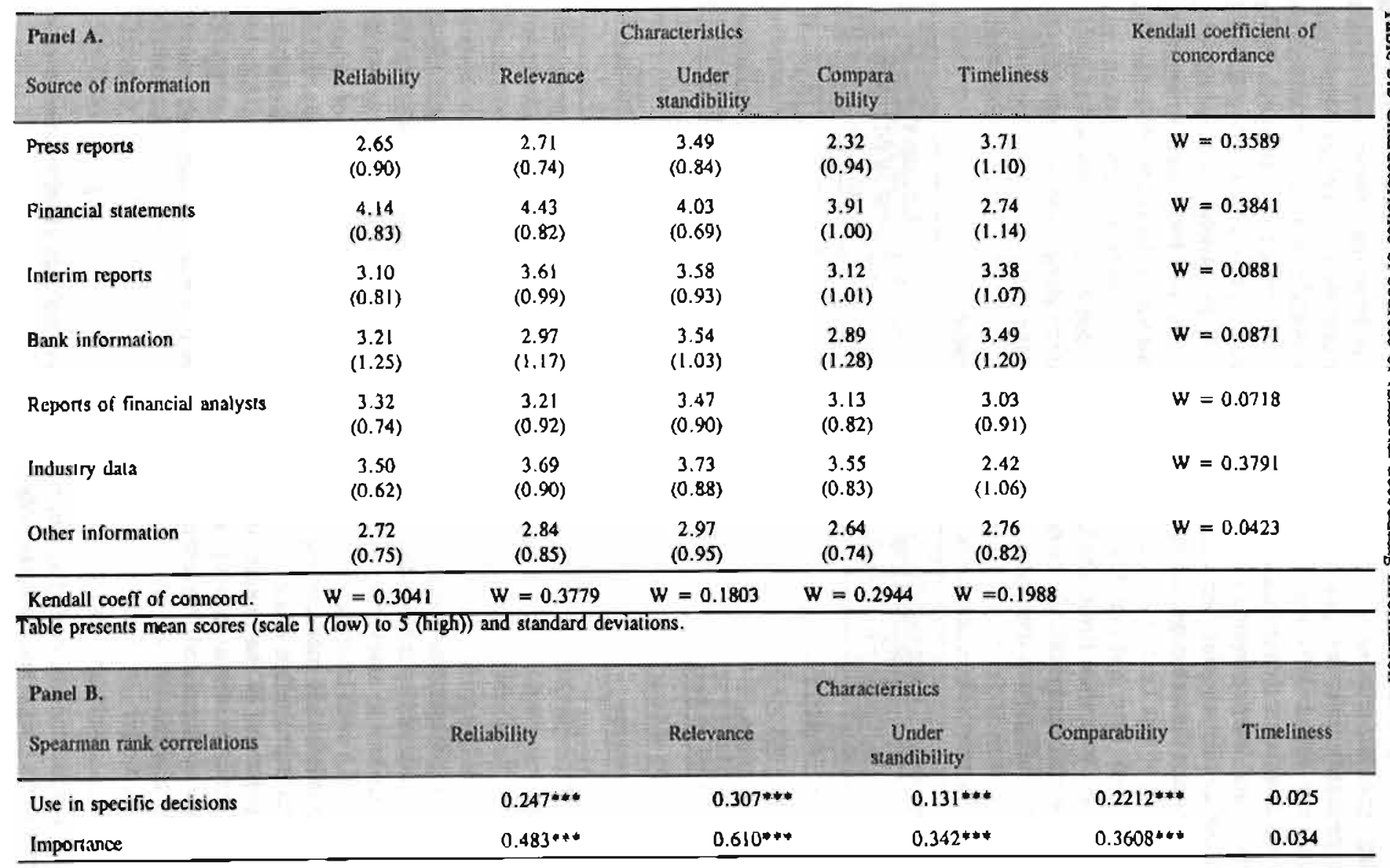


The perceived importance of an information-source is strongly related to its usefulness in making specific decisions (i.e. credit analysis) in the sense that information sources that are primarily used for general orientation, are perceived to be less important. Spearman rank- correlation coefficients for the usefulness and importance of information sources are positive and significant at the 0.01 level, except for the categories 'other information' and Interim reports for which the correlation is significant only at the 0.05 level and for the industry data for which the correlation is extremely low (see table 5.4, panel A). It seems that although industry data are primarily used for general orientation, the importance of this kind of information is still perceived to be relatively high. The results presented here indicate that although various sources of information may available on medium-sized firms, the information provided by most sources is not very well suited for making specific decisions and detailed information used in credit analysis is primarily available from the financial statements of the company.

Table 5.6 Importance of sources of financial accounting information

\begin{tabular}{|l|l|c|c|}
\hline Rank & Information source & Mean score & $\begin{array}{c}\text { Wilcoxon signed rank } \\
\text { test for difference of } \\
\text { mean-scores (z-score) }\end{array}$ \\
\hline 1 & Financial statements & 4.73 & $5.78^{* * *}$ \\
\hline 2 & Interim reports & 3.94 & $3.01^{* * *}$ \\
\hline 3 & Industry-data & 3.54 & $1.97 * *$ \\
\hline 4 & Bank information & 3.10 & 0.54 \\
\hline 5 & Reports of financial analysts & 2.96 & $2.62^{* * *}$ \\
\hline 6 & Other sources & 2.53 & 0.38 \\
\hline 7 & Press reports & 2.45 & \\
\hline
\end{tabular}

Significance levels are indicated as:

* significant with $\alpha=0.10$;** significant with $\alpha=0.05$; *** significant with $\alpha=0.01$.

Consensus among respondents on the importance of an individual source of accounting information is indicated by the standard deviations presented in panel A of table 5.4. An alternative procedure to assess the level of consensus among respondents is to use the scores provided for each information source to rank the perceived importance of sources for each respondent and measure the level of consistency of those rankings among respondents. This procedure is used to calculate the Kendall coefficient of concordance statistic (W) presented at the bottom of table 5.4. The score of $0.46^{5}$ that is found is significantly different from zero at the 0.01 level, indicates that the rankings of respondents are not unrelated. Nevertheless, the degree of consensus does not seem to be particularly high.

\footnotetext{
${ }^{5}$ A score of 1 would indicate perfect agreement between the rankings of information sources among respondents [Siegel and Castellan, 1988, pp. 262-272].
} 
The relative importance of accounting information sources may be further assessed by identifying various characteristics. Therefore, respondents were asked to indicate the relative strength of each information source in terms of (1) reliability, (2) relevance, (3) understandability, (4) comparability and (5) timeliness. The results are presented in panel A of table 5.5. The financial statements have the highest score in four of the five criteria. The relevance of the financial statements information ranks particularly high (score 4.4) and also reliability, understandability and comparability rank high with average scores of around 4 . Only in terms of timeliness are financial statements perceived to be inadequate (score 2.7).

The importance of any information source referred to in the first two questions of the questionnaire seems to be particularly related to the relevance of the information provided (see panel B of table 5.5). Also, reliability is highly correlated with importance. The use of an information source in either general orientation or in specific decision making processes is not particularly related to any of the characteristics listed.

These results again stress the importance of the financial statements as a source of accounting information to loan officers. Although there may be other sources available on medium-sized firms, and most of these sources provide more timely information, the financial statements are the primary source of information in specific decision making processes. Alternative sources of information typically lack the necessary reliability. Consequently, financial statements are very frequently used by loan officers and over $96 \%$ of the respondents indicate that they use over 10 annual reports yearly.

\subsubsection{Importance of financial statement elements}

Having established the relative importance of the financial statements compared to other information sources available, the next step is the determine the relative importance of the various elements of the annual report. Since the annual report of a firm includes a number of elements (e.g. director's report, balance-sheet, profit and loss account, notes to the financial statements, auditor's report), containing information on many subjects and presented in various formats, it is of interest to determine the use and importance of each separate element.

Firstly, respondents were asked to indicate the primary use of each of the elements of the annual accounts (see table 5.7, panel A). The results indicate that each element of the annual report contains at least some information that is of importance to loan officers, since few respondents indicate they do not use an item of the annual accounts at all. Also, most elements contain information that is used directly in decision making processes. In this respect the balance sheet, profit and loss account and the notes to the financial statements are most widely used, while the directors' report and the auditor's report contain information more often used for general orientation. 
Panel A

\begin{tabular}{|c|c|c|c|c|c|c|c|}
\hline \multicolumn{4}{|c|}{ Usage } & \multicolumn{3}{|c|}{ Importance } & \multirow{2}{*}{$\begin{array}{l}\text { Rank } \\
\text { correl. }\end{array}$} \\
\hline & $\begin{array}{l}\text { Not } \\
\text { used }\end{array}$ & $\begin{array}{l}\text { General } \\
\text { orientation }\end{array}$ & $\begin{array}{l}\text { Specifte } \\
\text { decision }\end{array}$ & Average & St.dev. & Rank & \\
\hline \multicolumn{2}{|c|}{ Director's report } & 42 & 32 & 3.66 & 1.09 & 6 & $0.51 \cdots$ \\
\hline \multicolumn{2}{|c|}{ Balance sheet } & 4 & 75 & 4.82 & 0.45 & 2 & 0.22 \\
\hline \multicolumn{2}{|c|}{ Profit and loss account } & 3 & 76 & 4.88 & 0.33 & 1 & 0.03 \\
\hline \multicolumn{2}{|c|}{ Notes to the financial statconents } & 10 & 67 & 4.56 & 0.73 & 3 & 0.18 \\
\hline \multicolumn{2}{|c|}{ Auditor's repont } & 24 & 53 & 4.15 & 0.91 & 4 & $0.43^{* \cdots+}$ \\
\hline \multicolumn{2}{|c|}{ Summary of operations } & 34 & 40 & 3.64 & 0.85 & 7 & $0.47 * \cdots$ \\
\hline \multicolumn{2}{|c|}{ Fund flow statement } & 21 & 52 & 3.74 & 1.06 & 5 & $0.65 * n+$ \\
\hline \multicolumn{8}{|c|}{ Panel B. } \\
\hline$A$ & Director's report & & & & & & \\
\hline B & Balance sheel & $6.03+*$ & & & & & \\
\hline $\mathrm{C}$ & Profit and loss account & $6.04 * * *$ & 1.60 & & & & \\
\hline D & Notes to the financial statements & $5.37^{+\infty}+$ & $3.40^{* * 4}$ & $3.62^{*+*}$ & & & \\
\hline $\mathrm{E}$ & Auditor's report & $3.77 * * *$ & $4.67 \cdot 6 *$ & $4.99 * * *$ & $2.76+t *$ & & \\
\hline $\mathbf{P}$ & $\begin{array}{l}\text { Summary of operations over } \\
\text { last 5-10 years }\end{array}$ & 0.06 & $6.45^{* * *}$ & $6.57^{* 0 *}$ & $5.77^{* * *}$ & $3.99 * * *$ & \\
\hline G & Pund flow statement & 0.47 & $5.71^{* 0 *}$ & $5.97 * * *$ & $4.64 * * *$ & 2.76 *** & 1.13 \\
\hline \multicolumn{2}{|c|}{ Wilcoxon signed rank tests (z-scores) } & A & B & c. & D & E & $\mathrm{F}$ \\
\hline
\end{tabular}

Kendal coefficient of concordance: $w=0.4340(p=0.000)$ 
The importance of an element of the annual accounts is positively related to its usefulness in decision making processes (table 5.7, panel A). A series of rank correlations indicates that elements that are read for general orientations are perceived to be less important than elements that are used in specific decision making processes. For making loan decisions, the most important element is perceived to be the profit and loss account (average score 4.88), closely followed by the balance sheet (average score 4.82 ) and the notes to the financial statements (average score of 4.56). For all other elements the scores were lower but even for elements found least important (the historical overview) the average score was still as high as 3.6. These results (see table 5.8) again stress the importance of the financial statements as a source of accounting information to loan officers.

Table 5.8 Importance of elements of financial statements

\begin{tabular}{|l|l|c|c|}
\hline Rank & Information source & Mean score & $\begin{array}{c}\text { Wilcoxon signed rank test } \\
\text { for difference of mean- } \\
\text { scores (z-score) }\end{array}$ \\
\hline 1 & Profit and loss account & 4.88 & 1.60 \\
\hline 2 & Balance sheet & 4.82 & \multirow{2}{*}{$3.40^{* * *}$} \\
\hline 3 & Notes to the financial statements & 4.56 & $2.76 * * *$ \\
\hline 4 & Auditor's report & 4.15 & $2.76^{* * *}$ \\
\hline 5 & Fund flow statement & 3.74 & 1.13 \\
\hline 6 & Director's report & 3.66 & 0.06 \\
\hline 7 & Summary of operations $(5-10 \mathrm{ys})$ & 3.64 & \multicolumn{2}{|c|}{0} \\
\hline
\end{tabular}

Significance levels are indicated as:

* significant with $\alpha=0.10$;** significant with $\alpha=0.05$; *** significant with $\alpha=0.01$.

One other important element in this context is the perceived quality of the information provided in the annual accounts of medium-sized firms. In this respect the outcomes are much less extreme and there is also much less consensus among the respondents. For the balance sheet and the profit and loss account the results are rather positive and none of the respondent found the quality of these elements to be low or very low (see table 5.9). However, most other elements receive less positive qualifications and particularly the director's report is disqualified by a considerable number of respondents. Also the notes to the financial statements seem to leave room for improvement.

Consensus among respondents on the quality of the annual report is not very high. Although the standard deviations indicate considerable agreement on the quality of each separate element, the ranking of elements per respondent, measured by the Kendall's coefficient of concordance, does not seem to be very consistent. 
Panel A.

\begin{tabular}{|c|c|c|c|c|c|c|c|c|}
\hline & $\begin{array}{c}1 \\
\text { (Jow) }\end{array}$ & 2 & 3 & 4 & $\begin{array}{c}\text { Quality } \\
5 \\
\text { (high) }\end{array}$ & Average & St.dey. & Rank \\
\hline Director's report & 5 & 22 & 42 & 7 & 1 & 2.70 & 0.78 & 7 \\
\hline Balance sheer & 0 & 0 & 17 & 53 & 10 & 3.91 & 0.58 & 1 \\
\hline Profit and loss account & 0 & 0 & 18 & 52 & 10 & 3.90 & 0.59 & 2 \\
\hline Notes to the financial statements & 0 & 15 & 27 & 33 & 4 & 3.33 & 0.84 & 5 \\
\hline Auditor's report & 0 & 8 & 30 & 32 & 10 & 3.55 & 0.84 & 3 \\
\hline Summary of operations & 1 & 10 & 39 & 21 & 6 & 3.27 & 0.84 & $\sigma$ \\
\hline Fund flow statement & 0 & 6 & 30 & 37 & 6 & 3.54 & 0.75 & 4 \\
\hline
\end{tabular}

Ponel B.

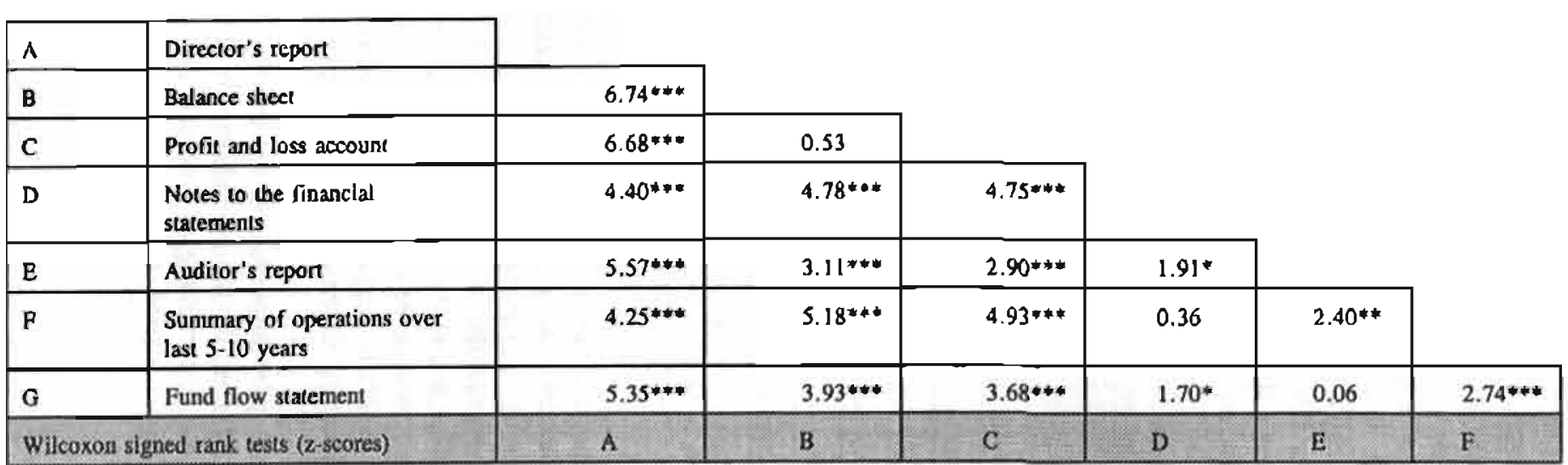

Kendall coefficient of concordance: $W=0.2829(p=0.000)$ 
Table 5.10 Quality of elements of financial statements

\begin{tabular}{|l|l|c|c|}
\hline Rank & Information source & Mean score & $\begin{array}{c}\text { Wilcoxon signed rank } \\
\text { test for difference of } \\
\text { mean-scores ( } z \text {-score) }\end{array}$ \\
\hline 1 & Balance sheet & 3.91 & 0.53 \\
\hline 2 & Profit and loss account & 3.90 & $2.90^{* * *}$ \\
\hline 3 & Auditor's report & 3.55 & 0.06 \\
\hline 4 & Fund flow statement & 3.54 & $1.70^{*}$ \\
\hline 5 & Notes to the financial statements & 3.33 & 0.36 \\
\hline 6 & Summary of operations (5-10 years) & 3.27 & $4.25^{* * *}$ \\
\hline 7 & Director's report & 2.70 & \\
\hline
\end{tabular}

Significance levels are indicated as:

* significant with $\alpha=0.10$; ${ }^{* *}$ significant with $\alpha=0.05$; ${ }^{* * *}$ significant with $\alpha=0.01$.

Respondents put great emphasis on the presence of an audit when dealing with mediumsized firms ${ }^{6}$. Over $80 \%$ of the respondents think the auditor's report is important or very important. Such high emphasis was placed on an audit particularly to ensure the quality of the information provided in the annual report (see table 5.11). Respondents were less convinced that an audit can effectively protect external users of the annual reports. Several other studies have looked at the importance of the auditor's report to loan officers when dealing with firms of smaller size. Falk et al. [1976] find that US loan officers frequently encourage small closely held companies to have audited financial statements. Baker [1990] presented to US loan officers one of the following financial statements: (1) a GAAP-based statement that had been audited, (2) a GAAP-based statement that had been reviewed, (3) an income based statement that had been audited and (4) an income based statement that had been reviewed. Respondents were asked to decide on the approval of a loan, to indicate the interest premium that should be charged and to indicate the understandability, usefulness and reliability of the information provided in the financial statements presented to them. The results show that the presence of an audit instead of a review did not affect the perceived understandability, reliability or usefulness of the financial statements, nor did it change the decisions on the approval of the loan. Respondents on average did charge a higher risk premium $(0.3 \%$ interest $)$ when they received a reviewed annual report. Also, respondents were

- As mentioned before, the study was conducted in 1990. At that time, medium-sized companies were mandated to have their annual reports audited. Before 1989 , such an obligation was part of the company law for all medium-sized and large companies but an exemption had been made for medium-sized firms with issued capital under $f 500,000$.-, or total assets under $f 8,000,000$.- or fewer than 100 employees, stalling the compulsory audit for these firms till 1989 [Beckman, 1988, p. 165]. 
much less confident with audited income tax based financial statements, since they had never seen an audited tax-based financial report.

Table 5.11 The audit of medium-sized firm annual reports

\begin{tabular}{|c|c|c|c|c|c|c|c|}
\hline \multirow{2}{*}{$\begin{array}{l}\text { Question: } \\
\text { The audit of the annual } \\
\text { report of a medium-sized } \\
\text { company is important: }\end{array}$} & \multicolumn{7}{|c|}{ Responses to the statement presented } \\
\hline & $\begin{array}{c}1 \\
\text { dis- } \\
\text { agree }\end{array}$ & 2 & 3 & 4 & $\begin{array}{c}5 \\
\text { agree }\end{array}$ & Average & St.dev. \\
\hline to protect external parties & 4 & 8 & 18 & 25 & 23 & 3.71 & 1.15 \\
\hline $\begin{array}{l}\text { to guarantee the quality of } \\
\text { the information provided }\end{array}$ & 0 & 1 & 4 & 29 & 44 & 4.49 & 0.66 \\
\hline $\begin{array}{l}\text { as a source of information } \\
\text { to company management }\end{array}$ & 4 & 4 & 17 & 27 & 26 & 3.86 & 1.10 \\
\hline $\begin{array}{l}\text { in relation to the fiscal } \\
\text { procedures }\end{array}$ & 3 & 7 & 21 & 29 & 18 & 3.67 & 1.05 \\
\hline to prevent fraud & 4 & 9 & 16 & 27 & 22 & 3.69 & 1.15 \\
\hline $\begin{array}{l}\text { to comply with company } \\
\text { law }\end{array}$ & 13 & 12 & 20 & 16 & 17 & 3.15 & 1.38 \\
\hline
\end{tabular}

\subsubsection{Information needs of loan officers and firm size}

A final essential question is whether the information needs of loan officers vary when dealing with firms of different sizes. Although the questionnaire did not contain detailed questions to analyze this particular problem, respondents were asked whether they felt they would require different information when dealing with small or medium-sized firms than when dealing with large firms. The answers to this questions were rather mixed, as $63 \%$ indicated that the size of the firm they were dealing with would not influence the need of accounting information, while $37 \%$ indicated that firm size was significant for information needs. These results are in line with the Abdel-Khalik study, where it was found that although half the responding loan officers would expect different disclosures from small private firms, only $20 \%$ indicated that they would evaluate loan applications from these firms differently, although there seems to be less reliance on the financial statements on small firms and more use of information obtained through other sources than the financial statements. The responses strongly indicate loan officers would tolerate less extensive disclosures from small firms but that these firms should follow the same accounting principles (measurement rules) as large firms [Abdel Khalik, 1983 , p. 81$]$. 
More detailed research into this topic has been conducted by Stanga and Tiller [1983]. In their study they confronted commercial bank loan officers with a list of 40 information items. In one version of the questionnaire a large public company context was established and in the other a small private company context. The former questionnaire was sent to loan officers of a large bank and the latter to loan officers of smaller banks. Based on the perceived importance of the information items in the questionnaire, it was found that there were few differences between respondents confronted with the 'large firm' questionnaire and those confronted with the 'small firm' questionnaire. Of the 40 items included in the survey, only 10 yielded significant differences in perceived importance. Also, it was found that there was considerable agreement between both groups in the ordering of items. Thus, the findings did not provide much evidence for differences in information needs of loan officers when dealing with firms of different sizes. Berry et al. [1987] did find differences between information needs of loan officers dealing with small versus large firms but the annual report was considered to be the most important source of information, irrespective of firm size. Morris and Omrod [1990, p. 20] tried to establish the reaction of loan officers to the filing of modified accounts of small and medium-sized firms. Respondents to their study indicated they could recover about half of the loss of information resulting from the filing of abridged accounts through other sources, but only at considerable costs. As to the perceived consequences of reduced disclosures by small and medium-sized companies, the respondents tended to disagree considerably.

\subsubsection{Analysis of results}

In this section, the results presented in the previous section will be analyzed by relating the responses provided by respondents to characteristics of the respondents. The tests performed were used to test the effect of age, experience as a loan officer and the effect of a respondent having had training in business economics, on the responses given. Thus, Spearman rank correlations were calculated for all responses and respondents' characteristics mentioned.

The results of these tests indicate that there is little influence of any of the characteristics tested on the responses given. There are however a few exceptions (see table 5.12). Older and more experienced respondents find the importance of the director's report and the auditor's report to be higher. Also the quality of the balance sheet, the profit and loss account and again the auditor's report are perceived to be higher by older and more experienced respondents. The effect of a respondent's training in business administration is almost completely absent. It seems, nevertheless, that respondents who have had training in business administration find the financial statements to be less important compared to other information sources, that they find the financial statements to be less timely and less reliable than other respondents and that they are less positive about the importance and quality of most elements of the annual report compared to other respondents. None of these findings, however, are statistically significant. 
Table 5.12 Significant effect of respondents' characteristics on responses given

\begin{tabular}{llcc}
\hline \multicolumn{1}{|c}{ Spearman rank correlations } & Age & $\begin{array}{c}\text { Years of } \\
\text { experience as } \\
\text { credit analyst }\end{array}$ & $\begin{array}{c}\text { Training in } \\
\text { business } \\
\text { administration }\end{array}$ \\
\hline Importance of the director's report & $0.341^{* * *}$ & $0.310^{* * *}$ & -0.055 \\
Importance of the auditor's report & $0.490^{* * *}$ & $0.260^{* *}$ & -0.141 \\
Quality of the balance sheet & $0.272^{* *}$ & $0.230^{* *}$ & -0.033 \\
Quality of the profit \& loss account & $0.256^{* *}$ & $0.273^{* *}$ & -0.004 \\
Quality of the auditor's report & $0.204^{*}$ & $0.239^{* *}$ & $-0.260^{* *}$ \\
\hline
\end{tabular}

\subsection{Concluding remarks}

In this chapter, evidence has been provided on the perceived usefulness to loan officers of financial reports disclosed by medium-sized companies. The views of respondents were elicited on (1) the importance of the annual report of medium-sized firms in relation to other sources of accounting information available, (2) the characteristics of various accounting information sources in terms of reliability, relevance, understandability, comparability and timeliness, (3) the importance and quality of separate elements of the annual reports provided by medium-sized firms and (4) differences in information needs when dealing with firms of different sizes.

The results strongly suggest that the annual report is perceived to be a primary source of information to loan officers when dealing with medium-sized firms. Although other sources of accounting information are available, and are used, loan officers seem to depend heavily on financial statements when making credit decisions. Financial reports are ranked first in terms of reliability, relevance, understandability and comparability. Only in terms of timeliness are other sources of accounting information perceived to be more adequate.

Among the elements within an annual report, the profit and loss account, balance sheet and accompanying notes are perceived to be the most important. Also the quality of the information provided in these items is generally considered to be adequate, although the notes to the financial statements are ranked somewhat lower. The director's report seems to be particularly open for improvement as it is ranked significantly lower in terms of quality than all other annual report elements.

The issue of differential information needs of loan officers when dealing with firms of different sizes remains largely unclear. Respondents strongly disagree on this point. In the case of the filing of abridged accounts by smaller firms, research has indicated that loan officers are able to compensate the loss of information only partly through other sources and at a substantial costs [Morris and Embrued, 1990, p. 20]. However, on this point respondents also tend to disagree substantially. 
The research presented in this chapter was directed towards medium-sized private firms and therefore deviates from the focus on small private firms in the previous empirical chapters. Nevertheless, the results found do have implications for the small firm context. The high emphasis placed on the profit and loss account would indicate that the exemptions on the disclosure regarding this account provided to small firms, would not be appreciated by loan officers. Also, the absence of a mandatory auditor's report would seem to hamper the use of the annual report information of small firms, as loan officers seem to strongly value the presence of an auditor's report to ensure the quality of the information provided in the annual report. Only the lack of timeliness is indicated as a serious drawback of using the information from annual reports.

The findings presented in this chapter would suggest that in the current situation, where small firms are partially exempted from accounting disclosure regulations, users (i.e. loan officers) still have to rely heavily on alternative sources of accounting information, since the information disclosed by small firms is both short of essential elements (i.e. the profit and loss statement) and may not be sufficiently reliable to be used as a primary source of information to loan officers. Thus, it seems that current differential disclosure regulations provides an inadequate solution to the issue of financial reporting of small private firms. It would seem that either small firm accounting information is useful and used by external parties in which case small firms should be obliged to prepare and disclose full accounts without any exemptions provided to them. Or else the disclosure of annual reports by small private firms has limited use and usefulness in which case these firms should be exempted from all disclosure requirements and the provision of accounting information of these firms should be left to private arrangements between the firm and users depending on this information. 


\section{Summary and Discussion}

\subsection{Introduction}

This chapter will summarize and discuss the research presented in this dissertation, and will provide some suggestions for further research in the area of financial reporting by small or privately held firms, and the regulation thereof. Section 6.2 summarizes the results of the dissertation and discusses some general conclusions, and section 6.3 discusses the limitations of the studies presented. Finally, section 6.4 will provide some suggestions for further research.

\subsection{Summary}

The objective of this dissertation is to contribute to the literature on the economic effects of financial reporting regulation with a special focus on the economic effects of such regulations for small and medium-sized private companies. The empirical chapters of the dissertation deal with the compliance of small private companies in the Netherlands with financial reporting regulations, the perceptions of small private firm managers on current financial reporting regulations in the Netherlands, the cost effects for Dutch small firms of the 1984 Dutch company law, and the perceptions of loan officers dealing with smaller companies.

Chapter 2 discusses theories of financial reporting regulations, that attempt to explain the existence of such regulations. Arguments from both public interest theory as well as private interest explanations are discussed and are focused on the financial reporting environment of small private companies. In both areas the arguments are mostly oriented to the experience of large public companies. Whether these arguments apply to the small private firm setting depends heavily on empirical evidence. Although there is a large body of literature in this area, most of this research has focused on large public companies. Though these studies do have implications for research on the economic effects of financial reporting regulation for smaller private companies, there seems to be a general lack of studies that have focused directly on the small private firm situation. 
Most theoretical and empirical studies on financial reporting regulation are oriented towards the US or UK regulatory system. In the US, financial reporting regulation is primarily focused on publicly listed firms. But in Europe most firms affected by company law are relatively small and mostly private firms that are unlisted. Therefore, the costs that accounting and disclosure standards impose on small private firms should be of much more concern in the European context than in the US. Also, since there is no rigid enforcement of the company law requirements, the level of compliance with financial reporting regulations in Europe may be much more of a problem than it seems to be in the US.

Chapters 3, 4, and 5 empirically investigate the financial reporting environment of small and medium-sized firms in the Netherlands. Firstly, an investigation of the level of compliance with company law requirements for small Dutch firms suggests that in 1990 , six years after the introduction of these regulations, $15 \%$ of all firms concerned violate these requirements by not disclosing any financial statements. Equally striking is the fact that a significant number of firms that eventually do file their financial statements fails to file their annual report with the Chambers of Commerce within the time span allowed by the company law. As a result, the financial statements of small private firm generally become available to the public only with great delay, which raises doubts about the usefulness of such disclosures to any interested party.

A detailed investigation of financial statements disclosed by small private companies, as presented in chapter 3, indicated that compliance with formal company law requirements, mostly facilitating the comparability of the information disclosed over time and over firms, does not seem to be an area of great concern. A common strategy followed by small firms is to take an exact copy of a standard model and leaving the items that are not applicable to the firm's situation open. Most compliance problems pertain to the notes to the balance sheet, and the amount of information disclosed in these notes is rather limited. It is, however, not always clear whether omissions are cases of non-compliance or just a result of the item not being applicable to the firm's situation.

From the study on the perceptions of small firm managers presented in chapter 4 it is clear that financial reporting and its regulation are not major issues for small firm managers. Also it is evident that small companies do not expect to gain much by disclosing financial accounting information or appreciate the usefulness of the financial statements to third parties. As far as the costs of complying with company law requirements are concerned, a significant effect of the change in company law in 1984 can be found. Accounting costs, however, only make up a small fraction of the total company costs. Nevertheless, it can be shown that smaller firms bear proportionately higher accounting costs compared to larger firms and that the exemptions provided by company law do not fully compensate for the higher costs imposed by financial reporting regulations on smaller firms. 
From the results of the study among loan officers dealing with medium-sized firms, it is clear that current medium-sized company annual reports are generally perceived to be important and adequate sources of accounting information. Only the timeliness of such reports seems to be inadequate. Whether loan officers require different accounting information from firms of different sizes remains unclear as respondents tend to disagree on this point.

From the theoretical discussion on financial reporting regulations for smaller or private firms and the results of existing empirical literature, the following observations can be made:

\section{Criteria for differential financial reporting regulations.}

The choice of firm size as a cornerstone of the differential financial reporting regulations introduced by the Fourth EC Directive may not be a very fortunate one. Firm size is a relative factor and whether a firm with a particular number of personnel, a particular amount of total assets or annual sales is to be called small or medium-sized heavily depends on other factors such as industry. Also, the cut off point between a small and a medium-sized firm and between a medium-sized and a large firm is inevitably subjective and hard to defend. From a private interest point of view firm size seems to be a weak indicator of the role of financial accounting information and consequently the costs and benefits of financial reporting activities. The degree of separation between ownership and control seems to be a more dominant factor and criteria based on the degree of separation between the ownership and the management of a firm may therefore provide a much more articulate basis for differential financial reporting regulations. Such criteria relate to the difference between private and public companies and may be indicated by the number of stockholders, the free transfer of stock or the degree of owners' equity held by the management.

\section{The effectiveness of financial reporting regulations.}

The enforcement of financial reporting regulations seems to be hampered considerably, given the large number of firms affected by such regulations. In the Netherlands there is no systematic check of firms' compliance with financial reporting regulations. The enforcement of compliance relies more on the initiative of interested parties who for example may complain about the contents of a firms' annual report to the Enterprise Chamber. In the small firm setting, however, the role of the Enterprise Chamber seems limited. Also the absence of a mandatory audit limits the reliability of the information disclosed by smaller firms. Although the level of non-disclosure is not dramatically high (15\% in 1990), the quality of the information disclosed and especially the timeliness of the disclosures of small firm seriously reduce the usefulness of such information to any user group. 


\section{The audit of small private firms}

The role of an audit for small firms is currently being heavily discussed in the Netherlands. At present there is no mandatory audit for small firms in the Netherlands. Due to a change in Dutch audit-regulations in 1993, accountantsadministratieconsulenten, which are particularly active in the small and medium-sized firm market, are legally authorized to perform an audit. As a result, the issue of a small firm audit has gained much in importance in the Netherlands. The discussion generally concentrates on the lack of internal control in smaller firms which may result in a large number of qualified opinions for such firms. The 'Nederlandse Orde van Accountants-Administratieconsulenten' (NOVAA) therefore has initiated a research project to come to a small firm audit program. To overcome the lack of internal control in small firms a small firm audit program might focus on more elaborate substantive testing, the involvement of the auditor in the preparation of the accounts, reliance on executive controls or the introduction of a separate small firm audit qualification [Meuwissen and Maijoor, 1994].

\section{The costs of financial reporting regulations for smaller firms.}

The basic argument for differential financial reporting regulations for small firms stems from the alleged costs effects of such regulations on smaller firms. However, the cost-reducing effect of current differential reporting regulations in the Netherlands seems to be limited as small firms still seem to bear proportionately higher costs of financial reporting despite all exemptions provided. Whether these cost effects are compensated by the benefit of the provision of more adequate financial information is doubtful, given the results of the compliance study indicating that, at-the-least, most information disclosed by small firms is strongly outdated and in many ways incomplete.

Although in 1985 a test for new legislation was introduced in the Netherlands (wetgevingstoets), according to which the costs related to proposed changes in regulations have to be evaluated as well as the effect on businesses, this test did not have much impact. Also, even if compliance costs of proposed regulations are assessed, these assessments usually are qualitative in nature and quantitative estimates of compliance costs are not presented. It seems that, so far, the Government has put great trust in technological innovations such as increased automation which are supposed to reduce compliance costs for businesses. As a result, the costs effects of current as well as new legislations still receive only marginal attention by Dutch politicians.

\subsection{Limitations of the study.}

This dissertation has investigated the economic effects of financial reporting regulations. As such it suffers from the inevitable flaw of all research in this area in 
that it can not include all costs and benefits related to the financial reporting regulation under investigation.

The study on the level of compliance with financial reporting regulations suffers from the difficulty to establish whether information that is not disclosed in annual accounts, although required by company law, relates to non-compliance with the regulations or relates to the fact that information is not relevant or not material for that particular firm. Therefore the level of non-compliance can only be established from a conservative point of view, assuming that any mandatory information that is not disclosed in the annual report of a firm is excluded because the item is not relevant for that particular firm, unless the non-compliance can be established positively for example from other information provided in the financial statements.

The use of questionnaires and the focus on perceptions of managers of small firms the loan officers dealing with medium-sized firms introduces a number of limitations inherent to this research method. The most important difficulty is dealing with strategic behaviour by respondents in filling out the questionnaire. Company managers may be inclined to exaggerate the effects of financial reporting regulations on their firms, especially when they are asked to provide an indication of the costs of complying with such regulations. Similarly, users of accounting information may overstate the importance of information that is of potential use to them because there is no charge for requiring more information than they actually need. Also, questionnaire studies typically have to deal with non-response problems that are hard to overcome. The generalisability of the results of such studies therefore often is hard to defend.

However, given the fact that there are few studies on the economic effects of financial reporting regulations present in the Netherlands and that practically no research is available on the economic effects of such regulations on small or private firms, a first study in this area is inevitably of a rather exploratory nature. Also, as far as the investigation of accounting costs is concerned, there seem to be few alternatives as such information is not available from any public source of information in the Netherlands.

\subsection{Suggestions for further research}

As mentioned before, Dutch research into the economic effects of financial reporting regulation and especially research on small and medium-sized firms is still in its infancy. It is therefore evident that there are numerous ways for future research in the area of financial accounting for smaller or privately held companies. Some proposals for such future research will be presented in this final section. 


\section{The role of financial accounting information within small firms.}

Current differential financial reporting regulations in the EC are primarily based on size criteria. However, the costs and benefits of financial reporting may depend more heavily on the degree separation of ownership and control. Therefore the impact of variables indicating the firm's degree of ownership and control on the costs and benefits of financial disclosures deserves further attention. In this context, the relationship between the number of shareholders or the proportion of capital held by management and the economic effects of accounting regulations should be further investigated.

\section{Empirical research on current small firm audit practice.}

At present there is virtually no empirical evidence on voluntary audits among small firms. From the compliance study in chapter 4 it is clear that some small firms do have their financial statements audited and even file the auditor's reports with the financial statements at the Chamber of Commerce, although this is not required by company law. Little is known, however, about why these firms voluntarily have their financial statements audited and to what extent qualified and unqualified opinions are expressed by auditors dealing with smaller firms.

In more general terms, little is known about the opportunities for good small firms to distinguish themselves from bad small firms. Just following the regulatory requirements for financial reporting seems to provide few possibilities for small firms to show good faith. Therefore, these firms may be looking for alternative or additional mechanisms such as a voluntary audit or the disclosure of additional accounting information not specifically required by company law, e.g. by ignoring the disclosure exemptions and disclosing the full financial statements instead of the abridged ones.

\section{The role of the external accountant in small firms}

Although it is clear from existing empirical evidence that, even in the absence of a mandatory audit, the external accountant very often is involved in small businesses, little is yet known about the characteristics of such external accountants or their impact on the quality of the information provided by small firms. If it can be shown that small firms' financial statements that are prepared by an external accountant have better characteristics in terms of timeliness and quality, the mandatory preparation of the small firm financial statements by an external auditor may provide a way to ensure the quality of the information disclosed as a substitute for a mandatory audit.

\section{Determinants of compliance with financial reporting regulation.}

Various studies from different countries have shown apparent non-compliance with financial reporting regulations among small firms, thus lowering the quality of the financial statements disclosed. Little research, however, has been spent on studying the determinants of non-compliance. Also, determinants of the timeliness of small firm financial statement disclosures are of interest here as many small Dutch 
companies fail to file their financial statements on time. Although some initial work on the relationship between compliance and timeliness versus firm characteristics has been presented in chapter 3, further research should focus on explaining why some firms do comply with financial reporting regulations while others do not. Such explanations may be based on research on differences in agency costs between complying and non-complying firms (see for example Buijink, 1992, pp. 41-42 and Maijoor, 1991, p. 155).

\section{Determinants of accounting costs}

Additional research into differences in accounting costs between firms of different sizes could shed further light on the determinants of proportionally higher accounting costs for firms of smaller sizes. Especially the increasing use of computerised financial information systems within small firms and the involvement of an external accountant in preparing the financial statements may have considerable effects on accounting costs for firms. In this context also the financial statements prepared for fiscal purposes may prove worthwhile. If firms were allowed to use the fiscal financial statements as a basis for the financial statements required by company law, the additional costs of the company law requirements may be reduced considerably. Little is known, however, about the differences between the fiscal financial statements of small firms and the financial statements that are filed at the Chambers of Commerce by these firms.

\section{The usefulness of small firm financial accounting disclosures}

This study has focused on the usefulness of financial statements for credit analysts dealing with medium-sized companies. Further research should focus on the usefulness of financial statements of smaller firms to banks and also to other potential user groups.

Also, further research into the role of financial accounting disclosures in actual decision processes may define more accurately the benefits to users from such disclosures. Studies by Keasey and Watson [1986a, 1986b, 1987, 1988] have focused on the potential of failure prediction for small firms using a set of financial ratios. To our knowledge, such research into the use of small firm financial accounting information in particular decision processes at present is non-existent in the Netherlands.

\section{The small firm and the regulatory process}

In the area of the role of smaller firms in the regulatory process, the lobbying of such firms may be investigated. At present it is largely unknown whether any lobbying activities are undertaken either by small firms individually or by bodies representing small and medium-sized firms and to what extent their lobbying activities are successful. In the Netherlands, however, such research is seriously hampered by the fact that there is no formalised procedure for submissions of interested parties to regulators and there is no systematic publication of such submissions [Maijoor, 1991, p. 161]. 


\section{Appendix \\ I \\ Implementations of Differential Financial Reporting Regulations}

Regulatory bodies in various countries in the past have shown a growing interest in, and concern for the impact that regulations might have on small firms. These concerns have led to the existence of legislation that either exempts smaller businesses from financial reporting regulations or imposes fewer requirements on smaller firms. This appendix delineates differential reporting regulations that exist in the European Community, the US and Australia. This description is intended to demonstrate that regulators have followed varying approaches in providing exemptions for small firms. In the European Community, with the introduction of the Fourth Directive there has been an articulate approach in exempting firms from part of the financial reporting requirements based primarily on firm size. In the US, the FASB generally rejected the idea of differential reporting regulations for small firms, but nevertheless has implemented various exemptions for these firms. Also, the federal financial reporting regulations in the US apply only to public companies. In Australia there is a movement towards full exemptions for certain classes of firms, particularly small private ones.

Defining a relative term like 'small' or 'large' evidently poses a problem that is in essence impossible to solve. In a daily routine it is often superfluous to have an exact definition and terms like 'small and medium-sized firms' are widely referred to without ever giving any precise definition. As a result, most definitions of small and medium-sized companies tend to be very broadly stated, often incorporating many different elements that are believed to be characteristic for these firms.

In their book on The Economics of Small Businesses, Brock and Evans also point out the futility of defining a small business

"Such definitions are arbitrary and not particularly helpful. Whether a business is small depends upon the particular industry in which it operates. [..] Whether a business is small also depends upon our reasons for talking about small versus large. [..]" [Brock and Evans, 1986, p. 4].

However, if differential regulation for small firms is to be implemented, a policy maker can not avoid defining the set of firms to which the various rules and regulations should apply. Obviously any solution which a policy maker might come 
up with is open to discussion and criticism, since there is always a certain degree of arbitrariness involved. Whether a business is small depends on the particular circumstances like the country or industry it operates within, and also on the policy area under consideration. As a result, different countries, and different agencies within these countries, and different departments within these agencies, define the small business sector in substantially different ways. Although it will not result in a single generally acceptable definition, it is interesting to discover how policy makers have dealt with the problem, how they have been criticized and what suggestions have been made to come to other criteria.

Two basic questions can be distinguished regarding the definition of small companies:

1. What criteria should be used to define a small firm? Most propositions come down to the choice of a combination of size criteria, like total assets, total sales and number of employees.

2. What cut-off point for each of the variables used should be established?

The size of a firm can be defined by using several variables like total sales, total assets, number of employees or total stock market value, or by using combinations of more than one variable. Currently, most definitions seem to include one or more of three variables:

- total assets

- total annual sales

- number of employees

Not only the definition of a small firm poses an evident problem for policy makers, also the control of a correct classification of firms is difficult. In a situation where all firms have their accounts audited, this task could be assigned to the external auditor by having him issue a statement that the company complies with the specified criteria to take advantage of the exemptions being used in preparing and filing the accounts. Without the obligation of an audit for all firms, an adequate control of the correct use of exemptions by firms seems to be very difficult to ensure.

\section{A. The European Community}

In the European Community, financial reporting regulation in the last few decades has been dominated by several EC Directives that have been implemented in the national legislations of its member-countries, mostly in the early 1980 ' $\mathrm{s}^{1}$. Before

\footnotetext{
${ }^{1}$ The most important Company Law Directives issued by the EC are:

- the First Company Directive, issued in 1968, stating that all limited companies and partnerships limited by shares must publish an annual balance sheet and profit and loss account;
} 
that, the situation in the European countries differed considerably. Financial disclosure regulations for small and medium-sized firms have been laid down in the Fourth Directive.

In the first draft for a proposal for the Fourth Directive, issued in 1968 by the study group 'Company Law' initiated by the European Commission, only public limited liability companies were subject to the disclosure requirements. In addition, section 2 of article 1 of the proposal provided the option to exempt small public limited liability companies or family owned companies up to a particular size, from some of the provisions of the proposed Directive. During the first discussions of the proposal in 1968 the provision to exempt small companies was deleted and replaced by the option to exempt banks and other financial institutions as well as insurance companies from the Directive.

Further discussions in 1969 concerned the extension of the scope of the Directive towards private limited liability companies. Until then the intention had been to issue a separate proposal for a Directive for private limited liability companies. This plan was now abandoned on the premise that there was no fundamental difference between public and private limited liability companies. As a result, in a draft proposal issued

- the Second Directive, issued in 1976, that lays down rules concerning the formation of public limited companies;

- the Third Directive, issued in 1978, dealing with mergers of public limited liability companies;

- the Fourth Directive, issued in 1978, governing detailed rules on annual accounts of limited liability companies;

- the Sixth Directive, issued in 1982 , on the divisions of public limited liability companies;

- the Directive on the information to be published on a regular basis by companies the shares of which have been admitted to official exchange listing, issued in 1982;

- the Seventh Directive, issued in 1983, dealing with consolidated accounts;

- the Eight Directive, issued in 1984, concerning the rights and duties of auditors;

- the Directive on the annual accounts and consolidated accounts of banks and other financial institutions, issued in 1986;

- the Eleventh Directive, issued in 1989, concerning disclosure requirements in respect of branches opened in a member state by certain types of companies governed by the law of another state;

- the Twelfth Directive, issued in 1989, on single member private limited liability companies;

- the Directive on the annual accounts and consolidated accounts of insurance companies, issued in 1991.

Financial disclosure regulations for small firms are dominated by the Fourth Directive. The thresholds used in the Directive to define small and medium-sized companies have been amended in 1984, 1990 and 1994. Also, the scope of the Fourth Directive has been extended in 1990. 
in 1970 the scope of the Directive was extended accordingly. It was recognised, however, that for private firms the requirements for the disclosure of the annual report could be relaxed, since within these firms shareholders are known and therefore can be sent the annual report by personal mail. Exempting private firms from the mandatory disclosure of the annual report could, however, harm creditors. Given the limited liability nature of private firms it was therefore felt that such an exemption could not be provided. However, for firms that have little economic impact (i.e. small firms) it was felt that disclosure of the annual report would not be essential. Based on these arguments a distinction was made between three different size-categories ${ }^{2}$ of private limited liability companies. For small and medium-sized private limited liability companies partial exemptions ${ }^{3}$ were foreseen (though neither the size-criteria to be used nor the exemptions to be provided were specified).

In its discussion of the proposal for the Fourth Directive that was issued in 1971, the European Parliament fully supported the scope of the Directive, although it requested to examine the possibility to extend the scope to all firms that exceeded a certain size, irrespective of their legal form. The Economic and Social Committee in 1973 also approved the scope of the proposed Fourth Directive. The Committee proposed to require Member States to provide the exemptions mentioned in the Directive, but this proposal was not followed and in the final text the provision of exemptions remained optional. In an amended version of the proposed Directive issued in $1977^{4}$ the size-categories not only applied to private companies but also were applicable to public companies, since it was felt that is was preferable to treat equally all companies of comparable size regardless of their legal structures.

${ }^{2}$ In the final version of the Fourth Directive (issued in 1978), the size-criteria were based on total assets, total sales and number of employees. These criteria were regarded to take into account the different characteristics of industrial companies, trading companies and companies providing services.

${ }^{3}$ In the original version of this amendment formulated by the study group, small companies were fully exempted from all disclosure requirements. In the final text of the proposal this suggestion, however, was not followed by the European Commission.

${ }^{4}$ There had been a revision of the proposal in 1974 , as a result of the entry into the EC of Great Britain, Denmark and Ireland. This amendment, however, had no effect on the exemptions provided to small and medium-sized firms.

5 In the Netherlands the Institute of Registered Accountants (NIVRA) criticized the proposed Directive with regard to private firms, as it felt that all private firms should be exempted from disclosing a profit and loss account. Also it felt that the size limits defining small and medium-sized companies mentioned in the proposal were far too low. The latter point was also made in a reaction of a European study group of accountants (Groupe d'Etudes des Experts Comptables de la EEC). As a result of these and other similar critics the size limits were raised considerably in the final version of the Fourth Directive. 
The impact of the Fourth Directive on small and medium-sized firms received great attention, especially in Germany where some 300,000 small and medium-sized private firms would be affected [Hagenau and Hauser, 1989]. At the time of the adaptation of the German law to the Fourth Directive, a number of authors suggested that small firms could easily escape the disclosure requirements since a sanction could only be evoked by interested parties (e.g. Autenrieth [1989, pp. 2581-2582], Hagenau and Hauser [1989, pp. 180-182] and Weilbach, 1990, pp. 1095-1097]). So for all firms where such interested parties did not exist (which was assumed to apply to most small firms), non compliance with the disclosure regulations would not have any implications. Later research has indicated that non compliance in Germany is extremely high (Weilbach, [1991, p. 800]). Also, a large number of limited liability companies changed their legal structure to avoid the financial reporting regulations. Over $60,000 \mathrm{GmbH}^{6}{ }^{6}$ (a limited liability company) changed their legal structure into a $\mathrm{GmbH}$ \& $\mathrm{Co} \mathrm{KG}$, which is an unlimited liability firms (kommanditgesellschaft (KG)) where all unlimited partners are limited liability companies (GmbH). All firm activities would be placed in the KG to which the financial reporting regulations did not apply. The $\mathrm{GmbH}$ that acted as partner of the KG, would still have to apply to the financial reporting regulations but it would have no activities and mostly would be a small company.

As a result, in 1986 a proposal was issued by the European Commission to extend the scope of the Fourth Directive to unlimited companies and partnerships of which the unlimited partners are all established as a limited liability company. In these firms, in spite of their unlimited nature, liability in effect was restricted to the net assets of the limited liability companies that acted as owner or partner. Such limited liability was regarded to be one of the essential reasons for issuing the Fourth Directive. Failure to subject the companies mentioned to the same accounting requirements as public and private limited liability companies was felt to be contrary to the spirit of the Fourth and Seventh Directive. The Economic and Social Committee supported the proposal although a minority of the members was against it for a number of reasons, one of which related to the large number of small and medium-sized companies that would be affected by the proposal ${ }^{7}$. In 1987 the proposal also was accepted by the European Parliament.

However, in 1988 the introduction of the proposed amendment of the Fourth and Seventh Directive was delayed because Germany, the Member State most affected by the amendment, requested that in return for the extension of the scope of the Directives, the exemptions for small and medium-sized firms should also be

\section{${ }^{6}$ Gesellschaft mit Beschränkter Haftung}

${ }^{7}$ Other reasons mentioned were that the proposal created a precedent to extend the scope of other Directives, and the fact that the problems dealt with by the proposal were already known when the Fourth and Seventh Directive were adopted and that at that time these problems were deliberately left to the Member States. 
extended. In Germany, the impact on the $\mathrm{GmbH}$ \& Co. KG of the proposed amendment of the Fourth Directive received great attention (see f.e. Hahn [1981, p. 2461], Das Betrieb [1986, p. 1416], Barth [1986, p. 2236], Meillicke [1986, pp. 2445-2450], Weilbach, 1992, pp. 955-957]) and there was strong opposition to any further extensions of the scope of the Fourth Directive where it was felt that lessening the requirements for small and medium-sized firms would be far more appropriate.

As a result of the German opposition, in 1988 a second amendment of the Fourth and Seventh Directive was proposed, extending the exemptions for small and medium-sized companies. The proposal entailed the complete exclusion of small closely held companies ${ }^{8}$ from the Fourth and Seventh Directive 9 . It was argued that for these companies the protection of members and other parties is not such an issue since there are no minority shareholders and the interest of creditors can be safeguarded by appropriate penalties for firms in case of a failure to keep proper accounts. Also these firms are not very likely to engage in intra-Community trade, so that the proposal would have little effect on the establishment of a common European market.

The proposal included:

- the creation of a new category of 'closely held companies' that would be completely exempted from all requirements of the Fourth Directive. Each member state would be free to set their own regime for this category of firms provided that it does not exceed the requirements of the Fourth Directive as applied to small companies;

- a mandatory exemption allowing small companies to disclose their accounts at the company's registered office instead of filing them at a central registry. Member states would be free to set the same exemption for medium-sized firms;

- more flexibility for member states to vary the existing financial thresholds defining small and medium-sized firms. Thresholds could be set by minus or plus $50 \%$ of the current maximum and to reduce the employment threshold by $50 \%$;

\footnotetext{
A closely held company was defined as a company:

- not affiliated with other undertakings;

- not linked to another undertaking by virtue of a participating interest;

- where the members or shareholders are natural persons and the same as the members of the administrative or management body;

- where the shares are registered and may not be transferred without the company's consent.
}

${ }^{9}$ During the preparation of the proposal it was also suggested to exempt all small and medium-sized companies from the Fourth Directive. This suggestion was not followed because it was felt that there was a danger that this would undermine the whole concept of harmonising accounting standards. Furthermore it would nullify the considerable effort Member States had invested in getting all companies to accept the new accounting rules. 
- an exemption for all small companies for preparing a directors' report under certain conditions;

- an option for member states to exempt all single director companies from disclosing information on loans to directors and directors' remuneration;

- a mandatory exemption for small companies from having their accounts audited.

The proposal, however, was not endorsed by the European Parliament ${ }^{10}$. A number of revised proposals to exclude "very small" companies or "very small closely held" companies were not accepted either. The final version of the Directive was adopted in 1990, together with a revised version of the 1986 proposal to extend the scope of the Directive. Although some additional exemptions were provided to small and medium-sized companies, no category of companies was excluded entirely from the scope of the Fourth and Seventh Directive. The incorporation of these amendments in the Dutch legislation therefore has not resulted in major changes for small firms. The thresholds have been raised slightly and small firms are no longer required to prepare a directors' report unless the company has a workers' council. More importantly, the scope of the company law has been extended so that general partnerships (Vennootschap onder Firma, VOF) and limited partnerships (Commanditaire Vennootschap, CV) also fall under the legal financial reporting requirements.

With the adaptation of the national company laws to the Fourth Directive, all EC countries will have some form of tiering regulation in which three groups of firms are distinguished based on three size criteria: total annual sales, total assets and number of employees. The difficulty for a policy-maker in setting cut-off points can be demonstrated by the wide range of size-criteria implemented by the membercountries $^{11}$. As can be concluded from table 1, the introduction of the Fourth Directive still left some substantial differences between thresholds in national legislations. Also, the thresholds have been reset on several occasions. The reason for these adaptations is to compensate for economic or monetary developments.

${ }^{10}$ Initially it seemed the European parliament supported the complete exemption of small closely held firms but later this support vanished, supposedly as a result of the dramatic changes taking place in Eastern Europe at that time [Weilbach, 1992, p. 955].

"The size criteria implemented in the national legislation of Member States may deviate no more than $10 \%$ from the criteria mentioned in the Fourth Directive. 
Table 1 Upper boundaries defining a small firm as incorporated in national legislation's of member states (adapted from Beckman, 1988]

\begin{tabular}{|c|c|c|c|c|c|c|c|c|}
\hline \multicolumn{2}{|c|}{ all amounts * 1.000} & \multicolumn{3}{|c|}{ Sates } & \multicolumn{3}{|c|}{ Total assets } & \multirow{2}{*}{$\begin{array}{r}\text { Employ } \\
\text { Company } \\
\text { law* }\end{array}$} \\
\hline State / Curren & & $\begin{array}{r}\text { Company } \\
\text { law }\end{array}$ & $\begin{array}{l}\text { Fourth } \\
\text { Directive }\end{array}$ & Deviation & $\begin{array}{r}\text { Company } \\
\text { law }\end{array}$ & $\begin{array}{l}\text { Fourth } \\
\text { Ditective }\end{array}$ & Deviation & \\
\hline Beigium* & BF & 145000 & 145500 & $0,34 \%$ & 70000 & 70500 & $0.71 \%$ & 50 \\
\hline Denmark & DKr & 4000 & 26200 & $84,73 \%$ & 2000 & 12700 & $84,25 \%$ & 10 \\
\hline France*t & FF & 3000 & 21900 & $86,30 \%$ & 1500 & 10600 & $85,85 \%$ & 10 \\
\hline Germany & DM & 8000 & 7300 & $-9,59 \%$ & 3900 & 3500 & $-11,43 \%$ & 50 \\
\hline Greece & Drach & 260000 & 236700 & $-9,84 \%$ & 130000 & 114650 & $-13,39 \%$ & 50 \\
\hline Ireland & f IrI & 2500 & 2300 & $-8,70 \%$ & 1250 & 1100 & $-13.64 \%$ & 50 \\
\hline Italy & Lina & NI & 4307040 & NI & NI & 2080000 & NI & NI \\
\hline Luxembourg & Flux & 160000 & 145500 & $-9,97 \%$ & 77000 & 70500 & $-9,22 \%$ & 50 \\
\hline Netheriands & HFI & 8000 & 8145 & $1,78 \%$ & 4000 & 3950 & $-1,27 \%$ & 49 \\
\hline Portugal & Esc & NA & 334530 & NA & NA & 162000 & NA & NA \\
\hline Spain & $\mathrm{Pta}$ & $\mathrm{NI}$ & 415400 & NI & NI & 200000 & NI & NI \\
\hline $\begin{array}{l}\text { United } \\
\text { Kingdom }\end{array}$ & $f$ & 2000 & 1900 & $-5,26 \%$ & 975 & 890 & $-9,55 \%$ & 50 \\
\hline
\end{tabular}

$\mathrm{NI}=$ The Fourth Directive has not yet been implemented in the national legislation at that time (1989].

$\mathrm{NA}=$ Threshold is not incorporated in the national legislation.

* the boundary for personnel included in the Fourth Directive is 50 .

** in Belgium these boundaries do not apply if a firm has over 100 employees

*** in France there is a further separation within the category of small firms

In 1994, a commission of independent experts was established to examine the impact of the EC and national legislation on employment and competitiveness with a view to finding ways of reducing and simplifying such legislations. In a report, issued in 1995, this committee devoted considerable attention to the matter of small and medium-sized companies (SMEs). With respect to company law, the commission notices that [CEC, 1995, p. 79]:

- The transposition of EU legislation has frequently added significantly to costs and rigidities (for example in implementing company law); enforcement can be insensitive to the particular needs of SMEs and is uneven across the Community and in national legislation has added significantly to the cumulative burden faced by SMEs.

- Company law [...] has frequently been driven by the needs of the larger company. For SMEs company law needs to achieve a better balance between cost and creating a secure framework for SME access to capital and credit.

The most important suggestions made by the Commission with respect to SMEs, are to substantially increase (by $50-100 \%$ ) the thresholds used in the Fourth Directive to define small and medium-sized companies, and to keep general disclosure requirements under close review to ensure that they provide an appropriate balance 
between costs and benefits. For new legislation the impact on SMEs and a cost benefit analysis should be published as a matter of routine.

The Commission recognizes that although previous attempts have been made to simplify financial reporting regulations for SMEs, these have met major political obstacles. In the near future it will become clear whether the recommendations of the Commission itself will be able to by-pass such obstacles.

\section{B. The US}

In the US, the discussion on differential disclosure regulation emerged in the 1970s, especially after a report of the Advisory Committee on Corporate Disclosure of the Securities and Exchange Commission (SEC) showed that the costs for certain disclosures were almost 200 times as high per dollar of sales for companies with assets of less than $\$ 100$ million than for large companies with assets of over $\$ 1$ billion. Furthermore the report showed that there was very little interest from sophisticated institutional investors in companies with a capitalization of less than \$50-100 million [Horwitz en Kolodny, 1982, p. 31 and SEC, 1977, Chapter XVII and pp. 514-515]. Since then the SEC has introduced several exemptions for smaller firms and has even considered creating a small business class whose reporting burden would be significantly reduced [Horwitz and Kolodny, 1982, p. 33].

In the US the regulation implemented by the SEC, the Securities Act 1934 relieves all companies whose assets fall below $\$ 5,000,000$ and whose number of shareholders falls below 500 at the end of any year, and all corporations whose number of shareholders falls below 300 from the obligation to file quarterly and annual financial statements in prescribed form and content, with independent accountant certification of the annual statement [Landau, 1988, p. 65]. Also, shelf registration is limited to companies with (a) aggregate market value of at least $\$ 150$ million or (b) aggregate market value of at least $\$ 100$ million and annual trading volume of at least three million shares [Atiase et al., 1988, p. 26].

Accountants' organisations seem to be quite positive about differential reporting regulation. The AICPA in 1983 recommended to the FASB it should provide

"...within the framework of generally accepted accounting principles, differential disclosure alternatives [..] as well as differential measurement alternatives for such [small non-public] entities." [AICPA, 1983, pp. 3-4].

However, until now the FASB has rejected the argument for differential recognition, measurement, and disclosure rules and has reaffirmed the need for one basic set of accounting standards for all firms [Wolk et al., 1992, p. 94, FASB, 1983].

The FASB has nevertheless initiated a research project into financial reporting by private and small public companies. When the FASB started its project, the problem 
of defining the firms under research was discussed in the invitation to comment in the issue in 1981. In the discussion of the topic of the invitation, it is noted that "authoritative accounting literature [..] has not defined small business" in the discussion on the characteristics of private firms, and also that "authoritative accounting literature does not distinguish [..] between small public companies and large ones". As a tentative guideline for classification the definition of the Small Business Administration (SBA), which is mainly based on sales-figures that are differentiated for several industries, is presented for private firms and with respect to small public firms, the numbers of public firms with total assets less than \$ 5 million and less than $\$ 10$ million are presented [FASB, 1981, pp. 32-35]. In the SFASs where differential standards are introduced, the FASB, instead of attempting to develop a single definition of what a small firm is, focuses on how specific accounting issues affect different businesses. This has lead to different criteria for small firms in different SFASs.

Differential reporting based on company size is very uncommon in SFASs but it was a theme in the exposure draft on SFAS 87 'Employer's accounting for pensions' although the final statement did not include any exemptions because disclosure requirements for all firms were reduced. SFAS 33 'Financial Reporting and Changing Prices' included exemptions for firms if inventories exceed \$125 million and total assets are less than $\$ 1$ billion. With the introduction of SFAS 89 , however, the requirements of SFAS 33 were dropped [Atiase et al., 1988, p. 26]. The FASB has implemented some exemptions for non-public and small public firms in several standards (e.g. SFAS 14, 69 and 79) ${ }^{12}$.

12 Based on studies by the AICPA of the application of generally accepted accounting principles (GAAP) to smaller and closely held enterprises, the FASB announced in SFAS 21 (April 1978) that non-public enterprises were relieved of the disclosure requirements of SFAS 14 regarding the reporting of earnings per share and the disclosure of segment information. But also, in section 8 of SFAS 21 it is clearly stated that "those suspensions, however, should not be construed as an indication that the Board has decided that the information requirements for those [non-public] enterprises are significantly different from those for an enterprise whose debt of equity securities are publicly traded".

In Appendix B to SFAS 69 (November 1982), it is mentioned that, based on responses received to the invitation to comment on the exposure draft, non-public firms are exempted from major parts of this standard. It is stated that "the informational needs of the users of financial reports are the same for enterprises that are publicly traded and enterprises that are not publicly traded. However, creditors and investors in enterprises that are not publicly traded, if they do not already have the information they require, usually are able to obtain it". The fact that this may not always be the case is acknowledged by the Board but is not seen as a widespread problem. In a final comment it is stated that "The Board may need to reassess a possible requirement for enterprises that are not publicly traded to provide the information [they are exempted from now] after completion of the Board's project on financial reporting by private and small public companies". 
Federal Securities Law, however, only applies to public companies, active on a national securities exchange. Accordingly, most small companies are predominantly affected by State Corporate laws. Although many State corporation laws have provisions requiring that some financial statements be made available or sent to shareholders, the form, contents and principles of preparation are not prescribed and independent certification is not required [Landau, 1988, p. 65]. Nevertheless, despite the absence of formal requirements to do so, many small companies have audited financial statements prepared at the request of banks or other financial credit sources, the company management, or the company board of directors [Choi and Mueller, 1984 , p. 96]

\section{Australia}

While in the US the FASB has chosen a standard-to-standard approach, evaluating the effect of each individual standard on certain groups of firms instead of defining a general classification of firms, in Australia the concept chosen has been quite differently on an entity-to-entity basis, referred to as the 'reporting entity concept'. In Australia, the fundamental approach concerning accounting standards remains that members of the accounting profession prepare all financial reports in accordance with all accounting standards and all standards apply to all entities except for a very few ${ }^{13}$ [McCahey, 1989].

The Australian Accounting Research Foundation (AARF) issued two proposals for Statements of Accounting Concepts involving the differential reporting problem. Statement ED46A 'Definitions of the Reporting Entity' (April 1988) and Statement ED48 'Proposed statement of policy on Differential Reporting' (January 1989) introduced a solution for the standards overload problem based on a conceptual framework for financial reporting that, regarding the standards overload problem, consisted of (1) a distinction between general purpose and specific purpose

SFAS 79 (February 1984) directly resulted from the research project initiated by the FASB regarding the financial reporting by private and small public companies. The standard restricted the application of Paragraph 96 of ABP Opinion 16 on the disclosure of pro forma results of operations to public enterprises only. In the appendix to SFAS 79 it is explicitly stated that the Board's decision to eliminate the requirements mentioned for nonpublic firms were based on the assessment that the costs to provide those disclosures generally exceeded the benefits to the users of non-public company financial statements [SFAS 79, Paragraph 14].

${ }^{13}$ Exemptions are included in ASRB 1105, Financial Reporting by Segments and ASRB 1007, Financial Statement of Sources and Applications of Funds. Although these exemptions are not based on firm size, it would be no exaggeration to suggest that the majority of companies exempted would fall within some definition of a small company [Ramsay and Sutcliffe, 1986, p. 49]. 
information and (2) a distinction between reporting entities and non-reporting entities. Reporting entities are defined as entities "in respect of which it is reasonable to expect the existence of users dependent on general purpose financial reports for information which will be useful to them for making and evaluating decisions on the allocation of scarce resources" (Par. 37, ED46A). Reporting entities would be compelled to provide general purpose reports in full compliance with all accounting standards. Non-reporting entities would not be determined by size or ownership structure but by (1) the separation of management from economic interests, (2) economical or political importance and (3) financial characteristics ${ }^{14}$. The proposed statements include no exact definition of a non-reporting entity. In fact, the choice of whether a company is a reporting or a non-reporting entity is left to the preparer of the financial statements. If a company would inappropriately define itself as a nonreporting entity. Its choice to define itself as a non-reporting entity, however, would be limited as a result of economical consequences (credit refusal, higher costs imposed, tighter financing restrictions) or disciplinary actions against its accountant [Goodwin and Newitt, 1990, p. 49, McCahey 1989, McCahey and Ramsay, 1989].

Company law in Australia is directed primarily towards public companies. Public firms can be incorporated as 'proprietary' companies if they fulfil certain restrictions regarding (1) the right to transfer its shares, (2) the number of members, (3) the placing of share capital among the public and (4) the deposit of money with or by the public. Furthermore, a distinction is drawn between proprietary companies which are really incorporated family businesses, described as 'exempt proprietary companies' and those which are completely or partly owned by a public company. All proprietary companies have certain administrative advantages but, in addition, exempt proprietary companies do not have to conform to the rigid rules of disclosure of information and audit which other types of company have to obey [Clift, 1989, pp. 10-11].

\footnotetext{
${ }^{14}$ It seems, however, that, although it is explicitly stated that non-reporting entities are not determined by size or ownership (Par. 33 ED46A), the criteria given are not that much different. It is mentioned however that the three criteria mentioned "are not the only factors that will be relevant in determining whether, in a particular circumstance, an entity is a reporting entity" (Par. 12, ED46A).
} 


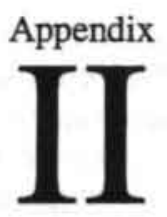

\section{Propositions for Implementing Differential Financial Reporting Regulations}

Various solutions to lighten the burden that financial reporting regulation imposes on small firms have been proposed and discussed. In general terms, five different solutions to the differential financial reporting problem have been suggested:
A. Differential disclosure;
B. Differential recognition;
C. Differential measurement;
D. Full exemption;
E. Overall simplified reporting;

In this appendix, these various solutions to implementing differential financial reporting regulations that have been proposed will be discussed. At various points in the following discussion there will be references to various instances of implementation of differential reporting regulations in a number of western countries. A more detailed description of existing differential reporting systems in the EC, US and Australia has been presented in Appendix I.

\section{A. Differential disclosure}

With this option small firms would be permitted to disclose less information about their affairs than large public firms while still having the obligation to prepare full accounts for the shareholders. This was the option presented primarily by the AICPA in 1976 [AICPA, 1976].

Differential disclosure will hardly have a reducing effect on the accounting costs of small firms. The major burden of accounting standards is in measurement, what goes into the financial statement totals, rather than what goes into the footnotes [Mosso, 1983, p.128]. Since full accounts, in accordance with all the measurement standards still have to be prepared, the production of an extra set of abbreviated accounts for disclosure will only enlarge costs for these firms. A positive effect would be that a small firm could be prevented from having to disclose information that is very sensitive for privacy or competitive reasons. 
Another cost-increasing effect could emerge because preparing two sets of accounts would give rise to problems if the accounts had to be audited. The auditor's opinion for the full accounts could hardly be applicable to the abbreviated accounts since, as a result of the loss of detail, these would barely give an identical view of the financial position of the firm. Instead of including the auditor's opinion of the full accounts with the disclosed financial report, it could be argued a new auditor's opinion should be set up specifically concerning the abbreviated disclosed accounts. In the UK, auditors have to add a special auditor's report to the abbreviated accounts to be disclosed, stating that (1) the directors are entitled to deliver modified accounts in respect of the financial year and (2) any accounts comprised in the documents delivered as modified accounts are properly prepared as such in accordance with the Companies Act. Similar arrangements can be found in other EC-states like Denmark, Germany and Ireland ${ }^{1}$. In contrast, in the Netherlands the auditor's report on the full accounts has to be disclosed as a part of the accounts disclosed even if these are abbreviated. No accessory auditor's statement is legally required, although some authors pleaded in favour of it [e.g. Beckman, 1986, Van der Tas, 1989]. The problems mentioned here, only apply to a relatively small number of medium-sized companies in the Netherlands since small companies are fully exempted from the audit requirements.

\section{B. Differential recognition}

Differential recognition deals with the decision to formally incorporate an item into the basic financial statements [Larson and Kelly, 1984, p. 79]. This option is seldom mentioned separately but mostly combined with the option of differential measurement (see below):

"Many who suggest that small business problems should be addressed through differential standards or measurement, are not talking about the measure of assets and liabilities. Rather, they are often asserting that an asset or a liability should be excluded from the statements of smaller companies" [Upton and Ostergaard, 1986, p. 98].

The purpose of differential recognition is not only to prevent certain items from being disclosed to external parties, but also to prevent certain items from being presented in the financial statements for the shareholders.

The concept of differential recognition avoids the audit difficulties introduced by differential disclosure, since the financial accounts prepared and disclosed would be

\footnotetext{
${ }^{1}$ In France and Belgium there is no distinction between the prepared and disclosed accounts and Greece has no exemptions for small or medium-sized companies. In the Netherlands the problem only applies to the relatively small number of medium-sized companies since small companies are exempted from the audit requirements.
} 
identical. Also, it would avoid the problems of differential measurement resulting from the introduction of multiple sets of accounting rules, since the underlying principles for the preparation of the accounts would still come from one set of principles. As a result the loss of uniformity and comparability in financial statements would be minimal since only the amount of information disclosed differs among firms but not the underlying accounting principles.

The problem, however, is to decide what information could be left out without harming the credibility of the financial statements. A distinction has to be made between what information to require in the statements of all entities and additional information [AICPA, 1976].

\section{Differential measurement}

Small firms could be excluded from measurement requirements that are particularly burdensome to them. This would result in small firms using a different set of accounting principles than large public firms. The idea of differential measurement has lead to a body of literature discussing the pros and cons of having two different sets of 'Generally Accepted Accounting Principles" (GAAP), one for large public firms (referred to as BIG-GAAP) and one for small firms (named LITTLE-GAAP). The distinction between both could go as far as the creation of a totally separate set of accounting rules for small firms or the continuing use of one set of GAAP based on a single set of concepts but with differential application of these unified concepts to different situations.

The idea of differential measurement as a general solution to the standards overload problem was firmly rejected by the FASB [Status Report FASB, 1983]. Firstly, having two sets of GAAP ultimately makes nonsense of the idea of "generally accepted accounting principles". Comparing firms of different sizes would be complicated because the concept of uniform requirements would be abandoned. Furthermore, as a firm grows it would at some point have to change from one set of rules to the other, with time leading to confusion and loss of consistency. It could also lead to the idea that the LITTLE-GAAP would be of lower quality and thus a second-class alternative for small firms. Nevertheless, the FASB did not entirely rule out the possibility of differential measurement but stated that it would be acceptable in cases "... supported by persuasive evidence that needs of external users of the financial statements of certain entities are different, or that the costs outweigh the benefits of the information" [Status Report FASB, 1983].

To escape the dilemma of a double GAAP-approach the use of a non-GAAP basis for small firms has been suggested [AICPA, 1980, AICPA, 1983]. The FASB also considered the use of a non-GAAP basis for small firms' financial statements but found that although accountants working for smaller firms indicated a higher use of income tax or cash based financial statements, even in this group the use of those 
bases was infrequent. Accountants indicated that tax-based financial statements lack credibility with lenders. Also, other users besides lenders prefer GAAP financial statements [Abdel-Khalik, 1983, p. 32]. Yet, for private firms, if the financial statements were prepared for use by the owners only, the application of the income tax basis in preparing financial statements was favoured by accountants [AbdelKhalik, 1983, p. 92]. Baker [1990] studied the response of commercial loan officers to income tax based financial statements and found that loan officers find GAAPreports to be more complete and more useful in making loan approval decisions than tax-based reports.

One other alternative would be to let the auditor decide to omit GAAP requirements not considered to be cost-beneficial and state this in the auditor's report [Mosso, 1983 , p. 128]. There has been, however, opposition to the introduction of negative connotations in the auditor's report and a more positive form of reporting has been asked for. Furthermore, there is concern that "leaving an accountant free to omit a required disclosure on the ground that, in his view, it does not serve the information needs of users would pose upon him an awesome responsibility as a well as increasing the risk that his judgement will be challenged in the courts" [Armstrong, 1977 , p. 89].

As mentioned before, research among users of financial statements indicates that they strongly oppose the idea of having two sets of GAAP because it would considerably reduce the credibility and usefulness of general purpose external financial reporting. Larson and Kelly [1984] dispute these results, based on the belief that the user groups mistakenly confuse conformity with GAAP as a basis for getting relevant information, with a belief that information is more reliable in an auditing sense. They see differential measurement only as an opportunity for firms to withhold information. The authors refer to several studies to support their views and conclude that user-groups, most importantly bankers, "overemphasize the importance of uniformity in the application of complex GAAP standards" [Larson and Kelly, 1984, p. 82].

\section{Full exemption.}

A complete exemption from all financial reporting regulation for small closely held firms would avoid the introduction of two sets of accounting principles. If a firm has no external use for financial statements and general purpose financial statements are not well designed for internal management purposes, it could well do without them [Solomons, 1986, p. 194]. General accounting principles would only be applied in special circumstances, such as an application to a bank for a loan, but they could be abandoned for routine accounting purposes and the preparation of statements designed for the use by management. 
A very similar approach has been introduced by the Australian Accounting profession in the proposed introduction of the term reporting entities, defined as entities of which it is reasonable to expect that there will be users who are dependent on the entities' financial reports for decision-making purposes, which are required to prepare general purpose financial reports, prepared in accordance with all accounting standards [McCahey, 1989. p. 60]. Entities that are not reporting entities are not obliged to prepare general purpose financial reports. The auditor and the management of the firm jointly decide whether the firm is a reporting entity depending on whether it is reasonable to expect that there will be users who are dependent on the entities' financial reports for decision making purposes ${ }^{2}$. Managers and auditors are motivated to make a proper choice through adverse economic consequences for the firm (e.g. financial restrictions or credit refusal) and disciplinary proceedings for the auditor [Goodwin and Newitt, 1990, p. 50]. Such an approach evidently avoids the difficulty of defining to which firms the exemptions should apply. For discriminating between non-reporting and reporting entities and to control the disclosure of accounting information by non-reporting entities, reliance is placed on market forces.

\section{E. Overall simplified reporting.}

The case for simplified financial reporting regulations for all firms has evolved from the concern that users of financial information are hardly able to use current financial reports, for a number of reasons (Hammill [1979, p. 7], Bird [1984]):

1. Users do not understand the accounting principles and methods used in financial accounts (e.g. Lee and Tweedie $[1977,1981])$.

2. Users do not understand many of the technical terms in the accounts.

3. The excessive amount of information in the accounts is hard to absorb (e.g. Newell and Simon [1972], Tversky and Kahneman [1974] and Libby [1981]).

It is argued that the usefulness of financial information is not determined by the quantity of information but by a clear presentation of essential elements. Company financial reports should not be over-burdened with unnecessary details so the costs of collecting and publishing the information are kept within reasonable bounds. This has led to suggestions for allowing companies to issue a streamlined form of financial

2 The 'reporting entity concept' introduced in ED 46A and ED 48 by the AARF, is not accompanied by strict criteria defining such an entity, although some suggestions are made. In ED 46 Paragraph 24 it is concluded, however, that all public companies and listed investment trusts would be regarded as reporting entities [Goodwin and Newitt, 1990, p. 49]. Paragraph 12 of ED 48 delineates those entities that will normally not have to prepare general purpose accounts and includes close companies, exempt proprietary companies (as defined in the Companies Code), privately-owned trusts, sole traders and wholly owned subsidiaries of Australian reporting entities [Holmes et al., 1991, p. 127]. 
statements, usually referred to as Summary Accounting Reports (SARs) or simplified accounts, for users who wish them, instead of sending the full accounts to all shareholders ${ }^{3}$. Users would still receive the full financial statements in addition to the summary annual report, or would at least be able to obtain full financial statements on request. SARs would typically include a more verbal presentation of the firm's financial situation and place greater emphasis on charts and graphs to present numerical data [Lee and Morse, 1990, p. 39] ${ }^{4}$.

Allowing the simplification of financial reports, however, also holds the inevitable risk that such reports will be lacking in completeness, comparability and understandability (Tweedie [1981, p. 141], Nair and Rittenberg [1990, p. 38]). The use of simplified reports and the obvious risk of simplifying the complex financial reality of a firm to the extent that the model of this reality - the financial statements gets so simple that it gives a false impression and does not present a true and fair view would also introduce difficulties with the audit of such a report. Given the nature of a summary annual report, there is a problem whether the auditor would be responsible for the quality of disclosures in the summary annual report and its adequacy in presenting a true and fair view [Nair and Rittenberg, 1990, p. 25].

SARs' primary function is to improve the quality and effectiveness of financial communication with users, but also to reduce disclosure costs [Rezaee and Porter, 1988]. Yet treating simplified reports only as a supplement to the full financial accounts would leave the reporting firms not only with the costs of collecting detailed information for the preparation of the full accounts but might even increase those costs if an additional simplified report would have to be prepared and printed. The net effect on publication costs depends on the portion of shareholders still requesting full accounts. As more shareholders request full accounts, publication costs will

${ }^{3}$ Cowan [1968, p. 99] has argued that the financial accounts should be aimed at the average shareholder with limited skills. Such an approach would reduce the need for a separate set of simplified accounts. Others, however, have argued that the target of financial accounts should be a reader with more than limited skills who is reasonably well informed about the accounting models and terminology [Bevis, 1962, p. 33 and FASB, 1978, p. viii] and that even average readers would be served best by the more and better information is available for the professional analyst [Buzby, 1974a, p. 46]. Indeed, it seems hard to defend that more sophisticated readers of financial statements should have to suffer to enable the less informed groups to receive simpler reports [Tweedie, 1981, p. 128].

4 Other ways of presenting the information in accounts are already incorporated in financial accounts by using charts and graphics. Also multistage reporting is used, starting with general information found in the balance sheet and profit and loss account, followed by more detailed information in the supporting notes. Also the use of the directors' report, summary tables, and a page with 'financial highlights' are ways to assist the reader in finding his way through the overwhelming amount of information in the financial accounts. 
increase as simplified accounts would be prepared and published in addition to the full accounts and not as substitutes for the full accounts ${ }^{5}$.

In the US the idea of summary annual accounts really got of the ground with a research project that was initiated by the Financial Executives Institute (FEI), and sponsored by the Financial Executives Research Foundation (FERF) [Nair and Rittenberg, 1990, p. 25]. When General Motors filed a request to the SEC to be permitted to issue a summary annual report in 1987, the SEC endorsed it. GM did not ask for a change in the disclosure requirements, but merely suggested that the disclosures be shifted to the proxy statement rather than run in the annual report [Rezaee and Porter, 1988, p. 44]. Specific guidelines for the form, content and methods of disseminating a summary annual report have not been established by the FASB. The SEC issued a guidance on preparing annual reports using the summary format, allowing SARs only as long as all disclosure regulations were met in other reports (e.g. 10K forms) [Schroeder and Gibson, 1992, p. 28].

In the UK the ICAEW issued a research study to consider the implications of simplified financial reporting as a reaction to a memorandum of the Consultative Committee of Accountancy Bodies [CCAB, 1977], where it was stated that:

\footnotetext{
"we believe there may be some merit in examining whether companies might be permitted, in place of the present requirement to send the full accounts to all shareholders, to issue to those who wish it, a simplified form of annual statement" [CCAB, 1977, p. 4].
}

The Companies Act 1989 includes a section (251) allowing listed public companies to issue a summary financial statement to shareholders as a substitute for the full statutory accounts. The Act, however, allows the sending of simplified accounts unless the shareholder explicitly requires full accounts, contradictory to the view of the ICAEW that the shareholder should take positive action to choose simplified accounts.

The reaction of reporting firms towards SARs in the US and UK seems to be characterised by a "wait and see" attitude [Nair and Rittenberg, 1990, p. 37, Hussey, 1991 , p.6]. As to the reasons why firms are so cautious in preparing SARs, one can only speculate. Large firms could hold on to full financial statements because the most important users would be sophisticated investors who have little interest in

${ }^{5}$ Calculations by Hammill indicate that a company issuing 20,000 reports would have no increase in total publication costs if no more than $50 \%$ of the shareholders requested full accounts. This 'break-even-percentage' drops if the total number of annual accounts published decreases [Hammill, 1979, pp. 87-90]. McKesson, which was the first major US corporation to issue a summary accounting report after the SEC consented to it, saved about $\$ 60,000$ net as a result of switching to the summary format [Rezaee and Porter, 1988, p. 46]. 
simplified financial statements. Small firms could be ignoring SARs because there are insufficient cost savings or they might even result in an increase in costs. However, very little is known about the incentives of management to issue (or not issue) SARs and also the use of SARs and satisfaction of users with SARs are largely unknown [Nair and Rittenberg, 1990, Lee and Morse, 1990, Schroeder and Gibson, 1992].

The idea of simplifying financial reporting requirements for all firms, at the least provides a consistent solution to the standards overload problem. This option would avoid many of the problems involved with most of the other options presented before. Basically, the idea of SARs is not a differential reporting solution, thus avoiding the problem of discriminating between which firms the simplifications should or should not apply to.

Whether overall simplified reporting will provide an adequate solution to the standards overload problem of small private firms remains open. Simplifying financial statements hardly seems a solution to the problem of users who do not understand accounting basics such as accounting principles and valuation methods. The accounting language used would still be the same while the use of non-technical terms may lead to the loss of precision and brevity and would only increase the problem of the excessive volume of the accounts. Also, the impact on accounting costs for firms seems limited since summary accounting reports can never fully replace the full financial statements. But most importantly, the idea of using SARs ignores all arguments that support the idea that financial reporting is different in the context of small private firms and that financial reporting requirement for these firms thus should be different from the requirements of large public firms. 


\section{Appendix III}

\section{Financial Reporting Requirements for Small Dutch Firms}

In this appendix the exemptions for small firms provided in the Dutch company law are discussed. A description of these requirements is essential, as they provide the basis for determining the level of compliance with statutory requirements. For example, the standard balance sheet model provided in the company law was used in the compliance study to determine the correct naming of balance sheet items in financial statements disclosed. Also, these models provide a point of reference for the volume of information to be disclosed in the balance sheet. The exemptions provided for small firms are defined in section 396 of Title 9 of the second book of the Civil Code and involve the preparation, the audit and the disclosure of the financial statements.

\section{A. The small firm regime}

Dutch company law distinguishes between three categories of firms based on firm size, by using three variables: total assets, total annual sales and number of employees (see table 1). The cut-off points incorporated in the Dutch company law to define small and medium-sized firms have since their introduction in 1983 been reset as early as 1985 as well as in 1991 and 1995. Small and medium-sized companies are defined as any company meeting at least two of the these criteria ${ }^{1,2}$. The criteria are specified in such a way that all exemptions for medium-sized firms also apply to small firms, since small firms automatically meet the criteria for medium-sized firms. The exemptions included

\footnotetext{
${ }^{1}$ Evaluation of the size criteria is based on the accumulated numbers of all firms that would be consolidated if consolidated accounts were required. The number of employees has to be fully cumulated regardless the portion of share capital of a subsidiary owned by the parent company. If a firm, based on the consolidated figures, meets the size criteria for a small or medium-sized firm then the same regime applies to the consolidated accounts (that is, if preparation of the consolidated accounts is required for the firm).
}

${ }^{2}$ The size criteria do not apply to banks and insurance companies. 
in the regulation are not mandatory, so a small firm can always follow the regime of medium-sized or large firms if so desired ${ }^{3}$.

Table 1. Size criteria for small and medium-sized firms

\begin{tabular}{|c|c|c|c|c|}
\hline & 1983 & 1985 & 1991 & 1995 \\
\hline \multicolumn{5}{|l|}{ Small } \\
\hline Total assets & $f 3,000,000$ & $f 4,000,000$ & $f 5,000,000$ & $f 6,000,000$ \\
\hline Net turnover & $f 6,000,000$ & $f 8,000,000$ & $f 10,000,000$ & $f 12,000,000$ \\
\hline Number of personnel & $<50$ & $<50$ & $<50$ & $<50$ \\
\hline \multicolumn{5}{|l|}{ Medium-sized } \\
\hline Total assets & $f 12,000,000$ & $f 17,000,000$ & $f 20,000,000$ & $f 24,000,000$ \\
\hline Net turnover & $f 24,000,000$ & $f 35,000,000$ & $f 40,000,000$ & $f 48,000,000$ \\
\hline Number of personnel & $<250$ & $<250$ & $<250$ & $<250$ \\
\hline
\end{tabular}

To avoid firms that are near the upper limits for small or medium-sized company changing regime every year as a result of small changes in firm size, rules have been introduced that specify when a firm can or should change from one set of rules to another. Three basic rules can be distinguished:

1. A starting firm, in its first two financial years, has to follow the regime conforming to the size-criteria that are applicable at the end of the first financial year (section 398, Title 9, Book 2, Civil Code).

2. A firm using the regime for a small or medium-sized firm should change regime only if it has not met the criteria for the regime it is currently using for two consecutive years (section 396 and 397, Title 9, Book 2, Civil Code).

3. A firm should apply the regime for a small or medium-sized firm only if it has met the size criteria for that regime for two consecutive years (section 396 and 397, Title 9, Book 2, Civil Code).

If, for example, a starting firm meets the size criteria for a small firm it should follow the regime for a small firm in the first two years (rule 1). In year three, it should still apply the small regime even if it meets the size criteria for a medium-sized firm (rule $2)^{4}$. In year 4 it has to comply with the regulation for medium-sized firms (rule 3 ) and remain doing so in year 5 (rule 2). Finally, in year 6 , rule 2 prohibits the firm from using any of the exemptions for small and medium-sized firms (see table below).

${ }^{3}$ The shareholders' meeting has to take a decision on following a different regime within six months after the start of the financial year (section 398, clause 2, Title 9, Book 2, Civil Code)

${ }^{4}$ If in year 3 or year 4 the firm should not meet the size criteria for a small or medium-sized firm, it would have to change from the small regime in year 3 to the requirements for large firms in year 4 (rule 2 demands a change of regime in year 4 but rule 3 prohibits the use of the medium regime in either year). 


\begin{tabular}{|l|c|c|c|c|c|c|}
\hline Year & 1 & 2 & 3 & 4 & 5 & 6 \\
\hline Criteria & Small & Small & Medium & Medium & Large & Large \\
Regime & Small & Small & Small & Medium & Medium & Large \\
\hline
\end{tabular}

\section{B. Requirements for the preparation of small company accounts}

Preparation requirements for small firms concern (1) the director's report, (2) the financial statements (balance sheet, profit and loss account and notes to the financial statements) and (3) complementary information. Requirements regarding the contents of the directors report are equal for small, medium-sized and large firms ${ }^{5}$. Also, regarding the contents of the complementary information there are no exemptions for small firms ${ }^{6}$.

For the balance-sheet and profit and loss account there are separate models to be used by small firms (see tables 2 and 3 ). These models contain less information compared to those of large firms, in the balance sheet mostly because detail-accounts are omitted and in the profit and loss account because some accounts can be combined ${ }^{7}$. The profit and loss account does not provide information on the net sales of the company but only on the gross-margin (net sales less cost of sales). Instead, a small firm has to provide the change in net sales in relation to the previous financial year. If consolidated accounts are available, the company profit and loss account should only provide information on the share in profit of subsidiaries.

${ }^{5}$ The director's report should give information about expectations on future developments concerning investments, company-financing, personnel, research and development and circumstances that might have an impact on the company sales or profitability (section 391, Title 9, Book 2, Civil Code).

It should be noted here that a recent change in the Dutch company law has resulted in the cancelling of the requirement for small companies to prepare the director's report unless the company has a works council (section 396, clause 6, Title 9, Book 2, Civil Code).

${ }^{6}$ Complementary information includes information on profit distribution, profit-sharing bonds, statutory rights of control and financial information on subsidiaries not part of the group.

'Models for the financial statements are included in the 'General Administrative Order on Models' of December 23, 1983, amended March 19, 1985. This Order includes two balancesheet models for large and medium-sized firms and two balance sheet models for small firms (in both cases a columnar and an account form model). For the profit and loss account there are four models for large and medium-sized firms and two models for small firms. The Order further entails a number of articles including detailed instructions as to when the name of an item may be changed, when items may be combined, added or left out and what changes in the sequence of items are allowed. 
Table 2. Standard abridged balance sheet.

Balance sheet per .../.../... before/after distribution of profits

\begin{tabular}{l|l}
\hline A. Fixed Assets & A. Shareholders Equity \\
I. Intangible fixed assets & I. Paid up and called up share capital \\
II. Tangible fixed assets & II. $\quad$ Share premium account \\
III. Fixed asset investments & III. Revaluation reserves \\
B. Current Assets & IV. $\quad$ Legal- and statutory reserves \\
I. Stocks & VI. Other reserves \\
II. Accounts receivable & \\
III. Securities & B. Provisions \\
IV. Cash & C. Long-term liabilities \\
& D. Current liabilities \\
\hline
\end{tabular}

The exemptions provided for small (and also medium-sized) firms all concern differential recognition, i.e. the incorporation of items in the financial statements. Dutch company law does not provide any differential measurement rules. So, as far as valuation methods and income measurement is concerned, no exemptions for small or medium-sized firms are provided.

The most extensive exemptions concern the notes on the financial statements. Detailed information on convertible loans, long-term loans, net sales, payment of directors and commissioners, provisions and fixed assets do not have to be provided by small firms. However, even with these exemptions the number of items to be included in the notes is still quite extensive (see table 4). Any exemption permitted by company law can be dismissed by the shareholders' meeting within six months after the ending of the financial year. The shareholders of a small firm can also, within the same period, decide to follow the regime of medium-sized or large firms.

Regarding the time table for the completion of the financial statements there are no exemptions for small firms, which means that the preparation of the accounts has to be completed within five months after the ending of the financial year. Within six month after the end of the financial year the financial statements have to be ready for approval by the shareholders' meeting ${ }^{8}$. If the accounts are not approved by the shareholders' meeting within seven months, the financial statements have to be disclosed anyway, including a deposition that the financial statements have not yet been approved. In the case of special circumstances, the shareholders' meeting can increase the period for

'In between, the shareholders' meeting has to convene and the accounts have to be kept at the head office of the firm for inspection by the shareholders. Often, however, the financial statements are sent to all shareholders. For large firms, a period of 1 month may be rather short to realise all this, but in small firms with a relatively small number of shareholders it should cause few problems. 
preparation by a maximum of six months. In that case, the financial statements have to be presented to the shareholders' meeting for approval within two months after the preparation is completed. So, the financial statements would have to be ready for approval by the shareholders' meeting no longer than thirteen months after the ending of the financial year (section 394). If the accounts have not been approved within this period, they have to be filed anyway to prevent firms from delaying the filing of the accounts infinitely.

Table 3. Standard abridged profit and loss account.

Profit and loss account over 19.

Gross-margin
Sales costs
Overhead costs
Profit on fixed asset investments
Other interest receivable
Revaluation of fixed asset investments
Interest payable

Profit on ordinary activities before taxation

Taxation

Minority interests

Profit after taxation

Extraordinary items

Extraordinary benefits

Extraordinary costs

Taxes on extraordinary items

Net profit

Small firms are exempted from the obligation to prepare consolidated accounts (section 407). If consolidated accounts are prepared anyway, the exemptions provided by the regime for small companies apply equally. Finally, firms can be exempted from preparing financial statements if they are part of a group and the financial statements are incorporated in the consolidated accounts of the parent company ${ }^{9}$. In that case, the content of the balance sheet is limited to five items (fixed assets, current assets, shareholders' equity, provisions and debts) and the profit and loss accounts consists of only two items (results of ordinary activities after tax and extraordinary results after tax). All other requirements for preparation of the financial statements do not apply.

\footnotetext{
9 There are some additional requirements that are laid down in section 403 of title 9 of the second book of the Dutch Civil Code.
} 
Table 4. Abridged notes to the financial statements

* valuation methods

* depreciation methods

* valuation of foreign currencies

* methods used for calculating taxes and provisions

* changes in policies including the impact of such changes on the equity and result of the company

* amortisation period for goodwill (if not 5 years) and mentioning of the reason

* debtors falling due within a year

* detailed information about issued and paid up capital, including the allotted share capital (in case the share capital has not been fully paid up) and the number of allotted shares and their nominal value by class.

* information about changes in share capital, including the number and nominal value of the company's shares allotted during the financial year, and the method of payment for shares and the nature of contracts relating to shares issued otherwise than for cash

* summary of changes in the revaluation reserve

* information about statutory reserves

* information about self owned share-capital, including the number and nominal value and the name of the reserves from which the value of such shares has been deduced.

* information about transactions in self owned share-capital (public companies only)

- reason for any difference between parent company capital and reserves and consolidated capital and reserves (consolidated accounts only)

* interest of outside shareholders of consolidated group companies (consolidated accounts only)

* liabilities due within a year

- liabilities not due within 5 years

* interest rate for long term liabilities

* amount of secured long term and current liabilities

* collateral provided for debts

- amount of long term and current liabilities for which the company has undertaken to charge or not to charge assets as security

* guarantees given in behalf of third parties, separate mentioning of guarantees for the benefit of group companies and for the benefit of affiliated non-group companies and a classification of guarantees to their legal nature.

* long term financial obligations not appearing on the balance sheet

* loans to directors, former directors, commissioners and former commissioners, including the outstanding amounts, rate of interest, important conditions and repayments.

* list of subsidiaries and participations, including the name and address and the percentage of capital held.

* name and address of the ultimate holding company.

* name, office address and place where the published consolidated accounts of each upstream consolidating company may be obtained

* list of consolidated company's and of participations held by them (consolidated accounts only)

* change in net sales compared with the previous year (in percentages)

* salaries, wages and social security premiums, separately stating pension costs

* number of employees, in total and analyzed by business

* notes on extraordinary items

* devaluation of fixed assets

* exceptional adjustments to value of current assets

- amount released from revaluation reserve

* retained profits

* impact of changes in revaluation reserves on profits

* details about any difference between parent company profit or loss and the consolidated profit or loss (consolidated accounts only) 


\section{Requirements for the audit of small company accounts}

Small firms do not have to have their accounts audited unless the shareholders meeting, within six months after the ending of the financial year decides otherwise. The obligation of an audit can also be part of the company's statutes.

\section{Requirements for the disclosure of small company accounts}

The disclosure requirements for small firms only apply to the balance sheet and the notes to the balance sheet. The director's report, the profit and loss account including the notes thereto, and the complementary information do not have to be filed with the Chamber of Commerce. The balance sheet has to be disclosed as prepared but several items in the notes to the financial statements are excluded from disclosure ${ }^{10}$. The profit and loss account, the directors report as well as the complementary information of a small firm is not disclosed, leaving information on the firm's profits and the proposal for the distribution of the profits unrevealed.

The information required has to be filed with the Commercial Register of the Chamber of Commerce in the district in which the legal entity has its registered office within eight working days after the approval of the financial statements by the shareholders' meeting. If the period for approval of the accounts has expired, the non-approved accounts have to be filed within two months after the date of expiration. This means that if the period for the completion of the accounts has been extended by the maximum of six months, the accounts would be disclosed at least thirteen months after the ending of the financial year.

Small firms are exempted from all disclosure requirements if the firm:

1 . is a non-profit organisation, and

2. sends the balance sheet and the accompanying notes to the debtholders and shareholders at their request and free of charge, and

3. files a statement with the Commercial Register by a public accountant stating that (1) the firm was not involved in any activities beyond the firm's objectives and (2) the relevant section in the company law applies (section 396, Par. 8, Title 9, Book 2 of the Dutch Civil Code).

Apart from the exemptions mentioned above based on the size of a firm, there are exemptions based on other than size-criteria ${ }^{11}$. Regarding small firms, the most

${ }^{10}$ The exemption applies to the information on movements in allotted share capital and self owned shares held as mentioned in section 378, clause 3 .

"These exemptions based on criteria of various natures can be found in section 12, Title 9 , Book 2 of the Dutch Civil Code and concern special requirements for insurance companies, banks and group-companies 
important one is that a group-firm, of which the financial data are being consolidated in the financial statements of the parent-firm, can be exempted from the disclosure of the complete financial statements if the parent company declares itself to be liable for all debts of the subsidiary. In that case, the accounts of the parent company have to be filed together with the statement of liability. Also, the preparation requirements for the accounts for these firms are restricted to an extremely small balance-sheet and profit and loss account, jointly containing only seven items ${ }^{12}$.

12 The items are (1) fixed assets, (2) current assets, (3) equity, (4) provisions and (5) liabilities for the balance sheet (6) results from normal company activities after taxes and (7) other results after taxes on the profit and loss account. Public companies have to disclose this summary balance sheet together with the accounts of the parent company and the statement of liability. 


\section{References}

Abdel-Khalik, R., 1983, Financial Reporting by Private Companies: Analysis and Diagnosis, Financial Accounting Standards Board, Stamfort, Connecticut.

ACE-Resultants, Eindrapportering van de pilot-study naar de administratieve lasten voor ondernemingen voortvloeiend uit wettelijk verplichte administraties, Utrecht.

AICPA, 1976, Report of the Committee on Generally Accepted Accounting Principles for Smaller and/or Closely Held Companies, American Institute of Certified Public Accountants, New York.

AICPA, 1980, Report of the Special Committee on Small and Medium-Sized Firms, American Institute of Certified Public Accountants, New York.

AICPA, 1983, Report of the Special Committee on Accounting Standards Overload, American Institute of Certified Public Accountants, New York.

Allers, M., 1994, Administrative and compliance costs of taxation and public transfers in the Netherlands, Wolters-Noordhoff, Groningen.

Alten van, B., Lelieveldt, S. en Nijhof, P., 1988, Jaarrapporten en jaarcijfers als informatiebron ten behoeve van concurrentieanalyse: enkele "casestudies", Maandblad voor Bedrijfsadministratie en Organisatie, No. 1092, pp. 65-67.

Armstrong, M.S., 1977, The Impact of FASB Statements on Small Business, Journal of Accountancy, August, pp. 88-90.

Ashton, R.H., J.J. Willingham, R.K. Elliot, 1987, Empirical Analysis of Audit Delay, Journal of Accounting Research, Vol. 25, No. 2, pp. 275-292.

Ashton, R.H., P.R. Graul, J.D. Newton, 1989, Audit Delay and the Timeliness of Corporate Reporting, Contemporary Accounting Research, Vol. 5, No. 2, pp. 657-673.

Atiase, R.K., 1980, Prediclosure Informational Asymetries, Firm Capitalization, Financial Reports and Security Price Behavior, Ph.D. Dissertation, University of California, Berkeley. 
Atiase, R.K., 1985, Predisclosure Information, Firm Capitalization, and Security Price Behavior Around Earnings Announcements, Journal of Accounting Research, Vol. 23, No. 1, pp. 21-36.

Atiase, R.K., 1987, Market Implications of Predisclosure Information: Size and Exchange Effects, Journal of Accounting Research, Vol. 25, No. 1, pp. 168-176.

Atiase, R.K., L.S. Bamber and R.N. Freeman, 1988, Accounting Disclosures Based on Company Size: Regulations and Capital Markets Evidence, Accounting Horizons, Vol. 2, No. 1, pp. 18-26.

Atiase, R.K., L.S. Bamber, S. Tse, 1989, Timeliness of Financial Reporting, the Firm Size Effect, and Stock Price Reactions to Annual Earnings Announcements, Contemporary Accounting Research, Vol. 5, No. 2, pp. 526-552.

Autenrieth, K., 1989, Zwangsgeld bei verstoss gegen die Veroffentlichungsplicht nach HGB bei kleinen Kapitalgesellschaften?, Der Betrieb, p. 2581-2582.

Bak, G.G.M., H.C. Dekker, H.P.A. Langendijk, 1985, Beheersing van (kosten van) accountantscontrole, NIVE, Kluwer, Deventer.

Baker, W.M., 1990, How Non-GAAP Financial Statements Affect Loan Officers and Borrowers, Journal of Commercial Bank Lending, May, pp. 23-29.

Ball, R., G. Foster, 1982, Corporate Financial Reporting: A Methodological Review of Empirical Research, Joumal of Accounting Research, Vol. 20, Supplement, pp. 161234.

Bamber, L.S., 1986, The Information Content of Annual Earnings Releases: A Trading Volume Approach, Journal of Accounting Research, Vol. 24, No. 1, pp. 40-56.

Bamber, L.S., 1987, Unexpected Earnings, Firm Size, and Trading Volume Around Quarterly Earnings Announcements, Accounting Review, Vol. 62, No. 3, pp. 510-532.

Bastable, C.W., 1977, Is SEC Replacement Cost Data Worth the Effort, Journal of Accountancy, October, pp. 68-76.

Beaver, W.H., 1989, Financial Reporting: An Accounting Revolution, Prentice Hall, Englewood Cliffs, New Jersey, second edition.

Becker, G.S., 1968, Crime and Punishment: An Economic Approach, Journal of Political Economy, Vol. 76, pp. 169-217.

Beckman, H., 1986, Accountantsverklaring en te Deponeren Jaarrekening, Maandblad voor Accountancy en Bedrijfshuishoudkunde, mei, pp. 192-209. 
Beckman, H., 1988, Financiële Verslaggeving door Kleine en Middelgrote Ondernemingen in de $E G$, Kluwer, Deventer.

Beckman, H., A.J. Bindenga, 1994, Het nieuwe jaarrekeningenrecht, Kluwer, Deventer, 12e druk.

Benjamin, J.J., K.G. Stanga, 1977, Differences in Disclosure Needs of Major Users of Financial Statements, Accounting and Business research, Vol. 7, No. 27, pp. 187-192.

Benston, G.J., 1980, Corporate Financial Disclosure in the UK and the USA, Saxon House, Hampshire.

Benston, G., 1984, The Cost of Complying with a Government Data Collection Program: The FTC's Line of Business Report, Journal of Accounting and Public Policy, Vol. 3, No. 2, pp. 123-137.

Berry, A., D. Citron, R. Jarvis, 1987, The information needs of bankers dealing with large and small companies, Chartered Association of Certified Accountants, London.

Bevis, H.W., 1962, The CPA's Attest Function in Society, Journal of Accountancy, February, pp. 28-35.

Bird, P., 1984, The Complexities of Simplified Accounts, in: Carsberg, B. and S. Dev, (ed.), 1984, External Financial Reporting, Prentice Hall, Englewood Cliffs, New Jersey, pp. 16-24.

Bollen, L.H.H., 1986, Jaarrekeningen na de aanpassingswet Vierde Richtlijn: een onderzoek van 94 gedeponeerde jaarrekeningen in de Kamer van Koophandel-districten Maastricht en Heerlen, Discussienota (WP 86-003), Rijksuniversiteit Limburg, Maastricht.

Bollen, L.H.H., 1990a, Regulering van jaarverslaggeving: een onderzoek naar percepties van ondernemingen (1), Maandblad voor Bedrijfsadministratie en Organisatie, Vol. 94, No. $1120 / 1121$, pp. $184-188$.

Bollen, L.H.H., 1990b, Regulering van jaarverslaggeving: een onderzoek naar percepties van ondernemingen (2), Maandblad voor Bedrijfsadministratie en Organisatie, Vol. 94, No. 1122 , pp. 228-235.

Bouma, J.L., 1988, Externe Verslaggeving: een Probleemgebied in Ontwikkeling, Maandblad voor Accountancy en Bedrijfshuishoudkunde, Vol. 62, juli/augustus, pp. 282-285.

Brinn, T., M.J. Peel, R. Roberts, 1991, Determinants of Audit Fees in the UK Unquoted Sector: Some New Evidence, Occasional Research Paper No. 11, Chartered Association of Certified Accountants, London. 
Brock, W.A., D.S. Evans, 1986, The Economics of Small Businesses: Their Role and Regulation in the U.S. Economy, Holmes and Meier, New York.

Bromwich, M., 1985, The Economics of Accounting Standards Setting, Prentice Hall, Englewood Cliffs, London.

Brown, L.D., E.H. Feroz, 1992, Does the FASB listen to corporations?, Journal of Business, Finance and Accounting, Vol. 19, No. 3, pp. 715-731.

Buijink, W.F.J., 1992, Empirical Financial Accounting Research: compliance with regulation, distributional properties of financial ratios and demand for external auditing, $\mathrm{Ph} . \mathrm{D}$. dissertation, Faculty of Economics and Business Administration, University of Limburg, Maastricht.

Butterworth, John E., Haim Falk, 1984, Accounting Standards: Percieved Cost/Benefit Relationships, Research Report, Social Sciences and Humanities Research Council of Canada.

Buzby, S.L., 1974a, The Nature of Adequate Disclosure, Journal of Accountancy, April, pp. 38-47.

Campbell, J.E., 1984, An Application of Protocol Analysis to the Little-GAAP controversy, Accounting, Organizations and Society, Vol. 99, No. 3/4, pp. 329-342.

Carsberg, B.V., M.J. Page, A.J. Sindall, I.D. Waring, 1985, Small Company Financial Reporting, Prentice Hall, London.

Carslaw, C.A.P.N., S.E. Kaplan, 1991, An Examination of Audit Delay: Further Evidence from New Zealand, Accounting and Business Research, Vol. 22, No. 85, pp. 21-32.

CCAB, 1977, The Future of Company Reports (Memorandum submitted to the Department of Trade), Consultative Committee of Accountancy Bodies.

Chambers, A.E., S.H. Penman, 1984, Timeliness of Reporting and the Stock Price Reaction to Earnings Announcements, Journal of Accounting Research, Vol. 22, No. 1, pp. 2147.

Chittenden, F., 1989, The Legal Structure of Small Firms, unpublished paper, Manchester Business School, Manchester.

Clift, R.C., 1989, Corporate Accounting, Prentice Hall, Sydney, Third edition.

Commission of the European Communities, 1995, Report of the Group of Independent Experts on Legislative and Administrative Simplification, CEC, Brussels.

Cooke, T.E., 1989, Disclosure in the Corporate Annual Report of Swedish Companies, Accounting and Business Research, Vol, 19, nr. 74, pp. 113-124. 
Courtis, J.K., 1976, Relationships between Timeliness in Corporate Reporting and Corporate Attributes, Accounting and Business Research, Vol. 7, No. 25, pp. 45-56.

Cowan, T.K., 1968, A Pragmatic Approach to Accounting Theory, Accounting Review, Vol. 43, No. 1, pp. 94-100.

Danos, P., D.L. Holt, E.A. Imhoff, 1989, The use of accounting information in bank lending decisions, Accounting, Organizations and Society, Vol. 14, No. 3, pp. 235-246.

Der Betrieb, 1986, Bundesregierung gegen Einbeziehung der GmbH \& Co. KG in die Prüfungs- und publizitätspflicht, Der Betrieb, p. 1416.

Department of Trade and Industry, 1986a, Accounting and auditing requirements for small firms, DTI, London.

Department of Trade and Industry, 1986b, The delivery of annual accounts and returns to the registrar of companies, DTI, London

Downs, A., 1957, An economic theory of democracy, Harper and Row, New York.

Drop, M., J.W.R. Schuit, 1992, De Financieringsstructuur van het Midden- en Kleinbedrijf, Delwel, Den Haag.

Duuren, C. van, 1986, Mijn financiën liggen nu op straat, Elseviers Weekblad, nr 8., maart.

Dyer, J.C., A.J. McHugh, 1975, The Timeliness of the Australian Annual Report, Journal of Accounting Research, Vol. 13, No. 2, pp. 204-219.

Easterbrook, F.H., D.R. Fishel, 1984, Mandatory Disclosure and the Protection of Investors, Virginia Law Review, Vol. 70, pp. 669-715.

Egginton, D.A., 1977, Accounting for the banker, Longman, London.

EIM, 1994, Administratieve lasten bedrijven 1993, EIM/Arbeidsvraagstukken, Zoetermeer.

Espahbodi, R., H. Hendrickson, 1986, A Cost-Benefit Analysis of Accounting for Inflation, Journal of Accounting and Public Policy, Vol. 5, No. 1, pp. 31-55.

Evans, David S., 1987, Tests of alternative Theories of Firm Growth, Journal of Political Economy, Vol. 95, no. 4, pp. 657-674)

Falk, H., B.C. Gobdel, J.H. Naus, 1976, Disclosure for Closely Held Corporations, Journal of Accountancy, October, pp. 85-89.

FASB, 1978, Objectives of Financial Reporting by Business Enterprises, Statement of Financial Accounting Concepts 1, FASB. 
FASB, 1981, Financial Reporting by Private and Small Public Companies: Invitation to Comment, Financial Accounting Standards Board, Stamford, Connecticut.

FASB, 1983, Status Report no. 181, FASB, Stamford, Connecticut.

Firth, M., 1978, A Study of the Consensus of the Perceived Importance of Disclosure of Individual Items in Corporate Annual Reports, International Journal of Accounting Education and Research, Vol. 14, No. 1, pp. 57-70.

Forker, J.J., 1992, Corporate Governance and Disclosure Quality, Accounting and Business Research, Vol. 22, no. 86, pp. 111-124.

Foster, G., 1980, Externalities and Financial Reporting, Journal of Finance, May, pp. 521533.

Foster, G., 1986, Financial Statement Analysis, Prentice Hall, Englewood Cliffs, New Jersey, second edition.

Francis, J.R., D.T. Simon, 1987, A Test of Audit Pricing in the Small-Client Segment of the U.S. Audit Market, Accounting Review, Vol. 62, No. 1, pp. 145-157.

Francis, J.R., D.J. Stokes, 1986, Audit Prices, Product Differentiation, and Scale Economies: Further Evidence from the Australian Market, Journal of Accounting Research, Vol. 24, No. 2, pp. 383-393.

Freeman, R.N., 1987, The Association Between Accounting Earnings and Security Returns for Large and Small Firms, Journal of Accounting and Economics, Vol. 9, No. 2, pp. 195228.

Gilling, D.M., 1977, Timeliness in Corporate Reporting: Some Further Comment, Accounting and Business Review, Vol. 8, No. 29, pp. 34-36.

Givoly D., D. Palmon, 1982, Timeliness of Annual Earnings Announcements: Some Empirical Evidence, Accounting Review, Vol. 57, No. 3, pp. 486-508.

Goodwin, J., D. Newitt, 1990, Vive La Differential Reporting, Charter, February, pp. 48-50.

Grant, E.B., 1980, Market Implications of Differential Amounts of Interim Information, Journal of Accounting Research, Vol. 18, no. 1, pp. 255-176.

Gray, S.J., C.B. Roberts, 1986, Voluntary information disclosure and the British multinationals: corporate perceptions of costs and benefits, unpublished paper presented at the DHS/ICAEW Accounting Research Symposium, London Business School. 
Griffin, P.A. (editor), 1987, Usefulness to Investors and Creditors of Information Provided by Financial Reporting, Financial Accounting Standards Board, Stamford, Connecticut.

Grinten, W.C.L. van der, 1981, Juridische Aspecten van de Totstandkoming van de Jaarrekening: de Publicatieplicht, in: De Jaarrekening en de Vierde EEG-Richtlijn, Monografieen vanwege het Van der Heijden-instituut te Nijmegen, deel 20, Kluwer, Deventer.

Gutberlet, L.G., 1983, An Opportunity - Differential Standards, Journal of Accounting Auditing and Finance, Vol. 7, No. 1, pp. 16-28.

Hagenau, G.F., M. Hauser, 1989, Die publizität des Jahresabschlusses - Eine nicht zwingende Vorschrift?, Betriebs-Berater, pp. 180-182.

Hahn, J., 1981, Jahresabschlussprüfung bald für 50.000 Unternehmen? GmbH-umfrage bringt Zahlen, Der Betrieb, pp. 2461-2462.

Hammill, A.E., 1979, Simplified Financial Statements, Institute of Chartered Accountants in England and Wales, London.

Haw, I., B.T. Ro, 1990, Firm Size, Reporting Lags and Market Reactions to Earnings Releases, Journal of Business Finance \& Accounting, Vol. 17, No. 4, pp. 557-574.

Holmes, S., D. Nicholls, 1989, Modelling the Accounting Information Requirements of Small Businesses, Accounting and Business Research, Vol. 19, no. 74, pp. 143-150.

Holmes, S., P. Kent, G. Downey, 1991, The Australian Differential Reporting Debate: A Survey of Practitioners, Accounting and Business Research, Vol. 21, No. 82, pp. 125132.

Horwitz, B., R. Kolodny, 1982, Financial Reporting Rules and Corporate Decisions: A Study of Public Policy, JAI Press, London.

Hulle van, K. 1987, The contribution of academic research to Harminisation of accounting standards in the European Community, unpublished paper.

Humphrey, C., S. Turley, 1986, The nature of the audit in small companies: an empirical investigation, Accountant's Magazine, research supplement, pp. 25-42.

Ingram, R., D. Guy, I. Merei, R. Justis, 1977, Disclosure Pratices in Unaudited Financial Statements of Small Businesses, Journal of Accountancy, August, pp. 81-86.

Jegers, M., W. Buijink, 1987, The reliability of financial accounting databases: some Belgian evidence, International Journal of Accounting Education and Research, Vol. 23, no. 1, pp. 1-21. 
Keasey, K., H. Short, 1990, The Accounting Burdens Facing Small Firms: An Empirical Research Note, Accounting and Business Research, Vol. 20, no. 80, pp. 307-313.

Keasey, K., R. Watson, 1986a, Current Cost Accounting and the Prediction of Small Company Performance, Journal of Business Finance \& Accounting, Vol. 13, No. 1, pp. 51-70.

Keasey, K., R. Watson, 1986b, The Prediction of Small Company Failure: Some Behavioural Evidence for the UK, Accounting and Business Research, Vol. 17, No. 65, pp. 49-57.

Keasey, K., R. Watson, 1987, Non-Financial Symptoms and the Prediction of Small Company Failure: A Test of Argenti's Hypotheses, Journal of Business Finance \& Accounting, Vol. 14, No. 3, pp. 335-354.

Keasey, K., R. Watson, 1988, The Non-Submission of Accounts and Small Company Financial Failure Prediction, Accounting and Business Research, Vol. 19, No. 73, pp. 47-54.

Keasey, K., R. Watson, 1993, Small Firm Management: Ownership, Finance and Performance, Blackwell, Oxford.

Keasey, K., R. Watson, P. Wynarczyk, 1988 The Small Company Audit Qualification: a Preliminary Investigation, Accounting and Business Research, Vol. 18, No. 72, pp. 323-333.

Keller, S.B., 1986, Reporting Timeliness in the Presence of Subject to Audit Qualifications, Journal of Business Finance \& Accounting, Vol. 13, No. 1, pp. 117-124.

Kelly-Newton, L., 1980, Accounting Policy Formulation: The Role of Corporate Management, Addison Wesley, Reading, Massachusetts.

Klaassen, J., H. Schreuder, 1980, Het Financiële Jaarverslag van Ondermemingen: een onderzoek onder gebruikers, H.E. Stenfert Kroese B.V., Leiden-Antwerpen.

Knutson, D.L., H. Wichmann, 1985, The Accounting Standards Overload Problem for American Small Businesses, Journal of Business Finance and Accounting, Vol. 12, No. 3, pp. 387-397.

Kross, W., D.A. Schroeder, 1984, An Empirical Investigation of the Effect of Quarterly Earnings Announcements Timing on Stock Returns, Journal of Accounting Research, Vol. 22, No. 1, pp. 153-176.

Kross, W., D.A. Schroeder, 1988, Firm Prominence and the Differential Information Content of Quarterly Earnings Announcements, Journal of Business Finance \& Accounting, Vol. 16, No 1, pp. 55-75. 
Landau, W.L., 1988, The Federal and State Roles in Regulating United States Business Corporations, in: Harmonisatie en Vennootschapsrecht: Ervaringen en Vooruitzichten in Europa en de Verenigde Staten, Katholieke Universiteit Brabant, Kluwer, Deventer.

Larson, R.E., T.P. Kelly, 1984, Differential Measurement in Accounting Standards: The Concept Makes Sense, Journal of Accountancy, November, pp. 70-90.

Lee, C., D., Morse, 1990, Summary Annual Reports, Accounting Horizons, Vol. 4, No. 1 , pp. 39-50.

Lee, T.A., D.P. Tweedie, 1977, The Private Shareholder and the Corporate Report, Institute of Chartered Accountants in England and Wales, London.

Lee, T.A., D.P. Tweedie, 1981, Institutional Use and Understanding of Corporate Financial Information, Institute of Chartered Accountants in England and Wales, London.

Lefwich, R., 1980, Market Failure Fallacies and Accounting Information, Journal of Accounting and Economics, Vol. 2, pp. 193-211.

Lev, B., 1988, Toward a Theory of Equitable and Efficient Accounting Policy, Accounting Review, Vol 63, No. 1, pp. 1-22.

Libby, R., 1975, Accounting Ratios and the Prediction of Failure: Some Behavioral Evidence, Joumal of Accounting Research, Vol. 13, No. 1, pp. 150-161.

Libby, R., 1981, Accounting and Human Information Processing: Theory and Applications, Prentice Hall, Englewood Cliffs, New Jersey.

Lindahl, F.W., 1987, Accounting Standards and Olsons's Theory of Collective Action, Journal of Accounting and Public Policy, Vol. 6, pp. 59-72.

Lobo, G.J., A.A.W. Mahmoud, 1989, Relationship between Differential Amounts of Prior Information and Security Return Variability, Journal of Accounting Research, Vol. 27, No. 1, pp. 116-134.

Maijoor, S., 1991, The Economics of Accounting Regulation: Effects of Dutch Accounting Regulation for Public Accountants and Firms, Ph. D. Dissertation, Faculty of Econimcs and Business Administration, University of Limburg, Maastricht.

Mautz, R.K., W.G. May, 1978, Financial Disclosure in a Competitive Economy, Financial Executives Research Foundation, New York.

McCahey, J., 1987, Differentiation in Corporate Reporting, Chartered Accountant in Australia, May, pp. 35-37.

McCahey, J., 1989, Differential Reporting: Diffusing the Knowledge, Chartered Accountant, July, pp. 59-61. 
McCahey J., A. Ramsay, 1989, Differential Reporting: Nature of the Accounting Standards Overload Problem and a Proposal for Its Resolution, AARF Discussion Paper No. 13.

McCaslin, T.E., K.G. Stanga, 1986, Similarities in Measurement Needs of Equity Investors and Creditors, Accounting and Business Research, Vol. 16, No. 62, pp. 151-156.

McKinnon, S.M., 1984, A cost-benefit study of disclosure requirements for multinational corporations, Journal of Business Finance \& Accounting, Vol. 11, No. 4, pp. 451-468.

Meillicke, W., 1986, Gestaltungen zur Verminderung der Publizität, Der Betrieb, pp. 24452450.

Mertens, G., 1991, Accounting Choice: Preliminary Evidence on the Effects of the Introduction of Accounting Regulation in the Netherlands in 1971, European Accounting, Vol. 3, pp. 44-55.

Meuwissen, R., S. Maijoor, 1994, Accountantscontrole bij kleine en middelgrote ondernemingen, NOvAA-publicatie no. 13, Nederlandse Orde van Accountants Administratieconsulenten, Den Haag.

Morris, R.D., 1984, Corporated Disclosure in a Substantially Unregulated Environment, Abacus, Vol. 20, No. 1, pp. 52-86.

Morris, R., P. Omrod, 1990, The Attitudes of Credit Analysts towards Reduced Disclosure by Small Companies, Paper presented at the 13th Annual Congress of the European Accounting Association, Budapest.

Mosso, D., 1983, Standards Overload - No Simple Solution, Journal of Accountancy, November, pp. 120-138.

Mumford, M.J., 1990, A Note on the Disclosure Size Exemptions in Technical Release 706, Accounting and Business Research, Vol. 20, no. 79, pp. 240-244.

Murray, D., R. Johnson, 1983, Differential GAAP and the FASB's Conceptual Framework, Journal of Accounting Auditing and Finance, Vol. 7, No. 1, pp. 4-5.

Nair, R.D., L.E. Rittenberg, 1983, Accounting Costs of Privately Held Businesses, Journal of Accounting Auditing and Finance, Vol. 6, No. 3, pp. 234-243.

Nair, R.D., L.E. Rittenberg, 1990, Summary Annual Reports: Background and Implications for Financial Reporting and Auditing, Accounting Horizons, Vol. 4, No. 1, pp. 25-38.

NOvAA, 1986, Publicatiejaarrekening kleine BV doorgelicht, Accountant Adviseur, special, december. 
NOvAA, 1991a, Financiële verslaggeving door middelgrote ondernemingen: een onderzoek naar percepties van ondermemingen, NOvAA-publicatie no. 11, Nederlandse Orde van Accountants Administratieconsulenten, Den Haag.

NOvAA, 1991b, Het gebruik van financiële informatie door banken, NOvAA-publicatie no. 12. Nederlandse Orde van Accountants Administratieconsulenten, Den Haag.

Oldham, K.M., 1981, Accounting Systems and Practice in Europe, Gower, Hants, England, second edition.

Olson, 1965, The Logic of Collective Action: Public Goods and the Theory of Groups, Harvard University Press, Cambridge.

Ordelheide D. (ed), 1995, Transnational Accounting, MacMillan, United Kingdom.

Page, M.J., 1984, Corporate Financial Reporting and the Small Independent Company, Accounting and Business research, Vol. 14, No. 55, pp. 271-282.

Patell, J.M., M.A. Wolfson, 1982, Good News, Bad News, and the Intraday Timing of Corporate Disclosures, Accounting Review, Vol. 57, No. 3, pp. 509-527.

Penno, M., D.T. Simon, 1986, Accounting Choices: Public versus Private Firms, Journal of Business Finance \& Accounting, Vol. 13, No. 4, pp. 561-569.

Philips, S., J. Zecher, 1981, The SEC and the Public Interest, MIT Press, Cambridge, Massachusetts.

Poel, J.H.R. van de, 1988, Als de Tekenen Bedriegen....., Wolters Noordhoff, Groningen.

Poorthuis, F., 1990, Deponeert u uw jaarstukken al ?, Financieel Economisch Magazine, januari, pp. 55-57.

Posner, R.A., 1992, An economic analysis of law, Little, Brown and Company, Boston, 4th edition.

Ramsay, A., P. Sutcliffe, 1986, Financial Reporting by Proprietary Companies, Australian Accountant, July, pp. 48-54.

Rezaee, Z., G.L. Porter, 1988, Summary Annual Reports: Is shorter Better?, Journal of Accountancy, May, pp. 42-54.

Robertson, A., 1986, Small company auditing and financial reporting, Accountant's Magazine, research supplement, p. 7-24.

Roos, J., 1992, De Naleving door Kleine Vennootschappen van Regelgeving ten aanzien van bij het Handelsregister Gedeponeerde Jaarstukken, doctoraalscriptie, Erasmus Universiteit, Rotterdam. 
Salamon, G.L., D.S. Dhaliwal, 1980, Company Size and Financial Disclosure Requirements with Evidence from the Segmental Reporting Issue, Journal of Business Finance \& Accounting, Vol. 7, No. 4, pp. 555-568.

Schroeder, N., C. Gibson, 1992, Are Summary Annual Reports Successful?, Accounting Horizons, Vol. 6, No. 2, pp. 28-37.

SEC, 1977, Report of the Advisory Committee on Corporate Disclosure, Securities and Exchange Commiittee, Washinhton D.C..

Simunic, D.A., 1980, The Pricing of Audit Services: Theory and Evidence, Journal of Accounting Research, Vol. 18, No. 1, pp. 161-190.

Slagter, W.J., 1983, De Toekomst van de BV, TVVS, No. 6, pp. 142-152.

Snijder, M.A., 1981, De invloed van de fiscus op het midden en kleinbedrijf, FED, Deventer.

Solomons, D., 1986, Making Accounting Policy, The Quest for Credibility in Financial Reporting, Oxford University Press, New York.

Stanga, K.G., M.G. Tiller, 1983, Needs of Loan Officers for Accounting Information from Large versus Small Companies, Accounting and Business Research, Vol. 14, No. 53, pp. 63-70.

Sutton, T.S., 1984, Lobbying of accounting standard-setting bodies in the UK and the USA: a Downsian analysis, Accounting, Organizations and Society, Vol. 9, No. 1, pp. 81-95.

Tas, van der, L.G., 1989, De Accountantsverklaring bij Vereenvoudigde Openbaarmaking, De Accountant, September, pp. 16-23.

Tas, van der, L.G., 1992, Harmonisation of Financial Reporting, Ph. D. Dissertation, Erasmus Universiteit, Rotterdam.

Taylor, P., S. Turley, 1986, The Regulation of Accounting, Basil Blackwell, Oxford.

Thurik, A.R., 1990, De plaats van het MKB in Economisch Onderzoek, Maandblad voor Accountancy en Bedrijfshuishoudkunde, april, pp. 138-148.

Tonkin, D.J., 1989, World Survey of Published Accounts: An anlysis of 200 Annual Reports from the World's Leading Companies, Lafferty Publications.

Traas, L., 1976, De Informatieve waarde van de jaarrekening, Maandblad voor Accountancy en Bedrijfshuishoudkunde, pp. 48-61.

Trueman, B., 1990, Theories of Earnings-Announcement Timing, Journal of Accounting and Economics, Vol. 13, No. 3, pp. 285-301. 
Tsang, W., 1986, Small Company Financial Reporting: Compliance with the Companies Act 1981, University of Southampton.

Tversky, A., D. Kahneman, 1974, Judgement under Uncertainty: Heuristics and Biasses, Science, Vol. 185, pp. 1124-1131.

Tweedie, D.P., 1981, Simplified Financial Statements, in: Lee, T.A. (ed.), 1981, Developments in Financial Reporting, Philip Alan, Dedington, Oxford.

Upton, W.S., C.L. Ostergaard, 1986, The FASB Response to Small Business, Journal of Accountancy, May, pp. 94-100.

Watts, R.L., J.L. Zimmerman, 1986, Positive Accounting Theory, Prentice Hall International, Englewood Cliffs, New Jersey.

Weilbach, E., 1990, Kann es eine Jahresabschluss ohne Gewinn- und Verlustrechnung geben?, Betriebs-Berater, pp. 1095-1097.

Weilbach, E., 1991, Vermeidung der Zwanslóschung einer $\mathrm{GmbH}$ nach verweigerung der Registerpublizität, Betriebs-Berater, pp. 800-801.

Weilbach, E.,1992, Die Wirkungen der verfehlten Mittelstands- und GmbH \& Co. Richtlinie, Betriebs-Berater, pp. 955-957.

Whittred, G., 1980, Audit Qualification and the Timeliness of Corporate Annual Reports, Accounting Review, Vol. 55, No. 4, pp. 563-576.

Wittenburg, D., 1985, Bedrijfsleven is nalatig bij Publicatieplicht, NRC Handelsblad, 17 augustus, p. 10.

Wolk, H.I., J.R. Francis, M.G. Tearney, 1992, Accounting Theory, PWS-KENT Publishing Company, Boston, third edition.

Zeff, S.A., 1994, A Perspective on the US Public/Private-Sector Approach to Standard Setting and Financial Reporting, University of Limburg, Maastricht.

Zeff, S.A., F. van der Wel, K. Camfferman, 1992, Company Financial Reporting: A Historical and Comparative Study of the Dutch Regulatory Process, North Holland, Amsterdam.

Zeghal, D., 1984, Firm Size and the Informational Content of Financial Statements, Journal of Financial and Quantitative Analysis, Vol. 19, No. 3, September, pp. 299-310 


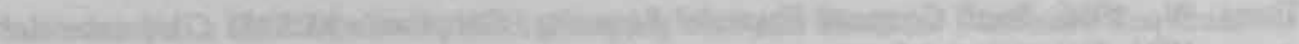

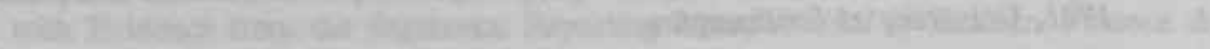

Q

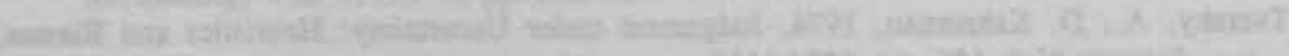

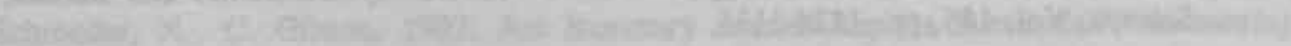

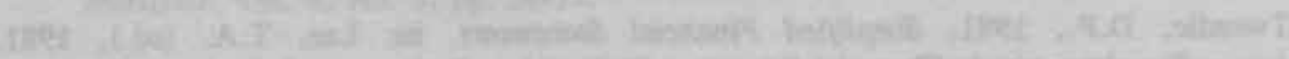

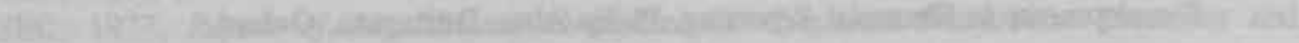

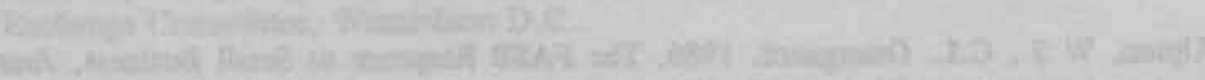
Wh

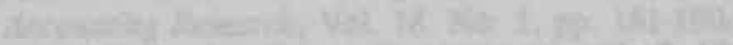

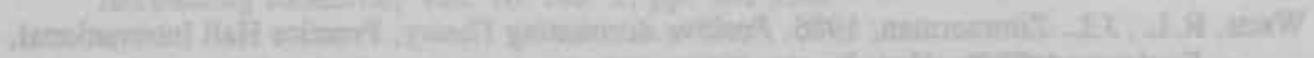

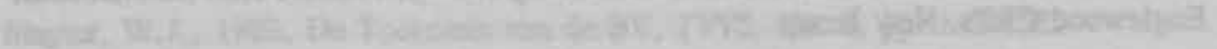

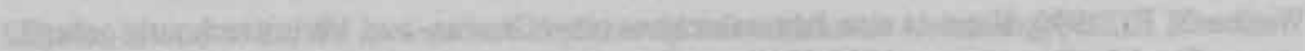

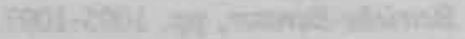

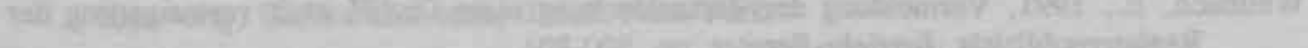

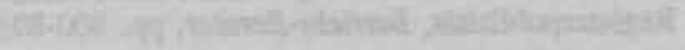

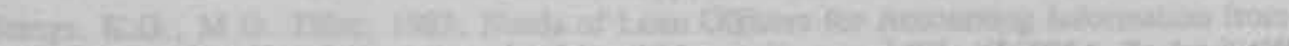

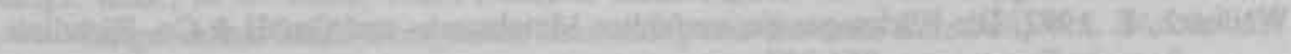

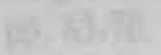

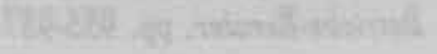

Q

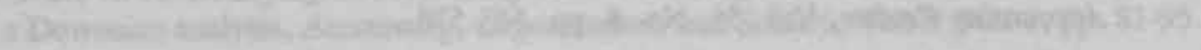

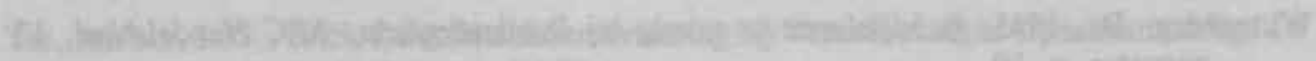

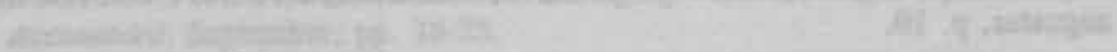

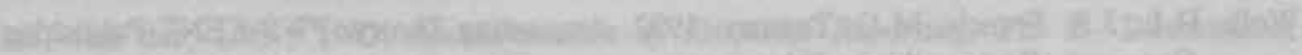

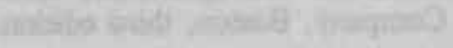

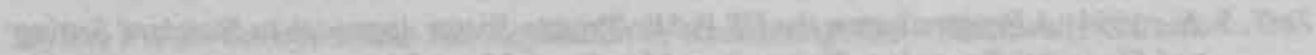

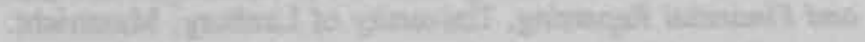

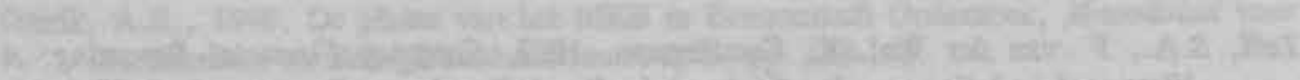

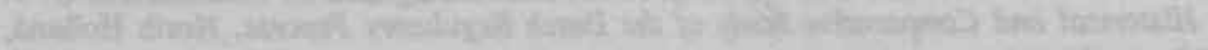

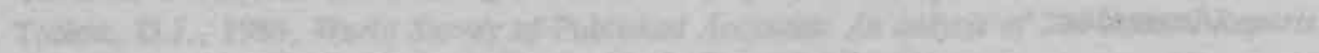
E⿱

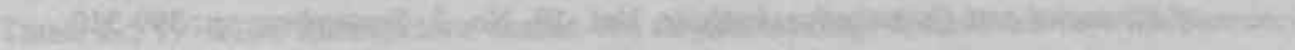

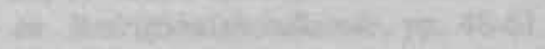

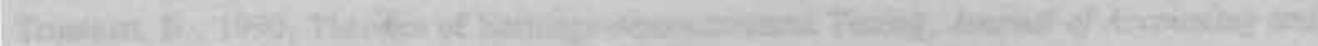

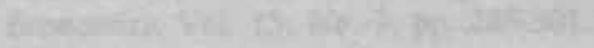




\section{Samenvatting}

Het doel van deze dissertatie is bij te dragen aan de literatuur op het gebied van de economische effecten van regelgeving van externe financiële verslaggeving door ondernemingen. Daarbij richt deze studie zich in het bijzonder op de economische gevolgen voor kleine en middelgrote ondernemingen. In het bijzonder worden de volgende vragen empirisch onderzocht:

- in hoeverre voldoen kleine ondernemingen aan de wettelijke verplichtingen die er in Nederland bestaan rond de externe financiële verslaggeving van ondernemingen?

- wat zijn de opvattingen van managers van kleine ondernemingen ten aanzien van het bestaan en de gevolgen van deze Nederlandse wet- en regelgeving?

- wat zijn de kosten voor kleine ondernemingen die zijn verbonden aan de samenstelling en publikatie van het financiële jaarverslag en in hoeverre zijn deze kosten beïnvloed door de bestaande wet- en regelgeving op dit gebied?

- wat zijn de opvattingen van gebruikers, met name bankmedewerkers, ten aanzien van het belang van het financiële jaarverslag van kleine en middelgrote ondernemingen?

Binnen het vakgebied van de financiële berichtgeving door ondernemingen (financial accounting) bestaat er een uitgebreide discussie omtrent het nut van en de noodzaak voor regelgeving van de financiële verslaggeving door ondernemingen. Deze discussie heeft zich met name toegespitst op de situatie rond grote (beurs-) ondernemingen. Een belangrijke reden hiervoor is dat in de VS, de federale regelgeving op dit gebied uitsluitend van toepassing is op beursondernemingen. Daardoor bestaat er binnen de VS relatief weinig aandacht voor de gevolgen van regelgeving voor kleine ondernemingen of voor ondernemingen die niet op een aandelenbeurs worden verhandeld.

Recente ontwikkelingen binnen de Europese Unie (EU) met betrekking tot de wetgeving voor de financiële jaarverslaggeving van ondernemingen, hebben er toe geleid dat in de EU-lidstaten deze wetgeving niet is beperkt tot grote ondernemingen maar ook van toepassing is op kleine en middelgrote ondernemingen. Daarmee ontstaat de vraag of de argumenten die in de discussie rond regelgeving van financiële verslaggeving door grote open ondernemingen worden gebruikt, op dezelfde wijze van toepassing zijn op kleine en middelgrote besloten ondernemingen.

Daarnaast doet het feit dat er binnen de EU wetgeving voor de financiële verslaggeving voor kleine en middelgrote ondernemingen bestaat, de vraag reizen wat de gevolgen van 
deze wettelijke regels voor de betrokken partijen zijn geweest. Met name het aspect van de naleving van de bestaande wettelijke regels lijkt in het kader van klein en middelgrote ondernemingen van bijzonder belang. Immers, gezien het grote aantal ondernemingen lijkt het, mede gezien het ontbreken van een verplichte accountantscontrole voor kleine ondernemingen, moeilijk een adequate controle op de naleving van de wettelijke vereisten uit te voeren.

In hoofdstuk 2 worden de economische theorieën met betrekking tot de wenselijkheid van wetgeving van financiële verslaggeving besproken. De argumenten die worden gebruikt binnen de public interest benadering en de private interest benadering worden hier behandeld. Tevens wordt een overzicht gegeven van de relevante empirische literatuur die op dit gebied is verschenen. Het hoofdstuk gaat in op de vraag of de argumenten die in beide theorieën worden gehanteerd in gelijke mate van toepassing zijn op kleine en middelgrote ondernemingen. Een belangrijk aspect hierbij is dat regelgeving niet alleen afhangt van de omvang van de betrokken onderneming maar ook van andere factoren, met name de ondernemingsvorm.

In het tweede deel van dit hoofdstuk wordt ingegaan op de vraag waarom regelgeving voor kleine en middelgrote ondernemingen anders zou moeten zijn dan regelgeving voor grote ondernemingen.

Daarnaast wordt uitgebreid aandacht geschonken aan de vraag of verschillen in ondernemingsvorm aanleiding geven om verschillen in regelgeving te beargumenteren. Hierbij wordt met name ingegaan op de verschillende rol die het financiële jaarverslag speelt bij naamloze vennootschappen en besloten vennootschappen.

In hoofdstuk 3 wordt een gedetailleerde analyse uitgevoerd met betrekking tot de financiële jaarverslagen die door kleine ondernemingen in Nederland worden gedeponeerd bij het handelsregister van de diverse Kamers van Koophandel. Daarbij is aandacht geschonken aan de tijdigheid van deponering en zijn een aantal kwaliteitsaspecten van de gepubliceerde jaarstukken onderzocht. In het onderzoek is gebruik gemaakt van jaarverslagen met betrekking tot het boekjaar 1984 en met betrekking tot het boekjaar 1991 . Het boekjaar 1984 is het eerste boekjaar waarop de Nederlandse regelgeving rond de financiële verslaggeving van kleine ondernemingen van toepassing is. Jaarverslagen uit 1991 zijn aan het onderzoek toegevoegd om te onderzoeken of de verschillende kwaliteitsaspecten van de gepubliceerde jaarstukken in de loop der tijd zijn veranderd.

Uit gegevens omtrent het aantal bij het handelsregister gedeponeerde jaarstukken kan worden afgeleid dat hoewel een belangrijk deel $( \pm 50 \%)$ van de kleine vennootschappen geen jaarstukken over het boekjaar 1984 heeft gedeponeerd, de naleving van de deponeringsplicht in latere jaren sterk is verbeterd en dat met betrekking tot het boekjaar 1991 zo'n $85 \%$ van alle betrokken kleine ondernemingen aan de deponeringsplicht heeft voldaan. Daarbij dient te worden aangetekend dat ook in latere jaren het overgrote deel van de gedeponeerde jaarstukken ( $91 \%$ met betrekking tot 1984 en $81 \%$ met betrekking tot 1991) later dan 13 maanden na het einde van het betreffende boekjaar wordt gedeponeerd. 
Als gevolg van een toenemende toepassing van de in de wetgeving opgenomen standaardmodellen voor de balans is de vergelijkbaarheid van de gedeponeerde jaarstukken van kleine ondernemingen toegenomen in de loop der tijd. Met betrekking tot de hoeveelheid en de gedetailleerdheid van de informatie in de gedeponeerde jaarstukken blijkt echter dat ook in 1991 veel jaarstukken een beperkte hoeveelheid informatie bevatten. Het is echter moeilijk om vast te stellen of het ontbreken van informatie-items die op basis van de wetgeving dienen te worden gepubliceerd door kleine onderneming een gevolg is van het niet naleven van de wettelijke regels door de betrokken ondernemingen of dat de betreffende gegevens niet van toepassing zijn op de betrokken ondernemingen.

Hoofdstuk 4 bevat de resultaten van een enquête onderzoek onder zo'n 560 managers en eigenaars van kleine Nederlandse ondernemingen. De enquête heeft enerzijds betrekking op de opvattingen van de respondenten omtrent de externe financiële verslaggeving in het algemeen en omtrent de gevolgen van de in 1983 geîntroduceerde wetgeving op dit gebied in het bijzonder. Uit de resultaten van deze studie blijkt de financiële verslaggeving binnen kleine ondernemingen geen belangrijk probleemgebied vormt. Hoewel het duidelijk is dat managers van kleine ondernemingen weinig nut zien in het publiceren van hun financiële jaarverslag, blijken de bestaande wettelijke regels geen systematisch negatieve reactie bij de respondenten op te roepen.

In het tweede deel van dit hoofdstuk wordt aandacht geschonken aan de kosten voor kleine ondernemingen die samenhangen met de samenstelling en publikatie van de financiële jaarstukken. Tevens is daarbij aandacht geschonken aan de vraag of de in 1983 geïntroduceerde wettelijke regels hebben geleid tot een significante verhoging van de verslaggevingskosten voor kleine ondernemingen. Hoewel kan worden aangetoond dat de aanpassing van de Nederlandse wetgeving heeft geleid tot een kostenverhoging voor kleine ondernemingen, dient hierbij te worden aangemerkt dat voor alle betrokken ondernemingen de verslaggevingskosten slechts een zeer beperkt deel van de totale kosten van de onderneming uitmaken. Wel kan worden aangetoond dat de relatieve verlaggevingskosten hoger zijn naarmate de omvang van de onderneming afneemt. In combinatie met ander bestaand onderzoek kan worden gedemonstreerd dat een dergelijk verband zich tevens uitstrekt over middelgrote en grote ondernemingen. Het feit dat de relatieve kosten voor kleine ondernemingen hoger zijn dan de relatieve kosten voor grote ondernemingen geeft een indicatie dat de bestaande vrijstellingen binnen de Nederlandse wetgeving geen volledige compensatie voor kleine ondernemingen inhouden.

Hoofdstuk 5 bevat een studie onder een belangrijke gebruikersgroep van financiële jaarverslagen: banken. In dit onderzoek zijn 200 medewerkers van banken die zijn betrokken bij het verstrekken van kredieten aan kleine en middelgrote ondernemingen door middel van een schriftelijke enquête benaderd. Doel van dit onderzoek is na te gaan in hoeverre de respondenten belang hechten aan de jaarlijkse publikatie van het financiële jaarverslag door kleine en middelgrote ondernemingen. De resultaten geven aan dat bij kredietaanvragen van middelgrote ondernemingen de jaarstukken een belangrijke bron van informatie voor de bank is maar dat daarnaast ook niet financiële 
informatie zoals eerdere contacten met het mangement van de onderneming en bedrijfsbezoeken een veel gevallen een grote rol spelen.

In combinatie met bestaand onderzoek op dit gebied kan tevens worden aangegeven dat naarmate de omvang van de onderneming afneemt, het belang van de financiële jaarstukken in het kredietverstrekkingsproces afneemt en er meer belang wordt gehecht aan andere bronnen van informatie. Hierbij dient echter te worden aangemerkt dat zowel in dit onderzoek als in ander vergelijkbaar onderzoek er met betrekking tot de vraag of de informatiebehoeften van banken afhangen van de omvang van de onderneming een grote mate van onenigheid onder respondenten bestaat. 


\section{Curriculum Vitae}

Laury Bollen werd in 1961 geboren in Heerlen. Hij slaagde in 1979 voor het eindexamen Atheneum aan het Jeanne d'Arc College te Maastricht. Hij studeerde Bestuurlijke Informatiekunde aan de HEAO te Sittard waar hij in 1985 cum laude afstudeerde.

Sinds 1985 is hij werkzaam bij de Faculteit der Economische Wetenschappen van de Rijksuniversiteit Limburg te Maastricht. Van 1985 tot 1987 was hij als onderzoeksassistent betrokken bij een project ter realisatie van een database met jaarverslaggegevens van Nederlandse ondernemingen. Van 1987 tot 1991 was hij toegevoegd onderzoeker bij de vakgroep Bedrijfseconomie en vanaf 1991 is hij aan de sectie Berichtgeving verbonden als universitair docent. Hij verricht daar onderzoek op het gebied van de Externe Berichtgeving, met als speciale aandachtsgebied het middenen kleinbedrijf. In dit kader is hij tevens betrokken geweest bij verschillende onderzoeksprojecten van het Maastricht Accounting and Auditing Research Center (MARC). Daarnaast verzorgt hij onderwijs, in het bijzonder op het gebied van Financiële Informatiesystemen en Informatiekunde.

Sinds 1992 is hij tevens part-time verbonden aan de Open Universiteit te Heerlen als studiebegeleider en als auteur en cursusteamlid van diverse cursussen op het gebied van de Externe Berichtgeving. 
| 